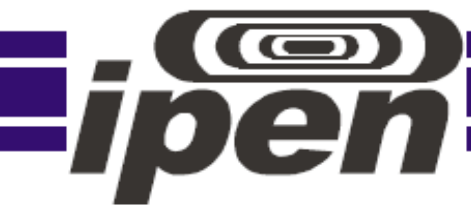

AUTARQUIA ASSOCIADA À UNIVERSIDADE DE SÃO PAULO

\title{
ESTUDO PARA O DESENVOLVIMENTO E CARACTERIZAÇÃO DE CONCRETOS DE MASSA ESPECÍFICA ELEVADA PARA PROTEÇÃO ÀS RADIAÇÕES GAMA E X
}

Sérgio Medeiros de Albuquerque

\author{
Tese apresentada como parte dos \\ requisitos para obtenção do Grau de \\ Doutor em Ciências na Área de Tecnologia \\ Nuclear - Aplicações \\ Orientador: \\ Prof. Dr. Gian-Maria Agostino Angelo Sordi
}


Aos meus familiares, amigos e aos meus pais.

À Jesus Cristo pela luz e caminho. 


\section{AGREDECIMENTOS}

Agradeço ao Dr. Gian-Maria A. A. Sordi, não apenas pela orientação dedicada, incentivo e pela oportunidade de realização deste trabalho, mas principalmente pela amizade e carinho.

Ao IPEN, à pós-graduação da USP e aos seus funcionários, pelo auxilio e atenção dispensada.

Ao Dr Carlos Roberto Apolloni, coordenador do Laboratorio de Física Nuclear Aplicada da Univercidade Estadual de Londrina, pelo apoio e utilização do laboratório.

Ao amigo Dr Avacir Candrello, professor e pesquisador do departamento de física da Universidade Estadual de Londrina, pela ajuda e ensaios realizados.

Ao Dr. Marcos Scapin, pelo incansável apoio e conselhos.

Ao amigo engenheiro Pedro Bilesky, pelo incansável auxilio e estimulo.

A Oxidray na pessoa do engenheiro Luis Eduardo, pela imprecinivel ajuda e apoio.

Aos professores do Instiuto de Pesquisas Energéticas e Nucleares, pela dedicação e ensinamentos.

Ao Instituto de Pequisas Tecnológicas do Estado de São Paulo, IPT, pelo auxilio e realização de ensaios.

Aos participantes da banca examinadora, pela importante contribuição.

E a todos que diretamente ou indiretamente contribuíram para o desenvolvimento deste trabalho de pesquisa.

A minha esposa, filhos e a meus pais pelo incentivo e apoio. 


\section{ESTUDO PARA O DESENVOLVIMENTO E CARACTERIZAÇÃO DE CONCRETOS DE MASSA ESPECÍFICA ELEVADA PARA PROTEÇÃO ÀS RADIAÇÕES GAMA E X}

\section{Sérgio Medeiros de Albuquerque}

\section{RESUMO}

Este trabalho de tese de doutorado visou identificar as matérias primas naturais produzidas no Brasil e possíveis de serem utilizadas na produção de concretos de elevada massa específica. Desenvolver uma metodologia para a caracterização, preparo, moldagem, ensaios para determinação do coeficiente de atenuação linear experimental, calculo do coeficiente de atenuação linear teórico, e determinação do $Z$ efetivo, culminando com a confecção de um banco de dados embrionário para os concretos de elevada massa específica preparados com matérias primas nacionais. Para tanto foram identificadas onze matérias primas produzidas no Brasil com caracteísticas adequadas para a produção de concretos de elevada densidade. Apresentamos os fundamentos teóricos ao bom entendimento do trabalho tanto no campo da proteção radiológica como naquela dos conceitos que podem ser usados para a produção de blindagem às radiações gama e $X$. Preparamos vinte e dois tipos de concretos de elevada massa específica com a utilização de matérias primas naturais e nacionais. Os concretos desenvolvidos foram preparados, moldados e ensaiados com uma fonte de ${ }^{137} \mathrm{Cs}$, de $3,710^{10}$ $\mathrm{Bq}(1 \mathrm{Ci})$ de atividade. Foram calculados os coeficientes de atenuação linear com a utilização das análises químicas dos concretos preparados e encontrados os coeficientes de atenução linear experimentais para comparação e avaliação da técnica proposta. Foram medidas as massas específicas dos concretos preparados em virtude de sua importância para a formação da seção de choque do composto quando da predominância do efeito Compton, e determinado o Z efetivo para a região predominante do efeito fotoelétrico. Por fim foram calculados os custos de produção levando-se em conta somente os custos das matérias primas. Para as massas específicas os concretos apresentaram uma variação de $2,74 \mathrm{~kg} / \mathrm{dm}^{3}$ até $3,76 \mathrm{~kg} / \mathrm{dm}^{3}$, já para o coeficiente de atenuação linear experimental a variação foi de $0,2137 \mathrm{~cm}^{-1}$ a $0,2860 \mathrm{~cm}^{-1}, \mathrm{O}$ efetivo variou de 19 a 25. Finalizando o trabalho foram discutidos os resultados e sugeridos preferências de concretos para utilização em blindagens com a aplicação de alguns conceitos. Comparando os resultados encontrados com vários outros publicados em trabalhos internacionais, verificamos o grau de similaridade. 
 \\ STUDY FOR THE DEVELOPMENT AND CHARACTERIZATION OF CONCRETES OF HIGH SPECIFIC MASS FOR PROTECTION TO THE GAMMA AND X RADIATION
}

\author{
Sérgio Medeiros de Albuquerque
}

\section{ABSTRACT}

This PhD thesis the natural raw materials produced in Brazil and in the production of high density concrete. Furthermore, we also develop a methodology for characterization, preparation, molding, testing to determine the linear attenuation coefficient of experimental, theoretical calculation of the linear attenuation coefficient, and determination of the effective $\mathrm{Z}$, culminating with the production of an embryo stock data for the specific high density prepared with local raw materials. For this, we identified eleven raw materials produced in Brazil with suitable characteristics for the production of high density concrete. We present the theoretical understanding of radiological protection and in the fundamental concepts that can be used to produce shielding for gamma and $X$ radiation. During the work, we prepared twenty-two concrete types of high specific weight, with the use of natural materials and domestic materials. These new concretes were prepared, molded and tested with a Cs-137 source $\left(3.7 .10^{10} \mathrm{~Bq}(1 \mathrm{Ci})\right.$ activity). The linear attenuation coefficients were calculated employing the chemical analyzes of the prepared concrete and the experimental linear attenuation coefficients were also determined for comparison and evaluation of the proposed technique. The specific masses of the concrete samples were determined, given their importance to the cross section for the Compton Effect predominance. The effective $\mathbf{Z}$ was also determined were the photoelectric effect was predominant. Finally, the production costs were considered, taking into account only the cost of the raw materials. For the specific masses, the concretes presented a variation from $2.74 \mathrm{~kg} / \mathrm{dm}^{3}$ to $3.76 \mathrm{~kg} / \mathrm{dm}^{3}$. In the case of the experimental linear attenuation coefficient the variation was from $0.2137 \mathrm{~cm}^{-1}$ to $0.2860 \mathrm{~cm}^{-1}$, and the effective $Z$ varied from 19 to 25 . As conclusion, the results were discussed e the preferred concretes for the shielding purposes were suggested. Comparing the results with other published international work, we find the degree of similarity. 
SUMÁRIO

2.1.2 Desenvolvimento de um projeto de radioproteção.

2.2 Concreto como blindagem às radiações gama $\mathrm{e}$.

2.2.1 Uso do concreto como proteção às radiações gama $\mathrm{X}$.

2.2.2 Concreto de elevada massa específica.

2.2.3 Importância da caracterização das matérias-primas empregadas.

2.2.4 Propriedades físicas e químicas das matérias-primas

2.2.5 Aglomerantes

2.2.6 Adições

2.2.7 Aditivos

2.2.8 Agregados para concreto

2.2.8.1 Condições gerais.

2.2.8.2 Agregados de elevada massa específica.

2.2.8.2.1 Classificação dos agregados de elevada massa específica.
$\mathrm{Pg} 1$

$\mathrm{Pg} 1$

$\mathrm{Pg} 3$

$\mathrm{Pg} 4$

Pg 5

Pg 6

Pg 7

Pg 9

Pg 9

Pg 9

$\mathrm{Pg} 10$

Pg 11

Pg 12

$\begin{array}{ll}\mathrm{Pg} & 12\end{array}$

$\mathrm{Pg} 13$

Pg 13

Pg 14

Pg 15

Pg 15

$\mathrm{Pg} 16$

Pg 17

$\begin{array}{ll}\mathrm{Pg} & 17\end{array}$

$\begin{array}{ll}\mathrm{Pg} & 19\end{array}$

Pg 20 


\section{ipen}

2.2.9 Formulação do traço de concreto

$\operatorname{Pg} 21$

2.3 Interação da radiação eletromagnética e gama com a matéria.

$\operatorname{Pg} 23$

2.3.1 Introdução

$\mathrm{Pg} 23$

2.3.2 Coeficiente de atenuação linear eletrônico, atômico e massa.

$\mathrm{Pg} 27$

2.3.3 Efeito fotoelétrico

$\operatorname{Pg} 29$

2.3.4 Espalhamento Compton

$\mathrm{Pg} 30$

2.3.5 Produção de pares.

$\mathrm{Pg} 31$

2.3.6 Seção de choque para a energia utilizada.

$\mathrm{Pg} 32$

2.3.7 Fator de crescimento "Buildup-Factor".

$\mathrm{Pg} 33$

3 CAPITULO 3

$\mathrm{Pg} 38$

3 DESENVOLVIMENTO DO TRABALHO

$\mathrm{Pg} 38$

3.1 Revisão Bibliográfica

$\mathrm{Pg} 38$

3.2

Identificação da energia à qual o concreto será submetido e definição das características necessárias

$\operatorname{Pg} 40$

Escolha das matérias-primas produzidas no Brasil para a

produção de elevada massa específica

$\operatorname{Pg} 40$

3.3.1 Aglomerantes.

$\mathrm{Pg} 40$

3.3.2 Agregados.

$\mathrm{Pg} 41$

3.3.3 Adições.

$\mathrm{Pg} 44$

3.3.4 Aditivo.

$\mathrm{Pg} 45$

3.3.5 Caracterização química dos materiais utilizados.

$\mathrm{Pg} 45$

3.4 Formulação dos traços de concreto.

$\mathrm{Pg} 46$

3.4.1 Primeiro passo:

$\mathrm{Pg} \quad 47$

3.4.2 Segundo passo:

$\mathrm{Pg} \quad 47$

3.4.3 Terceiro passo:

Pg 50

3.4.4 Quarto passo:

Pg 50

3.4.5 Quinto passo:

Pg 51 
3.4.6 Sexto passo:

$\operatorname{Pg} 51$

Preparo dos concretos, moldagem, cura e armazenamento dos corpos de prova.

$\operatorname{Pg} 52$

3.5.1 Preparo dos concretos e moldagem dos corpos de prova.

$\operatorname{Pg} 52$

3.5.2 Moldagem dos copos de prova.

$\operatorname{Pg} 52$

3.5.3 Cura e armazenagem dos corpos de pova.

$\mathrm{Pg} 53$

3.6

Ensaios para determinação dos coeficientes de atenuação linear experimental

$\mathrm{Pg} 54$

3.7 Caracterização física e química dos concretos preparados.

$\mathrm{Pg} 56$

3.7.1 Caracterização física dos concretos preparados.

$\mathrm{Pg} 56$

3.7.2 Análise química dos concretos preparados.

$\mathrm{Pg} 57$

3.8

Cálculo do coeficiente de atenuação linear dos concretos preparados

$\operatorname{Pg} \quad 59$

4 CAPITULO 4

$\mathrm{Pg} 60$

$4 \quad$ Resultados encontrados

$\mathrm{Pg} 60$

4.1

Resultados da caracterização física e química do aglomerante utilizado

$\mathrm{Pg} 60$

4.1.1 Caracterização física do cimento Portland CPV ARI-RS

$\mathrm{Pg} 60$

4.1.2 Ensaios químicos

$\mathrm{Pg} 61$

Resultados da caracterização física e química dos agregados e da adição

$\mathrm{Pg} 61$

4.2.1 Caracterização física

$\mathrm{Pg} 61$

4.2.2 Caracterização química

$\mathrm{Pg} 70$

4.3

Traços dos concretos formulados para as sete famílias escolhidas

$\operatorname{Pg} 77$

4.4 Caracterização física dos concretos preparados

$\mathrm{Pg} 85$

4.4.1

Massa específica dos corpos de prova no momento da desforma e antes da realização dos ensaios de atenuação

$\mathrm{Pg} 85$ 
4.4.2 Resistência à compressão

Pg 87

4.5 Composição química dos concretos preparados

Pg 87

4.6

Cálculo dos coeficientes de atenuação linear com a utilização

das composições químicas dos concretos preparados

Pg 99

4.7

Resultados dos ensaios para determinação dos coeficientes de atenuação linear para a energia de $660 \mathrm{keV}$

4.8 Determinação do Z efetivo similar

$\mathrm{Pg} 121$

4.9 Principais elementos presentes nos concretos ensaiados

$\mathrm{Pg} \quad 122$

4.10 Montagem do banco de dados

$\mathrm{Pg} \quad 123$

5

CAPITULO 5

$\mathrm{Pg} 124$

5.1 Massa específica

Pg 124

5.2 Coeficiente de atenuação linear experimental

$\mathrm{Pg} 125$

Coeficientes de atenuação linear calculados, comparados com os coeficientes de atenuação linear experimentais

Pg 127

5.4 Custos de produção

Pg 128

$5.5 \quad$ Resultados de outros trabalhos

$\operatorname{Pg} 129$

5.6

Discussões englobando a densidade, o coeficiente de atenuação linear e o custo do concreto

$\mathrm{Pg} 132$

CAPITULO 6

$\mathrm{Pg} 136$

6

Conclusões

Pg 136

7 Sugestões para trabalhos futuros

Pg 137

Referencias

Pg 138

Anexo 1

Pg 142

Anexo 2

Pg 148 


\section{ipen}

\section{LISTA DE TABELAS}

Tabela 1 Propriedades do concreto influenciadas pelas características Pg 19 do agregado adaptada (10). Pg 18

Tabela 2 Massa específica, massa atômica, número atômico, número $\mathrm{Pg} 28$ de elétrons por grama para vários materiais. Adaptada (15).

Tabela $3 \quad$ Tabela comparativa de informações identificadas. $\quad$ Pg 39

Tabela $4 \quad$ Identificação das matérias-primas utilizados. $\quad$ Pg 43

Tabela $5 \quad$ Resultados dos ensaios físicos do aglomerante (IPT/SP). $\quad$ Pg 60

Tabela 6 Resultados dos ensaios físicos dos ensaios mecânicos do $\mathrm{Pg} 60$ aglomerante (IPT/SP).

Tabela $7 \quad$ Resultados dos ensaios químicos do cimento por via úmida. $\quad \mathrm{Pg} 61$

Tabela $8 \quad$ Resultados da amostra AM2 "Óxido de Ferro". $\quad$ Pg 62

Tabela 9 Resultados da amostra AM3 "Óxido de Ferro Sintétio Pg 63 Vermelho".

Tabela $10 \quad$ Resultados da amostra AM4 “Magnetita Malha \#325”. Pg 64

Tabela $11 \quad$ Resultados da amostra AM6 "Areia de Hematita". $\quad$ Pg 64

Tabela 12 Resultados da amostra AM 7 “Areia de Hematita Graúda”. Pg 65

Tabela 13 Resultados da amostra AM8 "Granalha de Baixa Massa Pg 66 Específica".

Tabela $14 \quad$ Resultados da amostra AM9 "Brita de Hematita 0". Pg 67

Tabela 15 Resultados da amostra AM10 "Brita de Hematita 10 a Pg 68 $19 \mathrm{~mm}$.

Tabela 16 Resultados da amostra AM23 "Areia Barita". $\quad$ Pg 69

Tabela 17 Resultados da amostra "Areia de Hematita Tipo AG". $\quad$ Pg 69

Tabela 18 Códigos e nomes utilizados para identificação das amostras. Pg 70

Tabela 19 Composição química - AM1 Filer calcário. $\quad$ Pg 71

Tabela $20 \quad$ Composição química - AM2 Filer calcário. $\quad$ Pg 71

Tabela $21 \quad$ Composição química - AM3 Filer calcário. $\quad$ Pg 72 
Tabela 22 Composição química - AM4 Filer calcário.

$\operatorname{Pg} 72$

Tabela 23 Composição química - AM5 Magentita com areia.

$\operatorname{Pg} 73$

Tabela 24 Composição química - AM6 Areia de hematita.

$\operatorname{Pg} 73$

Tabela 25 Composição química - AM7 Areia de hematite graúda.

$\operatorname{Pg} 74$

Tabela 26 Composição química - AM8 Areia de hematite graúda.

$\operatorname{Pg} 74$

Tabela 27 Composição química - AM9 Brita 0 de hematita.

$\operatorname{Pg} 75$

Tabela 28 Composição química - AM10 Areia de hematita.

$\operatorname{Pg} 75$

Tabela 29 Composição química - AM10 Areia de hematita.

$\operatorname{Pg} 76$

Tabela $30 \quad$ Resumo geral das composições químicas das amostras das $\mathrm{Pg} 77$ matérias primas, percentual dos elementos químicos presentes nas amostras.

Tabela 31 Traço Concreto 1.

$\operatorname{Pg} 78$

Tabela 32 Traço Concreto 4.

$\operatorname{Pg} 78$

Tabela 33 Traço Concreto 5.

$\operatorname{Pg} 78$

Tabela 34 Traço Concreto 6.

$\operatorname{Pg} 79$

Tabela 35 Traço Concreto 2.

$\operatorname{Pg} 79$

Tabela 36 Traço Concreto 3.

$\operatorname{Pg} 79$

Tabela $37 \quad$ Traço Concreto 7.

Pg 80

Tabela 38 Traço Concreto 8.

$\mathrm{Pg} 80$

Tabela 39 Traço Concreto 9.

$\operatorname{Pg} 80$

Tabela 40 Traço Concreto 10.

Pg 81

Tabela 41 Traço Concreto 11.

Pg 81

Tabela 42 Traço Concreto 12. $\mathrm{Pg} 81$

Tabela 43 Traço Concreto 13. $\mathrm{Pg} 82$

Tabela 44 Traço Concreto 14. Pg 82

Tabela 45 Traço Concreto 15. Pg 82

Tabela 46 Traço Concreto 16. $\mathrm{Pg} 83$ 


\section{ipen}

Tabela 47 Traço Concreto 17.

$\operatorname{Pg} 83$

$\begin{array}{lll}\text { Tabela } 48 \quad \text { Traço Concreto } 18 . & \mathrm{Pg} 83\end{array}$

$\begin{array}{lll}\text { Tabela } 49 & \text { Traço Concreto } 19 . & \mathrm{Pg} 84\end{array}$

Tabela $50 \quad$ Traço Concreto $20 . \quad P g 84$

Tabela 51 Traço Concreto 21. Pg 84

Tabela 52 Traço Concreto 22. Pg 85

Tabela 53 Massa específica dos concretos ensaiados no momento da $\mathrm{Pg} 86$ moldagem e na desforma.

Tabela $54 \quad$ Análise química normalizada do concreto Com $1 . \quad P g 89$

Tabela $55 \quad$ Análise química normalizada do concreto Com $2 . \quad P g 89$

Tabela $56 \quad$ Análise química normalizada do concreto Com $3 . \quad P g 90$

Tabela $57 \quad$ Análise química normalizada do concreto Com $4 . \quad P g 90$

Tabela $58 \quad$ Análise química normalizada do concreto Com 5. Pg 91

Tabela $59 \quad$ Análise química normalizada do concreto Com 6. Pg 91

Tabela $60 \quad$ Análise química normalizada do concreto Com 7. Pg 92

Tabela $61 \quad$ Análise química normalizada do concreto Com $8 . \quad$ Pg 92

Tabela $62 \quad$ Análise química normalizada do concreto Com 9. Pg 93

Tabela $63 \quad$ Análise química normalizada do concreto Com $10 . \quad P g 93$

Tabela $64 \quad$ Análise química normalizada do concreto Com $11 . \quad P g 94$

Tabela $65 \quad$ Análise química normalizada do concreto Com 12. Pg 94

Tabela $66 \quad$ Análise química normalizada do concreto Com 13. Pg 95

Tabela $67 \quad$ Análise química normalizada do concreto Com $14 . \quad P g 95$

Tabela $68 \quad$ Análise química normalizada do concreto Com $15 . \quad$ Pg 96

Tabela $69 \quad$ Análise química normalizada do concreto Com $16 . \quad$ Pg 96

Tabela $70 \quad$ Análise química normalizada do concreto Com 17. Pg 97

Tabela $71 \quad$ Análise química normalizada do concreto Com $18 . \quad \operatorname{Pg} 97$ 
Tabela 72 Análise química normalizada do concreto Com 19.

$\operatorname{Pg} 98$

Tabela 73 Análise química normalizada do concreto Com 20.

$\operatorname{Pg} 98$

Tabela 74 Análise química normalizada do concreto Com 21.

$\operatorname{Pg} 99$

Tabela $75 \quad$ Análise química normalizada do concreto Com 22.

$\operatorname{Pg} 99$

Tabela 76 Coeficiente de atenuação linear calculado Com 1.

$\operatorname{Pg} 100$

Tabela 77 Coeficiente de atenuação linear calculado Com 2.

$\operatorname{Pg} 101$

Tabela 78 Coeficiente de atenuação linear calculado Com 3.

$\operatorname{Pg} 101$

Tabela 79 Coeficiente de atenuação linear calculado Com 4.

$\mathrm{Pg} 102$

Tabela 80 Coeficiente de atenuação linear calculado Com 5.

$\mathrm{Pg} 102$

Tabela $81 \quad$ Coeficiente de atenuação linear calculado Com 6.

$\operatorname{Pg} 103$

Tabela $82 \quad$ Coeficiente de atenuação linear calculado Com 7.

$\mathrm{Pg} 103$

Tabela $83 \quad$ Coeficiente de atenuação linear calculado Com 8.

$\mathrm{Pg} 104$

Tabela 84 Coeficiente de atenuação linear calculado Com 9.

Pg 104

Tabela 85 Coeficiente de atenuação linear calculado Com 10.

Pg 105

Tabela 86 Coeficiente de atenuação linear calculado Com 11.

$\operatorname{Pg} 105$

Tabela 87 Coeficiente de atenuação linear calculado Com 12.

$\operatorname{Pg} 106$

Tabela 88 Coeficiente de atenuação linear calculado Com 13.

$\operatorname{Pg} 106$

Tabela 89 Coeficiente de atenuação linear calculado Com 14.

Pg 107

Tabela 90 Coeficiente de atenuação linear calculado Com 15.

Pg 107

Tabela 91 Coeficiente de atenuação linear calculado Com 16.

$\operatorname{Pg} 108$

Tabela 92 Coeficiente de atenuação linear calculado Com 17.

$\operatorname{Pg} 108$

Tabela 93 Coeficiente de atenuação linear calculado Com 18.

Pg 109

Tabela 94 Coeficiente de atenuação linear calculado Com 19.

$\operatorname{Pg} 109$

Tabela 95 Coeficiente de atenuação linear calculado Com 20.

$\operatorname{Pg} 110$

Tabela 96 Coeficiente de atenuação linear calculado Com 21.

$\operatorname{Pg} 110$

Tabela 97 Coeficiente de atenuação linear calculado Com 22.

$\operatorname{Pg} 111$ 


\section{ipen}

Tabela 98 Resumos dos dados encontrados para os coeficientes de Pg 112 atenução linear calculados.

Tabela 99 Concreto 1, corpo de prova número AM 5.

$\operatorname{Pg} 113$

Tabela 100 Concreto 2, corpo de prova número AM 7

$\operatorname{Pg} 114$

Tabela 101 Concreto 3, corpo de prova número AM 12

$\operatorname{Pg} 114$

Tabela 102 Concreto 4, corpo de prova número AM 21.

$\operatorname{Pg} 114$

Tabela 103 Concreto 5, corpo de prova número AM 27.

$\operatorname{Pg} 115$

Tabela 104 Concreto 6 , corpo de prova número AM 33.

$\operatorname{Pg} 115$

Tabela 105 Concreto 7, corpo de prova número AM 36.

$\operatorname{Pg} 115$

Tabela 106 Concreto 8, corpo de prova número AM 44 .

$\operatorname{Pg} 116$

Tabela 107 Concreto 9, corpo de prova número AM 51.

$\operatorname{Pg} 116$

Tabela 108 Concreto 10, corpo de prova número AM 53.

$\operatorname{Pg} 116$

Tabela 109 Concreto 11, corpo de prova número AM 60.

$\operatorname{Pg} 117$

Tabela 110 Concreto 12, corpo de prova número AM 66.

$\operatorname{Pg} 117$

Tabela 111 Concreto 13, corpo de prova número AM 72 .

$\operatorname{Pg} 117$

Tabela 112 Concreto 14 , corpo de prova número AM 80 .

$\operatorname{Pg} 118$

Tabela 113 Concreto 15 , corpo de prova número AM 84 .

$\operatorname{Pg} 118$

Tabela 114 Concreto 16, corpo de prova número AM 90.

$\operatorname{Pg} 118$

Tabela 115 Concreto 17, corpo de prova número AM 96.

$\operatorname{Pg} 119$

Tabela 116 Concreto 18, corpo de prova número AM 102.

$\operatorname{Pg} 119$

Tabela 117 Concreto 19, corpo de prova número AM 107.

$\operatorname{Pg} 119$

Tabela 118 Concreto 20, corpo de prova número AM 114.

$\operatorname{Pg} 120$

Tabela 119 Concreto 21, corpo de prova número AM 119.

$\operatorname{Pg} 120$

Tabela 120 Concreto 22, corpo de prova número AM 125.

$\operatorname{Pg} 120$

Tabela 121 Dados dos ensaios para determinação dos coeficientes de $\operatorname{Pg} 121$ atenuação linear dos concretos.

Tabela 122 Seção de choque dos elementos químicos para as energias

$\operatorname{Pg} 122$ 


\section{ipen}

de $600,800,660(\mathrm{KeV})$.

Tabela 123 Coeficiente de atenuação linear experimental e elemento Pg 123 similar.

Tabela 124 Composição química dos elementos encontrados nos Pg 124 concretos ensaiados, normalizados para elementos presentes.

Tabela 125 Massas específicas dos concretos ensaiados.

$\operatorname{Pg} 125$

Tabela 126 Coeficientes de atenuação linear e densidades dos Pg 127 concretos ensaiados.

Tabela 127 Comparativo entre coeficientes.

$\operatorname{Pg} 128$

Tabela 128 Custos de produção dos concretos preparados.

$\operatorname{Pg} 130$

Tabela 129 Massa específica e coeficiente de atenuação linear Pg 131 encontrados em outros trabalhos publicados.

Tabela 130 Custos dos concretos corrigidos.

$\operatorname{Pg} 133$

Tabela 131 Resumo de dados para avaliação dos concretos cuja Pg 135 interação predominante é o efeito fotoelétrico. 


\section{ipen}

\section{LISTA DE FIGURAS}

Figura. 1 Absorção exponencial para o Cobre para fótons de

$\operatorname{Pg} 24$ energia de $1 \mathrm{MeV}$ para um coeficiente de atenuação linear $\mu=0,524 \mathrm{~cm}^{-1}$. Adaptada de Brownell e Hine (15).

Figura. 2 Colisão do fóton com energia $h v$ com um elétron livre no

$\operatorname{Pg} 30$ processo Compton. Adaptada de Brownell \& Hine (15).

Figura. 3 Processo de produção de pares. Adaptada de Brownell \& $\quad$ Pg 31 Hine (15). Pg 30

Figura. 4 Importância relativa dos três principais tipos de interação para radiação g. Aptada de Evans. (2). Pg 32

Figura. 5 Energia de absorção em função da energia do fóton para

$\operatorname{Pg} 36$ diferentes materiais. Pg 35

Figura. 6 Passo a passo para dosagem de CAA com o método Tutikian \& Dal Molin 2007 com acréscimo de propriedades no passo 5 (13). $\mathrm{Pg} 46$

Figura. 7 Organograma de combinações família 1.

Figura. 8 Organograma de combinações família 2.

Figura. 9 Organograma de combinações família 3.

Figura. 10 Organograma de combinações família 4.

Figura. 11 Organograma de combinações família 5.

Figura.12 Organograma de combinações família 6.

Figura.13 Organograma de combinações família 7.

Figura.14 Mesa vibratória.

$\operatorname{Pg} 53$

Figura.15 Molde para moldagem dos corpos de prova.

Figura.16 Caixa de armazenagem dos corpos de prova.

Figura.17 Caixa de armazenagem dos corpos de prova natleira para cura.

Figura.18 Mesa micrométrica e geometria de ensaio. 


\section{ipen}

Figura.19 Esquema de posicionamento dos pontos em corpo

$\operatorname{Pg} 56$

Figura.20 Amostra quebrada.

$\operatorname{Pg} 57$

Figura.21 Compartimento de moagem com amostra a ser moída.

$\operatorname{Pg} 57$

Figura.22 Moinho Herzog.

$\operatorname{Pg} 57$

Figura.23 Amostra moída para ensaio.

$\operatorname{Pg} 57$

Figura.24 Acondicionamento do material no porta-amostra.

$\operatorname{Pg} 58$

Figura.25 Porta-amostras.

$\operatorname{Pg} 58$

Figura.26 Espectrômetro RIX 3000 .

$\operatorname{Pg} 58$

Figura.27 Processamento dos dados pelo programa do

$\operatorname{Pg} 58$ equipamento.

Figura.28 Gráfico - Curva granulométrica da amostra AM2.

$\operatorname{Pg} 62$

Figura.29 Gráfico - Curva granulométrica da amostra AM3.

$\operatorname{Pg} 63$

Figura.30 Gráfico - Curva granulométrica da amostra AM6.

$\mathrm{Pg} 64$

Figura.31 Gráfico - Curva da granulométrica amostra AM7.

$\operatorname{Pg} 65$

Figura.32 Gráfico - Curva granulométrica da amostra AM8.

$\operatorname{Pg} 66$

Figura.33 Gráfico - Curva granulométrica da amostra.

$\operatorname{Pg} 67$

Figura.34 Gráfico - Curva granulométrica da amostra.

$\operatorname{Pg} 68$

Figura.35 Gráfico - Curva granulométrica da amostra.

$\operatorname{Pg} 69$

Figura.36 Importância relativa dos três principais tipos de interação $\operatorname{Pg} 134$ para radiação $\mathrm{g}$

Figura.37 Rocha de Barita Foto:Eurico Zimbres.

$\operatorname{Pg} 142$

Figura.38 Rocha de Hematita Foto: Eurico Zimbres.

$\operatorname{Pg} 144$

Figura.39 Rocha de Magnetita Foto:Eurico Zimbres.

$\operatorname{Pg} 146$ 


\section{INTRODUÇÃO}

Nos últimos anos, o desenvolvimento e a viabilização do uso dos equipamentos de radioterapia e radiodiagnóstico, assim como o incremento das aplicações industriais, fizeram com que se disseminassem instalações para abrigar tais equipamentos no país, aumentando a demanda por proteção e blindagem às radiações gama e X.

Para o atendimento às normas nacionais e internacionais, as instalações e os procedimentos devem ser planejados, realizados e projetados para que os indivíduos ocupacionalmente expostos e os indivíduos do público tomem as mais baixas possíveis doses dentro dos limites estabelecidos.

Uma das maneiras de se diminuir a exposição às radiações e consequentemente diminuir as doses é a utilização de barreiras às radiações (blindagens). Por se tratarem de partes indispensáveis para a proteção e operação em instalações de equipamentos geradores são, talvez, dentre os componentes utilizados na construção civil das salas, os que têm maior impacto sobre os custos das obras. (1)

Não diferentemente de outros países, no Brasil empregam-se vários tipos de materiais para a construção de proteções às radiações ionizantes.

Quando se trata de fótons de menores energias, em geral, a absorção fotoelétrica aumenta com o incremento do número atômico efetivo, e decresce com o aumento da energia da radiação (2). São utilizadas então pequenas espessuras, e empregam-se materiais como revestimentos de argamassas $^{1}$, com a utilização de barita como agregado ${ }^{2}$ miúdos e aditivos ${ }^{3}$ especiais, geralmente aplicados sobre uma estrutura já existente, como alvenaria, painéis de concreto ou gesso acartonado.

\footnotetext{
${ }^{1}$ Argamassa: mistura de agregado e aglomerante com granulometria fina, normalmente utilizado para revestimentos, reparos ou assentamento de tijolos ou blocos de concreto.

${ }^{2}$ Agregados são fragmentos de rochas, popularmente denominados "pedras" e "areias".

${ }^{3}$ Aditivo é qualquer material que não seja água, agregado, cimento hidráulico ou fibra, usado como ingrediente do concreto ou argamassa, e adicionado antes ou imediatamente à mistura, com objetivo de alterar certas características, como melhorar a plasticidade sem adicionar água, reduzir a exsudação e segregação, retardar ou acelerar o tempo de pega, dentre outros.
} 
Quando da necessidade de proteções para a energia de $660 \mathrm{keV}$, são observados, dentre outros, primordialmente o efeito Compton. A blindagem então geralmente requer maiores espessuras, e o concreto de massa específica elevada é uma boa opção. De fácil aplicação, o concreto de elevada massa específica é um material similar ao concreto convencional, bastante utilizado no país.

Quando se projeta uma estrutura com a utilização do concreto de elevada massa específica para atuar como proteção às radiações ionizantes, inúmeros materiais e arranjos podem ser compostos para a produção do concreto, porém, aspectos físicos, econômicos, sociais e ambientais devem ser analisados, e a viabilidade da solução deve estar embasada em critérios técnicos, econômicos e sociais.

Para a escolha do tipo de concreto a ser empregado na construção da proteção, o projetista deve previamente verificar que energia será blindada.

O desempenho estrutural, a segurança contra incêndio, a segurança no uso e operação, a durabilidade, a manutenção e a adequação ambiental da solução devem ser criteriosamente investigados, a fim de se conseguir uma solução segura, sob os diversos aspectos. Para facilitar o desenvolvimento do projeto à resposta, há algumas questões que podem ser úteis, dentre as quais podemos citar:

1 Qual a energia a ser blindada?

2 Quais características são necessárias para que o concreto de elevada massa específica apresente um bom desempenho?

3 Quais os agregados disponíveis, possíveis de serem utilizados para a produção de concretos de elevada massa específica?

$4 \quad$ Como escolher os agregados a serem utilizados?

5 Qual tipo de aglomerante é o mais adequado para a aplicação?

6 Como estimar o coeficiente de atenuação linear do concreto a ser preparado? 


\subsection{Identificação do Campo de Atuação do Presente Trabalho}

A utilização de concreto de elevada massa específica para a blindagem às radiações gama e $X$ têm aumentado significativamente com o crescimento do uso das radiações ionizantes nas nossas atividades laborais humanas. $O$ crescente desenvolvimento de equipamentos e técnicas de aplicação, em conjunto com a capacidade de consumo das diversas áreas, e o aumento das possibilidades de aplicação das radiações ionizantes, têm demandado a construção de novas e modernas instalações, assim como, consequentemente, a execução de blindagens para a proteção das pessoas e do meio ambiente.

Dentre os materiais utilizados como blindagem, o concreto de elevada massa específica apresenta-se, no Brasil, como uma das alternativas viáveis, e tem como fator positivo a similaridade de preparo ao concreto convencional e a tradição local de aplicação de concretos em várias situações.

O concreto de elevada massa específica apresenta um ótimo desempenho para a atenuação das radiações por ter elevada massa específica e poder ser preparado com uma grande combinação de tipos de agregados.

A fácil manutenção, a grande resistência física e a estabilidade química, em conjunto com a disponibilidade de matérias-primas e a facilidade de preparação, fazem do concreto uma ótima opção econômica para uso como barreira de proteção às radiações gama e $X$.

Significativo também é o fato de que, por apresentar um coeficiente de atenuação linear maior que o do concreto convencional, é possível diminuir a espessura da blindagem na parede, laje, piso ou teto, propiciando um melhor aproveitamento da área utilizada para implantação dos equipamentos de radiação.

Em contra partida, uma das dificuldades encontradas para a sua utilização está no fato de que poucos trabalhos de pesquisa foram publicados ou desenvolvidos no Brasil com a utilização de matérias-primas nacionais.

Para facilitar o entendimento sobre o comportamento do concreto de elevada massa específica preparado com matérias-primas nacionais, e disponibilizar ao meio técnico, dados e informações sobre o comportamento destes frente às radiações gama 
e X, desenvolveu-se este estudo sobre o comportamento e a caracterização de concretos com a utilização de matérias-primas disponíveis no território nacional, como cimentos, agregados e materiais de adições.

Concretos de elevada massa específica para uso como blindagem podem ser produzidos com uma ampla combinação de diferentes tipos de agregados, aglomerantes e materiais de adições, que podem apresentar massas específicas equivalentes, composições químicas diferentes e desempenhos distintos.

Fatores como a composição química dos materiais utilizados, a combinação granulométrica deles e o fator de forma ${ }^{4}$ influenciam na composição do traço, pois alteram as combinações e os resultados finais, como massa específica, consumo de matérias-primas e composição química do composto.

Para a prescrição e a aplicação do concreto de elevada massa específica em blindagens, e/ou a utilização de um material ou componente como proteção radiológica, é de suma importância que o projetista conheça o comportamento dos materiais, dos componentes e do produto final quando submetido às solicitações impostas pelo uso. Conhecer o comportamento pode signficar um melhor projeto e resultar em um melhor desempenho.

\subsection{Finalidades do Trabalho.}

Este trabalho visa identificar as matérias-primas minerais naturais, produzidas no Brasil e disponíveis no mercado para aquisição, que atendam às necessidades específicas para serem utilizadas na produção de concretos de elevada massa específica.

Desenvolver uma metodologia para a caracterização, preparo, moldagem e ensaios de concretos de elevada massa específica para a determinação do coeficiente de atenuação linear.

\footnotetext{
${ }^{4}$ Fator de forma: relação entre as três dimensões.
} 


\subsection{Objetivos do Trabalho.}

a) Efetuar uma pesquisa bibliográfica para identificar o estado da arte no preparo e aplicação de concretos de elevada massa específica.

b) Desenvolver uma metodologia para a caracterização, preparo, moldagem, ensaios para determinação do coeficiente de atenuação linear experimental, cálculo do coeficiente de atenuação linear teórico e determinação do $Z$ efetivo, culminando com a confecção de um banco de dados embrionário para os concretos de elevada massa específica preparados com matériasprimas nacionais.

c) Identificar a energia a ser utilizada no desenvolvimento do trabalho.

d) Obter dados e informações básicas sobre as características das matériasprimas produzidas no Brasil disponíveis e que atendam às necessidades técnicas para uso em concretos de elevada massa específica.

e) Selecionar matérias-primas para serem utilizadas no presente trabalho.

f) Caracterizar, física e quimicamente, os agregados, aglomerantes e adições utilizadas para a produção dos concretos a serem avaliados.

g) Formular traços de concreto de elevada massa específica para serem utilizados na blindagem às radiações gama $\mathrm{e} X$.

h) Preparar concretos e moldar corpos de prova para o desenvolvimento das pesquisas segundo a metodologia proposta. 
i) Ensaiar os corpos de prova para cada tipo de concreto formulado na energia definida, para medir os coeficientes de atenuação linear e determinar o Z efetivo na região do efeito fotoelétrico.

j) Calcular os coeficientes de atenuação linear teóricos e determinar o Z efetivo na região do efeito fotoelétrico.

k) Avaliar os resultados encontrados.

\subsection{Justificativa}

A utilização do concreto no Brasil está intimamente ligada às estruturas de pontes, viadutos, barragens, torres, edifícios, estações de tratamento, tubulações, estradas, portos, aeroportos e, em uma escala muito menor, à utilização como blindagem às radiações gama $\mathrm{e} X$.

Com o desenvolvimento de novos e modernos equipamentos emissores de radiações gama e $X$ utilizados na medicina nuclear radiodiagnóstica e radioterápica, e também na indústria, a melhora no poder aquisitivo da população no país e o aumento do aparelhamento do sistema de saúde, tem-se disseminado em todo o território nacional o uso das radiações como fonte de energia para as diversas aplicações.

O uso de componentes e fontes emissoras de radiações ionizantes, em virtude de seus efeitos nocivos à saúde quando ultrapassados os limites recomendados, obriga que as instalações sejam controladas e protegidas. Em virtude desses fatos, tanto os equipamentos como as fontes, e todos os materiais de proteção do conjunto, devem atender às normas de proteção e serem aprovados por uma autoridade competente.

Quando há a necessidade de executar e projetar blindagens para a proteção às radiações gama e $X$, os profissionais envolvidos devem ter conhecimento específico sobre a aplicação. Já que a tarefa é multidisciplinar, envolve conhecimentos sobre uma 
série de aspectos, dentre eles podemos citar a necessidade do projetista de conhecer o comportamento dos materiais e componentes empregados.

Quando da realização das pesquisas bibliográficas sobre o estado da arte, verificou-se que no Brasil não se publicaram muitos trabalhos científicos sobre o comportamento dos concretos preparados com matérias-primas nacionais para utilização em blindagem às radiações gama $\mathrm{e} X$.

Dos trabalhos de pesquisas consultados, a grande maioria foi realizada em outros países, com a utilização de matérias-primas oriundas do local onde foram efetuados ou com a aplicação de dados experimentais disponíveis em publicações.

Uma das principais justificativas para o desenvolvimento do estudo realizado é disponibilizar aos interessados informações sobre concretos de elevada massa específica utilizados para a proteção às radiações gama e $X$, preparados e caracterizados com matérias-primas nacionais.

\subsection{Originalidade}

A principal inovação do trabalho está no desenvolvimento de uma pesquisa inédita, que identifica, caracteriza, desenvolve e ensaia concretos de elevada massa específica produzidos no país com a utilização de matérias-primas nacionais, preparados de acordo com as normas vigentes e ensaiados na energia de $660 \mathrm{keV}$ com a utilização da metodologia desenvolvida.

Nos trabalhos consultados para a identificação do estado da arte, observamos que em alguns as análises e ensaios realizados foram desenvolvidos com a utilização de agregados e aglomerantes ${ }^{5}$ produzidos em outros países, matérias-primas estas que apresentam composições químicas e características físicas diferentes daquelas encontradas e produzidas no Brasil.

5 No caso, o cimento Portland, que é definido pela ASTM C 150 como cimento hidráulico produzido pela moagem de clínqueres constituidos essencialmente por silicatos de cálcio hidráulicos em uma pequena quantidade de uma ou mais formas de sulfato de cálcio. Clínqueres são nódulos de 5 a $25 \mathrm{~mm}$ de diâmetro de material sinterizado que é produzido quando uma mistura de matérias-primas de composição pré-determinada é aquecida em altas temperaturas. 
A composição química e as características físicas dos materiais encontrados no Brasil utilizados para a produção de concretos de elevada massa específica diferem daquelas dos materiais usados e encontrados em outros países. Como o desempenho dos concretos de elevada massa específica dependem, dentre outros aspectos, da composição química do composto, o comportamento dos concretos produzidos com matérias-primas nacionais podem apresentar desempenhos diferentes quando eles são submetidos às radiações gama e $X$.

A prescrição e a aplicação de concretos de elevada massa específica para a proteção às radiações gama e $X$ depende de informações básicas, como disponibilidade de matérias-primas e localização das fontes produtoras, composição dos agregados, traços utilizados e desempenho.

No âmago do trabalho tratou-se de investigar a importância que a composição química e as características físicas dos componentes têm na formação dos coeficientes de atenuação linear experimental do concreto.

Sugere-se que a escolha dos componentes e a formulação do traço de concreto a ser empregado para a proteção radiológica possam ser realizadas em função do tipo de interação predominante para a faixa de energia à qual será submetido, e, através do cálculo da seção de choque teórica, fato que é uma novidade no meio, escolher a melhor combinação de agregados e aglomerantes em função, dentre outros aspectos, da seção de choque resultante para o efeito predominante na faixa de energia da aplicação.

Complementando o trabalho, montou-se um banco de dados embrionário com as informações coletadas para concretos preparados com matérias-primas nacionais, que será disponibilizado aos interessados e poderá ser alimentado constantemente, servindo como fonte de informação e referência ao meio técnico e científico. 


\section{if \\ CAPITULO 2}

\section{FUNDAMENTOS TEÓRICOS}

\subsection{Proteção radiológica}

Para garantir a segurança dos indivíduos laboralmente expostos, pacientes e indivíduos do público, com o cumprimento das prescrições impostas pelas normas, é de suma importância o desenvolvimento de estudos de otimização que envolvam as rotinas e os projetos para abrigar a instalação de equipamentos emissores de radiação gama e $X$.

O desenvolvimento de um projeto de proteção a radiações é tarefa multidisciplinar, envolve profissionais de diversas áreas, com conhecimento específico da fonte de radiação e do comportamento dos materiais submetidos a esta, com o objetivo de atender às prescrições e garantir o desempenho da atividade.

Quando se projeta uma estrutura para atuar como proteção às radiações ionizantes, deve-se ter como principal objetivo a limitação das radiações a valores aceitáveis, dentro dos limites apropriados e viáveis. Inúmeros materiais e arranjos podem ser compostos, porém, aspectos físicos, econômicos, sociais e ambientais devem ser analisados e otimizados, e a viabilidade da solução deve estar embasada em critérios técnicos econômicos e sociais.

Para a escolha do material a ser empregado na construção da proteção o projetista deve previamente avaliar dentre outros o comportamento dos materiais e dos componentes frente aos vários tipos de energia e ao fluxo de radiações a que serão submetidos. O desempenho estrutural, a segurança contra incêndio, a segurança no uso e operação, a durabilidade, a manutenção e a adequação ambiental da solução devem ser criteriosamente investigados, a fim de se conseguir uma solução segura sob os diversos aspectos.

A proteção às radiações pode ser realizada de várias maneiras diferentes, a saber:

A) Diminuindo o tempo de exposição à fonte de radiação. 
B) Aumentando a distância entre a fonte de radiação e os indivíduos.

C) Interpondo barreiras entre a fonte de radiação e os indivíduos, fazendo uso de materiais atenuadores da radiação.

D) Fazendo uso de duas, das três metodologias citadas.

A primeira metodologia de proteção é excelente, mas tem na diminuição do tempo de exposição o fator limitante, uma vez que em muitas aplicações o valor da exposição resultante é diretamente proporcional ao tempo de exposição.

A aplicação da segunda metodologia está limitada ao espaço disponível para a instalação de equipamentos e às condições de trabalho e manuseio de instrumentos e ferramentas. Se por um lado a radiação decresce diretamente com a diminuição do quadrado da distância, por outro, os espaços para a instalação de equipamentos é limitado, e o manuseio de pinças e aparelhos auxiliares fica difícil com o aumento da distância do operador à fonte objeto do trabalho.

Porém, quando estas duas metodologias não são suficientes para atenuarem a radiação ao valor desejado, é necessário introduzir a terceira, isto é, a interposição de barreiras entre a fonte de radiação e/ou os equipamentos e indivíduos.

\subsubsection{Utilização de barreiras de proteção para atenuação das radiações gama e X.}

Quando definida a necessidade da utilização das barreiras às radiações (blindagens) como parte indispensável para a proteção e operação em instalações de equipamentos geradores, inicia-se o trabalho de projeto da estrutura física necessária a desempenhar tal papel na construção.

Em se tratando de instalações de blindagem para a radioproteção, pode-se afirmar que, dentre os componentes utilizados na construção civil, os que têm maior impacto sobre os custos das obras são as blindagens.

Não diferentemente de outros países, no Brasil empregam-se vários tipos de materiais para a construção de proteções à radiação ionizante. Quando se trata de fótons de menor energia, em geral, a absorção fotoelétrica aumenta com o incremento 
do número atômico efetivo, e decresce com o aumento da energia da radiação (2). São utilizadas então pequenas espessuras, e são empregados materiais como revestimentos de argamassas com a utilização de barita como agregado miúdo e aditivos especiais, geralmente aplicados sobre uma estrutura já existente, como alvenaria, painéis de concreto ou gesso acartonado.

Quando da necessidade de proteções para faixas de energias mais elevadas, situação em que são observados principalmente os efeitos fotoelétrico e Compton, a blindagem geralmente requer maiores espessuras, o concreto de massa específica normal, cuja massa específica é determinada entre $2,0 \mathrm{~kg} / \mathrm{dm}^{3}$ e $2,8 \mathrm{~kg} / \mathrm{dm}^{3}$ (3), é bastante empregado. Já em menor número de aplicações são utilizados os concretos de massa específica elevada com massa especificas superior a $2,8 \mathrm{~kg} / \mathrm{dm}^{3}$.

As chapas de chumbo, os painéis de aço e vidros pumblíferos são materiais também utilizados para a proteção às radiações ionizantes, e têm seu emprego restrito a áreas específicas em virtude do seu elevado custo.

2.1.2 Desenvolvimento de um projeto de radioproteção.

O desenvolvimento de um projeto para proteção às radiações gama e $X$ é tarefa que envolve aspectos físicos, químicos, econômicos, ambientais e legais.

Definido que a proteção será realizada com a utilização do concreto de elevada massa específica, algumas questões devem ser respondidas e avaliadas para que o concreto desenvolvido seja adequado.

Qual o concreto adequado à radiação que deverá atenuar?

Qual o efeito predominante na interação da radiação utilizada com a matéria?

Quais as matérias-primas disponíveis para a produção de concretos de elevada massa específica?

Quais são os coeficientes de atenuação linear dos concretos preparados no Brasil, com matérias-primas nacionais?

Qual o custo de produção destes concretos? 


\subsection{Concretos como blindagem às radiações gama e X.}

2.2.1 Uso do concreto como proteção às radiações gama e $X$.

Dentre os materiais utilizados no Brasil como barreira às radiações ionizantes, o concreto convencional é muito usado, e tem como vantagens o pequeno custo de aquisição, a tradição construtiva deste material, que é utilizado em grande escala no país para a execução de estruturas de edifícios, e a disponibilidade de matérias-primas disponíveis em quase todas as regiões do país.

Porém, algumas dificuldades podem ocorrer quando a escolha é a de utilizar concreto convencional para a proteção às radiações ionizantes; dentre elas podemos citar a falta de homogeneidade do material quando aplicado e o baixo coeficiente de atenuação linear, que pode comprometer a eficácia da proteção, tornando necessária a construção de paredes ou lajes com grandes espessuras para obtenção de uma proteção adequada, fazendo com que uma parte da área disponível para a instalação dos equipamentos e operação seja consumida pela área da parede, o que provoca um aumento do custo específico da construção em função da diminuição da área útil.

A escolha pelo concreto de elevada massa específica é uma escolha cuja ênfase é o desempenho, e pode proporcionar a diminuição da área ocupada pela parede e uma economia de área. 


\subsubsection{Concreto de elevada massa específica.}

Segundo Metha \& Monteiro "Concretos pesados geralmente são produzidos com o emprego de agregados naturais pesados. Os pesos específicos do concreto variam de 3.360 a $3.840 \mathrm{~kg} / \mathrm{m}^{3}$, que é aproximadamente $50 \%$ mais alto do que o peso específico do concreto contendo agregados de peso natural" (3)

Concretos de elevada massa específica são produzidos similarmente aos concretos de massa específica normal, formados por uma mistura de aglomerantes, agregados, adições e aditivos, porém, para a produção de concretos de elevada massa específica, é necessária a utilização de agregados de elevada massa específica.

Normalmente os agregados de elevada massa específica são minerais com presença acentuada de óxido de elementos químicos densos.

Os aglomerantes utilizados para o preparo dos concretos de elevada massa específica podem ser escolhidos entre os diversos tipos de cimentos Portland, produzidos e comercializados no Brasil, da mesma maneira os aditivos e as adições.

\subsubsection{Importância da caracterização das matérias-primas empregadas.}

Primeiramente, é fato que as matérias-primas utilizadas para a produção de concretos, quer para a fabricação dos aglomerantes, quer para a produção dos agregados, são de origem mineral, cuja exploração se faz em jazidas distribuídas pelo território nacional, jazidas estas que apresentam formações geológicas distintas, e, consequentemente, podem apresentar diferentes teores e combinações de elementos, e a composição química dos minerais produzidos pode variar significativamente em função das condições locais e da maneira como são explorados.

Grandes variações nos teores dos elementos presentes nos minerais podem alterar o comportamento do concreto preparado quando utilizado como blindagem, pois variações dos teores dos elementos presentes alteram a seção de choque do composto, e, consequentemente, o coeficiente de atenuação linear para as radiações gama e $X$. 
Para a prescrição dos agregados a serem utilizados no concreto para a blindagem é importante que se faça a caracterização química e física das matériasprimas. Matérias-primas de mesma massa específica podem comportar-se diferentemente quando submetidas a um fluxo de radiações, como exemplo podemos citar as seções de choque do Cálcio e da Sílica, dois elementos comunmente encontrados nos agregados de construção civil, utilizados para o preparo de concretos. Estes elementos apresentam uma variação significativa em suas seções de choque quando se trata da atenuação de pequenas energias, afetando diretamente na formação do coeficiente de atenuação linear ainda que apresentem massa especifica similares.

\subsubsection{Propriedades físicas e químicas das matérias-primas}

A escolha e a definição das matérias-primas a serem utilizadas para a produção de concretos de elevada massa específica têm grande influência sobre o comportamento do concreto quando submetido às radiações gama e X. É de suma importância que o profissional que definirá 0 traço ${ }^{6}$ de concreto conheça as características químicas e físicas das matérias-primas utilizadas, pois o desempenho do concreto frente às radiações depende das características químicas e físicas dos componentes utilizados. A combinação dessas características dará a massa específica e o número atômico efetivo do composto.

Convém lembrar que, conforme mencionado anteriormente, os componentes a serem utilizados para o preparo de concretos devem atender às normas técnicas existentes.

Concretos são produzidos com a utilização de matérias-primas locais, isto é, preferencialmente disponíveis na região onde serão preparados, em virtude do grande impacto que o frete tem sobre o preço final da matéria-prima.

Para a produção de concretos de elevada massa específica é de suma importância que se utilizem agregados de elevada massa específica, porém estes

\footnotetext{
${ }^{6}$ Traço, termo dado à receita do concreto, a quantidade necessária de cada elemento químico para a produção dele.
} 
agregados geralmente são minérios de ferro, e não estão disponíveis em todas as regiões do país.

Características como granulometria e forma dos agregados são fatores que devem ser bem avaliados, pois interferem na composição dos preços e no desempenho do concreto.

\subsubsection{Aglomerantes}

Os aglomerantes utilizados para a produção de concretos de elevada massa específica podem influir da mesma maneira que os agregados, variações na composição química dos cimentos podem provocar variações na massa específica e alterar o Z efetivo dos concretos, alterando a seção de choque e influenciando o coeficiente de atenuação linear.

Segundo a Associação Brasileira de Cimento Portland (ABCP) (4), "O mercado nacional dispõe de oito opções, que atendem com igual desempenho aos mais variados tipos de obras".

\subsubsection{Adições}

Segundo Maristela Gomes da Silva, "Adições de materiais finamente moídos, ao concreto, normalmente chamados de adições minerais são utilizados por razões que vão desde a melhoria da trabalhabilidade do concreto no estado fresco até a garantia da durabilidade necessária as condições de serviço”. (5)

As adições minerais podem ser divididas em três grandes categorias, quais sejam materiais cimentícios, como escórias de alto forno, materiais pozolânicos, como as cinzas volantes, sílica ativa, entre outros, e materiais não reativos, como o fíler de calcário.

As adições podem ser realizadas na produção do cimento, na produção do concreto e/ou combinada em ambas as fases. 
No Brasil, os principais materiais de adição disponíveis no mercado são a Microsilica, o Metacaulin e o Filer Calcário.

As aplicações no Brasil são realizadas na maioria das vezes quando da mistura do concreto.

\subsubsection{Aditivos}

Os aditivos para concreto têm como finalidade básica aumentar a trabalhabilidade, diminuir o fator água e aglomerante, diminuindo o consumo de cimento e mantendo a resistência, alterar o tempo de reação, aumentar o empacotamento, diminuir a permeabilidade, aumentando a durabilidade, e, no caso de nosso trabalho, aumentar a seção de choque para as radiações gama e X.

De acordo com a NBR 11768 (6) os aditivos são classificados de acordo com o tipo e finalidade.

Concretos de elevada massa específica sofrem grande ação das forças de gravidade em razão da elevada massa específica do agregado, que provoca um aumento do atrito interno dos materiais que, para minimizar, requerem um aumento do teor de argamassa e, consequentemente, um aumento de cimento, cujo objetivo é minimizar o efeito do atrito entre os agregados.

Normalmente, com o aumento do teor de argamassa o teor de finos aumenta, e pode haver necessidade de se utilizar fatores de água aglomerante, mais elevados.

O aumento do consumo de água pode provocar um aumento no volume de vazios e diminuir a massa específica, condição que, para concretos destinados a blindagem das radiações gama e $X$, em determinadas energias, pode não ser desejada.

A utilização de um aditivo redutor de água superplastificante pode ser uma alternativa para não se aumentar o fator água aglomerante a níveis inadequados, porém, para concretos de elevada massa específica há de se observar o efeito da densidade do agregado. 


\subsubsection{Agregados para concreto}

No Brasil, a ABNT (Associação Brasileira de Norma Técnica), através de normas específicas, define os critérios para aceitação, classificação, caracterização e aplicação destes materiais no concreto convencional, sendo as normas NBR 9935 (ABNT-1987) (7), Agregado - Terminologia e a NBR 7211 (ABNT - 1983) (8), Agregado para Concreto. Elas fixam as características exigíveis na recepção e produção dos agregados miúdos e graúdos, de origem natural já encontrados fragmentados ou resultantes do britamento de rochas destinados à produção de concretos.

As prescrições específicas da norma citada referem-se aos agregados sobre os quais o consumidor dispõe de histórico de desempenho em concretos de qualidade similar e em condições de exposição equivalentes às do concreto previsto.

Para os agregados sobre os quais não existem antecedentes de desempenho ou que vão ser utilizados pela primeira vez, ou para as regiões em que não seja economicamente possível a obtenção de agregados que preencham as condições desta norma, o consumidor poderá utilizá-los, desde que se comprove, mediante parecer, baseado em estudo experimental, que com os agregados disponíveis poderse-á produzir concreto de qualidade satisfatória.

\subsubsection{Condições gerais.}

A) Os agregados devem ser compostos por grãos de minerais duros, compactos, duráveis e limpos, não devem conter substâncias de natureza, e em quantidade que possam afetar a hidratação e o endurecimento do cimento, a proteção da armadura contra a corrosão, a durabilidade ou, quando for requerido, o aspecto visual externo do concreto. O exame petrográfico, realizado de acordo com a NBR 7389 (9) e interpretado por profissional capacitado, fornece ao consumidor alguns dos subsídios necessários para o cumprimento destas condições. 


\section{ipen}

B) Os agregados para uso em concreto ou argamassas que estarão sujeitos a umedecimento, incluindo-se a exposição à atmosfera úmida ou contato com o solo úmido, não devem conter qualquer material deleteriamente reativo com os álcalis do cimento em uma intensidade suficiente para causar uma expansão daargamassa e/ou do concreto, exceto nos casos em que o cimento empregado contiver menos que $0,6 \%$ de equivalente alcalino expresso em $\mathrm{Na}_{2} \mathrm{O}$ e for adicionado de substâncias que comprovadamente previnam a expansão prejudicial devido à reação álcali-agregado.

No caso dos concretos com cimento Portland, as diferentes características encontradas nos agregados interferem nas propriedades dos concretos. Na tabela (1), apresentada a seguir, são mostradas as relações entre estas características. 
Tabela 1 - Propriedades do concreto influenciadas pelas características do agregado adaptada (10)

\begin{tabular}{|c|l|}
\hline Propriedades do Concreto & Características Relevantes do Agregado \\
\hline Resistência mecânica & Resistência mecânica \\
& Textura superficial \\
& Limpeza \\
& Forma dos grãos \\
& Dimensão máxima \\
& Porosidade \\
& Superfície especifica \\
\hline Retração & Granulometria \\
\hline & Módulo de elasticidade \\
& Forma dos grãos \\
& Textura superficial \\
& Limpeza \\
& Dimensão máxima \\
& Superfície especifica \\
\hline Massa Unitária & Granulometria \\
\hline & Massa específica \\
& Forma dos grãos \\
& Granulometria \\
& Dimensão máxima \\
\hline Modulo de elasticidade & Superfície especifica \\
\hline Resistência a derrapagem & Granulometria \\
\hline Economia & Módulo de elasticidade \\
& Coeficiente de Poisson \\
\hline & Tendência ao polimento \\
& Forma do grão \\
& Granulometria \\
& Dimensão máxima \\
& Beneficiamento requerido \\
& Disponibilidade \\
& Constancia de fornecimento \\
\hline
\end{tabular}

No caso dos concretos de elevada densidade, algumas destas características interferem de forma mais acentuada, dentre elas podemos citar a densidade, a forma dos grãos e a composição química do mineral.

\subsubsection{Agregados de elevada massa específica.}

Segundo Metha \& Monteiro (3) "Os agregados são relativamente baratos e não entram em complexas reações químicas com a água. Por isso, tem sido comumente tratados como material de enchimento inerte do concreto. No entanto, devido a uma melhor compreensão do papel desempenhado pelos agregados na determinação de 
muitas propriedades importantes do concreto, a visão tradicional do agregado como um material inerte vem sendo seriamente questionada".

"Comparados ao concreto com agregado de peso normal, com massa específica típica de $2.400 \mathrm{~kg} / \mathrm{m}^{3}$, concretos pesados variam de 2.900 a $6.100 \mathrm{~kg} / \mathrm{m}^{3}$ e são principalmente usados para a blindagem de radiação nuclear."

Ainda segundo o autor acima citado (3) a massa específica dos agregados de elevada densidade variam de 3,4 a $7,8 \mathrm{~g} / \mathrm{cm}^{3}$.

Tratando de concretos de elevada massa específica, para a blindagem às radiações gama e $X$ as características dos agregados ganham importância ainda maior graças a grande influência que a composição química deles tem na determinação do coeficiente de atenuação linear (seção de coque).

Quando o concreto de elevada massa específica é destinado à blindagem, a escolha das matérias-primas a serem utilizadas deve ser feita em função da composição química do elemento que deve possuir seção de choque mais elevada para o efeito predominante.

Da mesma maneira que os agregados utilizados para a produção do concreto normal, os agregados utilizados para a produção dos concretos de elevada massa específica devem atender às prescrições impostas pelas normas acrescidas das complementares.

\subsection{Classificação dos agregados de elevada massa específica.}

No Brasil ainda não dispomos de uma norma específica que trate das características necessárias para os agregados a serem utilizados em concretos de elevada massa específica para atenuação às radiações, porém, as normas ASTM C 637 - 73 (11) e 638 - 73 (12) tratam respectivamente da nomenclatura empregada e das especificações dos agregados para aplicação em concretos de elevada massa específica. 
Segundo a ASTM 638-73 (11) os agregados são classificados em naturais ou artificiais de elevada massa específica e materiais sintéticos ou vidros com substancial presença de boro.

No presente trabalho utilizamos como agregados os agregados minerais naturais de elevada massa específica, que são, em sua maioria, formados por barita e minérios de ferro, sendo os principais a hematita, a barita e a magnetita, cujas características físicas e químicas são apresentadas no Anexo 1.

\subsubsection{Formulação do traço de concreto}

"Para se obter concreto com determinadas características de desempenho, uma criteriosa seleção dos materiais componentes é o primeiro passo. O passo seguinte é um processo chamado dosagem de concreto, que significa encontrar a combinação correta dos componentes" (3).

Os traços de concreto são desenvolvidos com o objetivo de atenderem às características necessárias para a utilização.

Normalmente em estruturas no Brasil as preocupações são com a resistência à compressão e durabilidade.

Para o caso específico do nosso trabalho, devemos adicionar às características acima mencionadas uma elevada seção de choque ao efeito fotelétrico e Compton.

Os traços de concreto também são formulados em função do tipo de matériasprimas e cimentos disponíveis na região que se pretende produzir o concreto, sendo o custo das matérias-primas e do cimento um dos fatores mais importantes.

A trabalhabilidade ou condição que o concreto apresentará depois de misturado no momento da aplicação é um dos itens que tem grande importância quando se formula um traço de concreto e se busca um desempenho adequado, pois além dos aspectos econômicos tem influência sobre a condição em que o concreto apresentará depois de curado.

Quando se utilizam agregados de elevada massa específica, a ação da força da gravidade proveniente da elevada massa dos agregados e a forma dos grãos 
dificultam o escoamento do concreto em virtude do aumento do atrito entre os agregados. Para a obtenção de uma boa trabalhabilidade é necessário, dentre outros aspectos, escolher agregados com forma adequada, fazer uma boa combinação de granulometrias e utilizar elevado teor de argamassa.

As técnicas de formulação de traços de concreto normais baseiam-se na escolha da combinação adequada entre agregados, aglomerantes e adições, que são combinados para se obter uma mistura de componentes que produzam um concreto com características como trabalhabilidade, resistência, massa específica, baixa permeabilidade etc.

Para o desenvolvimento dos traços de concretos algumas técnicas foram elaboradas no decorrer do tempo.

Segundo Paulo Helene e Tutikian (13) "Vários são os métodos de dosagem disponíveis na literatura especializada. Considera-se, no entanto, que o método proposto inicialmente por Eládio Petrucci (1965) e posteriormente modificado com contribuições de pesquisadores do IPT, Priszkulnik, Kirilos, Terzian e Tango, e da EPUSP, Helene, é um dos métodos mais versáteis, simples e capazes de fornecer uma resposta profícua aos requisitos exigidos de um concreto, atendendo tanto às exigências técnicas dos projetistas estruturais, quanto às econômicas, de sustentabilidade e de produtividade dos construtores e usuários dos concretos".

O método, na sua versão atual, busca obter o comportamento mecânico e reológico do concreto de forma unívoca com os materiais escolhidos. É um método que pode classificar-se como teórico-experimental, em que há uma parte experimental de laboratório precedida por uma parte analítica de cálculo baseada em leis de comportamento dos concretos.

O método considera a relação água e cimento como o parâmetro mais importante para o concreto estrutural. Definidos os materiais e a relação entre a quantidade de água utilizada para a produção do concreto e a de cimento, a resistência e durabilidade do concreto passam a ser únicas, sempre que seja mantida a mesma trabalhabilidade da mistura.

Esse método não exige conhecimentos prévios sobre o cimento, as adições e os agregados, apesar de que, sob o ponto de vista da durabilidade, sempre é conveniente contar com informação de ensaios prévios de laboratório, como: 
reatividade álcali-agregado, presença de sulfatos, de matérias carbonosas, presença de pó e de argila, granulometria e outros.

É um método que combina conceitos teóricos de comportamento do concreto de uma forma analítica desenvolvida em gabinete, mas continua requerendo um estudo experimental em laboratório. Esse experimento, nesse caso, é fundamental, pois, ao se fixar o mesmo abatimento para diferentes proporções de teor de argamassa seca, pretende-se encontrar a mínima quantidade de água para obter a trabalhabilidade especificada. Dessa forma, é otimizada a proporção entre agregados miúdos e graúdos com bases experimentais nas quais está implicitamente incluída a interferência do cimento, agregados, adições e de outros materiais utilizados.

Isso the confere uma vantagem em relação a outros métodos que apenas tratam de otimizar, por separado, por um lado, a mistura de agregado miúdo/agregado graúdo com bases em curvas granulométricas ideais, e por outro a pasta de cimento, adições e aditivos, esperando que, assim, isoladamente otimizadas, conduzirão a um concreto ótimo ao serem juntadas na betoneira.

Segundo Aitcin (15), "Como foi mostrado, no presente estado da arte, a fabricação com sucesso de concreto de alto desempenho depende de uma combinação de regras empíricas derivadas da experiência, do trabalho de laboratório e de uma grande dose de senso comum."

\subsection{Interação da radiação eletromagnética e gama com a matéria.}

\subsubsection{Introdução}

Segundo Brownell \& Hine (16) "Quando a radiação eletromagnética passa através da matéria, às partículas do material podem absorver parte da energia da radiação.Energias eletromagnéticas intermediarias interagem somente com elétrons livres ou quase livres do átomo, energias elevadas interagem com o núcleo do átomo."

A interação da radiação com a matéria é complexa, depende da natureza do processo que ocorre e está vinculado à energia da radiação e ao número atômico do 


\section{ipen}

material. Os principais efeitos que ocorrem com a interação da radiação com a matéria são o efeito fotoelétrico o espalhamento Compton e produção de pares.

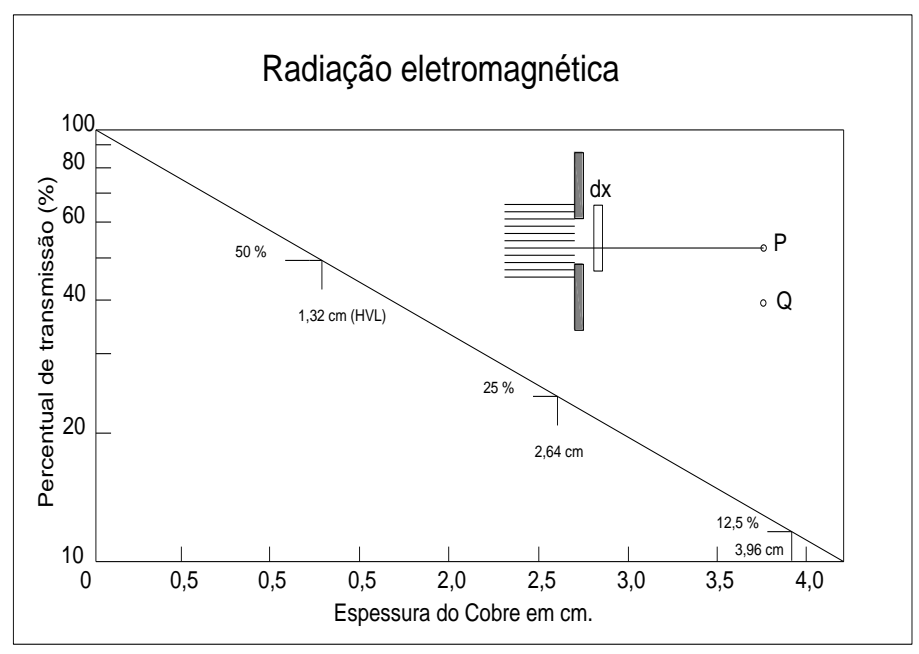

Figura. 1 - Absorção exponencial para o Cobre para fótons de energia de $1 \mathrm{MeV}$ para um coeficiente de atenuação linear $\mu=0,524 \mathrm{~cm}^{-1}$. Adaptada de Brownell e Hine (15).

Supomos que um equipamento grave a contagem do número de fótons $\mathrm{N}_{0}$ que sai da fonte e consegue passar pelo colimador sem ser desviado por unidade de tempo em um ponto $\mathrm{P}$, ver na figura (1), sem o material absorvedor.

Se um absorvedor de espessura $\mathrm{dX}$ for colocado entre a fonte de radiação e o detector, o número dN, equação (1), representa o número de fótons absorvidos ou desviados do caminho que não atingem o ponto $\mathrm{P}$. Portanto $\mathrm{dN}$, o número de fótons removidos, depende diretamente do número presente antes da interação e da espessura do absorvedor $\mathrm{dX}$. Se dN dobra, o número de fótons absorvidos ou desviados do caminho dobra, e a espessura dX dobra. Matematicamente então,

$$
d N=-\mu N d x
$$

sendo $\mu$ é a constante de proporcionalidade chamada de coeficiente de atenuação linear.

Mais usual é escrever a equação (2) em função da mudança de intensidade de energia do feixe, dl, e da intensidade de entrada, I. A intensidade é medida em função 
do número de fótons que incidem e do número de fótons que atravessam por unidade de área e pode ser expresso em ergs $/ \mathrm{cm}^{2}$-seg. Então teremos:

$$
d I=-\mu I d X
$$

O sinal negativo é incluído porque quando aumenta o feixe não colidido dl diminui.

$$
\begin{gathered}
\frac{d I}{I}=-\mu d x \\
\int_{\mathbf{0}}^{I_{0}} \frac{d I}{I}=-\int_{\mathbf{0}}^{x} \mu d X \\
\ln \frac{I}{I_{0}}=-\mu x \\
\frac{I}{I_{0}}=e^{-\mu x}(2 \mathrm{~d}) \\
I=I_{0} e^{-\mu x}(2 \mathrm{e})
\end{gathered}
$$

Supondo um feixe colimado como exposto na figura (1) parte direita superior, incidindo sobre um material absorvedor e em seguida na mesma direção um detector, a equação que nos fornece a intensidade de energia dos raios que não sofreram nenhuma interação com o absorvedor é dado pela equação (3), desde que a espessura do material seja inferior ou igual a um caminho livre médio da radiação no próprio material.

$$
I\left(E_{\mathbf{0}}\right)=I_{\mathbf{0}}\left(E_{\mathbf{0}}\right) e^{-\mu x}
$$

onde:

$I\left(E_{\mathbf{0}}\right)$ é a intensidade de energia para a radiação ionizante eletromagnética com energia inicial que não colidiu no material absorvedor e alcançou o detector. 
$I_{\mathbf{0}}\left(E_{\mathbf{0}}\right)$ é a intensidade de energia para a radiação eletromagnética que incide sobre o material absorvedor.

$\mu$ é o coeficiente de atenuação linear em unidades de $\mathrm{cm}^{-1}$.

$X$ é a espessura do material absorvedor em $\mathrm{cm}$.

A espessura do absorvedor deve ser pequena, isto é, menor ou igual a $\frac{1}{\mu} \mathrm{cm}$. Nesse caso diz-se que temos condições de boa geometria, e seu valor é conhecido como caminho livre médio entre duas interações sucessivas.

Se o absorvedor tiver uma espessura maior do que um caminho livre médio haverá a possibilidade da radiação ionizante eletromagnética sofrer mais de uma interação, e se houve espalhamento a radiação resultante poderá alcançar o detector com uma energia $E$ menor do que a inicial $E_{0}$, mas que será somada ao feixe não colimado. Nesse caso é chamada de má geometria ou geometria pobre, e, portanto, o receptor receberá uma intensidade dada pela equação (4).

$I(E)>I\left(E_{\mathbf{0}}\right)$ e, a equação inicial (3) se tornará $I(E)=B I_{\mathbf{0}}\left(E_{\mathbf{0}}\right) e^{-\mu x}(4)$, onde:

$B$ é conhecido como fator de crescimento, em inglês " Build-Up”.

Para se determinar o real $I(E)$ deveríamos ter um detector espelho que receba toda a radiação eletromagnética espalhada pelo absorvedor além daquela que não sofreu colisão. 
2.3.2 Coeficiente de atenuação linear eletrônico, atômico e massa.

Desde que a interação da radiação com a matéria envolva elétrons e átomos do material, é mais usual obter-se o coeficiente de atenuação linear por elétron de preferência por centímetro de espessura de material. $O$ coeficiente de atenuação linear por centímetro de espessura de material naturalmente depende da massa específica do material, ao passo que o coeficiente de atenuação linear por elétron é independente da condição física ou do estado químico do material.

Outros coeficientes de atenuação usuais utilizados são o coeficiente de atenuação de massa e o coeficiente de absorção de massa. Estes coeficientes são relacionados com a massa do material ( $\rho$ ), o número atômico $(Z)$, a massa atômica (A) e o número de Avogadro $\left(\mathrm{N}=6,02 \times 10^{23}\right)$.

Considerando a espessura do material $1 \mathrm{~cm}$ e a área $1 \mathrm{~cm}^{2}$, este centímetro cúbico terá a massa de $\rho$ gramas. Conterá $\frac{N}{A} \rho$ átomos e $\frac{N}{A} \rho Z$ elétrons. Portanto, as relações entre o coeficiente de atenuação linear e os demais, isto é, coeficiente de atenuação mássico, coeficiente de atenuação linear atômico e coeficiente de atenuação linear eletrônico são os que seguem com suas respectivas dimensões.

Coeficiente de atenuação $\quad$ Linear $=\mu \quad \mathrm{cm}^{-1}$

Coeficiente de atenuação linear Massa $=\frac{\mu}{\rho} \quad \mathrm{cm}^{2} \mathrm{~g}^{-1}$

Coeficiente de atenuação linear Atômico $=\frac{\mu}{\rho} \frac{A}{N} \quad \mathrm{~cm}^{2}$ átomo ${ }^{-1}$

Coeficiente de atenuação linear Eletrônico $=\frac{\mu}{\rho} \frac{A}{N} \frac{1}{Z} \mathrm{~cm}^{2}$ elétron ${ }^{-1}$

Na tabela (2), apresentada a seguir o número atômico, a massa específica e o número de elétrons por grama é dado para alguns materiais comuns.

O número de elétrons por grama e dado por $N(Z / A)$, mostrado na última coluna, é muito próximo para todos os materiais listados menos para o hidrogênio. Para a maioria dos materiais de pequeno número atômico $Z / A$ são muito próximos a 0,50 . $A$ 
relação cai aos poucos com 0 incremento de $Z$ até 0,39 para 0 urânio. Consequentemente, o coeficiente de absorção de massa pode ser obtido, aproximadamente, usando o fator $3 \times 10^{23}$ para a maioria dos materiais.

No exemplo da tabela (2), o coeficiente de absorção linear do cobre é $0,524 \mathrm{~cm}^{-1}$, o coeficiente de absorção de massa é $0,0587 \mathrm{~cm}^{2} / \mathrm{g}$, o coeficiente de absorção atomico $6,20 \times 10^{-24} \mathrm{~cm}^{2} /$ átomo e o coeficiente de absorção eletrônico 0,214 $x 10^{-24} \mathrm{~cm}^{2} /$ electron. Os resultados são derivados das equações apresentadas acima, onde para o cobre a massa específica é $\rho=8,93, A=29$ e $\mathrm{N}=6,02 \times 10^{-24}$.

Tabela. 2 - Massa específica, massa atômica, número atômico, número de elétrons por grama para vários materiais. Adaptada (16).

\begin{tabular}{ccccc}
\hline \multicolumn{2}{c}{ Densidade, Massa Atômica, Número Atômico, e Densidade Eletrônica, para Vários Materiais } \\
\hline Material & Densidade & Massa Atômica & Número Atômico & $\begin{array}{c}\text { Número de } \\
\text { eletrons }\end{array}$ \\
\hline Hidrogenio & $\mathrm{g} / \mathrm{cm}^{3}$ & $\mathrm{~A}$ & $\mathrm{Z}$ & eletrons/g \\
Carbono & 2,0000899 & 1,008000 & 1,00 & 5,97 \\
Nitrogenio & 0,2500000 & 12,010000 & 6,00 & 3,01 \\
Oxigenio & 0,0014290 & 14,008000 & 7,00 & 3,01 \\
Aluminio & 2,7000000 & 16,000000 & 8,00 & 3,01 \\
Cobre & 8,9000000 & 26,970000 & 13,00 & 2,90 \\
Chumbo & 11,3500000 & 63,570000 & 29,00 & 2,75 \\
Uranio & 18,7000000 & 207,210000 & 82,00 & 2,38 \\
Ar & 0,0012930 & 18,700000 & 92,00 & 2,33 \\
Agua & 1,0000000 & 0,001293 & 7,64 & 3,03 \\
\hline
\end{tabular}

Os coeficientes de absorção atômico e eletrônico têm dimensões de área. Por esta razão eles são chamados de seções de choque.

Se multiplicarmos a seção de choque pelo número de elétrons em um centímetro cúbico de um material teremos a área total dos elétrons em um centímetro cúbico que é igual ao coeficiente de atenuação linear. O coeficiente de absorção eletrônico é idêntico à seção de choque, e este termo pode ser usado para expressar a mesma coisa. Em física nuclear o termo "barn" é considerado como unidade da seção de choque e equivale a $10^{-24} \mathrm{~cm}^{2}$. 


\subsubsection{Efeito fotoelétrico}

Para fótons de pequena energia, isto é, inferiores a cerca de $0,1 \mathrm{MeV}$ com meios absorvedores de número atômico, $Z$, médio ou elevado, predomina o processo de interação denominado fotoelétrico.

A interação se dá com os elétrons ligados ao átomo nas suas camadas mais internas $\mathrm{K}, \mathrm{L}$..., portanto é considerado como uma interação do átomo como um todo. Foi verificado experimental e teoricamente que cerca de $80 \%$ das interações se dá na camada $\mathrm{K}$, e os restantes $20 \%$ nas demais camadas.

O que ocorre é que o fóton, interagindo com o átomo, expulsa um elétron preferencialmente da camada $\mathrm{K}$ com uma energia cinética $E_{\mathbf{0}}=h v-B_{e}(5)$.

Sendo:

$E_{\mathbf{0}}$ é a energia cinética do elétron ejetado.

$h v$ é a energia do fóton incidente.

$B_{e}$ é a energia de ligação do elétron ao átomo.

Nesse caso, o fóton desaparece, e, pela conservação da quantidade de movimento, há um recuo do átomo.

Como ao átomo falta um elétron da camada $\mathrm{K}$, outro elétron das camadas mais externas sofre transição para a camada $\mathrm{K}$ e emite um raio $\mathrm{X}$ característico de energia pequena igual a diferença entre as duas energias de ligação das camadas envolvidas.

Em virtude disso, supõe-se que toda a energia do fóton foi absorvida e não há espalhamento, isto é considera-se que esta pequena energia é loclamente absorvida.

A probabilidade absoluta de uma interação fotoelétrica é descrita pela seção de choque atômica. $a^{\tau} \mathrm{cm}^{2} /$ átomo.

A maior probabilidade de ocorrência do processo fotoelétrico se dá com energias do fóton logo acima da energia de ligação do elétron de interação e diminui abruptamente com o aumento da energia até alcançar a energia de ligação da camada seguinte. 
Para uma orientação grosseira podemos considerar como aproximação grosseira o resultado dado pela aplicação da equação (6).

$$
{ }_{a} \tau \cong \text { const } \frac{Z^{4}}{(h v)^{3}}{ }^{(6)}
$$

\subsubsection{Espalhamento Compton.}

Enquanto o processo fotoelétrico só pode ocorrer com os elétrons ligados ao átomo, o processo Compton ocorre com um elétron livre ou fracamente ligado. Dessa maneira, enquanto a interação fotoelétrica se dá com um átomo como um todo, o espalhamento Compton se dá com os elétrons das camadas de menor energia de ligação ou elétrons livres.

No processo Compton um fóton com energia $h v$ colide com um elétron em movimento e ele, próprio fóton, é espalhado com uma energia menor $h v^{\prime}$.

O processo é ilustrado na figura (2) a seguir, em que são mostradas as energias $T$ e as quantidades de movimento $P$, antes e depois da interação.

Radiação Eletromagnética

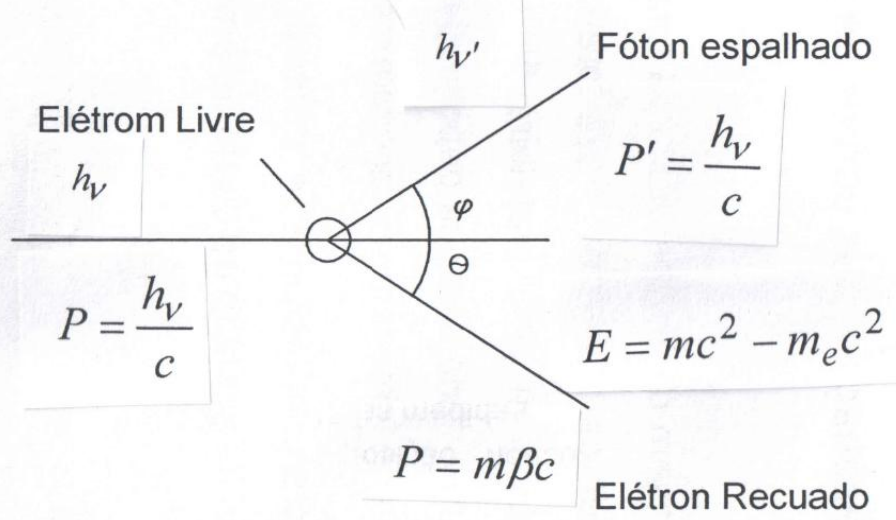

Figura. 2 - Colisão do fóton com energia $h v$ com um elétron livre no processo Compton. Adaptada de Brownell \& Hine (16). 


\subsubsection{Produção de pares.}

A energia associada a um elétron em repouso, como já vimos é $m_{\mathbf{0}} c^{2}=\mathbf{0 , 5 1} M e V$.

Um fóton com energia maior do que $2 m_{\mathbf{0}} c^{\mathbf{2}}=\mathbf{1 , 0 2} \mathrm{MeV}$ pode interagir com o núcleo de um átomo e desaparecer, formando dois elétrons, um positivo, pósitron, e outro negativo, elétron com energias cinéticas $T_{-}$e $T_{+}$

Na figura (3) é apresentado o processo de produção de pares.

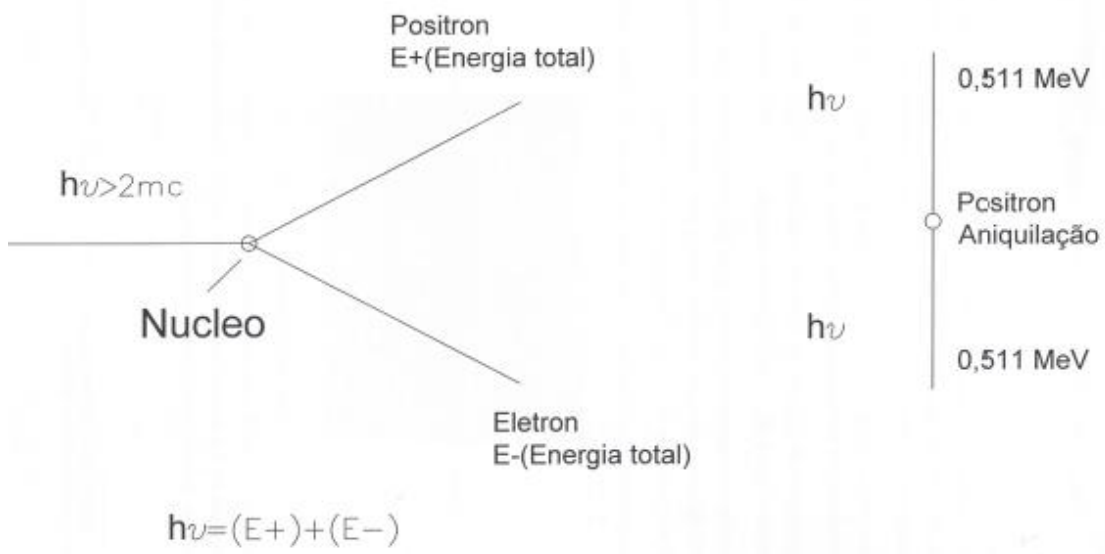

Figura. 3 - Processo de produção de pares. Adaptada de Brownell \& Hine (16).

Nessa interação o núcleo adquire uma quantidade de movimento indeterminado e uma energia cinética desprezível. Da conservação de energia equação (6), temos:

$$
h v-2 m_{0} c^{2}=\mathrm{T}_{-}+\mathrm{T}_{+}(6)
$$

Dessa maneira, se um fóton tiver $10 \mathrm{MeV}$ de energia, o pósitron e o elétron dividirão $9 \mathrm{MeV}$ de energia cinética restantes de diferentes maneiras que dependerá dos ângulos em que eles emergirão. 
2.3.6 Seção de choque para a energia utilizada.

Como no trabalho de pesquisa em apreço só usaremos uma fonte emissora gama com energia de $660 \mathrm{keV}$, não haverá produção de pares e, portanto, não entraremos em mais detalhes sobre $o$ assunto.

Dessa maneira, o nosso coeficiente de atenuação linear mássico atômico ${ }_{a} \mu$, poderá ser representado por equação (7):

$$
{ }_{a} \mu={ }_{a} \tau+{ }_{a} \sigma(7)
$$

$a^{\tau}$ é o coeficiente de atenuação linear mássico para o efeito fotoelétrico.

${ }_{a} \sigma$ é o coeficiente de atenuação linear mássico para o espalhamento Compton.

Como estes processos de atenuação possuem probabilidades diferentes para cada energia dos fótons, na figura (4), da energia do fóton contra o número atômico do absorvedor construimos duas linhas nas quais as probabilidades de ocorrer o processo são iguais. Isso faz com que a figura fique dividida em três regiões de maior probabilidade de cada processo.

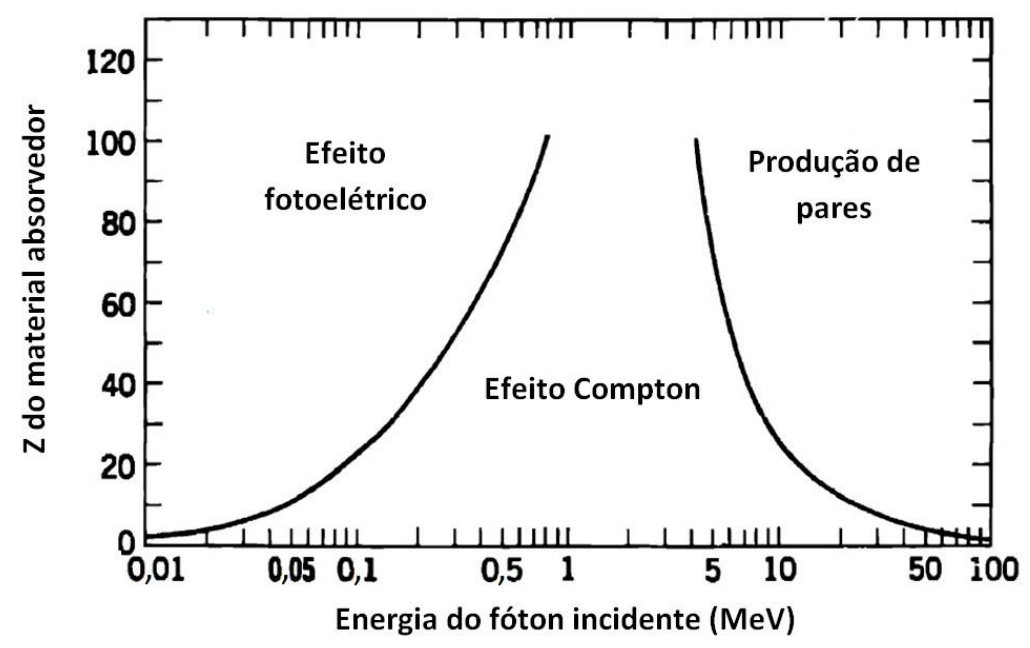

Figura. 4 - Importância relativa dos três principais tipos de interação para radiação $\gamma$. Aptada de Evans. (2) 


\subsubsection{Fator de crescimento "Buildup-Factor".}

Retornando novamente ao caso de geometria de irradiação pobre, podemos definir o fator de crescimento como a razão do fluxo real de radiação gama que pode ser calculado a partir da simples atenuação exponencial, usando o coeficiente de atenuação linear.

Nesse caso, a dose E detectada equação (8), no instrumento após o material absorvedor, será dada por;

$$
E=\frac{S_{0} B^{e-\mu x}}{\Gamma 4 \pi r^{2}}(8)
$$

Sendo:

$E$ é a taxa de dose efetiva.

$S_{0}$ é a fonte puntiforme de radiação gama (fótons por segundo).

$B$ é o fator de crescimento, admensional.

$\mu$ é o coeficiente de atenuação linear (recíproco de comprimento $\mathrm{cm}^{-1}$ )

x é a espessura do material absorvedor colocado entre a fonte de radiação e o receptor.

$\Gamma$ é a constante especifica da radiação gama

$r$ é a distância fonte, receptor.

Calculo de $B$

Os melhores dados de fatores de crescimento para uma fonte isotrópica puntiforme, emissora gama em um meio infinito são aqueles fornecidos no relatório NYO 3075 (17) e por Rockwell (18).

a) Estes dados foram apresentados no relatório WAPD-TN-217 (19) e foram ajustados a uma somatória de exponenciais, das quais fazendo uso unicamente dos 


\section{ipen}

dois primeiros termos os seus desvios são de no máximo $40 \%$ acima do valor real e $5 \%$ abaixo.

Sendo a expressão que utilizamos equação (9);

$$
B_{m s t}\left(\mu x, E_{\mathbf{0}}\right)=\Sigma_{n=1}^{2} A_{n} e^{-\alpha \mu x} \text { (9) onde: }
$$

$A_{n \text { e }} \alpha_{n}$ são funções de $E_{\mathbf{0}}$ para cada meio absorvedor.

$E_{\mathbf{0}}$ é a energia da radiação incidente.

$\mu$ é o coeficiente de atenuação linear.

b) Para misturas homogêneas.

Se os meios blindantes formam uma mistura homogênea como o concreto, o fator de crescimento pode ser obtido por um método sugerido por Goldstein-Wilkins e calculado por Obeshain para o concreto que será sucintamente apresentado (Rockwell) (18).

Para se obter um fator de crescimento para uma mistura deve-se conhecer um número atômico efetivo $Z_{\mathbf{0}}$.

O fator de crescimento para vários elementos químicos podem ser colocado como função do número atômico $Z$ para um determinado valor $E_{\mathbf{0}}$ como o número de caminhos livres médios e como parâmetro $(\mu x)$.

Agora, o problema reside em encontrar algum elemento que tenha as mesmas propriedades da mistura com relação ao espalhamento e a atenuação da radiação gama em questão.

As características de um material para a obtenção e espalhamento da radiação gama são determinados pela fração do número total de elétrons associados a cada núcleo. A fração eletrônica pode ser determinada pela equação (10). 


$$
\beta_{i}=\frac{a_{i}^{Z_{i} / A_{i}}}{{\underset{i=1}{n} a_{i} Z_{i} / A_{i}}_{n}}
$$

Onde: $a_{i}$ é a fração em massa do $i$ - esimo elemento de todos os participantes, $Z_{i}$ é o número atômico e $A_{i}$ é a massa atômica ou molecular.

O coeficiente de atenuação $\mu$ por elétron é $\mu_{i}$ e o coeficiente de atenuação total do material é dado pela equação (11).

$$
\mu(E)=\sum_{i} \beta_{i} \mu_{i}(E)(11)
$$

O primeiro critério para calcular $Z$ é que a forma da curva dos coeficientes de atenuação casem com os coeficientes de atenuação dos elementos. Para efetuar isso os coeficientes de atenuação lineares mássicos contra a energia em vários elementos foram normalizadas em $2 \mathrm{MeV}$.

A comparação entre esta curva e os coeficientes da mistura mostrou um $Z$ efetivo de 18, isto é o argônio.

O segundo critério é que a razão entre a seção de choque de espalhamento e a seção de choque total da mistura deve variar com a energia do mesmo modo que o elemento natural. A seção de choque de espalhamento $\sigma_{s}$ pode ser obtida do mesmo modo da seção de choque total equação (12).

$$
\sigma_{\mathbf{1}}(E)=\sum_{i=\mathbf{1}}^{n} \beta_{i} \sigma_{s \mathbf{1}}(E)
$$

A razão $\sigma_{\mathbf{1}}\left(E_{\mathbf{0}}\right) / \mu\left(E_{\mathbf{0}}\right)$ foi colocada em função de $Z$ para os elementos químicos conhecidos para várias energias e a mesma razão da mistura foi colocada no gráfico figura (5). Feito isso para o concreto resultou que o $Z$ efetivo era 18, argônio. 


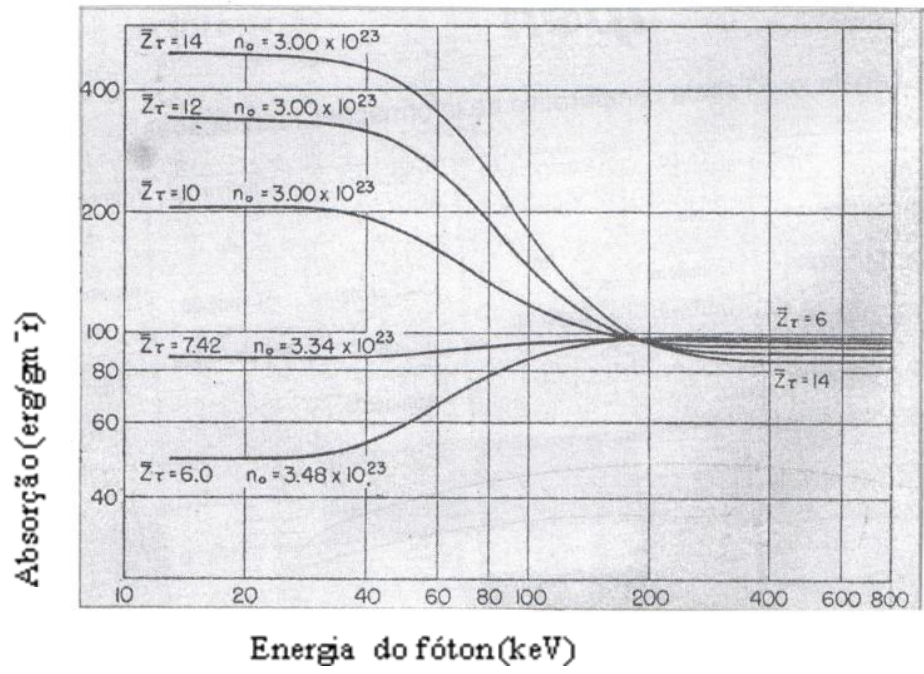

Figura. 5 - Energia de absorção em função da energia do fóton para diferentes materiais Adaptada de Brownell \& Hine (16).

Pelos dois métodos chegou-se ao:

Cálculo de $Z$ efetivo para substâncias complexas como os tecidos do corpo.

Suponhamos que a substância é composta de uma fração $P_{i}$ em massa, de um elemento químico de número atômico $Z_{i}, \rho_{\mathbf{2}}$ do elemento químico $Z_{\mathbf{2}}$ etc, nesse caso o coeficiente de abosorção energia linear mássico será dado pela equação (13);

$$
\mu_{e n} / \rho=\frac{p_{1} \mu_{e n \mathbf{1}}}{\rho_{\mathbf{1}}}+\frac{p_{\mathbf{2}} \mu_{e n \mathbf{2}}}{\rho_{\mathbf{2}}}(13)
$$

Como ${ }_{q} \mu_{e n}={ }_{q} \tau_{e n}{ }^{+}{ }_{q} \sigma_{e n}{ }_{q} K_{e n}$

E pela equação (13) temos : $\quad{ }_{a} \tau \cong$ const $\frac{Z^{4}}{(h v)}$ (14)

Podemos desenvolver a equação em termos de $Z$, desconsiderando a produção de pares. Então a equação (15) se torna:

$$
{ }_{a} \mu_{e n} / \rho=\frac{p_{\mathbf{1}} N}{A_{\mathbf{1}}}\left(b Z_{\mathbf{1}}{ }^{m} \lambda^{n}+Z_{\mathbf{1} e} \sigma_{a}+c Z_{\mathbf{1}}^{\mathbf{2}}\right)+\frac{p_{\mathbf{2}} N}{A_{\mathbf{2}}}\left(b Z_{\mathbf{2}}^{m} \lambda^{n}+Z_{\mathbf{2} e} \sigma_{a}+c Z_{\mathbf{2}}^{\mathbf{2}}+\ldots \ldots\right.
$$

Onde

A é o número atômico.

$N$ é o número de Avogadro. 
$X^{n}$ fornece a variação de $\tau$ como o comprimento de onda $\lambda(\cong 3)$.

$m$ expoente de $Z(\cong \mathbf{4})$

${ }_{q} \sigma_{e n}$ coeficiente de absorção de energia por elétron.

Esta equação pode ser rearranjada em termos de $n_{0}$, isto é, o número de elétrons por grama da substancia $e \alpha_{1}, \alpha_{2} \ldots \ldots . .0$ conteúdo fracional de elétrons dos elementos químicos

$$
Z_{1}, Z_{2}
$$

Neste caso a equação (16) representa.

$$
\begin{aligned}
& { }_{q} \mu_{e n} / \rho=n_{\mathbf{0}}\left[b \lambda^{n} \Sigma\left(\alpha_{\mathbf{1}} Z^{m-\mathbf{1}} \mathbf{1}+\ldots \ldots . .{ }_{e} \sigma_{e n}\right](16)\right. \text { onde } \\
& n_{\mathbf{0}}=N \Sigma\left(p_{\mathbf{1}} Z_{\mathbf{1}} / A_{\mathbf{1}}+p_{\mathbf{2}} Z_{\mathbf{2}} / A_{\mathbf{2}}+\ldots \ldots \ldots . .\right) \mathrm{e} \\
& \alpha \mathbf{1}=N_{p_{\mathbf{1}}} Z_{\mathbf{1}} / n_{\mathbf{0}} A_{\mathbf{1}}, \text { e expressões similares para } \alpha_{e} \text { etc. }
\end{aligned}
$$

Desta equação, podemos definir como $Z$ efetivo a expressão (17).

$$
\bar{Z}_{\tau}=\alpha_{\mathbf{1}} Z_{\mathbf{1}}^{m-1}+\alpha_{\mathbf{2}} Z_{\mathbf{2}}^{m-1}+
$$

Que só é verdade na ausência de produção de pares. 


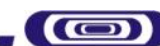 \\ ipen \\ CAPITULO 3}

\section{DESENVOLVIMENTO DO TRABALHO}

\subsection{Revisão Bibliográfica}

As pesquisas para identificação do estado da arte foram realizadas em visitas realizadas nos acervos das bibliotecas, Biblioteca Terezine Arantes Ferraz no Instituto de Pesquisas Energéticas e Nucleares e da Biblioteca da Escola Politécnica da Universidade de São Paulo.

Em consultas pela internet, nos "sites" das editoras científicas, "Radiation Safety Journal Health Physics", "Elsevier" America Latina, nos "sites" das associações como Associação Brasileira de Normas Técnicas, "American Society for Testing and Materials", "Americam Concrete Institute", Instituto Brasileiro do Concreto, "International Atomic Energy Agency", "International Comission on Radiatiological Protection", "National Council on Radiation Protection and Measurements", Comissão Nacional de Energia Nuclear, "National Institute of Standards and Technology", "Oak Ridge National Laboratory", Comitê Cientifico Sobre os Efeitos das Radiações Atômicas das Nações Unidas.

Após avaliarmos os trabalhos consultados por ocasião das pesquisas bibliográficas, constatamos que no Brasil não se publicaram muitos trabalhos científicos que avaliam e estudam o comportamento dos concretos de elevada massa específica preparados com matérias-primas nacionais para serem utilizados como blindagem as radiações ionizantes.

Dos trabalhos consultados e disponíveis, a grande maioria foi realizada em outros países com o uso de matérias-primas locais ou com a utilização de dados experimentais disponíveis em publicações científicas.

Nos trabalhos consultados algumas informações importantes não são publicadas e o entendimento da influência que os materiais utilizados têm no real 
comportamento do concreto frente às radiações não pode ser avaliado, e o ensaio às vezes não pode ser repetido.

Foram consultados vinte e quatro trabalhos (20-47) que tratavam do tema, comportamento de concretos destinados à blindagem as radiações.

Avaliando os dados publicados verificamos que muitos deles não foram citados, na tabela (3), nas colunas estão indicados os itens os quais entendemos serem importantes para a reprodução dos concretos estudados, em cada linha é indicado se o trabalho, contem ou não o item indicado, a cor cinza indica a não existência da informação e a ausência da cor cinza indica que o dado foi fornecido.

Tabela 3 - Tabela comparativa de informações identificadas.

\begin{tabular}{|c|c|c|c|c|c|c|c|c|}
\hline $\begin{array}{l}\text { Caracterizaç̃ão } \\
\text { Física } \\
\text { dos } \\
\text { Agregados }\end{array}$ & $\begin{array}{l}\text { Caracterização } \\
\text { Química } \\
\text { dos } \\
\text { Agregados }\end{array}$ & $\begin{array}{c}\text { Caracterização } \\
\text { Física } \\
\text { Química } \\
\text { dos } \\
\text { Aglomerantes }\end{array}$ & $\begin{array}{c}\text { Identificação } \\
\text { do } \\
\text { Traço } \\
\text { do } \\
\text { Concreto } \\
\text { Utilizado } \\
\end{array}$ & \begin{tabular}{|l} 
Composição \\
Química \\
do \\
Concreto
\end{tabular} & $\begin{array}{c}\text { Coeficiente } \\
\text { de } \\
\text { Atenuacão } \\
\text { Calculado }\end{array}$ & \begin{tabular}{|c|} 
Coeficiente \\
de \\
Atenuação \\
Experimental
\end{tabular} & $\begin{array}{c}\text { Geometria } \\
\text { do } \\
\text { Ensaio }\end{array}$ & $\begin{array}{c}\text { Caracterização } \\
\text { da } \\
\text { Moldagem }\end{array}$ \\
\hline & & & & & & & & \\
\hline & & & & & & & & \\
\hline & & & & & & & & \\
\hline & & & & & & & & \\
\hline & & & & & & & & \\
\hline & & & & & & & & \\
\hline & & & & & & & & \\
\hline & & & & & & & & \\
\hline & & & & & & & & \\
\hline & & & & & & & & \\
\hline & & & & & & & & \\
\hline & & & & & & & & \\
\hline & & & & & & & & \\
\hline & & & & & & & & \\
\hline & & & & & & & & \\
\hline & & & & & & & & \\
\hline & & & & & & & & \\
\hline & & & & & & & & \\
\hline & & & & & & & & \\
\hline & & & & & & & & \\
\hline & & & & & & & & \\
\hline & & & & & & & & \\
\hline & & & & & & & & \\
\hline & & & & & & & & \\
\hline & & & & & & & & \\
\hline & & & & & & & & \\
\hline
\end{tabular}


3.2 Identificação da energia à qual o concreto será submetido e definição das características necessárias

Para o desenvolvimento do trabalho foi escolhida a energia $660 \mathrm{keV}$, energia esta que é utilizada para a calibração de muitos equipamentos de proteção radiológica e equipamentos de radioterapia.

A fonte radioativa utilizada nos ensaios foi $0^{137} \mathrm{Cs}$, com atividade de $37 \mathrm{GBq}$.

3.3 Escolha das matérias-primas produzidas no Brasil para a produção de elevada massa específica

\subsubsection{Aglomerantes.}

Para a produção de concretos os aglomerantes mais utilizados são os cimentos Portland, dentre os vários tipos de cimentos produzidos no Brasil optamos por avaliar dois tipos que apresentam significativa diferença nos teores de $\mathrm{CaO}$ e $\mathrm{SiO}_{2}$ dentre os principais elementos.

No Brasil os cimentos que apresentam diferentes teores dos óxidos citados são os cimentos do tipo CPV, ARI e CPIV, respectivamente.

Para avaliarmos e definirmos qual a melhor opção, preparamos, curamos e ensaiamos dois tipos de pasta de cimento, uma com a utilização de Cimento Portland do tipo CPIV e outra com CPV-ARI, que após curados foram ensaiados na energia de $660 \mathrm{keV}$ para a determinação do coeficiente de atenuação linear experimental.

Avaliando os resultados obtidos, que serão apresentados no capitulo quatro do presente trabalho, optamos pela utilização do cimento Portland tipo CPV-ARI da ABNT, cimento que é encontrado facilmente no mercado e apresenta uma alta resistência inicial.

Após a definição do aglomerante a ser utilizado, este foi caracterizado no Instituto de Pesquisas Tecnológicas do Estado de São Paulo de acordo com os 
critérios e verificado nos limites estabelecidos pela norma ABNT NBR 5733:1991 (48) Cimento Portland de alta resistencia inicial - Especificações.

- Perda ao fogo.

- $\quad$ Anidrido silícico.

- $\quad$ Óxido de alumínio.

- $\quad$ Óxido férrico.

- $\quad$ Óxido de cálcio.

- $\quad$ Óxido de magnésio.

- $\quad$ Anidrido sulfúrico.

- $\quad$ Óxido de sódio.

- $\quad$ Óxido de potássio.

- Equivalente alcalino.

- $\quad$ Óxido e cálcio livre.

- Residuo insolúvel.

- Anidrido carbonatico.

- $\quad$ Água para pasta normal.

- $\quad$ Início e fim de pega.

- $\quad$ Resistência à compressão.

\subsubsection{Agregados.}

Por meio do telefone e através do envio de e-mail, consultamos o Departamento Nacional de Pesquisa Mineral, a Associação Brasileira de Metalurgia Materiais e Mineração e as Companhias Vale do Rio Doce e MMX Mineradora, com o objetivo de localizar possíveis produtores de minerais de elevada massa específica, porém não tivemos sucesso, os órgãos e as empresas consultados não dispunham de informações atualizadas ou não forneceram as informações solicitadas. 
Através de contatos feitos com profissionais da área e colegas de profissão identificamos o nome de alguns possíveis produtores, porém não conseguimos contactá-los, alguns não atenderam às nossas chamadas e outros não retornaram nossas ligações.

Tentamos visitar as áreas onde se localizam diversas mineradoras no estado de Minas Gerais, em vão, pois solicitado o contacto ou o acesso nas portarias das instalações o pedido foi negado.

No estado do Mato Grosso do Sul estivemos no pátio e depósito de minérios da mina de Urucum da Companhia Vale do Rio Doce, localizamos vários tipos de minérios possíveis de serem utilizados, porém não conseguimos amostras para execução dos ensaios, apesar de inúmeras tentativas e telefonemas.

Porém, com as informações e sugestões recebidas de amigos e colegas, e outras encontradas em publicações, identificamos que no Brasil os principais agregados naturais de elevada massa específica produzidos, que podem ser utilizados na produção de concretos de elevada massa específica, são basicamente óxidos de ferro, como hematita, magnetita e alguns tipos de granalhas originadas no processamento do minério de ferro, areias de bário também podem ser encontradas e adiquiridas.

Mas somente com o auxilio de uma empresa localizada no estado de São Paulo, no município de Arujá, que atua no ramo de comercialização de minérios de elevada massa específica para indústria química e para a produção de concretos de elevada massa específica é que obtivemos as informações necessárias e precisas sobre os agregados minerais naturais disponíveis produzidos no Brasil. A empresa não só forneceu os dados e a identificação dos produtores como também gentilmente doou as amostras necessárias para o desenvolvimento do trabalho.

Dos materiais disponíveis selecionamos os que apresentavam características visuais adequadas e que atendiam às nossas necessidades, como granulometria e massa específica.

A relação e a identificação das matérias-primas utilizadas no presente trabalho encontram-se na tabela (4); 
Tabela 4 - Identificação das matérias-primas utilizados.

\begin{tabular}{|c|c|c|c|}
\hline Código & Material & $\begin{array}{l}\text { Código do } \\
\text { Fornecedor }\end{array}$ & Origem \\
\hline AM 1 & Filer Calcário & & Calpar-Castro Pr. \\
\hline AM 2 & Óxido de Ferro HEP & $7000-01$ & Mina Vargem Grande - VALE - SP \\
\hline AM 3 & Sintético Vermelho & $1005-03$ & SAMARCO - ES \\
\hline AM 4 & Magnetita Malha 325 & $1023-15$ & VALE - Cajati - SP \\
\hline AM 5 & Magnetita com Areia & $1023-03$ & VALE - Cajati - SP \\
\hline AM 6 & Areia de Hematita & $7000-02$ & Mina Vargem Grande - VALE - MG \\
\hline AM 7 & Areia de Hematita Graúda & $7000-00$ & Mina Vargem Grande - VALE - MG \\
\hline AM 8 & Granalha de Baixa Massa Específica & $7018-00$ & SAMARCO - ES \\
\hline AM 9 & Brita de Hematita 0 & $7012-01$ & Mina Vargem Grande - VALE - MG \\
\hline AM 10 & Brita de Hematita 1 & $7006-01$ & Mina Vargem Grande - VALE - MG \\
\hline \multirow[t]{2}{*}{ AM 23} & Areia de Barita & & Mineradora Juquiá - Juquiá - SP \\
\hline & Cimento CP V -ARI RS & & Cia Votorantin - Sorocaba -SP \\
\hline
\end{tabular}

Da mesma forma, os agregados selecionados foram caracterizados segundo os critérios prescritos pelas normas nacionais da Associação Brasileira de Normas Técnicas, especificamente a norma NBR 7211-2009 (8), Agregados para concreto Especificações, que fixa as características exigíveis na produção dos agregados miúdos e graúdos de origem natural, já encontrados fragmentados ou resultantes do processo de britagem de rochas e destinados à produção de concretos.

Caracterização Física - Os ensaios de caracterização física foram realizados no Laboratório de Materiais de Construção do Instituto de Pesquisas Tecnológicas do Estado de São Paulo, conforme listados a seguir.

Para os agregados finos:
Absorção (8)
Massa específica saturada com superfície seca (8)
Massa específica aparente NBR NM-52/03. (8)
Material fino passante em peneira de $75 \mu \mathrm{m}$ - NBR NM-46/03. (8)
Para os agregados graúdos: 
Granulometria NBR-7217/87. (8)

Modulo de finura NBR-7211. (8)

Dimensão máxima característica NBR-7211. (8)

Absorção (8)

Massa específica saturada com superfície seca (8)

Massa específica aparente NBR NM-52/03. (8)

Massa específica no estado seco (8)

Material fino passante em peneira de $75 \mu \mathrm{m}$ - NBR NM-46/03. (8)

\subsubsection{Adições.}

No Brasil, são utilizadas, na maioria dos casos, três tipos de adições: normalmente, a microssilica, o metacaulim e o filer calcário.

Como a composição química dos três materiais, são diferentes, optamos por avaliar qual seria o material que melhor desempenho apresentaria quando adicionado ao concreto de elevada massa específica, destinado à blindagem das radiações gama e X, na energia de $660 \mathrm{keV}$.

Preparamos três concretos, um para cada tipo de adição. Posteriormente ensaimos os concretos na energia de $660 \mathrm{keV}$ e encontramos os coeficientes de atenuação linear de cada um deles, e, de posse dos resultados, escollhemos a opção que apresentou melhor desempenho.

Como poderemos ver no próximo capítulo, o melhor desempenho ocorreu para o material filer calcário, que, além de apresentar o melhor coeficiente de atenuação linear, é um material fácil de ser adiquirido, disponível em quase todo o território nacional e tem baixo preço.

A adição escolhida, por não ser reativa, foi caracterizada segundo os critérios prescritos pelas normas nacionais da Associação Brasileira de Normas Técnicas NBR 7211-2009 (8), Agregados para concreto - Especificações, que fixa as características exigíveis na recepção e produção dos agregados miúdos e graúdos, de origem natural, 
já encontrados fragmentados ou resultantes da britagem de rochas e destinados à produção de concretos.

\subsubsection{Aditivo.}

Inúmeros são os aditivos produzidos no Brasil, porém, fatores como experiência e aplicação prática nos levaram a optar pela utilização de um aditivo em que dispomos de um histórico de aplicação. $\mathrm{O}$ aditivo utilizado foi um aditivo do tipo superplastificante e redutor de água, cuja base química é éter policarboxilico, líquido que atende os requisitos das normas NBR 11768 (6) (tipo P e SP).

No caso, o aditivo não foi caracterizado, pois as quantidades utilizadas não ultrapassam a $0,12 \%$ da massa total do concreto.

\subsubsection{Caracterização química dos materiais utilizados.}

As análises químicas foram realizadas no Instituto de Pesquisas Energéticas e Nucleares, IPEN-SP, por meio da técnica de espectrometria de fluorescência de raio X, por dispersão de compriemto de onda (WDXRF). A metodologia utilizada foi não destrutiva e direta, ou seja, tratamentos químicos prévios na preparação das amostras não foram aplicados. O equipamento utilizado foi um WDXRF, modelo RIX 3000, produzido pela Rigaku, Co... Os parâmetros de operação do espectrômetro foram: tubo de raios $X$ de Ródio, $50 \mathrm{kV}$ x $50 \mathrm{~mA}$; colimador de $20 \mathrm{~mm}$; detector de cintilação $(\mathrm{Nal}(\mathrm{TI}))$ para os elementos pesados $(Z>20)$ e proporcional de fluxo para os elementos leves $(Z \leq 10)$.

A determinação semiquantitativa foi realizada por meio do método dos Parâmetros Fundamentais (PF), utilizando-se o modo 2 theta Scan, disponível no software acoplado ao espectrômetro. Os elementos hidrogênio, lítio, berílio, boro, carbono, nitrogênio e oxigênio não foram determinados porque a metodologia não se aplica para tais elementos.

Conhecendo-se os elementos químicos presentes no composto e suas respectivas frações, o coeficinte de atenuação linear teórico pode ser calculado. 
A presença dos três elementos nos concretos é parecida, considerando que a influência deles na composição da seção de choque do composto é pequena na maioria dos casos dos concretos preparados para a tese, não determinamos a presença deles pois o método não permite.

\subsection{Formulação dos traços de concreto.}

De acordo com o método Tutikian \& Dal Molin (49) na figura 6, apresentamos o fluxograma de atividades com o acréscimo da determinação das propriedades físicas, químicas e nucleares, no qual são demonstradas as etapas a serem realizadas:

2) Determinação do esqueleto granular.

3) Determinação da relação água cimento ou percentual de aditivo.

4) Mistura dos traços, rico, intermediário, pobre.

5) Determinação das propriedades mecanicas, durabilidade, físicas, químicas e nucleares.

Figura 6 - Passo a passo para dosagem de CAA com o método Tutikian \& Dal Molin 2007 com acréscimo de propriedades no passo 5 (49).
6) Desenho dos diagramas de dosagem e de desempenho

\begin{tabular}{|c|}
\hline 4) Mistura dos traços, rico, intermediário, pobre. \\
\hline $\begin{array}{c}\text { 5) Determinação das propriedades mecanicas, } \\
\text { durabilidade, físicas, químicas e nucleares. }\end{array}$ \\
\hline
\end{tabular}
acréscimo de propriedades no passo 5 (49). 


\subsubsection{Primeiro passo:}

Escolha dos materiais.

Escolhemos os materiais nacionais a serem utilizados para o preparo dos concretos destinados a blindagem das radiações gama e $X$ na energia de $660 \mathrm{keV}$, que apresentassem as características necessárias para serem utilizados na produção de concretos de elevada massa específica, possíveis de serem adquiridos no mercado nacional e que tivessem constância de produção.

\subsubsection{Segundo passo:}

Determinação do esqueleto granular.

As matérias-primas selecionadas foram divididas em função da composição granulométrica para podermos preparar uma série de concretos com as mais diversas combinações. Nesta fase não tivemos a intenção de preparar o melhor ou mais denso concreto, e sim de preparar uma quantidade razoável de tipos com as mais diversas combinações e massas específicas, para podermos avaliar as diferenças e a validade da proposta do trabalho de se utilizar a composição química como referência para determinar o coeficiente de atenuação linear projetado.

Para fazermos a mistura dos agregados e obtermos para cada combinação a maior massa específica, dividimos as combinações em famílias cujos organogramas formulados são apresentados a seguir nas figuras 7 a13.

Para cada um dos concretos, misturamos os agregados, combinando-os com o objetivo de se conseguir a melhor densidade específica da combinação. 


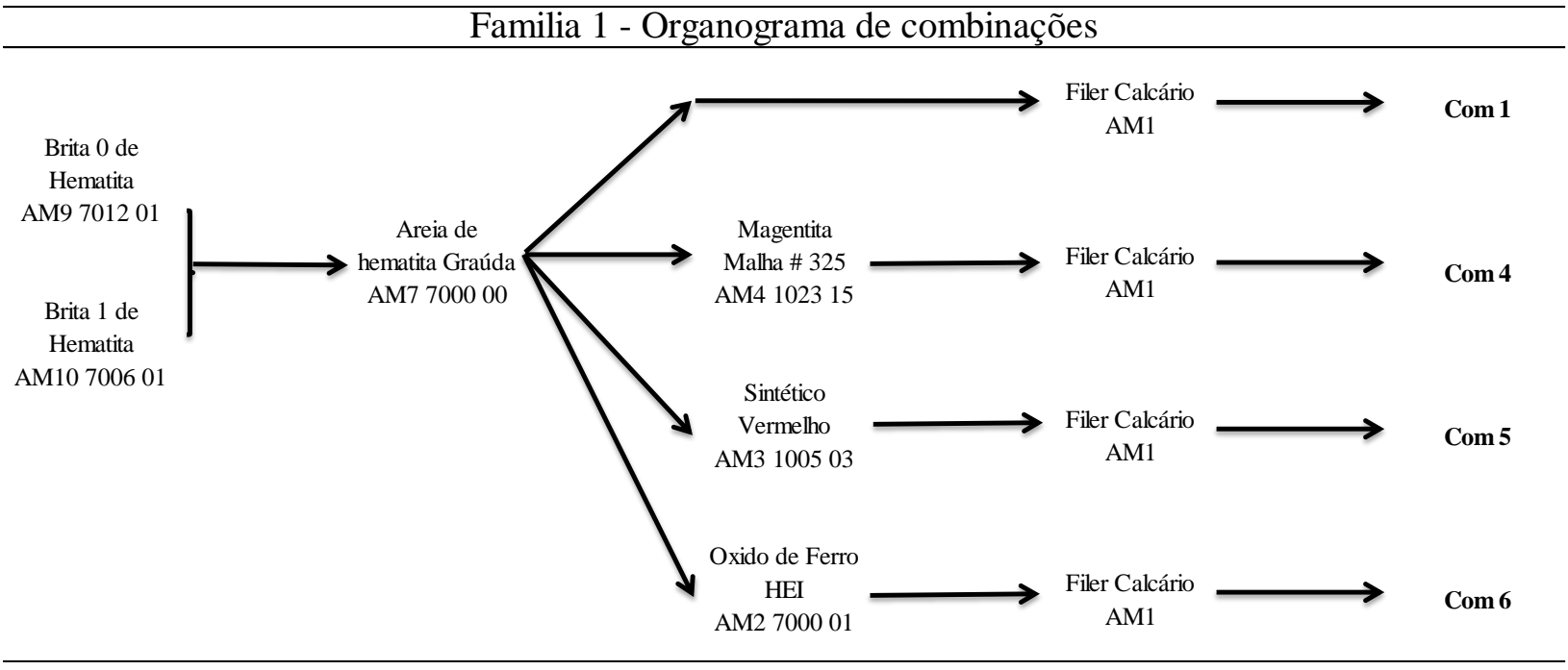

Figura 7 - Organograma de combinações família 1.

Familia 2 - Organograma de combinações

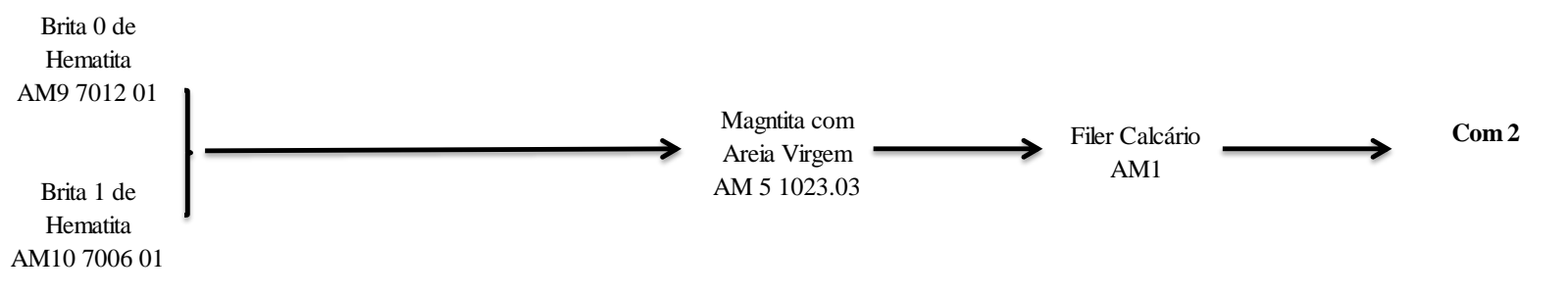

Figura 8 - Organograma de combinações família 2

\section{Familia 3 - Organograma de combinações}

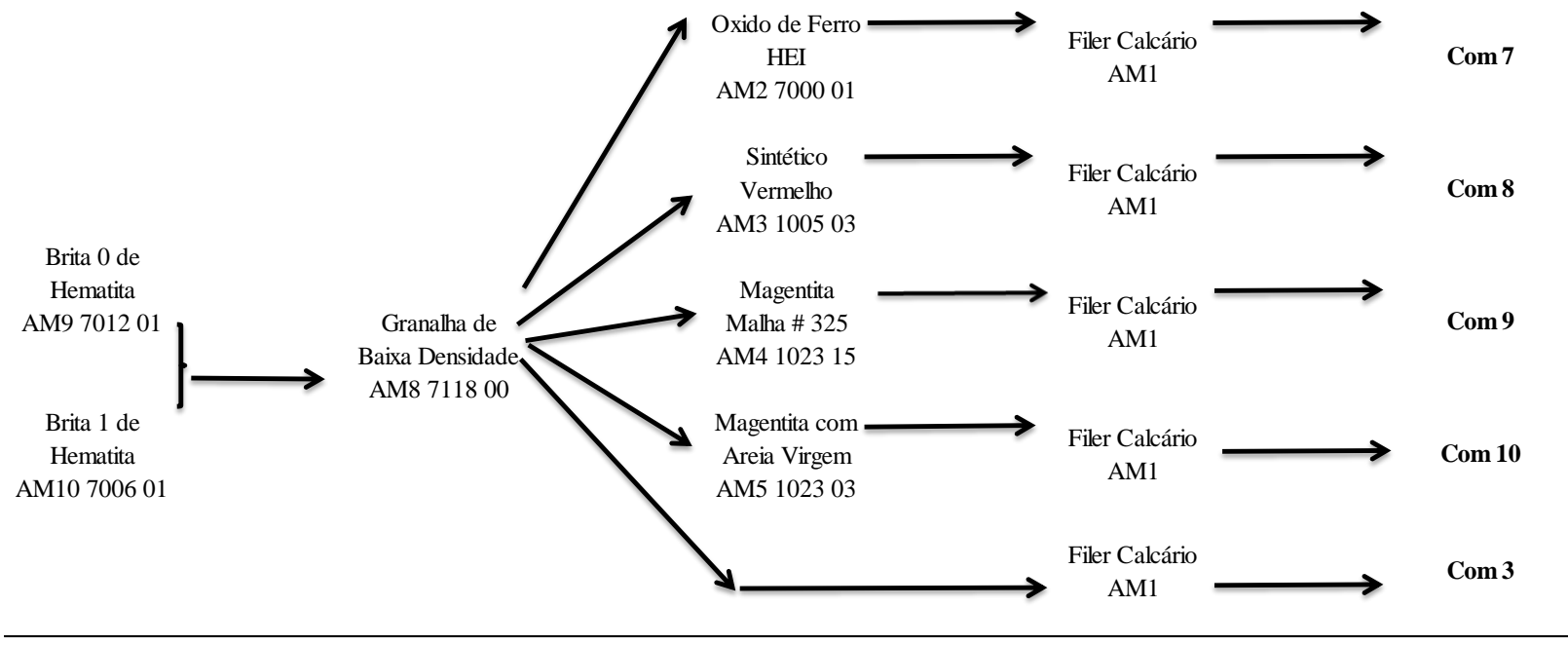

Figura 9 - Organograma de combinações família 3 
Areia de Hematita Graúd AM7 7000.00

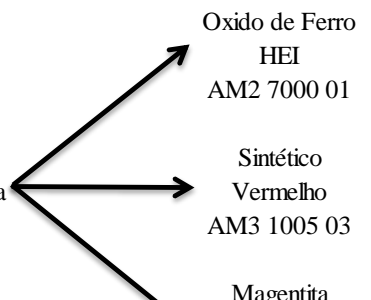

Magentita

Malha \# 325 AM4 102315
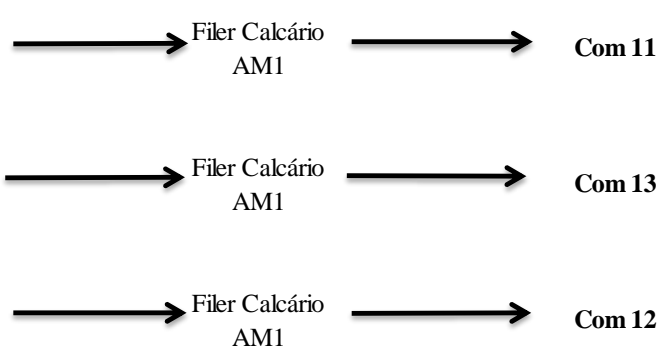

Figura 10 - Organograma de combinações família 4.

Familia 5 - Organograma de combinações

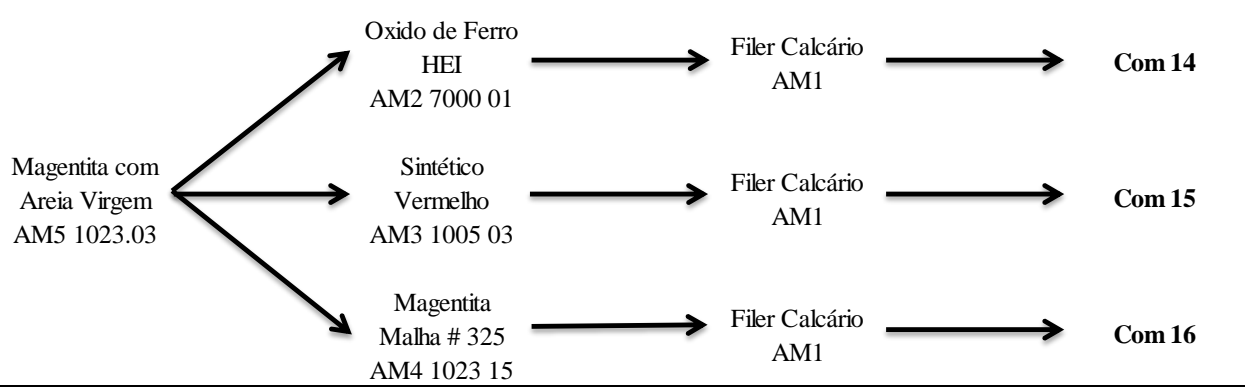

Figura 11 - Organograma de combinações família 5.

Familia 6 - Organograma de combinações

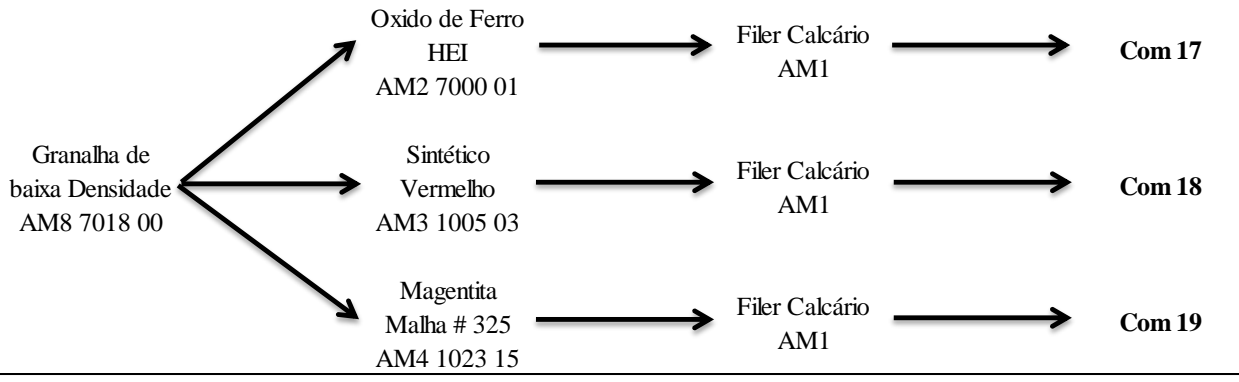

Figura 12 - Organograma de combinações família 6.

Famila 7 - Organograma de combinações
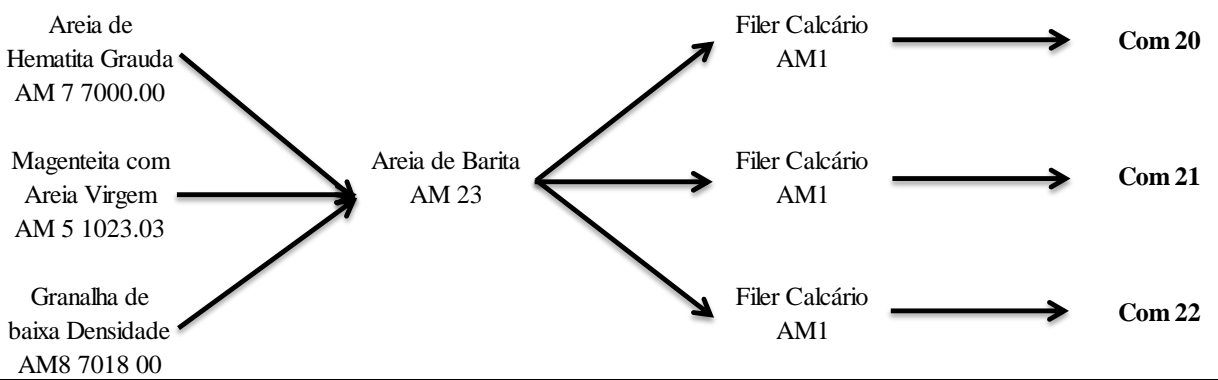

Figura 13 - Organograma de combinações família 7. 
Para cada concreto os agregados foram misturados um a um na sequência de maior para menor granulometria. Foi definida a melhor compacidade da mistura, que posteriormente foi mesclada à parcela seguinte de maneira a se obter a maior massa específica das combinações. A parcela de filer calcário não foi acrescentada por ocasião da realização das misturas, sendo a quantidade a ser utilizada definida posteriormente.

\subsubsection{Terceiro passo:}

Definição do fator água/cimento.

A determinação do fator água/cimento foi feita experimentalmente no momento do preparo do concreto, e, de acordo com a necessidade de água de cada traço, a quantidade de água necessáia foi determinada com o objetivo de se conseguir a trabalhabilidade mínima de adensamento da mistura.

O fator água/cimento variou de concreto para concreto em função da granulometria, do fator de forma e da superfície específica dos agregados utilizados.

\subsubsection{Quarto passo:}

Mistura dos traços.

Tendo em vista a quantidade de matérias-primas disponíveis, não utilizamos a técnica de preparo de três traços, um com consumo pequeno de cimento e outros dois com traços de maior consumo, mas optamos pelo preparo de traços com o consumo de cimento já conhecido e utilizado pelo autor na produção de concretos de elevada densidade que foram usados em outros trabalhos. 
Definidas as combinações a serem utilizadas para a produção dos concretos optamos por preparar somente traços ricos ${ }^{7}$.

\subsubsection{Quinto passo:}

Determinação das propriedades físicas, químicas e nucleares.

A determinação das propriedades se concentrou na caracterização física das matérias-primas e na determinação da composição química. Para os concretos preparados, as mesmas determinações foram feitas com o acréscimo da resistência a compressão de alguns concretos.

Especial atenção foi dada a determinação e identificação da quantidade dos elementos químicos presentes, com o objetivo de verificar a acurácia da proposta de calcular o coeficiente de atenuação linear do concreto sem a necessidade de ensaiá-lo à radiação.

A identificação da capacidade atenuante foi feita com a realização do ensaio de atenuação, que será demonstrado a seguir, após a descrição do sexto passo.

\subsubsection{Sexto passo:}

Montagem do diagrama de dosagem.

A montagem do diagrama de dosagem com os dados adquiridos não foi realizado pelo fato de que as relações entre o coeficiente de atenuação mássico linear

${ }^{7}$ Traço rico é definido como o traço que tem o maior consumo de cimento da série comparativa que normalmente é montada com a confecção de um traço chamado de pobre, pouco consumo de cimento, um traço intermediário com a utilização de um consumo entre o rico e o pobre e o traço rico com consumo maior que os anteriores. 
$(\mu / \rho)$ e a relação densidade e coeficiente de atenuação linear $(\mu)$ não se desenvolvem linearmente entre si, o que difiulta a montagem de um gráfico.

As relações água/cimento não são constantes, e a sua variação não tem grande interferência na definição do coeficinete de atenuação linear.

3.5 Preparo dos concretos, moldagem, cura e armazenamento dos corpos de prova.

3.5.1 Preparo dos concretos e moldagem dos corpos de prova.

O preparo dos concretos foi realizado nas instalações da empresa em que trabalha o autor desta tese. Os materiais foram pesados na condição de seco ao tempo ${ }^{8}$ para posteriormente serem misturados em uma vasilha plástica, para não contaminarem as amostras, e a mistura foi realizada em quantidades que variavam de 3 a $5 \mathrm{~kg}$ para o concreto úmido.

Conforme citado anteriormente, foram formulados 22 tipos de concretos, que optamos por dividir em sete famílias, conforme a base graulométrica utilizada.

3.5.2 Moldagem dos copos de prova.

A moldagem e o adensamento do concreto foram feitos com a utilização de moldes especiais e de uma mesa de vibração especialmente projetada para o trabalho, que é apresentada a seguir na figura (14), na qual o tempo de vibração e a energia podem ser controlados.

Quatro conjuntos de moldes, conforme modelo apresentado na figura (15), mostrada em seguida, também especialmente desenvolvidos para a aplicação, foram

${ }^{8}$ Seco ao tempo é definido como o tipo de secagem em que o material é seco nas condições naturais, sem a utilização de fontes de calor ou ventilação artificiais. 


\section{ipen}

utilizados para cada concreto. Cinco a seis peças foram preparadas, sendo as dimensões $40 \mathrm{~mm}$ de espessura, $100 \mathrm{~mm}$ de comprimento e $50 \mathrm{~mm}$ de altura.

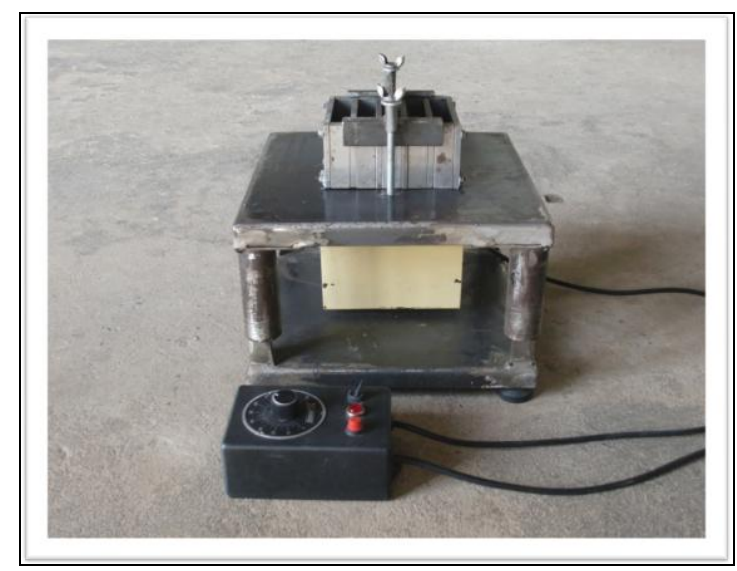

Fig 14 - Mesa vibratória

Moldados os corpos de prova, estes eram pesados em uma balança da marca Urano Us 20/2 com precisão de $2 \mathrm{~g}$ e capacidade de pesagem de $20 \mathrm{~kg}$, devidamente aferida para determinar a massa do concreto úmido no momento da dosagem.

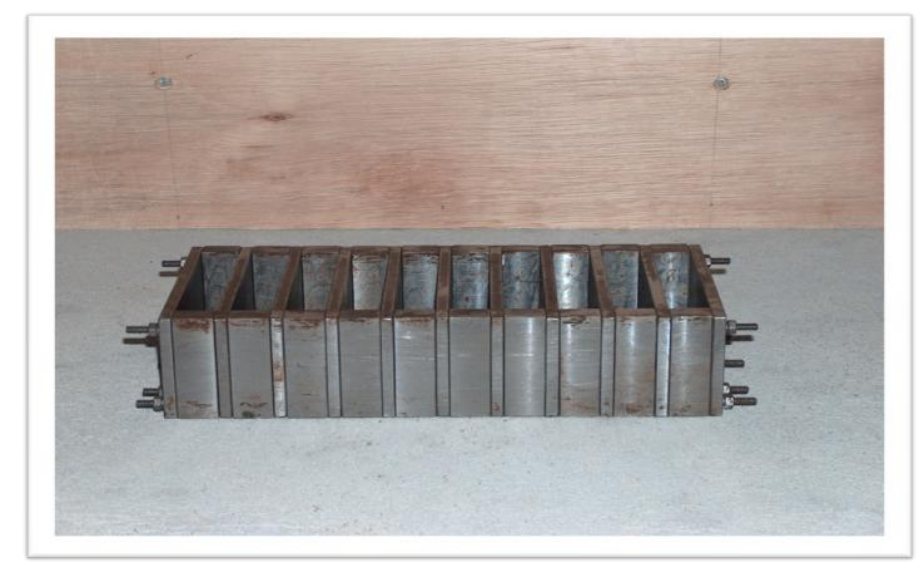

Figura 15 - Molde para moldagem dos corpos de prova

\subsubsection{Cura e armazenagem dos corpos de pova.}

Após dois dias da moldagem, os corpos de prova foram desmoldados, e determinada a massa pós-desforma. Em seguida os corpos de prova foram colocados em caixas plásticas, figura (16), para serem depositadas em uma prateleira, figura (17), em local protegido das intempéries, com uma pequena quantidade de água depositada 


\section{ipen}

internamente em um recipiente plástico, figuras (16) e (17), cujo objetivo foi manter o ambiente interno da caixa na condição úmida.

Os corpos de prova foram enumerados, e, anotada a massa específica pósdesforma, este número do molde também foi anotado no corpo de prova.

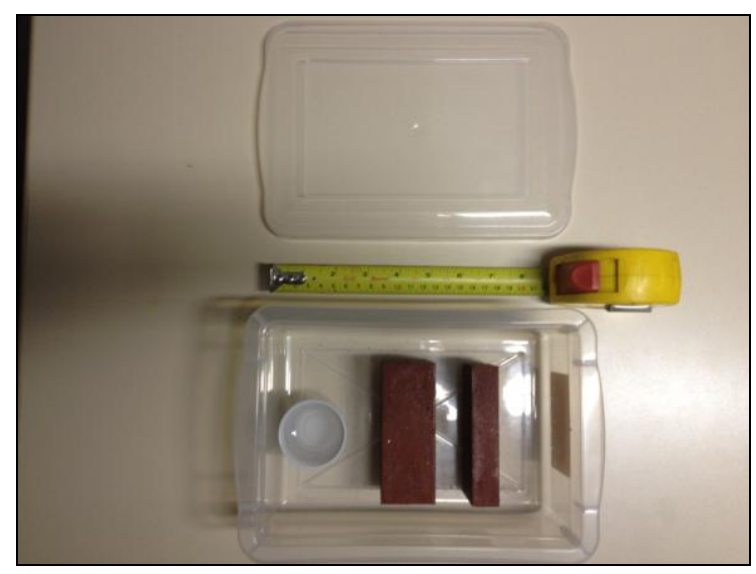

Figura 16 - Caixa de armazenagem dos corpos de prova.

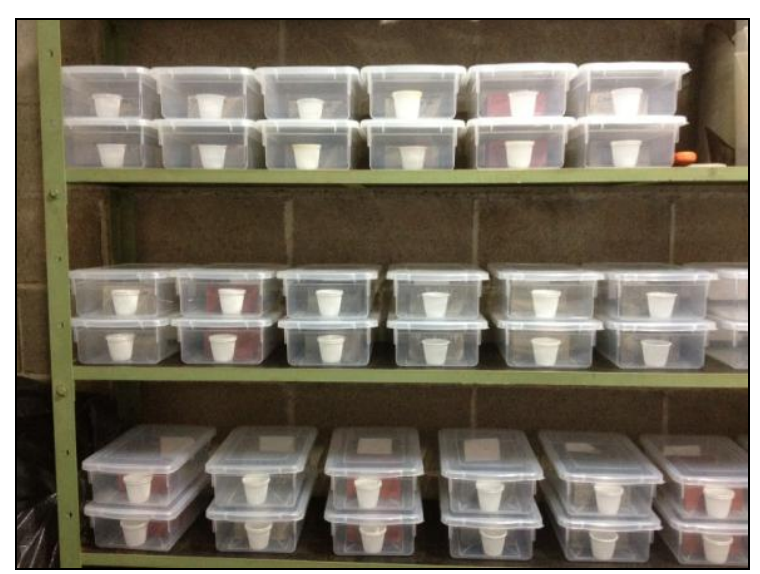

Figura 17 - Caixa de armazenagem dos corpos de prova na pratleira para cura.

3.6 Ensaios para determinação dos coeficientes de atenuação linear experimental

Conforme mencionado anteriormente, a energia utilizada para a caracterização do desempenho dos concretos frente às radiações foi de $660 \mathrm{keV}$.

Para a aquisição dos dados foi utilizado uma mesa micrométrica automatizada, com sistema de deslocamento controlado por omputador que comada o movimento 


\section{ipen}

dos eixos $x$ e y, fonte ${ }^{137} \mathrm{Cs}$ com atividade de $37 \mathrm{GBq}$ e energia $\mathrm{E}=661 \mathrm{keV}$, colimador de saída da fonte em chumbo com abertura de $2 \mathrm{~mm}$, sendo o colimador de entrada do detector com as mesmas características.

Detector da marca Ortec com 3", Nal(TI) iodeto de sódio ativado com tálio, com eletrônica padrão composta por amplificador, fonte de tensão, multicanal e funcionalidade de monocanal.

Na figura (18) é apresentado o esquema da geometria utilizado nos ensaios de atenuação.

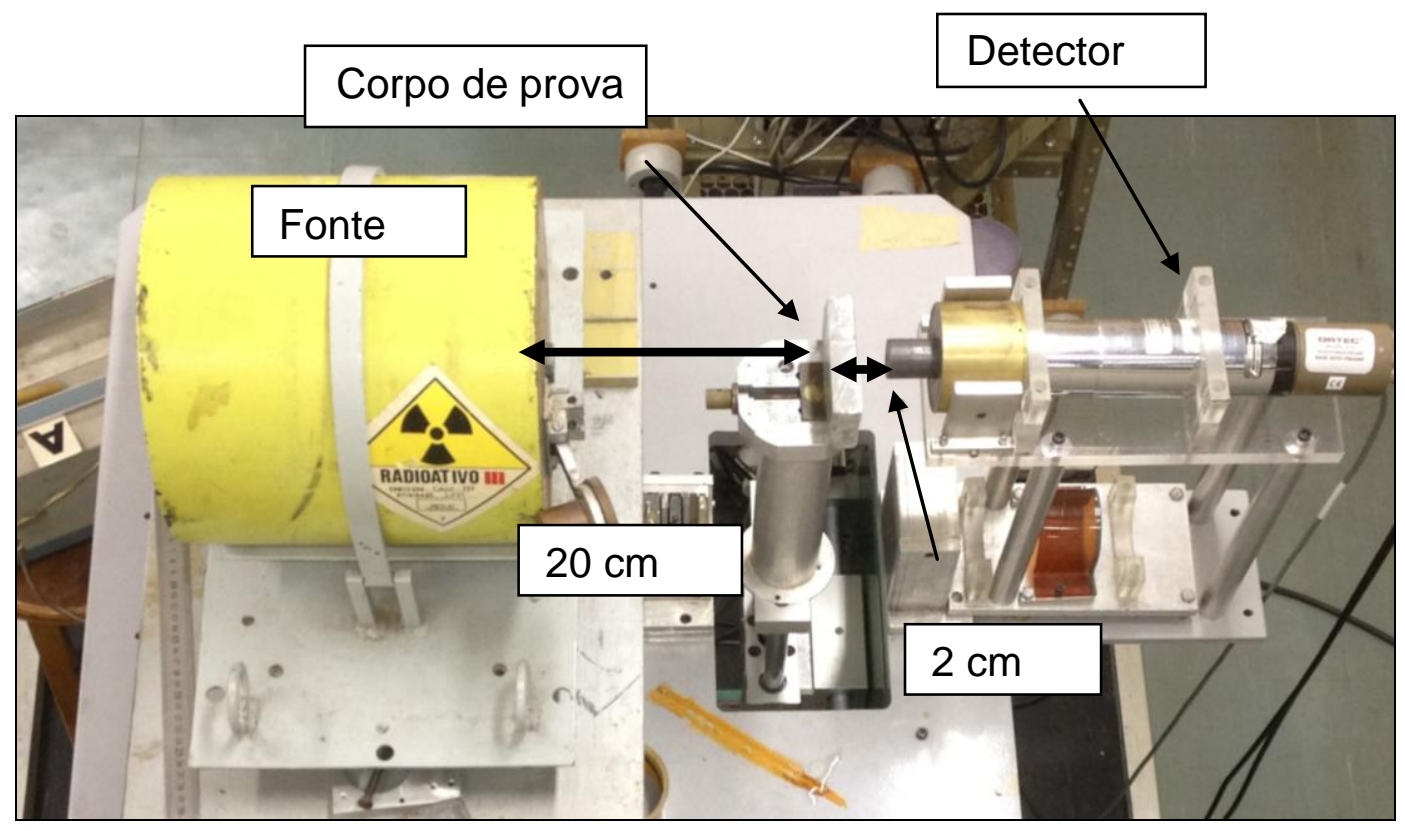

Fig 18 - Mesa micrométrica e geometria de ensaio.

Após curado, de cada concreto escolhemos uma amostra para ser ensaiada, cuja massa se aproximasse da média do referido concreto.

As amostras foram curadas e determinadas as massas unitárias, para posteriormente serem levadas ao Laboratório de Física Nuclear da Universidade Estadual de Londrina para a realização dos ensaios e determinação dos coeficientes de atenuação linear.

Em cada corpo de prova foram realizadas medições em 20 pontos, distribuídos em cinco colunas e quatro linhas, conforme figura (19), apresentada. As cotas com a posição relativa exata dos pontos, a contagem dos fótons e o valor do coeficiente de atenuação linear encontrado estão identificadas resumidamente na tabela (122), apresentadas no capitulo 4 resultados. 


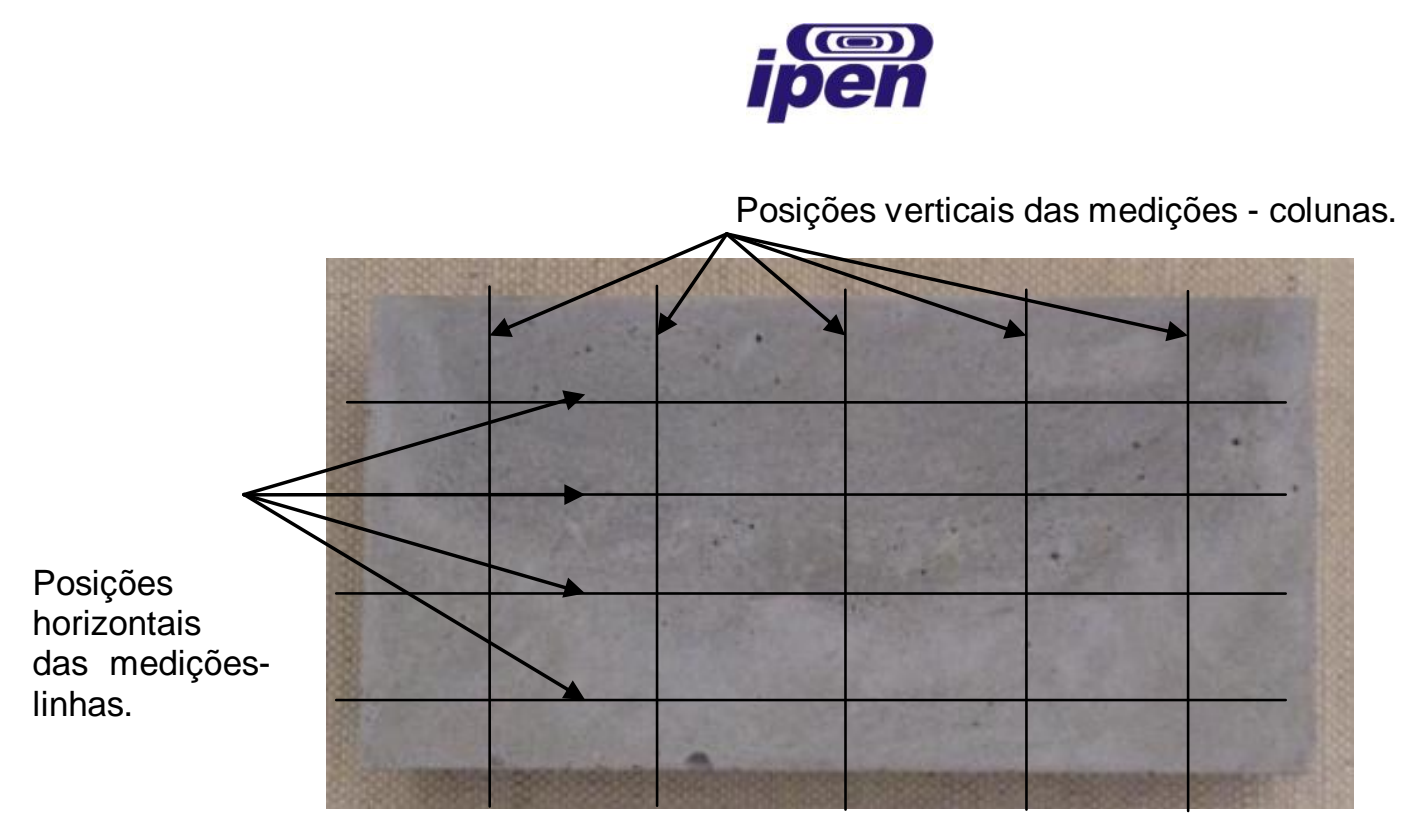

Figura. 19 - Esquema de posicionamento dos pontos medidos em corpo de prova.

\subsection{Caracterização física e química dos concretos preparados.}

3.7.1 Caracterização física dos concretos preparados.

A caracterização física se deu basicamente com a verificação dimensional das amostras e pela identificação da massa específica na desmoldagem e na data de realização dos ensaios para determinação do coeficiente de atenuação linear, dados os quais são apresentados no capitulo (4), resultados.

A resistência à compressão dos concretos foi realizada nos concretos escolhidos em função das massas específicas, os corpos de prova foram moldados e ensaiados à compressão após sete dias de cura, de acordo com os procedimentos da norma ABNT, e os resultados podem ser encontrados no capítulo (4), resultados. 


\section{ipen}

3.7.2 Análise química dos concretos preparados.

Cada um dos corpos de prova ensaiados à radiação foram preparados e analisados para determinação de sua composição química.

Primeiramente, as amostras eram quebradas e uma parcela era separada por uma amostragem representativa, conforme figura (20), posteriormente eram acomodadas no recipiente com o conjunto de argolas figura (21), para serem moídas por dois minutos em um moinho de argolas da marca Herzog, figura (22). Após moídas, apresentavam um diâmetro máximo das partículas de 200 mesh, conforme figura (23) e sequência de figuras apresentadas.

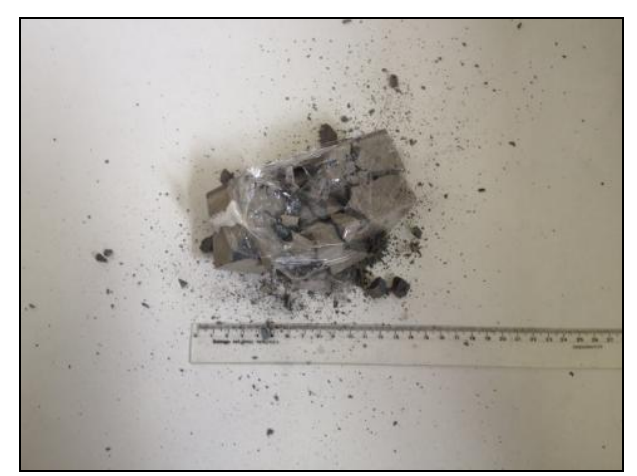

Figura 20 - Amostra quebrada.

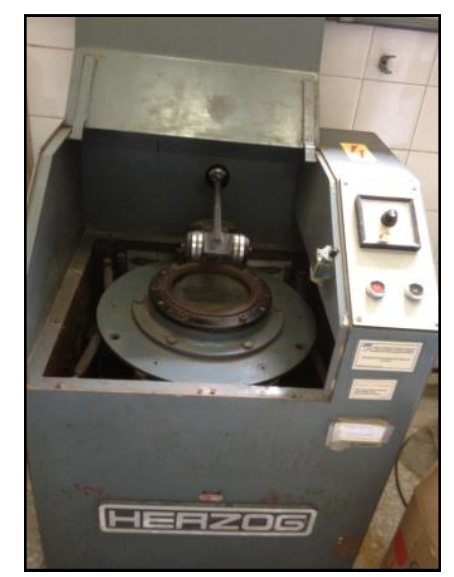

Figura 22 - Moinho Herzog.

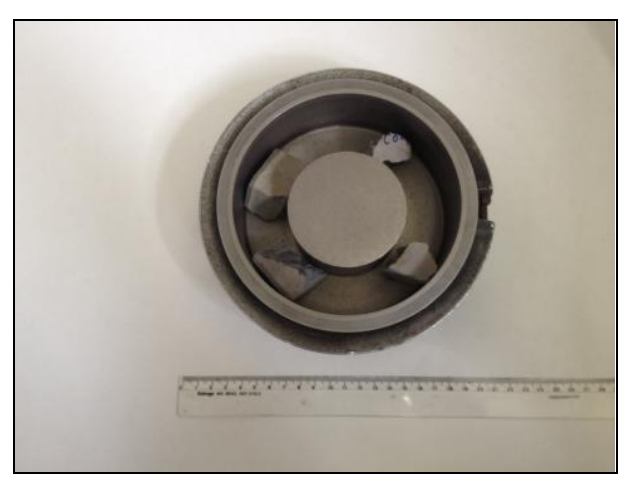

Figura 21 - Compartimento de moagem com amostra a ser moída.

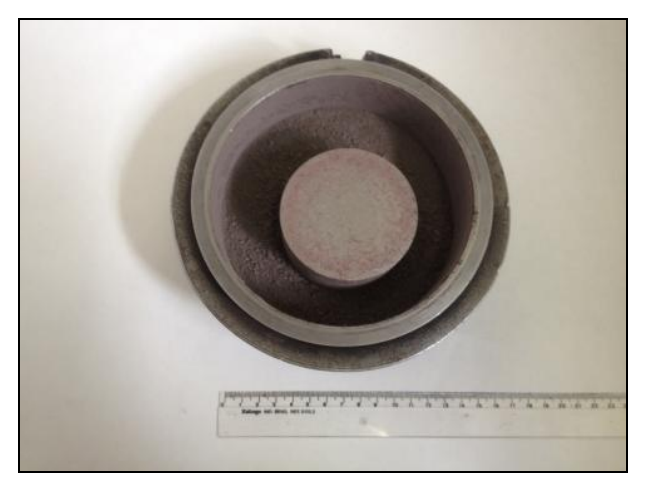

Figura 23 - Amostra moída para ensaio. 


\section{ipen}

Após moídas, figura (23), uma parcela de cada uma das vinte e duas amostras foram colocadas uma a uma em porta-amostras, conforme figura (24), e (25) para serem acondicionadas no equipamento espectrômetro RIX 3000 figura (26), e a realização das análises químicas.

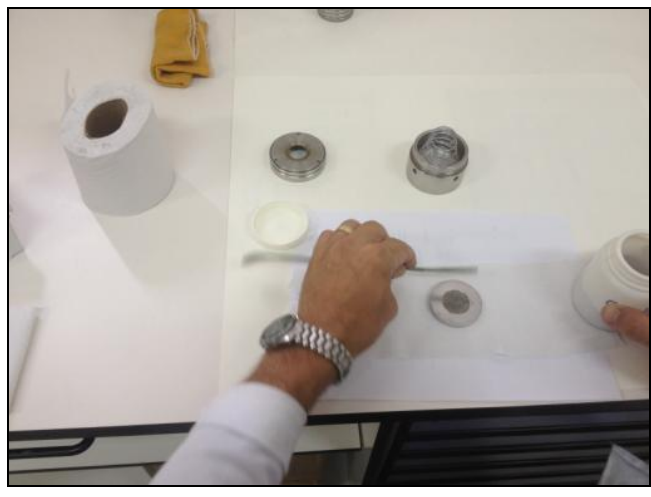

Figura 24 - Acondicionamento do material no porta-amostra.

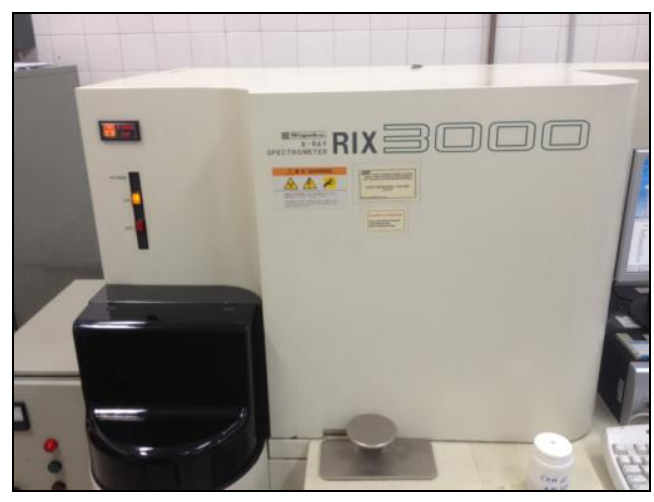

Figura 26 - Espectrômetro RIX 3000.

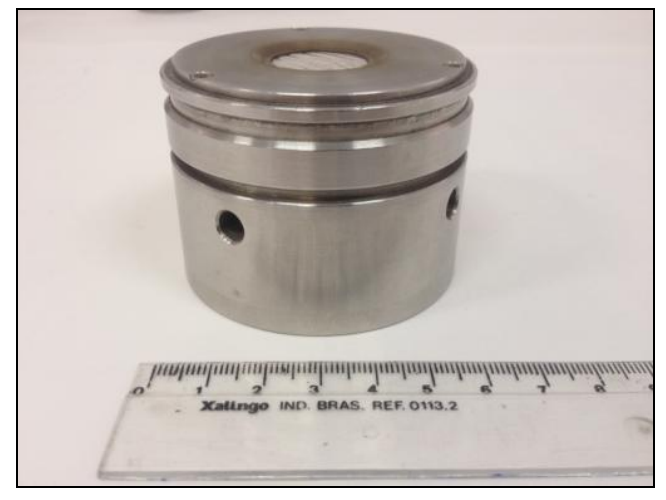

Figura 25 - Porta-amostras.

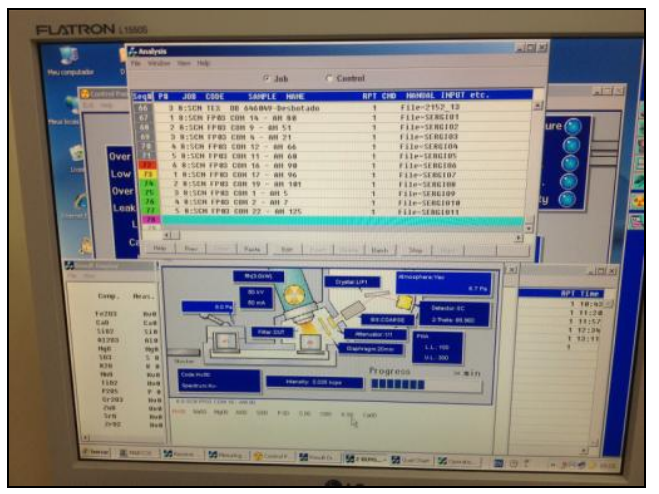

Figura 27 - Processamento dos dados pelo programa do equipamento.

Nas figuras (26) e (27), apresentamos as imagens que mostram os equipamentos de espectrografia e do computador anexo que computa e intrerpreta os dados coletados para a determinação dos elementos presentes.

As análises químicas dos concretos, num total de vinte e duas, são mostradas no capitulo (4). 


\subsection{Cálculo do coeficiente de atenuação linear dos concretos preparados}

Conhecendo as composições químicas dos traços dos concretos a serem utilizados, calculamos os coeficientes de atenuação linear para cada traço com o objetivo de compará-lo com o coeficiente de atenuação do concreto a ser preparado.

Após identificarmos os elementos químicos e a quantidade de cada um presente nos concretos preparados, calculamos os coeficientes de atenuação linear projetados com a utilização das tabelas NIST (14), que listam as seções de choque por elemento químico em função da energia da radiação.

O calculo da seção de choque do composto é realizado multiplicando-se a seção de choque de cada elemento presente na amostra encontrada na tabela NIST (14), pela quantidade encontrada, a soma das seções de choque do produto nos fornecerá o coeficiente de atenuação linear mássico que dividido pela densidade do composto nos dará o coeficiente de atenuação linear. 


\section{RESULTADOS}

\subsection{Resultados da caracterização física e química do aglomerante utilizado}

\subsubsection{Caracterização física do cimento Portland CPV ARI-RS.}

\section{Ensaios físicos}

Nas tabelas (5) e (6) são apresentados os dados dos ensaios físicos realizados pelo Instituto de Pesquisas Tecnológicas do Estado de São Paulo.

Tabela 5 - Resultados dos ensaios físicos do aglomerante (IPT/SP).

\begin{tabular}{|c|c|c|}
\hline & & Limites da NBR 5733/91 \\
\hline & & Cimento CP V ARI \\
\hline Água para pasta normal (NBR-NM-43/03) (\% massa do cimento) & 32,3 & \begin{tabular}{l|l|} 
& --------- \\
\end{tabular} \\
\hline Início de pega (NBR-NM-65/03) (h:min) & 02:40 & $\geq 60 \min (01 \mathrm{~h})$ \\
\hline Fim de pega (NBR-NM-65/03) (h:min) & 04:15 & $\leq 600 \min (10 \mathrm{~h})$ \\
\hline Expansibilidade (NBR-11582/91) - Frio (mm) & 0,0 & \\
\hline Expansibilidade (NBR-11582/91) - Quente (5h) (mm) & 0,0 & \\
\hline Massa específica (NBR-NM-23/01) $\left(\mathrm{g} / \mathrm{cm}^{3}\right)$ & 3,04 & \\
\hline Finura - Método de Blaine (NBR-NM-76/98) $\left(\mathrm{cm}^{2} / \mathrm{g}\right)$ & 4980 & \\
\hline Finura - Método de Blaine $\left(\mathrm{m}^{2} / \mathrm{kg}\right)$ & 498 & $\geq 300,0 \mathrm{~m}^{2} / \mathrm{kg}$ \\
\hline
\end{tabular}

Tabela 6 - Resultados dos ensaios físicos dos ensaios mecânicos do aglomerante (IPT/SP).

\begin{tabular}{|c|c|c|c|c|c|c|c|}
\hline \multicolumn{8}{|c|}{ Resistência à compressão (MPa) - (NBR-7215/96) } \\
\hline Idade & \multicolumn{4}{|c|}{ Corpo de Prova $\mathrm{n}^{\circ}$} & Média & DRM & Limites da NBR 5733/91 \\
\hline (dias) & 1 & 2 & 3 & 4 & & $(\%)$ & CP V ARI \\
\hline 1 & 33,0 & 31,1 & 31,2 & 31,5 & 31,7 & 4,1 & $\geq 14,0 \mathrm{MPa}$ \\
\hline 3 & 40,6 & 40,3 & 39,8 & 41,9 & 40,7 & 2,9 & $\geq 24,0 \mathrm{MPa}$ \\
\hline 7 & 46,8 & 44,5 & 45,5 & 44,9 & 45,4 & 3,1 & $\geq 34,0 \mathrm{MPa}$ \\
\hline 28 & 49,2 & 54,1 & 52,2 & 51,6 & 51,8 & 5,0 & ---------- \\
\hline
\end{tabular}




\subsubsection{Ensaios químicos}

$\mathrm{Na}$ tabela (7) apresentamos os dados resultantes dos ensaios de caracterização química realizados no Instituto de Pesquisas Ecologicas do Estado de São Paulo, IPT.

Tabela 7 - Resultados dos ensaios químicos do cimento por via úmida.

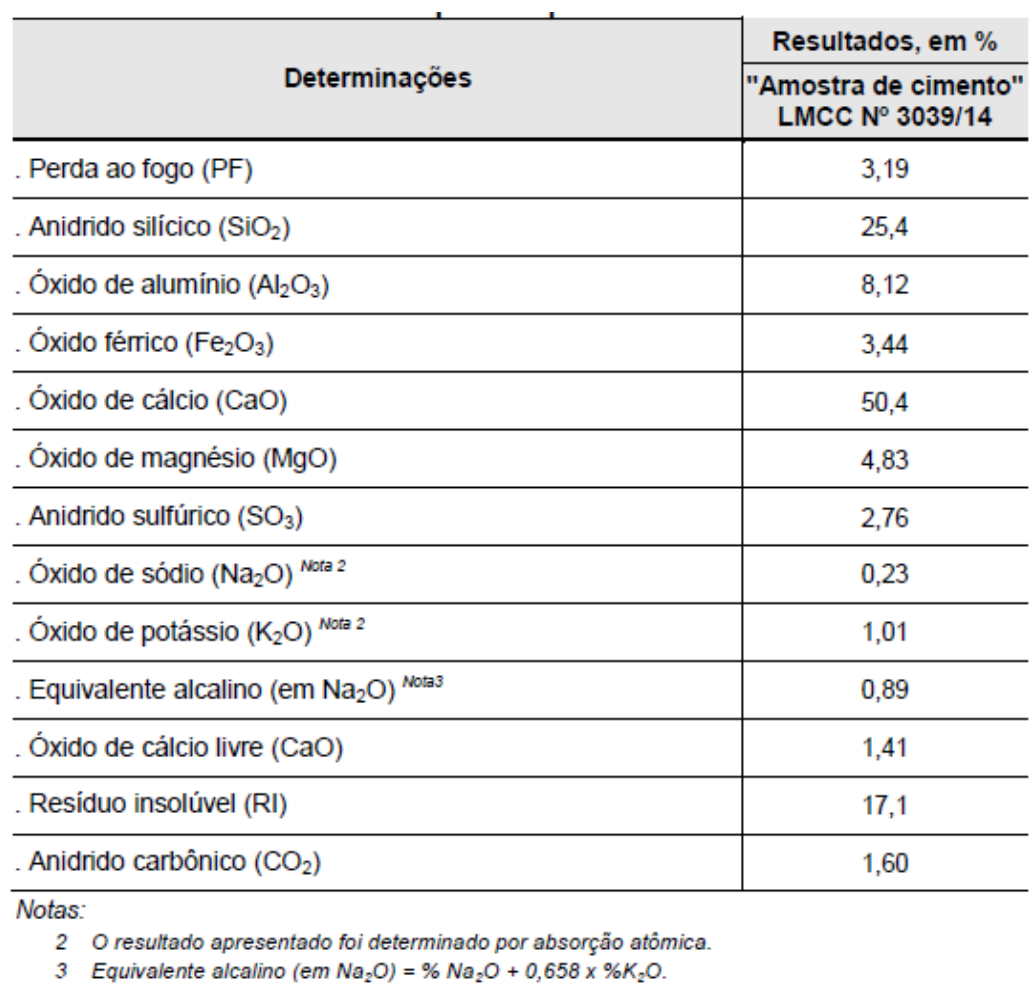

4.2 Resultados da caracterização física e química dos agregados e da adição.

\subsubsection{Caracterização física.}

Nas tabelas (8-17) e figuras (28-35), apresentadas a seguir, são mostrados os dados referentes às características físicas dos agregados utilizados, caracterização esta feitas no IPT. Os dados referem-se a granulometria, absorção e massa específica. 
Tabela 8 - Resultados da amostra AM2 "Óxido de Ferro"

Determinação da composição granulométrica - NBR-7217/87.

\begin{tabular}{|c|c|c|}
\hline Peneiras & \multicolumn{2}{|c|}{ Material retido (\%) } \\
\hline Abertura $(\mathrm{mm})$ & Individual & Acumulada \\
\hline 9,5 & 0 & 0 \\
\hline 6,3 & 0 & 0 \\
\hline 4,75 & 0 & 0 \\
\hline 2,4 & 0 & 0 \\
\hline 1,18 & 0 & 0 \\
\hline 0,6 & 0 & 0 \\
\hline 0,3 & 0 & 0 \\
\hline 0,15 & 4 & 4 \\
\hline$<0,15$ & 96 & 100 \\
\hline \multicolumn{2}{|l|}{ Módulo de finura } & 0,05 \\
\hline \multicolumn{2}{|l|}{ Dimensão máxima característica $(\mathrm{mm})$} & 0,15 \\
\hline \multicolumn{2}{|l|}{ Absorção (\%) } & $0,40 \%$ \\
\hline \multicolumn{2}{|l|}{ Massa específica saturada superfície seca $\left(\mathrm{g} / \mathrm{cm}^{3}\right)$} & 5,23 \\
\hline \multicolumn{2}{|l|}{ Massa específica aparente $\left(\mathrm{g} / \mathrm{cm}^{3}\right)$} & 5,23 \\
\hline \multicolumn{2}{|l|}{ Massa específica $\left(\mathrm{g} / \mathrm{cm}^{3}\right)$} & 5,24 \\
\hline \multicolumn{2}{|c|}{ Material fino passante na peneira de $75 \mu \mathrm{m}$ por lavagem (\%) } & $28,15 \%$ \\
\hline
\end{tabular}

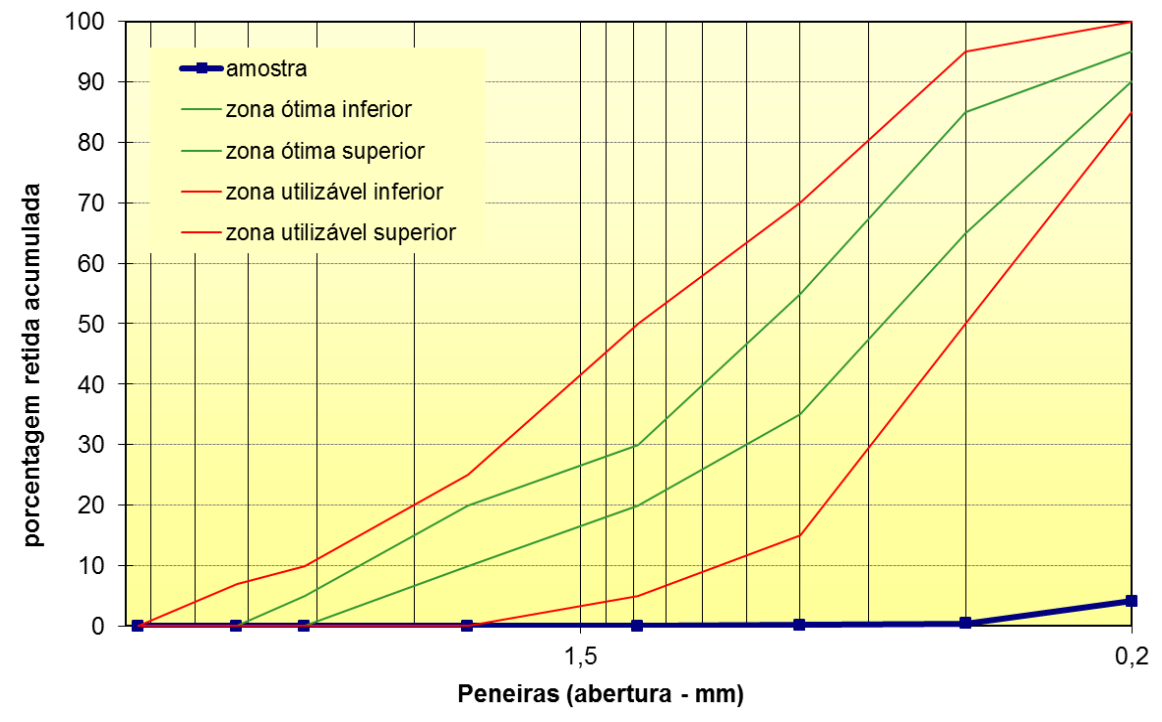

Figua 28 Gráfico - Curva granulométrica da amostra AM2. 
Tabela 9 - Resultados da amostra AM3 "Óxido de Ferro Sintétio Vermelho"

\begin{tabular}{|c|c|c|}
\hline \multicolumn{3}{|c|}{ Determinação da composição granulométrica - NBR-7217/87. } \\
\hline Peneiras & \multicolumn{2}{|c|}{ Material retido (\%) } \\
\hline Abertura (mm) & individual & Acumulada \\
\hline 9,5 & 0 & 0 \\
\hline 6,3 & 0 & 0 \\
\hline 4,75 & 0 & 0 \\
\hline 2,4 & 0 & 0 \\
\hline 1,18 & 0 & 0 \\
\hline 0,6 & 0 & 0 \\
\hline 0,3 & 82 & 82 \\
\hline 0,15 & 17 & 99 \\
\hline$<0,15$ & 1 & 100 \\
\hline \multicolumn{2}{|l|}{ Módulo de finura } & 1,80 \\
\hline \multicolumn{2}{|l|}{ Dimensão máxima característica (mm) } & 0,6 \\
\hline \multicolumn{2}{|l|}{ Absorção (\%) } & $14,06 \%$ \\
\hline \multicolumn{2}{|l|}{ Massa específica saturada superfície seca $\left(\mathrm{g} / \mathrm{cm}^{3}\right)$} & 3,33 \\
\hline \multicolumn{2}{|l|}{ Massa específica aparente $\left(\mathrm{g} / \mathrm{cm}^{3}\right)$} & 3,05 \\
\hline \multicolumn{2}{|l|}{ Massa específica $\left(\mathrm{g} / \mathrm{cm}^{3}\right)$} & 4,26 \\
\hline \multicolumn{2}{|c|}{ Material fino passante na peneira de $75 \mu \mathrm{m}$ por lavagem (\%) } & $88,57 \%$ \\
\hline
\end{tabular}

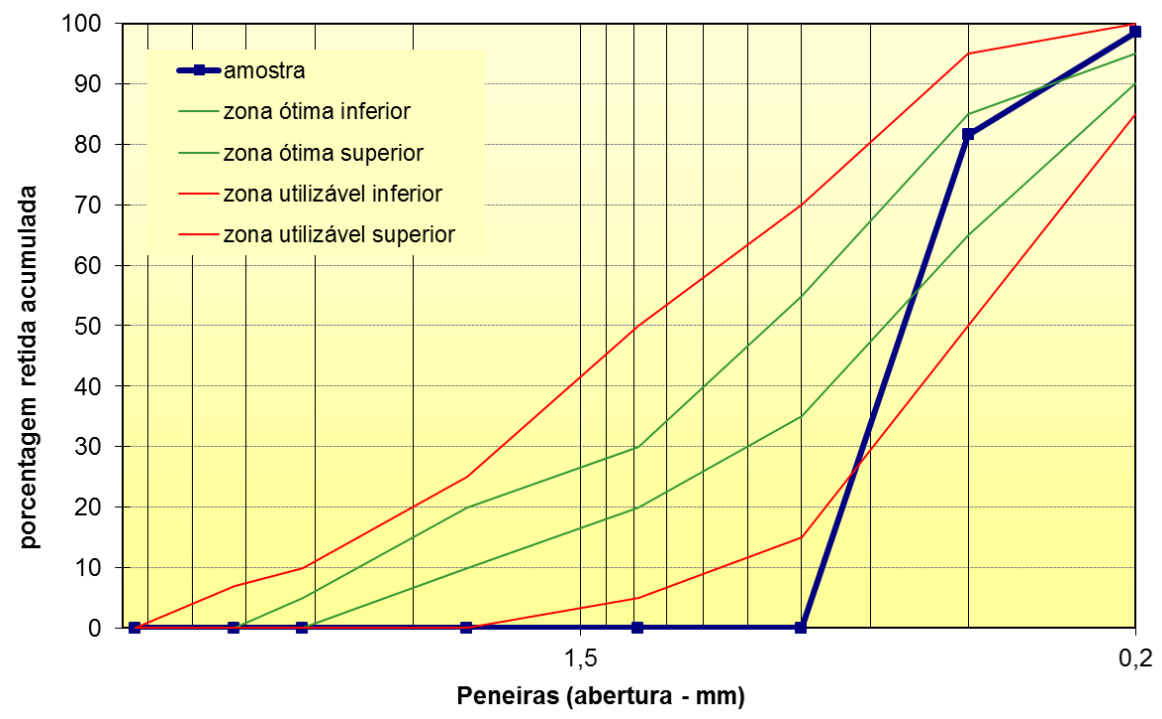

Figua 29 Gráfico - Curva granulométrica da amostra AM3. 
Tabela 10 - Resultados da amostra AM4 "Magnetita Malha \#325"

Por se tratar de um material muito fino, foi utilizado o método de ensaio aplicado para cimento e materiais em pó, não foi determinada a curva granulométrica e nem os ouros parâmetros utilizados para materiais com granulométrica mais graúda.

Tabela 11 - Resultados da amostra AM6 "Areia de Hematita"

\begin{tabular}{|c|c|c|}
\hline \multicolumn{3}{|c|}{ Determinação da composição granulométrica - NBR-7217/87. } \\
\hline Peneiras & \multicolumn{2}{|c|}{ Material retido (\%) } \\
\hline Abertura $(\mathrm{mm})$ & Individual & Acumulada \\
\hline 9,5 & 0 & 0 \\
\hline 6,3 & 1 & 1 \\
\hline 4,75 & 0 & 1 \\
\hline 2,4 & 1 & 2 \\
\hline 1,18 & 2 & 4 \\
\hline 0,6 & 8 & 13 \\
\hline 0,3 & 13 & 26 \\
\hline 0,15 & 23 & 48 \\
\hline$<0,15$ & 52 & 100 \\
\hline \multicolumn{2}{|l|}{ Módulo de finura } & 0,94 \\
\hline \multicolumn{2}{|c|}{ Dimensão máxima característica $(\mathrm{mm})$} & 1,2 \\
\hline \multicolumn{2}{|l|}{ Absorção (\%) } & $0,27 \%$ \\
\hline \multicolumn{2}{|c|}{ Massa específica saturada superfície seca $\left(\mathrm{g} / \mathrm{cm}^{3}\right)$} & 5,07 \\
\hline \multicolumn{2}{|c|}{ Massa específica aparente $\left(\mathrm{g} / \mathrm{cm}^{3}\right)$} & 5,09 \\
\hline \multicolumn{2}{|l|}{ Massa específica $\left(\mathrm{g} / \mathrm{cm}^{3}\right)$} & 5,18 \\
\hline \multicolumn{2}{|c|}{ Material fino passante na peneira de $75 \mu \mathrm{m}$ por lavagem (\%) } & $11,90 \%$ \\
\hline
\end{tabular}

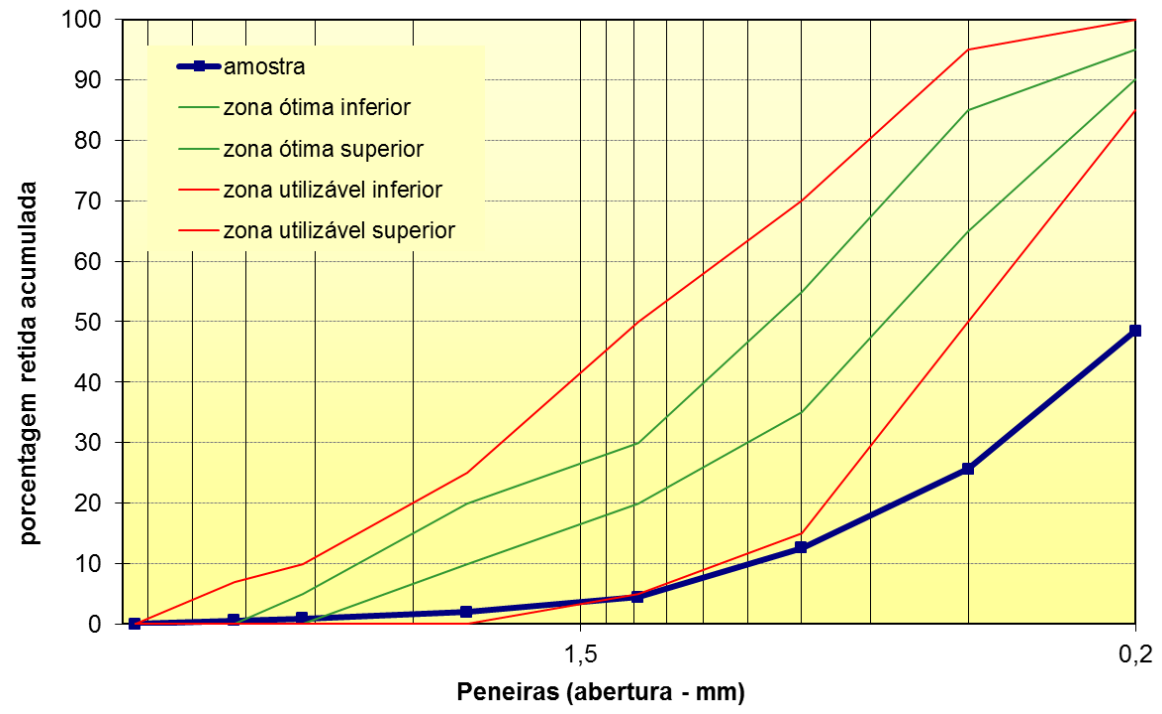

Figua 30 Gráfico - Curva granulométrica da amostra AM6. 
Tabela 12 - Resultados da amostra AM 7 "Areia de Hematita Graúda"

\begin{tabular}{|c|c|c|}
\hline \multicolumn{3}{|c|}{ Determinação da composição granulométrica - NBR-7217/87. } \\
\hline Peneiras & \multicolumn{2}{|c|}{ Material retido (\%) } \\
\hline Abertura $(\mathrm{mm})$ & Individual & Acumulada \\
\hline 9,5 & 0 & 0 \\
\hline 6,3 & 0 & 0 \\
\hline 4,75 & 0 & 0 \\
\hline 2,4 & 0 & 0 \\
\hline 1,18 & 0 & 0 \\
\hline 0,6 & 15 & 15 \\
\hline 0,3 & 41 & 57 \\
\hline 0,15 & 27 & 84 \\
\hline$<0,15$ & 16 & 100 \\
\hline \multicolumn{2}{|l|}{ Módulo de finura } & 1,56 \\
\hline \multicolumn{2}{|c|}{ Dimensão máxima característica $(\mathrm{mm})$} & 1,2 \\
\hline \multicolumn{2}{|c|}{ Absorção (\%) } & $0,50 \%$ \\
\hline \multicolumn{2}{|c|}{ Massa específica saturada superfície seca $\left(\mathrm{g} / \mathrm{cm}^{3}\right)$} & 4,44 \\
\hline \multicolumn{2}{|c|}{ Massa específica aparente $\left(\mathrm{g} / \mathrm{cm}^{3}\right)$} & 4,47 \\
\hline \multicolumn{2}{|c|}{ Massa específica $\left(\mathrm{g} / \mathrm{cm}^{3}\right)$} & 4,56 \\
\hline \multicolumn{2}{|c|}{ Material fino passante na peneira de $75 \mu \mathrm{m}$ por lavagem (\%) } & $2,56 \%$ \\
\hline
\end{tabular}

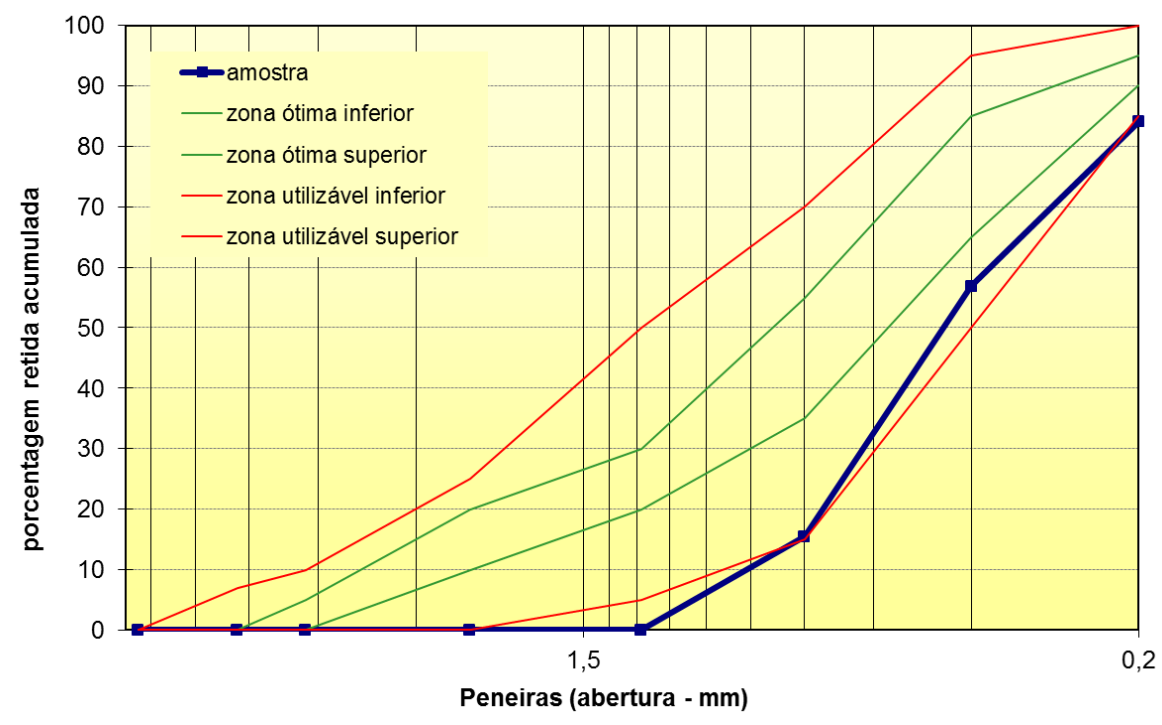

Figua 31 Gráfico - Curva da granulométrica amostra AM7. 
Tabela 13 - Resultados da amostra AM8 "Granalha de Baixa Massa Específica"

\begin{tabular}{|c|c|c|}
\hline \multicolumn{3}{|c|}{ Determinação da composição granulométrica - NBR-7217/87. } \\
\hline Peneiras & \multicolumn{2}{|c|}{ Material retido (\%) } \\
\hline Abertura (mm) & Individual & Acumulada \\
\hline 9,5 & 0 & 0 \\
\hline 6,3 & 0 & 0 \\
\hline 4,75 & 0 & 0 \\
\hline 2,4 & 0 & 0 \\
\hline 1,18 & 14 & 15 \\
\hline 0,6 & 39 & 53 \\
\hline 0,3 & 39 & 92 \\
\hline 0,15 & 7 & 99 \\
\hline$<0,15$ & 1 & 100 \\
\hline \multicolumn{2}{|l|}{ Módulo de finura } & 2,58 \\
\hline \multicolumn{2}{|c|}{ Dimensão máxima característica $(\mathrm{mm})$} & 2,4 \\
\hline \multicolumn{2}{|l|}{ Absorção (\%) } & $0,28 \%$ \\
\hline \multicolumn{2}{|c|}{ Massa específica saturada superfície seca $\left(\mathrm{g} / \mathrm{cm}^{3}\right)$} & 5,11 \\
\hline \multicolumn{2}{|c|}{ Massa específica aparente $\left(\mathrm{g} / \mathrm{cm}^{3}\right)$} & 5,12 \\
\hline \multicolumn{2}{|c|}{ Massa específica $\left(\mathrm{g} / \mathrm{cm}^{3}\right)$} & 5,16 \\
\hline \multicolumn{2}{|c|}{ Material fino passante na peneira de $75 \mu \mathrm{m}$ por lavagem (\%) } & $9,80 \%$ \\
\hline
\end{tabular}

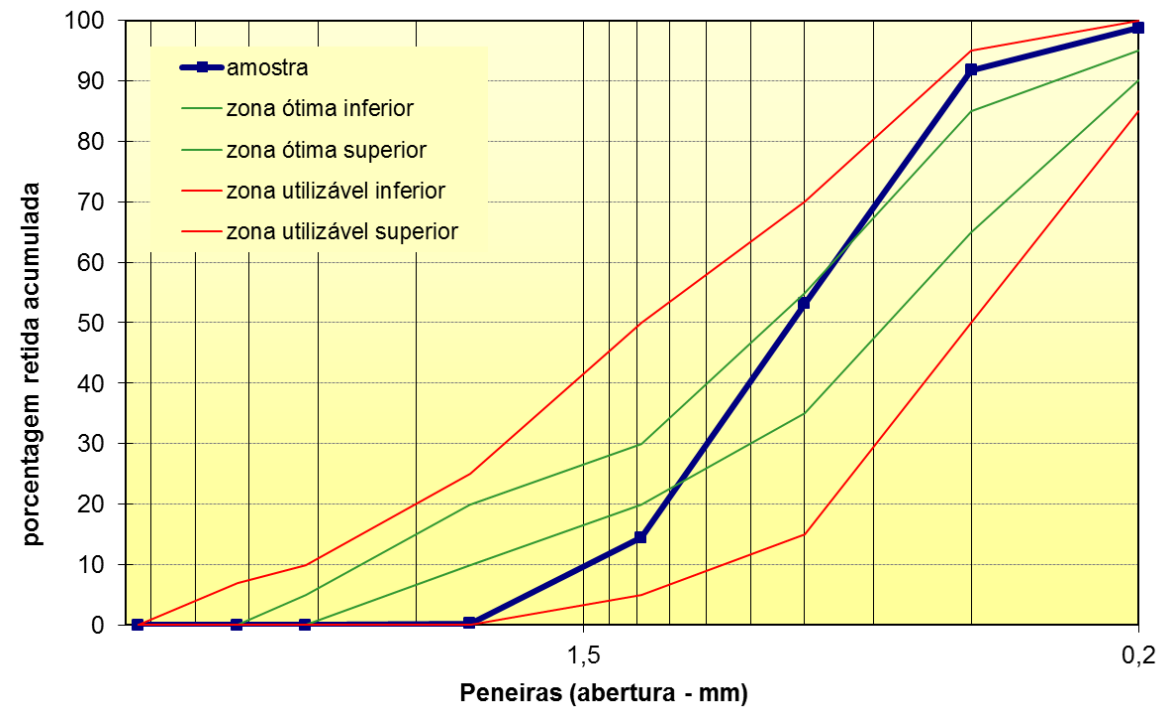

Figua 32 Gráfico - Curva granulométrica da amostra AM8. 
Tabela 14 - Resultados da amostra AM9 "Brita de Hematita 0"

\begin{tabular}{|c|c|c|}
\hline \multicolumn{3}{|c|}{ Determinação da composição granulométrica - NBR-7217/87. } \\
\hline Peneiras & \multicolumn{2}{|c|}{ Material retido (\%) } \\
\hline Abertura $(\mathrm{mm})$ & Individual & Acumulada \\
\hline $37,5^{*}$ & 0 & 0 \\
\hline 31,5 & 0 & 0 \\
\hline 25 & 0 & 0 \\
\hline $19 *$ & 12 & 12 \\
\hline 12,5 & 46 & 58 \\
\hline $9,5^{*}$ & 23 & 81 \\
\hline 6,3 & 11 & 92 \\
\hline $4,75^{*}$ & 2 & 94 \\
\hline $2,36^{*}$ & 2 & 96 \\
\hline $1,18^{*}$ & 0 & 96 \\
\hline $0,6^{*}$ & 0 & 96 \\
\hline $0,3^{*}$ & 0 & 96 \\
\hline $0,15^{*}$ & 0 & 96 \\
\hline$<0,15$ & 4 & 100 \\
\hline \multicolumn{2}{|l|}{ Módulo de finura } & 6,67 \\
\hline \multicolumn{2}{|c|}{ Dimensão máxima característica $(\mathrm{mm})$} & $25 \mathrm{~mm}$ \\
\hline \multicolumn{2}{|c|}{ Absorção (\%) } & $0,14 \%$ \\
\hline \multicolumn{2}{|c|}{ Massa específica saturada superfície seca $\left(\mathrm{g} / \mathrm{cm}^{3}\right)$} & 4,78 \\
\hline \multicolumn{2}{|c|}{ Massa específica aparente $\left(\mathrm{g} / \mathrm{cm}^{3}\right)$} & 4,81 \\
\hline \multicolumn{2}{|c|}{ Massa específica seca $\left(\mathrm{g} / \mathrm{cm}^{3}\right)$} & 4,77 \\
\hline \multicolumn{2}{|c|}{ Material fino passante na peneira de $75 \mu \mathrm{m}$ por lavagem (\%) } & $0,56 \%$ \\
\hline
\end{tabular}

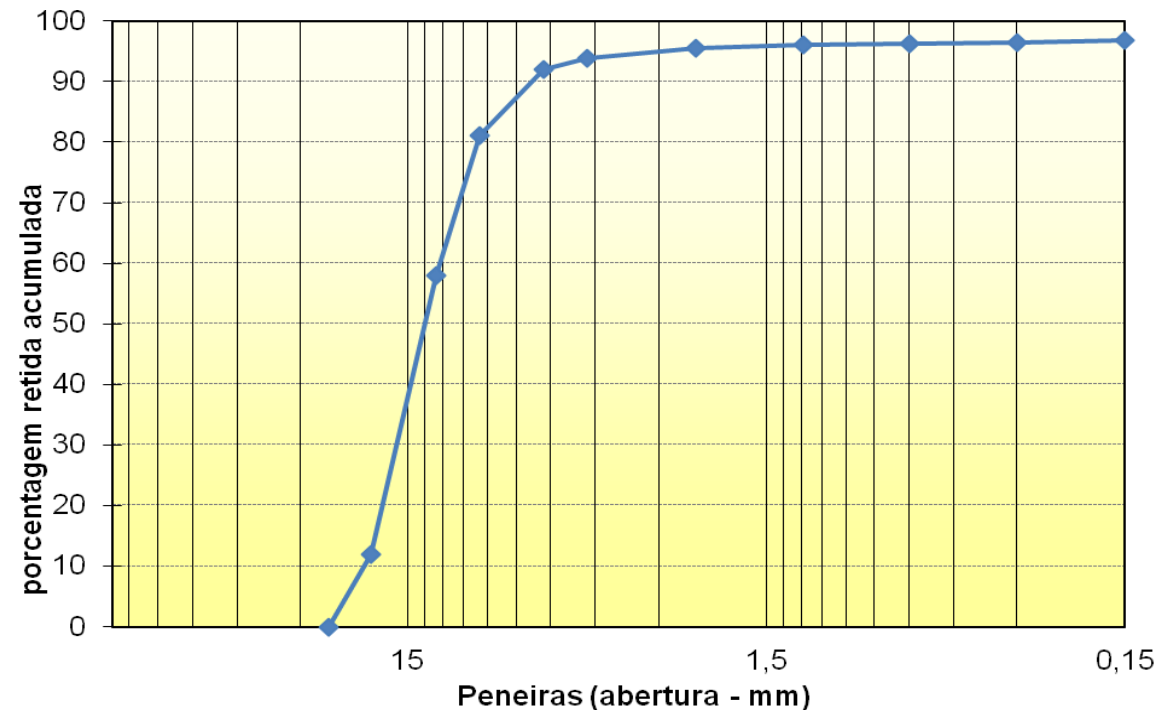

Figua 33 Gráfico - Curva granulométrica da amostra. 
Tabela 15 - Resultados da amostra AM10 "Brita de Hematita 10 a 19mm"

Determinação da composição granulométrica - NBR-7217/87.

\begin{tabular}{|c|c|c|}
\hline Peneiras & \multicolumn{2}{|c|}{ Material retido (\%) } \\
\hline Abertura (mm) & Individual & Acumulada \\
\hline $37,5^{*}$ & 0 & 0 \\
\hline 31,5 & 0 & 0 \\
\hline 25 & 0 & 0 \\
\hline $19 *$ & 8 & 8 \\
\hline 12,5 & 31 & 39 \\
\hline $9,5^{*}$ & 28 & 67 \\
\hline 6,3 & 22 & 89 \\
\hline $4,75^{*}$ & 3 & 92 \\
\hline $2,36 *$ & 2 & 94 \\
\hline $1,18^{*}$ & 1 & 95 \\
\hline $0,6^{*}$ & 0 & 95 \\
\hline $0,3^{*}$ & 0 & 95 \\
\hline $0,15^{*}$ & 0 & 95 \\
\hline$<0,15$ & 5 & 100 \\
\hline \multicolumn{2}{|l|}{ Módulo de finura } & 6,41 \\
\hline \multicolumn{2}{|c|}{ Dimensão máxima característica (mm) } & $25 \mathrm{~mm}$ \\
\hline \multicolumn{2}{|l|}{ Absorção (\%) } & $1,49 \%$ \\
\hline \multicolumn{2}{|c|}{ Massa específica saturada superfície seca $\left(\mathrm{g} / \mathrm{cm}^{3}\right)$} & 4,60 \\
\hline \multicolumn{2}{|c|}{ Massa específica aparente $\left(\mathrm{g} / \mathrm{cm}^{3}\right)$} & 4,86 \\
\hline \multicolumn{2}{|c|}{ Massa específica seca $\left(\mathrm{g} / \mathrm{cm}^{3}\right)$} & 4,53 \\
\hline \multicolumn{2}{|c|}{ Material fino passante na peneira de $75 \mu \mathrm{m}$ por lavagem (\%) } & $3,19 \%$ \\
\hline
\end{tabular}

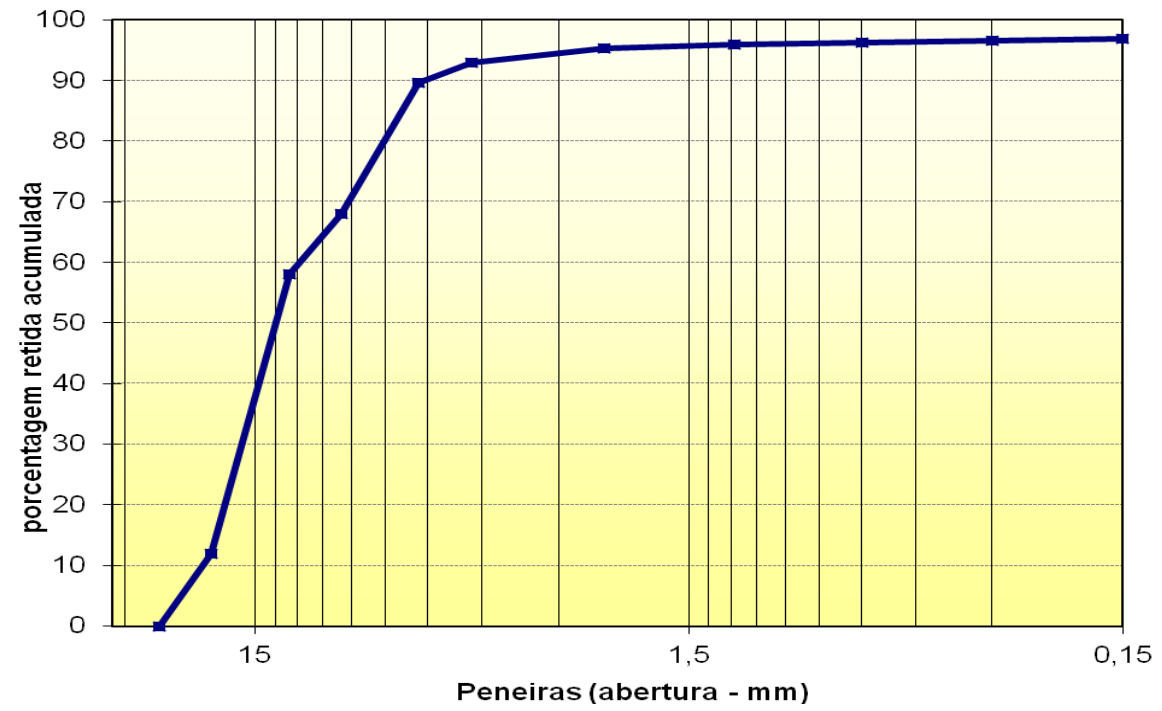

Figua 34 Gráfico - Curva granulométrica da amostra. 
Tabela 16 - Resultados da amostra AM23 "Areia Barita"

Determinação da composição granulométrica - NBR-7217/87

Não determinada - Material muito fino, $82 \%$ passanta na peneira $75 \mu \mathrm{m}$

\begin{tabular}{l|c}
\hline Absorção (\%) & $0,30 \%$ \\
\hline Massa específica saturada superfície seca $\left(\mathrm{g} / \mathrm{cm}^{3}\right)$ & 3,80 \\
\hline Massa específica aparente $\left(\mathrm{g} / \mathrm{cm}^{3}\right)$ & 3,83 \\
\hline Massa específica $\left(\mathrm{g} / \mathrm{cm}^{3}\right)$ & 3,90 \\
\hline Material fino passante na peneira de $75 \mu \mathrm{m}$ por lavagem $(\%)$ & $82,07 \%$ \\
\hline
\end{tabular}

Tabela 17 - Resultados da amostra "Areia de Hematita Tipo AG"

Determinação da composição granulométrica - NBR-7217/87.

\begin{tabular}{|c|c|c|}
\hline Peneiras & \multicolumn{2}{|c|}{ Material retido (\%) } \\
\hline Abertura (mm) & Individual & Acumulada \\
\hline 9,5 & 0 & 0 \\
\hline 6,3 & 1 & 1 \\
\hline 4,75 & 0 & 1 \\
\hline 2,4 & 1 & 2 \\
\hline 1,18 & 7 & 9 \\
\hline 0,6 & 31 & 40 \\
\hline 0,3 & 48 & 88 \\
\hline 0,15 & 6 & 94 \\
\hline$<0,15$ & 6 & 100 \\
\hline \multicolumn{2}{|l|}{ Módulo de finura } & 2,35 \\
\hline \multicolumn{2}{|c|}{ Dimensão máxima característica (mm) } & 2,4 \\
\hline \multicolumn{2}{|l|}{ Absorção (\%) } & $1,03 \%$ \\
\hline \multicolumn{2}{|c|}{ Massa específica saturada superfície seca $\left(\mathrm{g} / \mathrm{cm}^{3}\right)$} & 4,63 \\
\hline \multicolumn{2}{|c|}{ Massa específica aparente $\left(\mathrm{g} / \mathrm{cm}^{3}\right)$} & 4,67 \\
\hline \multicolumn{2}{|l|}{ Massa específica $\left(\mathrm{g} / \mathrm{cm}^{3}\right)$} & 4,86 \\
\hline \multicolumn{2}{|c|}{ Material fino passante na peneira de $75 \mu \mathrm{m}$ por lavagem (\%) } & $0,80 \%$ \\
\hline
\end{tabular}

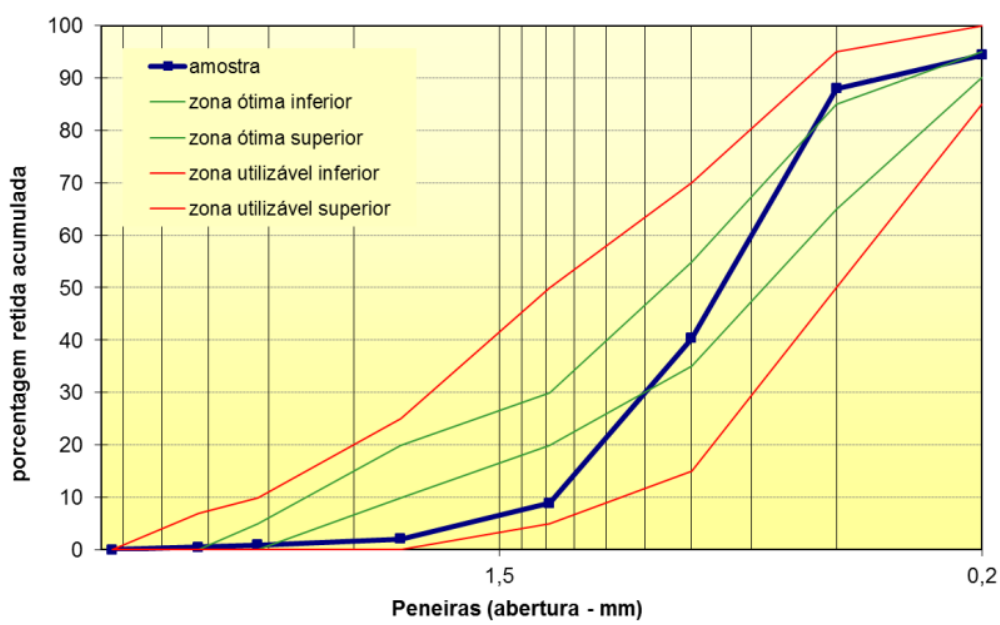

Figua 35 Gráfico - Curva granulométrica da amostra. 


\subsubsection{Caracterização química.}

As amostras dos agregados escolhidos e coletados, classificadas e codificadas conforme tabela (4), apresentada na tabela (19).

Tabela 18 - Códigos e nomes utilizados para identificação das amostras.

\begin{tabular}{|c|c|c|c|}
\hline $\begin{array}{c}\text { Código das } \\
\text { amostras }\end{array}$ & Material & $\begin{array}{c}\text { Código } \\
\text { do } \\
\text { Fornecedor }\end{array}$ & Origem \\
\hline AM1 & Filer Calcário & & Calpar - Castro - Pr \\
\hline AM2 & Oxido de Ferro HEP & $7000-01$ & Mina Vargem Grande - VALE - SP \\
\hline AM3 & Sintético Vermelho & $1005-03$ & SAMARCO - ES \\
\hline AM4 & Magnetita Malha 325 & $1023-15$ & VALE - Cajati - SP \\
\hline AM5 & Magnetita com Areia & $1023-03$ & VALE - Cajati - SP \\
\hline AM6 & Areia de Hematita & $7000-02$ & Mina Vargem Grande - VALE - MG \\
\hline AM7 & Areia de Hematita Graúda & $7000-00$ & Mina Vargem Grande - VALE - MG \\
\hline AM8 & Granalha de Baixa Massa específica & $7018-00$ & SAMARCO - ES \\
\hline AM9 & Brita de Hematita 0 & $7012-01$ & Mina Vargem Grande - VALE - MG \\
\hline AM10 & Brita de Hematita 1 & $7006-01$ & Mina Vargem Grande - VALE - MG \\
\hline AM23 & Areia de Barita & & Mineradora Juquiá - Juquiá - SP \\
\hline & Cimento CP V & Cia Votorantin - Sorocaba -SP \\
\hline
\end{tabular}


A seguir apresentamos as análises químicas das matérias-primas utilizadas, cujos ensaios foram realizados conforme anteriormente descrito.

Os dados apresentados estão identificados pelos códigos das amostras anteriormente apresentados.

Adição -AM1 Filer calcário.

Tabela 19 - Composição química - AM1 Filer calcário.

\begin{tabular}{ccccc}
\hline \multicolumn{1}{l}{ AM1 } & \multicolumn{5}{l}{} \\
\hline Componente & Meas. C. & Espectro & Intensidade & Resultado \\
\hline Al & Al00 & K -KA & 0,3071 & 0,4969 \\
$\mathrm{Ca}$ & Ca00 & Al-KA & 185,3409 & 75,5817 \\
$\mathrm{Fe}$ & Hv00 & Mg-KA & 1,0686 & 0,4910 \\
K & K 00 & Ni-KA & 0,4978 & 0,2312 \\
Mg & Mg00 & Ca-KA & 5,0123 & 20,8433 \\
Ni & Hv00 & Si-KA & 0,1036 & 0,0234 \\
S & S 00 & S -KA & 0,1993 & 0,0492 \\
Si & Si00 & Fe-KA & 1,7370 & 2,2671 \\
Sr & Hv00 & Sr-KA & 0,3828 & 0,0140 \\
Zr & Hv00 & Zr-KA & 0,0799 & 0,0023 \\
\hline
\end{tabular}

Agregado - AM2 Óxido de ferro HEP, código do fornecedor 7000-01.

Tabela 20 - Composição química - AM2 Filer calcário.

\begin{tabular}{ccccc}
\hline AM2 & & & & \\
\hline Componente & Meas. C. & Espectro & Intenidade & Resultado \\
\hline & & & $(\mathrm{kcps})$ & (mass\%) \\
\hline $\mathrm{Al}$ & Al00 & Al-KA & 0,3686 & 0,5564 \\
$\mathrm{Ca}$ & $\mathrm{Ca00}$ & Ca-KA & 0,1480 & 0,0322 \\
$\mathrm{Fe}$ & Hv00 & Fe-KB1 & 112,5779 & 98,4940 \\
$\mathrm{Mn}$ & Hv00 & Mn-KA & 0,5476 & 0,0984 \\
P & P 00 & P -KA & 0,2459 & 0,0383 \\
S & S 00 & S -KA & 0,0275 & 0,0063 \\
Si & Si00 & Si-KA & 0,5512 & 0,6933 \\
Ti & Hv00 & Ti-KA & 0,1546 & 0,0812 \\
\hline
\end{tabular}




\section{ipen}

AM3 Sintético vermelho, código do fornecedor 1005-03.

Tabela 21 - Composição química - AM3 Filer calcário.

\begin{tabular}{ccccc}
\hline \multicolumn{1}{l}{ AM3 } & \multicolumn{5}{l}{} \\
\hline \multicolumn{1}{c}{ Componente } & Meas. C. & Espectro & $\begin{array}{c}\text { Intenidade } \\
\text { (kcps) }\end{array}$ & $\begin{array}{c}\text { Resultado } \\
\text { (mass\%) }\end{array}$ \\
\hline Al & Al00 & Al-KA & 0,0000 & 0,0000 \\
Ca & Ca00 & Ca-KA & 0,0785 & 0,0146 \\
Cl & Cl00 & Cl-KA & 0,2845 & 0,2901 \\
Cr & Hv00 & Cr-KA & 0,2549 & 0,0395 \\
Cu & Hv00 & Cu-KA & 0,0868 & 0,0179 \\
Fe & Hv00 & Fe-KB1 & 131,1966 & 99,1220 \\
Mn & Hv01 & Mn - Ka & 2,2663 & 0,3489 \\
P & P 00 & P -KA & 0,1133 & 0,0149 \\
S & S 00 & S -KA & 0,6547 & 0,1263 \\
Si & Si00 & Si-KA & 0,0183 & 0,0197 \\
Ti & Hv00 & Ti-KA & 0,0139 & 0,0062 \\
\hline
\end{tabular}

Agregado - AM4 Magnetita malha 325, código do fornecedor 1023-15.

Tabela 22 - Composição química - AM4 Filer calcário.

\begin{tabular}{|c|c|c|c|c|}
\hline \multicolumn{5}{|l|}{ AM4 } \\
\hline Componente & Meas. C. & Espectro & Intenidade & Resultado \\
\hline & & & (kcps) & (mass\%) \\
\hline Al & Al00 & Al-KA & 0,7020 & 0,9276 \\
\hline $\mathrm{Ca}$ & $\mathrm{CaOO}$ & Ca-KA & 20,8841 & 4,4114 \\
\hline Co & Hv0O & Co-KA & 0,3375 & 0,0367 \\
\hline $\mathrm{Cr}$ & Hv0O & Cr-KB1 & 0,2165 & 0,2469 \\
\hline $\mathrm{Fe}$ & Hv00 & Fe-KB1 & 95,7896 & 82,1601 \\
\hline $\mathrm{K}$ & K 00 & $\mathrm{~K}-\mathrm{KA}$ & 0,4269 & 0,1407 \\
\hline $\mathrm{Mg}$ & Mg00 & Mg-KA & 1,0274 & 4,9190 \\
\hline $\mathrm{Mn}$ & Hv00 & $\mathrm{Mn}-\mathrm{KA}$ & 3,2589 & 0,6094 \\
\hline $\mathrm{Nb}$ & Hv00 & $\mathrm{Nb}-\mathrm{KA}$ & 0,0813 & 0,0024 \\
\hline $\mathrm{Ni}$ & Hv00 & $\mathrm{Ni}-\mathrm{KA}$ & 0,0991 & 0,0240 \\
\hline$P$ & P 00 & P -KA & 3,6389 & 0,5049 \\
\hline$S$ & S 00 & S-KA & 7,7501 & 1,5908 \\
\hline $\mathrm{Si}$ & SiO0 & Si-KA & 1,5170 & 1,6739 \\
\hline $\mathrm{Sr}$ & Hv00 & Sr-KA & 0,4701 & 0,0205 \\
\hline $\mathrm{Ti}$ & Hv00 & Ti-KA & 4,1089 & 2,4527 \\
\hline v & Hv0O & $V-K A$ & 0,5773 & 0,1940 \\
\hline $\mathrm{Zn}$ & Hv0O & $Z n-K A$ & 0,5367 & 0,0787 \\
\hline $\mathrm{Zr}$ & Hv00 & $\mathrm{Zr}-\mathrm{KA}$ & 0,1837 & 0,0063 \\
\hline
\end{tabular}




\section{ipen}

Agregado - AM5 Magnetita com areia, código do fornecedor 1023-03.

Tabela 23 - Composição química - AM5 Magentita com areia.

\begin{tabular}{|c|c|c|c|c|}
\hline AM5 & & & & \\
\hline \multirow[t]{2}{*}{ Componente } & Meas. C. & Espectro & Intensidade & Resultado \\
\hline & & & (kcps) & (mass\%) \\
\hline Al & Al00 & Al-KA & 0,5135 & 0,7510 \\
\hline $\mathrm{Ca}$ & $\mathrm{CaOO}$ & Ca-KA & 47,2350 & 11,7929 \\
\hline $\mathrm{Cr}$ & Hv00 & $\mathrm{Cr}-\mathrm{KA}$ & 0,2020 & 0,0633 \\
\hline $\mathrm{Cu}$ & Hv00 & Cu-KA & 0,0966 & 0,0211 \\
\hline $\mathrm{Fe}$ & Hv00 & Fe-KA & 384,8820 & 74,3351 \\
\hline K & K 00 & $\mathrm{~K}-\mathrm{KA}$ & 0.4190 & 0,1582 \\
\hline $\mathrm{Mg}$ & $\mathrm{Mg00}$ & $\mathrm{Mg}-\mathrm{KA}$ & 0,8662 & 4,5961 \\
\hline $\mathrm{Mn}$ & Hv00 & $M n-K B$ & 10,4967 & 0,6439 \\
\hline $\mathrm{Nb}$ & Hv00 & $\mathrm{Nb}-\mathrm{KA}$ & 0,0766 & 0,0025 \\
\hline $\mathrm{Ni}$ & Hv00 & $\mathrm{Ni}-\mathrm{KA}$ & 0,0937 & 0,0253 \\
\hline$P$ & P 00 & $P-K A$ & 7,9087 & 1,2239 \\
\hline$S$ & S 00 & $S-K A$ & 6,7742 & 1,5682 \\
\hline $\mathrm{Si}$ & Si00 & Si-KA & 1,6799 & 2,0486 \\
\hline $\mathrm{Sr}$ & Hv00 & Sr-KA & 2,1538 & 0,1039 \\
\hline $\mathrm{Ti}$ & Hv00 & Ti-KA & 2,7794 & 2,3799 \\
\hline V & Hv00 & $V-K A$ & 0,4559 & 0,2200 \\
\hline $\mathrm{Zn}$ & Hv00 & $\mathrm{Zn}-\mathrm{KA}$ & 0,3216 & 0,0524 \\
\hline $\mathrm{Zr}$ & $\mathrm{Hv0O}$ & Zr-KA & 0,3667 & 0,0139 \\
\hline
\end{tabular}

Agregado - AM6 Areia de Hematita, código do fornecedor 7000-02.

Tabela 24 - Composição química - AM6 Areia de hematita.

\begin{tabular}{ccccc}
\hline AM6 & & & & \\
\hline Componente & Meas. C. & Espectro & Intensidade & Resultado \\
\hline Al & & & (kcps) & (mass\%) \\
Ca & Al00 & Al-KA & 0,9295 & 1,3075 \\
Cr & Hv00 & Ca-KA & 0,0912 & 0,0196 \\
Fe & Hv00 & Cr-KA & 0,1090 & 0,0196 \\
K & Fe-KB1 & 113,4334 & 94,5189 \\
Mg 00 & K -KA & 0,0551 & 0,0189 \\
Mn & Mg00 & Mg-KA & 0,0199 & 0,1070 \\
P & Hv00 & Mn-KA & 1,6832 & 0,2903 \\
Si & P 00 & P -KA & 0,1972 & 0,0300 \\
Ti & Si00 & Si-KA & 3,0507 & 3,6183 \\
& Hv00 & Ti-KA & 0,1345 & 0,0699 \\
\hline
\end{tabular}




\section{ipen}

Agregado - AM7 Areia de Hematita graúda, código do fornecedor 7000-00.

Tabela 25 - Composição química - AM7 Areia de hematite graúda.

\begin{tabular}{ccccc}
\hline AM7 & \multicolumn{3}{c}{} \\
\hline Componente & Meas. C. & Espectro & Intensidade & Resultado \\
\hline Al & & & (kcps) & (mass\%) \\
Ca & Al00 & Al-KA & 0,9030 & 1,2993 \\
Cr & Ca00 & Ca-KA & 0,0779 & 0,0176 \\
Fe & Hv00 & Cr-KA & 0,1440 & 0,0272 \\
K & Hv00 & Fe-KB1 & 107,6708 & 92,7729 \\
Mg & K 00 & K -KA & 0,0609 & 0,0220 \\
Mn & Mg00 & Mg-KA & 0,0234 & 0,1288 \\
P & Hv00 & Mn-KA & 2,2116 & 0,3956 \\
Si & P 00 & P-KA & 0,1857 & 0,0296 \\
Ti & Si00 & Si-KA & 4,3187 & 5,2485 \\
& Hv00 & Ti-KA & 0,1073 & 0,0587 \\
\hline
\end{tabular}

Agregado - AM8 Granalha de baixa massa específica, código do fornecedor. 7018-00.

Tabela 26 - Composição química - AM8 Areia de hematite graúda.

\begin{tabular}{ccccc}
\hline $\begin{array}{c}\text { AM8 } \\
\text { Componente }\end{array}$ & Meas. C. & Espectro & Intensidade & Resultado \\
\hline Al & & & $(\mathrm{kcps})$ & (mass\%) \\
\hline $\mathrm{Ca}$ & Al00 & Al-KA & 0,2296 & 0,3414 \\
$\mathrm{Cr}$ & Ca00 & Ca-KA & 2,8288 & 0,6082 \\
Fe & Hv00 & Cr-KA & 0,1534 & 0,0281 \\
K & Hv00 & Fe-KB1 & 111,7780 & 97,5741 \\
Mg & K 00 & K -KA & 0,1319 & 0,0451 \\
Mn & Mg00 & Mg-KA & 0,0346 & 0,1974 \\
P & Hv00 & Mn-KA & 1,9837 & 0,3552 \\
S & P 00 & P-KA & 0,2166 & 0,0332 \\
Si & S 00 & S-KA & 0,1590 & 0,0356 \\
& Si00 & Si-KA & 0,6326 & 0,7816 \\
\hline
\end{tabular}




\section{ipen}

Agregado - AM9 Brita 0 de Hematita, código do fornecedor 7012-01.

Tabela 27 - Composição química - AM9 Brita 0 de hematita.

\begin{tabular}{ccccc}
\hline AM9 & \multicolumn{3}{c}{} \\
\hline Componente & Meas. C. & Espectro & $\begin{array}{c}\text { Intensidade } \\
\text { (kcps) }\end{array}$ & $\begin{array}{c}\text { Resultado } \\
\text { (mass\%) }\end{array}$ \\
\hline Al & Al00 & Al-KA & 1,5681 & 2,1695 \\
Ca & Ca00 & Ca-KA & 0,2008 & 0,0420 \\
Cr & Hv00 & Cr-KA & 0,1818 & 0,0317 \\
Fe & Hv00 & Fe-KB1 & 116,9429 & 95,2833 \\
K & K 00 & K -KA & 0,1317 & 0,0439 \\
Mn & Hv00 & Mn-KA & 0,9383 & 0,1583 \\
P & P 00 & P -KA & 0,4661 & 0,0691 \\
S & S 00 & S -KA & 0,0508 & 0,0110 \\
Si & Si00 & Si-KA & 1,8121 & 2,1315 \\
Ti & Hv00 & Ti-KA & 0,1181 & 0,0597 \\
\hline
\end{tabular}

Agregado - AM10 Brita de Hematita 1, código do fornecedor 7006-01.

Tabela 28 - Composição química - AM10 Areia de hematita.

\begin{tabular}{ccccc}
\hline AM10 & & & & \\
\hline Componente & Meas. C. & Espectro & Intensidade & Resultado \\
\hline Al & Al00 & Al-KA & (kcps) & (mass\%) \\
Ca & Ca00 & Ca-KA & 0,9921 & 1,4244 \\
Cr & Hv00 & Cr-KA & 0,1364 & 0,0229 \\
Fe & Hv00 & Fe-KB1 & 113,0447 & 0,0246 \\
Mn & Hv00 & Mn-KA & 0,7731 & 95,4378 \\
P & P 00 & P -KA & 0,2332 & 0,1351 \\
S & S 00 & S-KA & 0,0255 & 0,0360 \\
Si & Si00 & Si-KA & 2,4052 & 0,0057 \\
& & & & 2,9135 \\
\hline
\end{tabular}




\section{ipen}

Agregado - AM23 Areia de Barita, código do fornecedor 7012-01.

Tabela 29 - Composição química - AM10 Areia de hematita.

\begin{tabular}{ccccc}
\hline AM23 & & & & \\
\hline Componente & Meas. C. & Espectro & Intensidade & Resultado \\
\hline Al & & & (kcps) & (mass\%) \\
Ba & Al00 & Al-KA & 0.4271 & 0,8428 \\
Ca & Hv00 & Ba-LA & 112.617 & 60,7960 \\
Fe & Ca00 & Ca-KA & 119.699 & 5,8578 \\
K & Hv00 & Fe-KA & 220.164 & 12,5643 \\
Mg & K 00 & K -KA & 0.1840 & 0,1365 \\
Mn & Mg00 & Mg-KA & 0.1626 & 1,1216 \\
Nb & Hv00 & Mn-KA & 0.2620 & 0,2155 \\
Ni & Hv00 & Nb-KA & 0.3995 & 0,0155 \\
P & Hv00 & Ni-KA & 0.0985 & 0,0310 \\
S & P 00 & P -KA & 101.929 & 2,4526 \\
Si & S 00 & S -KA & 306.357 & 11,3375 \\
Sr & Si00 & Si-KA & 20.818 & 3,8663 \\
Ti & Hv00 & Sr-KA & 45.227 & 0,2530 \\
Zn & Hv00 & Ti-KA & 0.2965 & 0,4755 \\
Zr & Hv00 & Zn-KA & 0.1220 & 0,0230 \\
& Hv00 & Zr-KB1 & 0.0533 & 0,0111 \\
\hline
\end{tabular}


Tabela 30 - Resumo geral das composições químicas das amostras das matérias primas e percentual dos elementos químicos presentes nas amostras.

\begin{tabular}{|c|c|c|c|c|c|c|c|c|c|c|c|}
\hline & AM1 & AM2 & AM3 & AM4 & AM5 & AM6 & AM7 & AM8 & AM9 & AM10 & AM23 \\
\hline $\mathrm{Al}$ & 0,4969 & 0,5564 & 0,0000 & 0,9276 & 0,7510 & 1,3075 & 1,2993 & 0,3414 & 2,1695 & 1,4244 & 0,8428 \\
\hline $\mathrm{Ba}$ & & & & & & & & & & & 60,7960 \\
\hline $\mathrm{Ca}$ & 75,5817 & 0,0322 & 0,0146 & 4,4114 & 11,7929 & 0,0196 & 0,0176 & 0,6082 & 0,0420 & 0,0229 & 5,8578 \\
\hline $\mathrm{Cl}$ & & & 0,2901 & & & & & & & & \\
\hline $\mathrm{Co}_{0}$ & & & & 0,0367 & & & & & & & \\
\hline $\mathrm{Cr}$ & & & 0,0395 & 0,2469 & 0,0633 & 0,0196 & 0,0272 & 0,0281 & 0,0317 & 0,0246 & \\
\hline $\mathrm{Cu}$ & & & 0,0179 & & 0,0211 & & & & & & \\
\hline $\mathrm{Fe}$ & 0,4910 & 98,4940 & 99,1220 & 82,1601 & 74,3351 & 94,5189 & 92,7729 & 97,5741 & 95,2833 & 95,4378 & 12,5643 \\
\hline $\mathrm{K}$ & 0,2312 & & & 0,1407 & 0,1582 & 0,0189 & 0,0220 & 0,0451 & 0,0439 & & 0,1365 \\
\hline $\mathrm{Mg}$ & 20,8433 & & & 4,9190 & 4,5961 & 0,1070 & 0,1288 & 0,1974 & & & 1,1216 \\
\hline $\mathrm{Mn}$ & & 0,0984 & 0,3489 & 0,6094 & 0,6439 & 0,2903 & 0,3956 & 0,3552 & 0,1583 & 0,1351 & 0,2155 \\
\hline $\mathrm{Nb}$ & & & & 0,0024 & 0,0025 & & & & & & 0,0155 \\
\hline$\overline{N_{1}}$ & 0,0234 & & & 0,0240 & 0,0253 & & & & & & 0,0310 \\
\hline $\mathrm{P}$ & & 0,0383 & 0,0149 & 0,5049 & 1,2239 & 0,0300 & 0,0296 & 0,0332 & 0,0691 & 0,0360 & 2,4526 \\
\hline $\mathrm{S}$ & 0,0492 & 0,0063 & 0,1263 & 1,5908 & 1,5682 & & & 0,0356 & 0,0110 & 0,0057 & 11,3375 \\
\hline $\mathrm{Si}$ & 2,2671 & 0,6933 & 0,0197 & 1,6739 & 2,0486 & 3,6183 & 5,2485 & 0,7816 & 2,1315 & 2,9135 & 3,8663 \\
\hline $\mathrm{Sr}$ & 0,0140 & & & 0,0205 & 0,1039 & & & & & & 0,2530 \\
\hline $\mathrm{Ti}$ & & 0,0812 & 0,0062 & 2,4527 & 2,3799 & 0,0699 & 0,0587 & & 0,0597 & & 0,4755 \\
\hline $\mathrm{V}$ & & & & 0,1940 & 0,2200 & & & & & & \\
\hline $\mathrm{Zn}$ & & & & 0,0787 & 0,0524 & & & & & & 0,0230 \\
\hline $\mathrm{Zr}$ & 0,0023 & & & 0,0063 & 0,0139 & & & & & & 0,0111 \\
\hline
\end{tabular}

\subsection{Traços dos concretos formulados para as sete famílias escolhidas.}

Os traços com as quantidades de cada material aplicado são apresentados a seguir nas tabelas $(31$ - 52), para as sete famílias, e mostram as quantidades de materiais utilizados por metro cúbico de concreto.

Cada família foi composta pelos concretos, conforme apresentado a seguir.

Família 1 - Concretos 1,4,5,6.

Família 2 - Concretos 2,3,7,8,9,10.

Família 4 - Concretos 11, 12, 13.

Família 5 - Concretos 14,15,16.

Família 6 - Concretos 17, 18, 19.

Família 7- Concretos 20, 21, 22 
Tabela 31 - Traço Concreto 1

Com 1 - Consumo por $\mathrm{m}^{3}$ de materiais secos

\begin{tabular}{lcc}
\hline \multicolumn{1}{c}{ Traço do concreto } & Quantidade & Unidade \\
\hline consumo de cimento por m3 & 573,65 & $\mathrm{~kg}$ \\
\hline adição de filer calcario por (m3) & 57,05 & $\mathrm{~kg}$ \\
\hline água total & 275,84 & $\mathrm{~kg}$ \\
\hline teor de argamassa & 0,55 & $\mathrm{~kg}$ \\
\hline ar aprisionado & não aferido & \\
\hline consistencia do concreto fresco & não aferida & \\
\hline massa específica & 3.740 & $\mathrm{~kg} / \mathrm{m3}$ \\
\hline areia de hematita graúda (AM7 Codigo fornecedor & & \\
7000.00) & 1290,8 & $\mathrm{Kg}$ \\
\hline brita 1 de hematita (AM 10 codigo do fornecedor 7006.01) & 631,05 & $\mathrm{Kg}$ \\
\hline brita 0 de hematita (AM 9 codigo do fornecedor 7012.01) & 956,4 & $\mathrm{Kg}$ \\
\hline aditivo superplastificante 0,5\% & 2,87 & $\mathrm{Kg}$ \\
\hline
\end{tabular}

Tabela 32 - Traço Concreto 4

\begin{tabular}{|c|c|c|}
\hline \multicolumn{3}{|c|}{ Com 4 - Consumo por $\mathrm{m}^{3}$ de materiais secos } \\
\hline Traço do concreto & Quantidade & Unidade \\
\hline consumo de cimento por m3 & 566,00 & $\mathrm{Kg}$ \\
\hline adição de filer calcario por (m3) & 28,30 & $\mathrm{Kg}$ \\
\hline água total & 254,70 & $\mathrm{Kg}$ \\
\hline teor de argamassa & 0,56 & $\mathrm{Kg}$ \\
\hline ar aprisionado & não aferido & \\
\hline consistencia do concreto fresco & não aferida & \\
\hline massa específica & 3460,00 & $\mathrm{~kg} / \mathrm{m} 3$ \\
\hline magnetita malha 325 (AM4 Codigo fornecedor 1023.15) & 283,00 & $\mathrm{Kg}$ \\
\hline areia de hematita (AM 6 codigo do fornecedor 7000.02) & 933,90 & $\mathrm{Kg}$ \\
\hline brita 1 de hematita (AM 10 codigo do fornecedor 7006.01) & 560,34 & $\mathrm{Kg}$ \\
\hline brita 0 de hematita (AM 9 codigo do fornecedor 7012.01) & 840,51 & $\mathrm{Kg}$ \\
\hline aditivo superplastificante $0,5 \%$ & 3,00 & $\mathrm{Kg}$ \\
\hline
\end{tabular}

Tabela 33 - Traço Concreto 5.

Com 5 - Consumo por $\mathrm{m}^{3}$ de materiais secos

\begin{tabular}{lcc}
\hline \multicolumn{1}{c}{ Traço do concreto } & Quantidade & Unidade \\
\hline consumo de cimento por $\mathrm{m} 3$ & 519,40 & $\mathrm{Kg}$ \\
\hline adição de filer calcario por (m3) & 25,97 & $\mathrm{Kg}$ \\
\hline água total & 233,73 & $\mathrm{Kg}$ \\
\hline teor de argamassa & 0,57 & $\mathrm{Kg}$ \\
\hline ar aprisionado & & \\
\hline consistencia do concreto fresco & 3150,00 & $\mathrm{~kg} / \mathrm{m} 3$ \\
\hline massa específica & 259,70 & $\mathrm{Kg}$ \\
\hline óxido de ferro vermelho (AM 3 codigo do fornecedor 1005.03) & 857,01 & $\mathrm{Kg}$ \\
\hline areia de hematita (AM 6 codigo do fornecedor 7000.02) & 514,21 & $\mathrm{Kg}$ \\
\hline brita 1 de hematita (AM 10 codigo do fornecedor 7006.01) & 771,31 & $\mathrm{Kg}$ \\
\hline brita 0 de hematita (AM 9 codigo do fornecedor 7012.01) & 3,00 & $\mathrm{Kg}$ \\
\hline aditivo superplastificante 0,5\% & & \\
\hline
\end{tabular}


Tabela 34 - Traço Concreto 6.

\begin{tabular}{lcc}
\hline \multicolumn{3}{c}{ Com 6 - Consumo por $\mathrm{m}^{3}$ de materiais secos } \\
\hline \multicolumn{1}{c}{ Traço do concreto } & Quantidade & Unidade \\
\hline consumo de cimento por $\mathrm{m} 3$ & 566,02 & $\mathrm{Kg}$ \\
\hline adição de filer calcario por (m3) & 28,30 & $\mathrm{Kg}$ \\
\hline água total & 233,73 & $\mathrm{Kg}$ \\
\hline teor de argamassa & 0,57 & $\mathrm{Kg}$ \\
\hline ar aprisionado & & \\
\hline consistencia do concreto fresco & 3590,00 & $\mathrm{~kg} / \mathrm{m} 3$ \\
\hline massa específica & 283,01 & $\mathrm{Kg}$ \\
\hline oxido de ferro HEI (AM 2 codigo do fornecedor 7000.01) & 948,72 & $\mathrm{Kg}$ \\
\hline areia de hematita (AM 7 codigo do fornecedor 7000.00) & 557,98 & $\mathrm{Kg}$ \\
\hline brita 1 de hematita (AM 10 codigo do fornecedor 7006.01) & 839,38 & $\mathrm{Kg}$ \\
\hline brita 0 de hematita (AM 9 codigo do fornecedor 7012.01) & 2,83 & $\mathrm{Kg}$ \\
\hline aditivo superplastificante 0,5\% & &
\end{tabular}

Tabela 35 - Traço Concreto 2.

\begin{tabular}{|c|c|c|}
\hline \multicolumn{3}{|c|}{ Com 2 - Consumo por $\mathrm{m}^{3}$ de materiais secos } \\
\hline Traço do concreto & Quantidade & Unidade \\
\hline consumo de cimento por $\mathrm{m} 3$ & 528,00 & $\mathrm{Kg}$ \\
\hline adição de filer calcario por (m3) & 132,00 & $\mathrm{Kg}$ \\
\hline água total & 212,00 & $\mathrm{Kg}$ \\
\hline teor de argamassa & 0,56 & $\mathrm{Kg}$ \\
\hline ar aprisionado & não aferido & \\
\hline consistencia do concreto fresco & não aferida & \\
\hline massa específica & 3440,00 & $\mathrm{~kg} / \mathrm{m} 3$ \\
\hline magnetita com areia virgem (AM5 Codigo fornecedor 1023.03) & 1188,00 & $\mathrm{Kg}$ \\
\hline brita 1 de hematita (AM 10 codigo do fornecedor 7006.01) & 580,00 & $\mathrm{Kg}$ \\
\hline brita 0 de hematita (AM 9 codigo do fornecedor 7012.01) & 871,20 & $\mathrm{Kg}$ \\
\hline aditivo superplastificante $0,5 \%$ & 2,64 & $\mathrm{Kg}$ \\
\hline
\end{tabular}

Tabela 36 - Traço Concreto 3.

Com 3 - Consumo por $\mathrm{m}^{3}$ de materiais secos

\begin{tabular}{|c|c|c|}
\hline Traço do concreto & Quantidade & Unidade \\
\hline consumo de cimento por $\mathrm{m} 3$ & 566,44 & $\mathrm{Kg}$ \\
\hline adição de filer calcario por (m3) & 35,03 & $\mathrm{Kg}$ \\
\hline água total & 254,90 & $\mathrm{Kg}$ \\
\hline teor de argamassa & 0,63 & \\
\hline ar aprisionado & não aferido & \\
\hline consistencia do concreto fresco & não aferida & \\
\hline massa específica & 3700,00 & $\mathrm{~kg} / \mathrm{m} 3$ \\
\hline $\begin{array}{l}\text { granalha de baixa massa específica (AM8 Codigo fornecedor } \\
7018.00 \text { ) }\end{array}$ & 1595,27 & $\mathrm{Kg}$ \\
\hline brita 1 de hematita (AM 10 codigo do fornecedor 7006.01 ) & 520,20 & $\mathrm{Kg}$ \\
\hline brita 0 de hematita (AM 9 codigo do fornecedor 7012.01 ) & 786,07 & $\mathrm{Kg}$ \\
\hline aditivo superplastificante $0,5 \%$ & 2,83 & $\mathrm{Kg}$ \\
\hline
\end{tabular}


Tabela 37 - Traço Concreto 7.

Com 7 - Consumo por $\mathrm{m}^{3}$ de materiais secos

\begin{tabular}{lcc}
\hline \multicolumn{1}{c}{ Traço do concreto } & Quantidade & Unidade \\
\hline consumo de cimento por $\mathrm{m3}$ & 623,92 & $\mathrm{~kg}$ \\
\hline adição de filer calcario por $(\mathrm{m} 3)$ & 31,20 & $\mathrm{Kg}$ \\
\hline água total & 268,29 & $\mathrm{Kg}$ \\
\hline teor de argamassa & 0,67 & \\
\hline ar aprisionado & não aferido \\
\hline consistencia do concreto fresco & não aferida & \\
\hline massa específica & 3750,00 & $\mathrm{~kg} / \mathrm{m3}$ \\
\hline oxido de ferro (AM 2 codigo do fornecedor 7000.01) & 311,96 & $\mathrm{Kg}$ \\
\hline granalha de baixa massa específica (AM8 Codigo fornecedor & & \\
7018.00) & 1417,29 & $\mathrm{Kg}$ \\
\hline brita 1 de hematita (AM 10 codigo do fornecedor 7006.01) & 461,91 & $\mathrm{Kg}$ \\
\hline brita 0 de hematita (AM 9 codigo do fornecedor 7012.01) & 698,01 & $\mathrm{Kg}$ \\
\hline aditivo superplastificante 0,5\% & 3,12 & $\mathrm{Kg}$ \\
\hline
\end{tabular}

Tabela 38 - Traço Concreto 8.

Com 8 - Consumo por $\mathrm{m}^{3}$ de materiais secos Traço do concreto

Quantidade Unidade

consumo de cimento por $\mathrm{m} 3$

adição de filer calcario por (m3)

$526,06 \quad \mathrm{~kg}$

água total

26,30 $\mathrm{kg}$

teor de argamassa

341,94

ar aprisionado

0,67

consistencia do concreto fresco

não aferido

massa específica

não aferida

sintetico vermelho (AM 3 codigo do fornecedor 1005.03)

3270,00

granalha de baixa massa específica (AM8 Codigo fornecedor 7018.00)

263,03

brita 1 de hematita (AM 10 codigo do fornecedor 7006.01)

1195,00

389,47

brita 0 de hematita (AM 9 codigo do fornecedor 7012.01)

588,53

aditivo superplastificante $0,5 \%$

2,63

$\mathrm{kg}$

Tabela 39 - Traço Concreto 9.

Com 9 - Consumo por $\mathrm{m}^{3}$ de materiais secos

\begin{tabular}{lcc}
\hline \multicolumn{1}{c}{ Traço do concreto } & Quantidade & Unidade \\
\hline consumo de cimento por m3 & 578,69 & $\mathrm{~kg}$ \\
\hline adição de filer calcario por (m3) & 28,93 & $\mathrm{~kg}$ \\
\hline água total & 250,75 & $\mathrm{~kg}$ \\
\hline teor de argamassa & 0,63 & \\
\hline ar aprisionado & não aferido & \\
\hline consistencia do concreto fresco & não aferida & \\
\hline massa específica & 3490,00 & $\mathrm{~kg} / \mathrm{m3}$ \\
\hline magnetita malha \# 325 (AM 4 codigo do fornecedor 1023.15) & 289,34 & $\mathrm{~kg}$ \\
\hline granalha de baixa massa específica (AM8 Codigo fornecedor 7018.00) & 1314,54 & $\mathrm{~kg}$ \\
\hline brita 1 de hematita (AM 10 codigo do fornecedor 7006.01) & 428,43 & $\mathrm{~kg}$ \\
\hline brita 0 de hematita (AM 9 codigo do fornecedor 7012.01) & 647,41 & $\mathrm{~kg}$ \\
\hline aditivo superplastificante 0,5\% & 2,89 & $\mathrm{~kg}$ \\
\hline
\end{tabular}


Tabela 40 - Traço Concreto 10.

\begin{tabular}{|c|c|c|}
\hline \multicolumn{3}{|c|}{ Com 10 - Consumo por $\mathrm{m}^{3}$ de materiais secos } \\
\hline Traço do concreto & Quantidade & Unidade \\
\hline consumo de cimento por $\mathrm{m} 3$ & 622,69 & $\mathrm{~kg}$ \\
\hline adição de filer calcario por (m3) & 31,13 & $\mathrm{~kg}$ \\
\hline água total & 249,08 & $\mathrm{~kg}$ \\
\hline teor de argamassa & 0,67 & \\
\hline ar aprisionado & não aferido & \\
\hline consistencia do concreto fresco & não aferida & \\
\hline massa específica & 3700,00 & $\mathrm{~kg} / \mathrm{m} 3$ \\
\hline magnetita com areia virgem (AM 5 codigo do fornecedor 1023.03) & 311,34 & $\mathrm{~kg}$ \\
\hline granalha de baixa massa específica (AM8 Codigo fornecedor 7018.00) & 1414,49 & $\mathrm{~kg}$ \\
\hline brita 1 de hematita (AM 10 codigo do fornecedor 7006.01) & 461,00 & $\mathrm{~kg}$ \\
\hline brita 0 de hematita (AM 9 codigo do fornecedor 7012.01) & 696,63 & $\mathrm{~kg}$ \\
\hline aditivo superplastificante $0,5 \%$ & 3,11 & $\mathrm{~kg}$ \\
\hline
\end{tabular}

Tabela 41 - Traço Concreto 11.

Traço de concreto - Com 11 - Consumo por $\mathrm{m}^{3}$ de materiais secos

Traço do concreto Quantidade

\begin{tabular}{lcc}
\hline consumo de cimento por $\mathrm{m} 3$ & 536,45 & $\mathrm{~kg}$ \\
\hline adição de filer calcario por (m3) & 26,82 & $\mathrm{~kg}$ \\
\hline água total & 386,40 & $\mathrm{~kg}$ \\
\hline teor de argamassa & 0,31 & \\
\hline ar aprisionado & não aferido & \\
\hline consistencia do concreto fresco & não aferida & \\
\hline massa específica & 3300,00 & $\mathrm{~kg} / \mathrm{m} 3$ \\
\hline oxido de ferro HEl (AM2 Codigo fornecedor 7000.01) & 377,04 & $\mathrm{~kg}$ \\
\hline areia de hematita grauda (AM 7 codigo do fornecedor 7000.00) & 2137,26 & $\mathrm{~kg}$ \\
\hline aditivo superplastificante 0,5\% & 2,68 & $\mathrm{~kg}$ \\
\hline
\end{tabular}

Tabela 42 - Traço Concreto 12.

Com 12 - Consumo por $\mathrm{m}^{3}$ de materiais secos

\begin{tabular}{lcc}
\hline \multicolumn{1}{c}{ Traço do concreto } & Quantidade & Unidade \\
\hline consumo de cimento por $\mathrm{m3}$ & 514,80 & $\mathrm{~kg}$ \\
\hline adição de filer calcario por $(\mathrm{m} 3)$ & 25,74 & $\mathrm{~kg}$ \\
\hline água total & 353,00 & $\mathrm{~kg}$ \\
\hline teor de argamassa & 0,31 & \\
\hline ar aprisionado & não aferido & \\
\hline consistencia do concreto fresco & não aferida & \\
\hline massa específica & 3200,00 & $\mathrm{~kg} / \mathrm{m3}$ \\
\hline magnetita malha \# 325 (AM4 Codigo fornecedor 1023.15) & 361,82 & $\mathrm{~kg}$ \\
\hline areia de hematita grauda (AM 7 codigo do fornecedor 7000.00) & 2051,01 & $\mathrm{~kg}$ \\
\hline aditivo superplastificante 0,5\% & 2,57 & $\mathrm{~kg}$
\end{tabular}


Tabela 43 - Traço Concreto 13.

Com 13 - Consumo por $\mathrm{m}^{3}$ de materiais secos

\begin{tabular}{|c|c|c|}
\hline Traço do concreto & Quantidade & Unidade \\
\hline consumo de cimento por m3 & 436,48 & $\mathrm{~kg}$ \\
\hline adição de filer calcario por (m3) & 21,82 & $\mathrm{~kg}$ \\
\hline água total & 436,48 & $\mathrm{~kg}$ \\
\hline teor de argamassa & 0,31 & \\
\hline ar aprisionado & não aferido & \\
\hline consistencia do concreto fresco & não aferida & \\
\hline massa específica & 2870,00 & $\mathrm{~kg} / \mathrm{m} 3$ \\
\hline sintetico vermelho (AM 3 Codigo fornecedor 1005.03) & 309,48 & $\mathrm{~kg}$ \\
\hline \multirow[t]{2}{*}{ areia de hematita grauda (AM 7 codigo do fornecedor 7000.00 ) } & 1738,98 & $\mathrm{~kg}$ \\
\hline & 2 & \\
\hline aditivo superplastificante $0,5 \%$ & ,57 & $\mathrm{kg}$ \\
\hline
\end{tabular}

Tabela 44 - Traço Concreto 14.

\begin{tabular}{|c|c|c|}
\hline \multicolumn{3}{|c|}{ Com 14 - Consumo por $\mathrm{m}^{3}$ de materiais secos } \\
\hline Traço do concreto & Quantidade & Unidade \\
\hline consumo de cimento por $\mathrm{m} 3$ & 528,88 & $\mathrm{~kg}$ \\
\hline adição de filer calcario por (m3) & 26,44 & $\mathrm{Kg}$ \\
\hline água total & 279,25 & $\mathrm{Kg}$ \\
\hline teor de argamassa & 0,31 & \\
\hline ar aprisionado & não aferido & \\
\hline consistencia do concreto fresco & não aferida & \\
\hline massa específica & 3260,00 & $\mathrm{~kg} / \mathrm{m} 3$ \\
\hline oxido de ferro HEI (AM2 Codigo fornecedor 7000.01) & 371,72 & $\mathrm{Kg}$ \\
\hline magnetita com areaia virgem (AM 5 codigo do fornecedor 1023.03) & 2107,11 & \\
\hline aditivo superplastificante $0,5 \%$ & 2,64 & $\mathrm{Kg}$ \\
\hline
\end{tabular}

Tabela 45 - Traço Concreto 15

\begin{tabular}{|c|c|c|}
\hline \multicolumn{3}{|c|}{ Com 15 - Consumo por $\mathrm{m}^{3}$ de materiais secos } \\
\hline Traço do concreto & Quantidade & Unidade \\
\hline consumo de cimento por $\mathrm{m} 3$ & 433,84 & $\mathrm{Kg}$ \\
\hline adição de filer calcario por (m3) & 21,69 & $\mathrm{Kg}$ \\
\hline água total & 402,60 & $\mathrm{Kg}$ \\
\hline teor de argamassa & 0,31 & \\
\hline ar aprisionado & não aferido & \\
\hline consistencia do concreto fresco & não aferida & \\
\hline massa específica & 2820,00 & $\mathrm{~kg} / \mathrm{m} 3$ \\
\hline sintetio vermelho (AM3 Codigo fornecedor 1005.03) & 307,60 & $\mathrm{~kg}$ \\
\hline magnetita com areaia virgem (AM 5 codigo do fornecedor 1023.03) & 1728,46 & \\
\hline aditivo superplastificante $0,5 \%$ & 2,17 & $\mathrm{~kg}$ \\
\hline
\end{tabular}


Tabela 46 - Traço Concreto 16.

Com 16 - Consumo por $\mathrm{m}^{3}$ de materiais secos Traço do concreto

Quantidade

Unidade

consumo de cimento por $\mathrm{m} 3$

\begin{tabular}{cc}
528,53 & $\mathrm{~kg}$ \\
\hline 26,42 & $\mathrm{~kg}$ \\
\hline 294,44 & $\mathrm{~kg}$ \\
0,31 &
\end{tabular}

adição de filer calcario por (m3)

0,31

teor de argamassa

não aferidc

ar aprisionado

não aferida

consistencia do concreto fresco

3150,00

magnetita malha \# 325 ( AM4 codigo do fornecedor 1023.15)

371,47

magnetita com areaia virgem (AM 5 codigo do fornecedor 1023.03)

2105,70

aditivo superplastificante $0,5 \%$

2,64

$\mathrm{kg}$

Tabela 47 - Traço Concreto 17.

\begin{tabular}{|c|c|c|}
\hline \multicolumn{3}{|c|}{ Com 17 - Consumo por $\mathrm{m}^{3}$ de materiais secos } \\
\hline Traço do concreto & Quantidade & Unidade \\
\hline consumo de cimento por $\mathrm{m} 3$ & 572,53 & $\mathrm{~kg}$ \\
\hline adição de filer calcario por (m3) & 28,62 & $\mathrm{~kg}$ \\
\hline água total & 400,77 & $\mathrm{~kg}$ \\
\hline teor de argamassa & 0,30 & \\
\hline ar aprisionado & não aferido & \\
\hline consistencia do concreto fresco & não aferida & \\
\hline massa específica & 3720,00 & $\mathrm{~kg} / \mathrm{m} 3$ \\
\hline oxido de ferro HEI (AM2 Codigo fornecedor 7000.01) & 407,28 & $\mathrm{~kg}$ \\
\hline $\begin{array}{l}\text { granalha de baixa massa específica (AM } 8 \text { codigo do fornecedor } \\
7018.00 \text { ) }\end{array}$ & 2308,33 & \\
\hline aditivo superplastificante $0,5 \%$ & 2,86 & $\mathrm{~kg}$ \\
\hline
\end{tabular}

Tabela 48 - Traço Concreto 18.

Com 18 - Consumo por $\mathrm{m}^{3}$ de materiais secos

\begin{tabular}{lcc}
\hline \multicolumn{3}{c}{ Com 18 - Consumo por $\mathrm{m}^{3}$ de materiais secos } \\
\hline Traço do concreto & Quantidade & Unidade \\
\hline consumo de cimento por $\mathrm{m} 3$ & 572,00 & $\mathrm{~kg}$ \\
\hline adição de filer calcario por $(\mathrm{m} 3)$ & 28,60 & $\mathrm{~kg}$ \\
\hline água total & 277,82 & $\mathrm{~kg}$ \\
\hline teor de argamassa & 0,22 & \\
\hline ar aprisionado & não aferido \\
\hline consistencia do concreto fresco & não aferida \\
\hline massa específica & 3520,00 & $\mathrm{~kg} / \mathrm{m3}$ \\
\hline Sintetico vermelho (AM3 Codigo fornecedor 1005.03) & 135,08 & $\mathrm{~kg}$ \\
\hline granalha de baixa massa específica (AM 8 codigo do fornecedor & & \\
7018.00) & 2546,70 & \\
\hline aditivo superplastificante 0,5\% & 2,86 & $\mathrm{~kg}$ \\
\hline
\end{tabular}


Tabela 49 - Traço Concreto 19.

Com 19 - Consumo por $\mathrm{m}^{3}$ de materiais secos Traço do concreto Quantidade Unidade

consumo de cimento por $\mathrm{m} 3$ $578,86 \quad \mathrm{~kg}$

adição de filer calcario por (m3) 28,93

água total 264,60 $\mathrm{kg}$

teor de argamassa

ar aprisionado não aferido

consistencia do concreto fresco não aferida

massa específica 3510,00

magnetita malha \# 325 (AM4 Codigo fornecedor 1023.15)

406,85 $\mathrm{kg} / \mathrm{m} 3$

granalha de baixa massa específica (AM 8 codigo do fornecedor

7018.00)

2306,25

aditivo superplastificante $0,5 \%$

2,89

$\mathrm{kg}$

Tabela 50 - Traço Concreto 20.

Com 20 - Consumo por $\mathrm{m}^{3}$ de materiais secos

Traço do concreto

consumo de cimento por $\mathrm{m} 3$

Quantidade

Unidade

adição de filer calcario por $(\mathrm{m} 3)$

água total

teor de argamassa

505,47

25,27

346,60

0,30

ar aprisionado

não aferido

consistencia do concreto fresco

não aferida

massa específica

areia de barita (AM23 codigo fornecedor.)

areia de hematita grauda (AM7 codigo do fornecedor 7000.00)

aditivo superplastificante $0,5 \%$

\begin{tabular}{cc}
3160,00 & $\mathrm{~kg} / \mathrm{m} 3$ \\
\hline 355,27 & $\mathrm{~kg}$ \\
2013,85 & $\mathrm{~kg}$ \\
\hline 2,53 & $\mathrm{~kg}$
\end{tabular}

Tabela 51 - Traço Concreto 21.

Com 21 - Consumo por $\mathrm{m}^{3}$ de materiais secos

Traço do concreto

\begin{tabular}{cc} 
Quantidade & Unidade \\
504,06 & $\mathrm{~kg}$ \\
\hline 25,20 & $\mathrm{~kg}$ \\
\hline 345,64 & $\mathrm{~kg}$ \\
\hline 0,30 & \\
não aferido & \\
\hline não aferida & \\
3170,00 & $\mathrm{~kg} / \mathrm{m3}$ \\
\hline 357,39 & $\mathrm{~kg}$ \\
\hline 2008,24 & $\mathrm{~kg}$ \\
\hline 2,52 & $\mathrm{~kg}$
\end{tabular}


Tabela 52 - Traço Concreto 22.

Com 22 - Consumo por $\mathrm{m}^{3}$ de materiais secos

\begin{tabular}{|c|c|c|}
\hline Traço do concreto & Quantidade & Unidade \\
\hline consumo de cimento por $\mathrm{m} 3$ & 584,67 & $\mathrm{~kg}$ \\
\hline adição de filer calcario por (m3) & 29,23 & $\mathrm{~kg}$ \\
\hline água total & 275,61 & $\mathrm{~kg}$ \\
\hline teor de argamassa & 0,30 & \\
\hline ar aprisionado & não aferido & \\
\hline consistencia do concreto fresco & não aferida & \\
\hline massa específica & 3580,00 & $\mathrm{~kg} / \mathrm{m} 3$ \\
\hline areia de barita (AM23 codigo fornecedor.) & 410,93 & $\mathrm{~kg}$ \\
\hline $\begin{array}{l}\text { granalha de baixa massa específica (AM8 codigo do fornecedor } \\
7018.00 \text { ) }\end{array}$ & 2329,39 & $\mathrm{~kg}$ \\
\hline aditivo superplastificante $0,5 \%$ & 2,92 & $\mathrm{~kg}$ \\
\hline
\end{tabular}

\subsection{Caracterização física dos concretos preparados.}

4.4.1 Massa específica dos corpos de prova no momento da desforma e antes da realização dos ensaios de atenuação.

Na tabela (53), apresentada, a coluna 1 refere-se aos números das amostras dos concretos, pois para cada concreto, conforme já informado, moldamos de quatro a cinco corpos de prova, e apenas um de cada família foi ensaiado às radiações. AM é o número que identifica as amostras ensaiadas à nomenclatura (Com $\left.n^{\circ}\right)$, identifica o número do concreto. Nas demais colunas, o enunciado identifica os dados informados. 
Tabela 53 - Massa específica dos concretos ensaiados no momento da moldagem e na desforma.

\begin{tabular}{|c|c|c|c|}
\hline $\begin{array}{c}\text { Amostra/Concreto } \\
\text { Número da amostra e } \\
\text { concreto }\end{array}$ & $\begin{array}{c}\text { Massa específica dos corpos } \\
\text { de prova úmidos após a } \\
\text { moldagem }(40 \mathrm{~mm} \times 50 \mathrm{~mm} \\
\times 100 \mathrm{~mm}) \mathrm{kg} / \mathrm{dm}^{3}\end{array}$ & $\begin{array}{c}\text { Massa específica dos corpos de } \\
\text { prova antes do ensaio de } \\
\text { atenuação }\left(\begin{array}{c}40 \mathrm{~mm} \times 50 \mathrm{~mm} \times 100 \\
\mathrm{~mm}) \\
\mathrm{kg} / \mathrm{dm}^{3}\end{array}\right.\end{array}$ & $\begin{array}{c}\text { Diferença } \\
\text { entre as } \\
\text { massas } \\
(\mathrm{kg})\end{array}$ \\
\hline AM 5 / Com 1 & 3,74 & 3,72 & 0,02 \\
\hline AM 7 / Com 2 & 3,44 & 3,44 & 0,00 \\
\hline AM 12 / Com 3 & 3,70 & 3,70 & 0,00 \\
\hline AM 21 / Com 4 & 3,46 & 3,47 & 0,01 \\
\hline AM 27 / Com 5 & 3,15 & 3,14 & 0,01 \\
\hline AM 33 / Com 6 & 3,59 & 3,59 & 0,00 \\
\hline AM 36 / Com 7 & 3,75 & 3,76 & 0,01 \\
\hline AM 44 / Com 8 & 3,27 & 3,27 & 0,00 \\
\hline AM 51 / Com 9 & 3,49 & 3,49 & 0,00 \\
\hline AM 53 / Com 10 & 3,70 & 3,72 & 0,02 \\
\hline AM 60 / Com 11 & 3,30 & 3,30 & 0,00 \\
\hline AM 66 / Com 12 & 3,20 & 3,19 & 0,01 \\
\hline AM 72 / Com 72 & 2,87 & 2,87 & 0,00 \\
\hline AM 80 / Com 14 & 3,26 & 3,23 & 0,03 \\
\hline AM 84 Com 15 & 2,82 & 2,74 & 0,08 \\
\hline AM 90 / Com 16 & 3,15 & 3,14 & 0,01 \\
\hline AM 96 Com 17 & 3,72 & 3,69 & 0,03 \\
\hline AM 102 / Com 18 & 3,52 & 3,53 & 0,01 \\
\hline AM 107 / Com 19 & 3,51 & 3,53 & 0,02 \\
\hline AM 114 / Com 20 & 3,16 & 3,15 & 0,01 \\
\hline AM 119 / Com 21 & 3,17 & 3,17 & 0,00 \\
\hline AM 125 / Com 22 & 3,58 & 3,58 & 0,00 \\
\hline
\end{tabular}

As massas específicas obtidas são similares as encontradas em outros trabalhos, os resultados obtidos com as massas específicas são proporcionados principalmente pela utilização de agregados com a grande presença do minérios de ferro.

O consumo de cimento por $\mathrm{m}^{3}$ nos concretos preparados foi fortemente influenciado pela elevada densidade dos agregados utilizados. A massa específica elevada dos agregados aumentam as forças de atrito e arrasto entre os componentes do concreto, para que o concreto tenha a trabalhabilidade necessária, necessita que o teor de argamassa seja mais elevado se comparado aos concretos convencionais, sendo necessário aumentar a utilização de agregados miúdos e consequentemente o consumo de água.

Avaliando os resultados encontrados, da mesma maneira que nos concretos convencionais, pode-se observar que a utilização de teor de argamassa aumenta o 
consumo de água o que resulta no aumento dos vazios e consequentemente diminui a massa específica do concreto.

Os concretos de número 5, 13 e 15, são concretos que utilizaram elevado consumo de materiais finos e apresentaram as menores massas específicas dentre os concretos preparados, já os concretos de números 1, 10 e 7 apresentaram as mais elevadas densidades e tem em comum a utilização de teores de argamassa menores.

4.4.2 Resistência à compressão.

A resistência à compressão foi realizada de acordo com a norma ABNT NBR $5739(50)$.

No presente trabalho, optamos por avaliar a resistência à compressão em quatro concretos escolhidos em função de sua densidade, dois apresentavam massas específicas um pouco mais baixas comparados com as massa específicas obtidas nos concretos preparados, e dois apresentavam massas específicas elevadas. Por não se tratar de característica preponderante na utilização como blindagem, uma vez que concretos ricos em consumo de cimento com agregados de elevada densidade tendem a apresentar resistências mínimas adequadas para utilização como concreto para blindagem.

Escolhemos os concretos de números 6, 11, 9, e 15 para ensaia-los a compressão, os resultados encontrados foram;

Concreto número 6, resistência aos 28 dias 33,20 MPa.

Concreto número 9, resistência aos 28 dias 36,20 MPa.

Concreto número 11, resistência aos 28 dias 24,00 MPa.

Concreto número 15, resistência aos 28 dias 22,70 MPa. 


\section{ipen}

4.5 Composição química dos concretos preparados.

A seguir são apresentados, nas tabelas (54-75), os resultados das análises químicas, com a quantidade de cada elemento em relação à massa da amostra que serviu para o cálculo do coeficiente de atenuação linear teórico. 
Tabela 54 - Análise química normalizada do concreto Com 1.

\begin{tabular}{cccrc}
\hline Com 1 & & & & \\
\hline Elemento & Meio & Espectro & Intensidade & Resultado \\
\hline & & & (kcps) & (massa \%) \\
\hline Fe & Hv00 & Fe-KB1 & 78,4343 & 71,0443 \\
$\mathrm{Ca}$ & Ca00 & Ca-KA & 64,3092 & 14,5605 \\
$\mathrm{Si}$ & Si00 & Si-KA & 7,4466 & 7,7125 \\
$\mathrm{Al}$ & Al00 & Al-KA & 2,5277 & 3,0252 \\
Mg & Mg00 & Mg-KA & 0,5153 & 2,2913 \\
S & S 00 & S -KA & 2,8501 & 0,5925 \\
K & K 00 & K -KA & 1,1947 & 0,4027 \\
Mn & Hv00 & Mn-KA & 0,7092 & 0,1498 \\
Ti & Hv00 & Ti-KA & 0,1604 & 0,1299 \\
P & P 00 & P -KA & 0,4289 & 0,0606 \\
Zn & Hv00 & Zn-KA & 0,1501 & 0,0205 \\
Sr & Hv00 & Sr-KA & 0,1950 & 0,0079 \\
Zr & Hv00 & Zr-KA & 0,0700 & 0,0022 \\
\hline
\end{tabular}

Tabela 55 - Análise química normalizada do concreto Com 2.

\begin{tabular}{|c|c|c|c|c|}
\hline Com 2 & & & & \\
\hline \multirow[t]{2}{*}{ Elemento } & Meio & Espectro & Intensidade & Resultado \\
\hline & & & (kcps) & (massa \%) \\
\hline $\mathrm{Fe}$ & Hv00 & Fe-KB1 & 48,1317 & 54,4889 \\
\hline $\mathrm{Ca}$ & $\mathrm{CaOO}$ & Ca-KA & 101,3540 & 26,5533 \\
\hline $\mathrm{Si}$ & SiO0 & Si-KA & 7,2051 & 7,6922 \\
\hline $\mathrm{Mg}$ & Mg00 & Mg-KA & 0,9244 & 4,1005 \\
\hline Al & Al00 & Al-KA & 2,6247 & 3,2245 \\
\hline$S$ & S 00 & S-KA & 5,7335 & 1,2501 \\
\hline $\mathrm{Ti}$ & Hv00 & Ti-KA & 0,9003 & 1,0540 \\
\hline K & K 00 & K -KA & 2,0074 & 0,7401 \\
\hline$P$ & P 00 & P -KA & 2,2934 & 0,3378 \\
\hline $\mathrm{Mn}$ & Hv00 & $\mathrm{Mn}-\mathrm{KA}$ & 0,9188 & 0,2581 \\
\hline $\mathrm{V}$ & Hv00 & V -KA & 0,1490 & 0,0984 \\
\hline $\mathrm{Sr}$ & Hv00 & Sr-KA & 1,4308 & 0,0572 \\
\hline $\mathrm{Zn}$ & Hv00 & $Z n-K A$ & 0,3803 & 0,0520 \\
\hline $\mathrm{Cr}$ & Hv00 & $\mathrm{Cr}-\mathrm{KA}$ & 0,1052 & 0,0431 \\
\hline $\mathrm{Ni}$ & Hv00 & $\mathrm{Ni}-\mathrm{KA}$ & 0,1037 & 0,0236 \\
\hline $\mathrm{Cu}$ & Hv00 & $\mathrm{Cu}-\mathrm{KA}$ & 0,0873 & 0,0161 \\
\hline $\mathrm{Zr}$ & Hv0O & Zr-KA & 0,2766 & 0,0087 \\
\hline $\mathrm{Nb}$ & Hv0O & $\mathrm{Nb}-\mathrm{KA}$ & 0,0536 & 0,0015 \\
\hline
\end{tabular}


Tabela 56 - Análise química normalizada do concreto Com 3.

\begin{tabular}{ccccc}
\hline Com 3 & \multicolumn{5}{c}{} \\
\hline Elemento & Meio & Espectro & Intensidade & Resultado \\
\hline Fe & Hv00 & Fe-KB1 & (kcps) & (massa \%) \\
Ca & Ca00 & Ca-KA & 89,2356 & 60,9899 \\
Si & Si00 & Si-KA & 7,1090 & 22,4917 \\
Al & Al00 & Al-KA & 3,1497 & 7,6553 \\
Mg & Mg00 & Mg-KA & 0,6526 & 3,8704 \\
S & S00 & S-KA & 3,6780 & 2,9464 \\
K & K 00 & K-KA & 1,9891 & 0,7997 \\
Ti & Hv00 & Ti-KA & 0,1637 & 0,7173 \\
Mn & Hv00 & Mn-KA & 0,6300 & 0,1719 \\
P & P 00 & P -KA & 0,4585 & 0,1613 \\
Cr & Hv00 & Cr-KA & 0,1239 & 0,0677 \\
Zn & Hv00 & Zn-KA & 0,2651 & 0,0448 \\
$\mathrm{Ni}$ & Hv00 & Ni-KA & 0,1023 & 0,0369 \\
Sr & Hv00 & Sr-KA & 0,3973 & 0,0236 \\
Zr & Hv00 & Zr-KA & 0,1148 & 0,0162 \\
Y & Hv00 & Y-KA & 0,0911 & 0,0037 \\
\end{tabular}

Tabela 57 - Análise química normalizada do concreto Com 4.

\begin{tabular}{|c|c|c|c|c|}
\hline Com 4 & & & & \\
\hline \multirow[t]{2}{*}{ Elemento } & Meio & Espectro & Intensidade & Resultado \\
\hline & & & (kcps) & (massa \%) \\
\hline $\mathrm{Fe}$ & Hv00 & Fe-KB1 & 76,2176 & 70,8469 \\
\hline $\mathrm{Ca}$ & $\mathrm{CaOO}$ & Ca-KA & 66,2221 & 15,1518 \\
\hline $\mathrm{Si}$ & SiOO & Si-KA & 6,4557 & 6,7841 \\
\hline Al & Al00 & Al-KA & 2,3665 & 2,8826 \\
\hline Mg & Mg00 & Mg-Ka & 0,5359 & 2,4228 \\
\hline$S$ & s 00 & S-Ka & 3,5957 & 0,7499 \\
\hline K & Mg00 & K-KA & 1,3830 & 0,4690 \\
\hline $\mathrm{Ti}$ & Hv00 & Ti-KA & 0,4527 & 0,3762 \\
\hline $\mathrm{Mn}$ & P 00 & $M n-K A$ & 0,6933 & 0,1506 \\
\hline $\mathrm{P}$ & Hv00 & P -KA & 0,6615 & 0,0938 \\
\hline $\mathrm{Cr}$ & Hv00 & $\mathrm{Cr}-\mathrm{KA}$ & 0,1160 & 0,0334 \\
\hline $\mathrm{Zn}$ & Hv00 & $Z n-K A$ & 0,1960 & 0,0272 \\
\hline $\mathrm{Sr}$ & Hv00 & Sr-KA & 0,2263 & 0,0093 \\
\hline $\mathrm{Zr}$ & Hv00 & Zr-KA & 0,0745 & 0,0024 \\
\hline
\end{tabular}




\section{ipen}

Tabela 58 - Análise química normalizada do concreto Com 5.

Com 5

\begin{tabular}{|c|c|c|c|c|}
\hline Elemento & Meio & Espectro & Intensidade & Resultado \\
\hline & & & (kcps) & (massa \%) \\
\hline $\mathrm{Fe}$ & Hv00 & Fe-KB1 & 65,6347 & 67,3318 \\
\hline $\mathrm{Ca}$ & $\mathrm{CaOO}$ & Сa-KA & 80,1161 & 19,4486 \\
\hline $\mathrm{Si}$ & SiOO & Si-KA & 6,2220 & 6,7253 \\
\hline Al & Al00 & Al-KA & 2,2509 & 2,8186 \\
\hline $\mathrm{Mg}$ & Mg00S & $\mathrm{Mg}-\mathrm{KA}$ & 0,3489 & 1,6379 \\
\hline$S$ & S 00 & $S-K A$ & 3,2464 & 0,6972 \\
\hline K & K 00 & $\mathrm{~K}-\mathrm{KA}$ & 1,5385 & 0,5427 \\
\hline $\mathrm{Mn}$ & Hv00 & $\mathrm{Mn}-\mathrm{KA}$ & 1,3442 & 0,3269 \\
\hline $\mathrm{Ti}$ & Hv0O & Ti-KA & 0,1787 & 0,1720 \\
\hline $\mathrm{Cl}$ & $\mathrm{Cl} 00$ & Cl-KA & 0,1292 & 0,1497 \\
\hline$P$ & P 00 & P -KA & 0,4861 & 0,0710 \\
\hline $\mathrm{Zn}$ & Hv00 & $Z n-K A$ & 0,2363 & 0,0342 \\
\hline $\mathrm{Cr}$ & Hv00 & $\mathrm{Cr}-\mathrm{KA}$ & 0,0877 & 0,0291 \\
\hline $\mathrm{Sr}$ & Hv0O & Sr-KA & 0,2862 & 0,0122 \\
\hline $\mathrm{Zr}$ & Hv00 & Zr-KA & 0,0806 & 0,0027 \\
\hline
\end{tabular}

Tabela 59 - Análise química normalizada do concreto Com 6.

\begin{tabular}{|c|c|c|c|c|}
\hline \multicolumn{5}{|l|}{ Com 6} \\
\hline Elemento & Meio & Espectro & Intensidade & Resultado \\
\hline & & & (kcps) & (massa \%) \\
\hline $\mathrm{Fe}$ & Hv00 & Fe-KB1 & 67,1356 & 67,8509 \\
\hline $\mathrm{Ca}$ & $\mathrm{CaOO}$ & Ca-KA & 65,3530 & 16,4276 \\
\hline $\mathrm{Si}$ & Si00 & Si-KA & 7,4575 & 8,3293 \\
\hline Al & Al00 & Al-KA & 2,7572 & 3,5288 \\
\hline $\mathrm{Mg}$ & Mg00 & Mg-KA & 0,4363 & 2,0775 \\
\hline$S$ & S 00 & $S-K A$ & 3,0220 & 0,6846 \\
\hline K & K 00 & K -KA & 1,4971 & 0,5541 \\
\hline $\mathrm{Mn}$ & Hv00 & $\mathrm{Mn}-\mathrm{KA}$ & 1,0962 & 0,2610 \\
\hline $\mathrm{Ti}$ & Hv00 & Ti-KA & 0,1663 & 0,1550 \\
\hline$P$ & P 00 & P -KA & 0,3461 & 0,0533 \\
\hline $\mathrm{Cr}$ & Hv00 & $\mathrm{Cr}-\mathrm{KA}$ & 0,0792 & 0,0254 \\
\hline $\mathrm{Zn}$ & Hv00 & $Z n-K A$ & 0,1462 & 0,0214 \\
\hline $\mathrm{Ni}$ & Hv0O & $\mathrm{Ni}-\mathrm{KA}$ & 0,0759 & 0,0184 \\
\hline $\mathrm{Sr}$ & Hv0O & Sr-KA & 0,2151 & 0,0093 \\
\hline $\mathrm{Zr}$ & Hv00 & Zr-KA & 0,0969 & 0,0033 \\
\hline
\end{tabular}


Tabela 60 - Análise química normalizada do concreto Com 7.

\begin{tabular}{|c|c|c|c|c|}
\hline Com 7 & & & & \\
\hline \multirow[t]{2}{*}{ Elemento } & Meio & Espectro & Intensidade & Resultado \\
\hline & & & (kcps) & (massa \%) \\
\hline $\mathrm{Fe}$ & Hv00 & Fe-KB1 & 52,4104 & 60,3266 \\
\hline $\mathrm{Ca}$ & $\mathrm{CaOO}$ & Ca-KA & 85,5496 & 23,3773 \\
\hline $\mathrm{Si}$ & Si00 & Si-KA & 7,0752 & 8,1323 \\
\hline Al & Al00 & Al-KA & 2,7089 & 3,5623 \\
\hline $\mathrm{Mg}$ & Mg00 & Mg-Ka & 0,5052 & 2,4571 \\
\hline $\mathrm{S}$ & S 00 & $S-K A$ & 3,7969 & 0,0082 \\
\hline $\mathrm{K}$ & K 00 & $\mathrm{~K}-\mathrm{KA}$ & 1,9128 & 0,7448 \\
\hline $\mathrm{Mn}$ & Hv00 & $\mathrm{Mn}-\mathrm{KA}$ & 0,6618 & 0,1856 \\
\hline $\mathrm{Ti}$ & Hv00 & Ti-KA & 0,1491 & 0,1723 \\
\hline$P$ & P 00 & P -KA & 0,3706 & 0,0589 \\
\hline $\mathrm{Zn}$ & $\mathrm{Hv0O}$ & $Z n-K A$ & 0,2579 & 0,0386 \\
\hline $\mathrm{Cr}$ & $\mathrm{Hv00}$ & $\mathrm{Cr}-\mathrm{KA}$ & 0,0901 & 0,0358 \\
\hline $\mathrm{Sr}$ & Hv00 & Sr-KA & 0,3584 & 0,0158 \\
\hline $\mathrm{Zr}$ & Hv00 & Zr-KA & 0,1274 & 0,0044 \\
\hline
\end{tabular}

Tabela 61 - Análise química normalizada do concreto Com 8.

\begin{tabular}{|c|c|c|c|c|}
\hline Com 8 & & & & \\
\hline \multirow[t]{2}{*}{ Elemento } & Meio & Espectro & Intensidade & Resultado \\
\hline & & & (kcps) & (massa \%) \\
\hline $\mathrm{Fe}$ & Hv00 & Fe-KB1 & 51,3651 & 61,4590 \\
\hline $\mathrm{Ca}$ & $\mathrm{CaOO}$ & Ca-KA & 85,2288 & 23,7359 \\
\hline $\mathrm{Si}$ & Si00 & Si-KA & 5,4087 & 6,4927 \\
\hline $\mathrm{Al}$ & Al00 & Al-KA & 2,9496 & 4,0334 \\
\hline $\mathrm{Mg}$ & Mg00 & Mg-KA & 0,4088 & 2,0799 \\
\hline$S$ & S 00 & $S-K A$ & 3,2969 & 0,7862 \\
\hline K & K 00 & $\mathrm{~K}-\mathrm{KA}$ & 1,6784 & 0,6657 \\
\hline $\mathrm{Mn}$ & $\mathrm{Hv0O}$ & $\mathrm{Mn}-\mathrm{KA}$ & 0,7665 & 0,2227 \\
\hline $\mathrm{Ti}$ & $\mathrm{Hv} 00$ & Ti-KA & 0,1536 & 0,1831 \\
\hline $\mathrm{Cl}$ & $\mathrm{ClOO}$ & $\mathrm{Cl}-\mathrm{KA}$ & 0,1152 & 0,1487 \\
\hline $\mathrm{P}$ & P 00 & P -KA & 0,4573 & 0,0741 \\
\hline $\mathrm{Zn}$ & Hv00 & $Z n-K A$ & 0,2450 & 0,0385 \\
\hline $\mathrm{Cr}$ & Hv0O & $\mathrm{Cr}-\mathrm{KA}$ & 0,0937 & 0,0384 \\
\hline $\mathrm{Ni}$ & Hv0O & $\mathrm{Ni}-\mathrm{KA}$ & 0,0789 & 0,0206 \\
\hline $\mathrm{Sr}$ & Hv00 & Sr-KA & 0,3675 & 0,0169 \\
\hline $\mathrm{Zr}$ & $\mathrm{Hv} 00$ & Zr-KA & 0,1176 & 0,0042 \\
\hline
\end{tabular}




\section{ipen}

Tabela 62 - Análise química normalizada do concreto Com 9.

\begin{tabular}{|c|c|c|c|c|}
\hline \multicolumn{5}{|l|}{ Com 8} \\
\hline Elemento & Meio & Espectro & Intensidade & Resultado \\
\hline & & & (kcps) & (massa \%) \\
\hline $\mathrm{Fe}$ & Hv00 & Fe-KA & 249,9513 & 56,6552 \\
\hline $\mathrm{Ca}$ & $\mathrm{CaOO}$ & Ca-KA & 90,5547 & 25,6279 \\
\hline $\mathrm{Si}$ & SiOO & Si-KA & 6,8902 & 8,0134 \\
\hline $\mathrm{Mg}$ & Mg00 & Mg-KA & 0,6380 & 3,1323 \\
\hline Al & ALOO & Al-KA & 2,3329 & 3,1249 \\
\hline$S$ & S 00 & S-KA & 5,0103 & 1,1877 \\
\hline K & $\mathrm{K} 00$ & $\mathrm{~K}-\mathrm{KA}$ & 2,0143 & 0,8037 \\
\hline $\mathrm{Ti}$ & Hv00 & Ti-KA & 0,5051 & 0,6292 \\
\hline $\mathrm{Mn}$ & Hv00 & Mn-KB1 & 0,3406 & 0,5370 \\
\hline$P$ & P 00 & $P-K A$ & 0,7349 & 0,1181 \\
\hline $\mathrm{Cr}$ & Hv00 & $\mathrm{Cr}-\mathrm{KA}$ & 0,1613 & 0,0698 \\
\hline $\mathrm{Zn}$ & Hv00 & $Z n-K A$ & 0,3550 & 0,0537 \\
\hline $\mathrm{Sr}$ & Hv00 & Sr-KA & 0,4756 & 0,0211 \\
\hline $\mathrm{Ni}$ & Hv00 & $\mathrm{Ni}-\mathrm{KA}$ & 0,0781 & 0,0197 \\
\hline $\mathrm{Zr}$ & Hv0O & $\mathrm{Zr}-\mathrm{KA}$ & 0,1513 & 0,0052 \\
\hline
\end{tabular}

Tabela 63 - Análise química normalizada do concreto Com 10.

\begin{tabular}{|c|c|c|c|c|}
\hline Com 10 & & & & \\
\hline \multirow[t]{2}{*}{ Elemento } & Meio & Espectro & Intensidade & Resultado \\
\hline & & & (kcps) & (massa \%) \\
\hline $\mathrm{Fe}$ & Hv00 & $\mathrm{Fe}-\mathrm{KB} 1$ & 61,7634 & 66,1063 \\
\hline $\mathrm{Ca}$ & $\mathrm{CaOO}$ & $\mathrm{Ca}-\mathrm{KA}$ & 69,5705 & 18,1996 \\
\hline $\mathrm{Si}$ & Si00 & Si-KA & 6,3408 & 7,3490 \\
\hline $\mathrm{Al}$ & Al00 & Al-KA & 2,6951 & 3,5822 \\
\hline $\mathrm{Mg}$ & Mg00 & Mg-KA & 0,5365 & 2,6346 \\
\hline$S$ & S 00 & $S-K A$ & 3,5713 & 0,8305 \\
\hline K & K 00 & $\mathrm{~K}-\mathrm{KA}$ & 1,5377 & 0,5874 \\
\hline $\mathrm{Ti}$ & Hv00 & Ti-KA & 0,3290 & 0,3315 \\
\hline $\mathrm{Mn}$ & Hv00 & $\mathrm{Mn}-\mathrm{KA}$ & 0,6623 & 0,1687 \\
\hline $\mathrm{P}$ & P 00 & $P-K A$ & 0,7360 & 0,1162 \\
\hline $\mathrm{Cr}$ & Hv00 & $\mathrm{Cr}-\mathrm{KA}$ & 0,1056 & 0,0367 \\
\hline $\mathrm{Zn}$ & Hv00 & $Z n-K A$ & 0,2083 & 0,0314 \\
\hline $\mathrm{Sr}$ & Hv00 & Sr-KA & 0,4939 & 0,0219 \\
\hline $\mathrm{Zr}$ & Hv00 & Zr-KA & 0,1153 & 0,0040 \\
\hline
\end{tabular}


Tabela 64 - Análise química normalizada do concreto Com 11.

\begin{tabular}{|c|c|c|c|c|}
\hline Com 11 & & & & \\
\hline \multirow[t]{2}{*}{ Elemento } & Meio & Espectro & Intensidade & Resultado \\
\hline & & & (kcps) & (massa \%) \\
\hline $\mathrm{Fe}$ & Hv00 & Fe-KB1 & 75,0271 & 69,8796 \\
\hline $\mathrm{Ca}$ & $\mathrm{CaOO}$ & Ca-KA & 67,5771 & 15,6020 \\
\hline $\mathrm{Si}$ & SiOO & Si-KA & 7,3178 & 7,6564 \\
\hline Al & Al00 & Al-KA & 2,4653 & 2,9819 \\
\hline $\mathrm{Mg}$ & Mg00 & Mg-KA & 0,5169 & 2,3214 \\
\hline$S$ & S 00 & S-KA & 3,3973 & 0,7136 \\
\hline K & K 00 & $\mathrm{~K}-\mathrm{KA}$ & 1,2767 & 0,4366 \\
\hline $\mathrm{Mn}$ & Hv00 & $\mathrm{Mn}-\mathrm{KA}$ & 0,8216 & 0,1793 \\
\hline $\mathrm{Ti}$ & Hv00 & Ti-KA & 0,1590 & 0,1342 \\
\hline$P$ & P 00 & P -KA & 0,3113 & 0,0445 \\
\hline $\mathrm{Cr}$ & Hv00 & $\mathrm{Cr}-\mathrm{KA}$ & 0,0755 & 0,0219 \\
\hline $\mathrm{Zn}$ & Hv00 & $\mathrm{Zn}-\mathrm{KA}$ & 0,1479 & 0,0204 \\
\hline $\mathrm{Sr}$ & Hv00 & Sr-KA & 0,1619 & 0,0066 \\
\hline $\mathrm{Zr}$ & Hv00 & Zr-KA & 0,0536 & 0,0017 \\
\hline
\end{tabular}

Tabela 65 - Análise química normalizada do concreto Com 12.

\begin{tabular}{|c|c|c|c|c|}
\hline Com 12 & & & & \\
\hline \multirow[t]{2}{*}{ Elemento } & Meio & Espectro & Intensidade & Resultado \\
\hline & & & (kcps) & (massa \%) \\
\hline $\mathrm{Fe}$ & Hv00 & Fe-KB1 & 64,4108 & 66,8160 \\
\hline $\mathrm{Ca}$ & $\mathrm{CaOO}$ & Ca-KA & 68,7654 & 17,4121 \\
\hline $\mathrm{Si}$ & SiO0 & Si-KA & 6,6522 & 7,4844 \\
\hline Al & Al00 & Al-KA & 2,3525 & 3,0567 \\
\hline $\mathrm{Mg}$ & Mg00 & $\mathrm{Mg}-\mathrm{KA}$ & 0,5687 & 2,7280 \\
\hline$S$ & S 00 & $S-K A$ & 4,1861 & 0,9462 \\
\hline K & K 00 & K -KA & 1,4449 & 0,5366 \\
\hline $\mathrm{Ti}$ & Hv00 & Ti-KA & 0,5102 & 0,4904 \\
\hline $\mathrm{Mn}$ & Hv00 & $\mathrm{Mn}-\mathrm{KA}$ & 1,0785 & 0,2648 \\
\hline$P$ & P 00 & $P-K A$ & 0,5836 & 0,0896 \\
\hline $\mathrm{Cr}$ & Hv00 & $\mathrm{Cr}-\mathrm{KA}$ & 0,1799 & 0,0600 \\
\hline $\mathrm{V}$ & Hv00 & $V-K A$ & 0,0997 & 0,0540 \\
\hline $\mathrm{Zn}$ & Hv00 & $Z n-K A$ & 0,2059 & 0,0304 \\
\hline $\mathrm{Ni}$ & Hv00 & $\mathrm{Ni}-\mathrm{KA}$ & 0,0738 & 0,0181 \\
\hline $\mathrm{Sr}$ & Hv00 & Sr-KA & 0,2463 & 0,0107 \\
\hline $\mathrm{Zr}$ & Hv00 & Zr-KA & 0,0592 & 0,0020 \\
\hline
\end{tabular}


Tabela 66 - Análise química normalizada do concreto Com 13.

\begin{tabular}{|c|c|c|c|c|}
\hline \multicolumn{5}{|l|}{ Com 13} \\
\hline Elemento & Meio & Espectro & Intensidade & Resultado \\
\hline & & & (kcps) & (massa \%) \\
\hline $\mathrm{Fe}$ & Hv00 & Fe-KB1 & 68,2912 & 70,9636 \\
\hline $\mathrm{Ca}$ & $\mathrm{CaOO}$ & Ca-KA & 67,0406 & 16,7328 \\
\hline $\mathrm{Si}$ & $\mathrm{SiOO}$ & Si-KA & 5,3884 & 6,1578 \\
\hline $\mathrm{Al}$ & Al00 & Al-KA & 1,8142 & 2,4181 \\
\hline $\mathrm{Mg}$ & $\mathrm{Mg} 00$ & Mg-KA & 0,3630 & 1,8113 \\
\hline$S$ & S 00 & S -KA & 2,8783 & 0,6472 \\
\hline K & K 00 & $\mathrm{~K}-\mathrm{KA}$ & 1,4250 & 0,5227 \\
\hline $\mathrm{Mn}$ & Hv0O & $M n-K A$ & 1,0237 & 0,2488 \\
\hline $\mathrm{Cl}$ & $\mathrm{ClOO}$ & Cl-KA & 0,1589 & 0,1923 \\
\hline $\mathrm{Ti}$ & Hv00 & Ti-KA & 0,1623 & 0,1525 \\
\hline$P$ & P 00 & P -KA & 0,4620 & 0,0707 \\
\hline $\mathrm{Cr}$ & Hv00 & $\mathrm{Cr}-\mathrm{KA}$ & 0,0907 & 0,0293 \\
\hline $\mathrm{Zn}$ & Hv00 & $Z n-K A$ & 0,1393 & 0,0214 \\
\hline $\mathrm{Ni}$ & Hv00 & $\mathrm{Ni}-\mathrm{KA}$ & 0,0747 & 0,0190 \\
\hline Sr & Hv00 & Sr-KA & 0,2200 & 0,0100 \\
\hline $\mathrm{Zr}$ & Hv00 & Zr-KA & 0,0701 & 0,0025 \\
\hline
\end{tabular}

Tabela 67 - Análise química normalizada do concreto Com 14.

\begin{tabular}{|c|c|c|c|c|}
\hline Com 14 & & & & \\
\hline \multirow[t]{2}{*}{ Elemento } & Meio & Espectro & Intensidade & Resultado \\
\hline & & & (kcps) & (massa \%) \\
\hline $\mathrm{Fe}$ & Hv0O & Fe-KA & 285,2228 & 54,0618 \\
\hline $\mathrm{Ca}$ & $\mathrm{CaOO}$ & Ca-KA & 110,5407 & 26,1256 \\
\hline $\mathrm{Si}$ & Si00 & Si-KA & 7,9260 & 7,5869 \\
\hline $\mathrm{Mg}$ & Mg00 & Mg-KA & 1,1103 & 4,4112 \\
\hline $\mathrm{Al}$ & Al00 & Al-KA & 2,7034 & 2,9881 \\
\hline$S$ & S 00 & S-KA & 8,2863 & 1,6230 \\
\hline $\mathrm{Ti}$ & Hv00 & Ti-KA & 1,3232 & 1,3860 \\
\hline K & K 00 & $\mathrm{~K}-\mathrm{KA}$ & 2,1875 & 0,7293 \\
\hline$P$ & P 00 & $\mathrm{P}-\mathrm{KA}$ & 3,5366 & 0,4667 \\
\hline $\mathrm{Mn}$ & Hv00 & Mn-KB1 & 0,3168 & 0,4194 \\
\hline $\mathrm{Sr}$ & Hv00 & Sr-KA & 1,5219 & 0,0545 \\
\hline $\mathrm{Zn}$ & Hv00 & $Z n-K A$ & 0,4089 & 0,0500 \\
\hline $\mathrm{Cr}$ & Hv00 & $\mathrm{Cr}-\mathrm{KA}$ & 0,1175 & 0,0433 \\
\hline $\mathrm{Ni}$ & Hv00 & $\mathrm{Ni}-\mathrm{KA}$ & 0,1107 & 0,0225 \\
\hline $\mathrm{Cu}$ & Hv00 & $\mathrm{Cu}-\mathrm{KA}$ & 0,1326 & 0,0219 \\
\hline $\mathrm{Zr}$ & Hv00 & $\mathrm{Zr}-\mathrm{KA}$ & 0,2844 & 0,0080 \\
\hline $\mathrm{Nb}$ & Hv00 & $\mathrm{Nb}-\mathrm{KA}$ & 0,0680 & 0,0017 \\
\hline
\end{tabular}




\section{ipen}

Tabela 68 - Análise química normalizada do concreto Com 15.

\begin{tabular}{|c|c|c|c|c|}
\hline \multicolumn{5}{|l|}{ Com 15} \\
\hline Elemento & Meio & Espectro & Intensidade & Resultado \\
\hline & & & (kcps) & (massa \%) \\
\hline $\mathrm{Fe}$ & Hv0O & Fe-KB1 & 44,8896 & 60,6386 \\
\hline $\mathrm{Ca}$ & $\mathrm{CaOO}$ & Ca-KA & 80,1054 & 24,5410 \\
\hline $\mathrm{Si}$ & SiOO & Si-KA & 4,5915 & 5,9830 \\
\hline $\mathrm{Mg}$ & Mg00 & Mg-KA & 0,4706 & 2,6479 \\
\hline Al & Al00 & Al-KA & 1,5110 & 2,2988 \\
\hline$S$ & S 00 & $S-K A$ & 4,3271 & 1,1189 \\
\hline $\mathrm{Ti}$ & Hv00 & Ti-KA & 0,7752 & 1,0358 \\
\hline K & K 00 & $\mathrm{~K}-\mathrm{KA}$ & 1,6543 & 0,7178 \\
\hline $\mathrm{Mn}$ & Hv00 & $\mathrm{Mn}-\mathrm{KA}$ & 1,0568 & 0,3475 \\
\hline$P$ & P 00 & $P-K A$ & 1,3826 & 0,2422 \\
\hline $\mathrm{Cl}$ & $\mathrm{ClOO}$ & Cl-KA & 0,1450 & 0,2042 \\
\hline $\mathrm{Sr}$ & Hv00 & Sr-KA & 1,3385 & 0,0683 \\
\hline $\mathrm{Zn}$ & Hv00 & $\mathrm{Zn}-\mathrm{KA}$ & 0,3023 & 0,0525 \\
\hline $\mathrm{Cr}$ & Hv00 & $\mathrm{Cr}-\mathrm{KA}$ & 0,0935 & 0,0437 \\
\hline $\mathrm{Ni}$ & Hv00 & $\mathrm{Ni}-\mathrm{KA}$ & 0,0883 & 0,0255 \\
\hline $\mathrm{Cu}$ & Hv00 & Cu-KA & 0,0984 & 0,0230 \\
\hline $\mathrm{Zr}$ & Hv00 & Zr-KA & 0,2444 & 0,0098 \\
\hline $\mathrm{Nb}$ & Hv00 & $\mathrm{Nb}-\mathrm{KA}$ & 0,0472 & 0,0016 \\
\hline
\end{tabular}

Tabela 69 - Análise química normalizada do concreto Com 16.

\begin{tabular}{|c|c|c|c|c|}
\hline \multicolumn{5}{|l|}{ Com 16} \\
\hline Elemento & Meio & Espectro & Intensidade & Resultado \\
\hline & & & (kcps) & (massa \%) \\
\hline $\mathrm{Fe}$ & Hv0O & Fe-KA & 228,2025 & 53,8972 \\
\hline $\mathrm{Ca}$ & $\mathrm{CaOO}$ & Ca-KA & 90,8866 & 26,1460 \\
\hline $\mathrm{Si}$ & Si00 & Si-KA & 5,7786 & 6,8141 \\
\hline $\mathrm{Mg}$ & Mg00 & Mg-KA & 0,8660 & 4,2768 \\
\hline Al & Al00 & Al-KA & 1,9946 & 2,7300 \\
\hline $\mathrm{Ti}$ & Hv00 & Ti-KA & 1,5798 & 2,0312 \\
\hline$S$ & S 00 & $S-K A$ & 6,5967 & 1,5717 \\
\hline K & K 00 & $\mathrm{~K}-\mathrm{KA}$ & 1,8559 & 0,7514 \\
\hline $\mathrm{Mn}$ & $\mathrm{Hv00}$ & Mn-KB1 & 0,3484 & 0,5754 \\
\hline $\mathrm{P}$ & P 00 & $P-K A$ & 2,5916 & 0,4165 \\
\hline $\mathrm{Na}$ & $\mathrm{NaOO}$ & Na-KA & 0,0256 & 0,3321 \\
\hline V & Hv00 & V -KA & 0,2173 & 0,1576 \\
\hline $\mathrm{Cr}$ & $\mathrm{Hv00}$ & $\mathrm{Cr}-\mathrm{KA}$ & 0,2157 & 0,0989 \\
\hline $\mathrm{Sr}$ & $\mathrm{Hv00}$ & Sr-KA & 1,7693 & 0,0785 \\
\hline $\mathrm{Zn}$ & Hv00 & $\mathrm{Zn}-\mathrm{KA}$ & 0,4355 & 0,0660 \\
\hline $\mathrm{Ni}$ & Hv00 & $\mathrm{Ni}-\mathrm{KA}$ & 0,0966 & 0,0244 \\
\hline $\mathrm{Cu}$ & Hv00 & Cu-KA & 0,0870 & 0,0178 \\
\hline $\mathrm{Zr}$ & $\mathrm{Hv00}$ & $\mathrm{Zr}-\mathrm{KA}$ & 0,3515 & 0,0122 \\
\hline $\mathrm{Nb}$ & Hv00 & $\mathrm{Nb}-\mathrm{KA}$ & 0,0715 & 0,0022 \\
\hline
\end{tabular}




\section{ipen}

Tabela 70 - Análise química normalizada do concreto Com 17.

\begin{tabular}{ccccc}
\hline Com 17 & & & & \\
Elemento & Meio & Espectro & Intensidade & Resultado \\
\hline Fe & & & (kcps) & (massa \%) \\
\hline Ca & Hv00 & Fe-KB1 & 63,8050 & 60,3611 \\
Si & Sa00 & Ca-KA & 105,4027 & 23,5657 \\
Al & Al00 & Si-KA & 8,4850 & 7,9922 \\
Mg & Mg00 & Ml-KA & 3,0409 & 3,2911 \\
S & S 00 & S -KA & 0,6604 & 2,6379 \\
K & K 00 & K -KA & 5,0411 & 0,9642 \\
Ti & Hv00 & Ti-KA & 0,1622 & 0,6892 \\
Mn & Hv00 & Mn-KA & 0,2229 & 0,2118 \\
P & P 00 & P-KA & 0,3472 & 0,1607 \\
Zn & Hv00 & Zn-KA & 0,2932 & 0,0451 \\
Cr & Hv00 & Cr-KA & 0,0921 & 0,0361 \\
Sr & Hv00 & Sr-KA & 0,3270 & 0,0301 \\
Zr & Hv00 & Zr-KA & 0,1035 & 0,0118 \\
\end{tabular}

Tabela 71 - Análise química normalizada do concreto Com 18.

\begin{tabular}{|c|c|c|c|c|}
\hline Com 18 & & & & \\
\hline \multirow[t]{2}{*}{ Elemento } & Meio & Espectro & Intensidade & Resultado \\
\hline & & & (kcps) & (massa \%) \\
\hline $\mathrm{Fe}$ & Hv00 & Fe-KB1 & 44,3598 & 52,2213 \\
\hline $\mathrm{Ca}$ & $\mathrm{CaOO}$ & $\mathrm{Ca}-\mathrm{KA}$ & 118,0744 & 31,1750 \\
\hline $\mathrm{Si}$ & Si00 & Si-KA & 7,6597 & 7,9941 \\
\hline $\mathrm{Al}$ & Al00 & Al-KA & 2,7294 & 3,2678 \\
\hline $\mathrm{Mg}$ & Mg00 & $\mathrm{Mg}-\mathrm{KA}$ & 0,5962 & 2,6313 \\
\hline$S$ & S 00 & $S-K A$ & 4,7165 & 1,0066 \\
\hline K & K 00 & $\mathrm{~K}-\mathrm{KA}$ & 2,4423 & 0,8868 \\
\hline $\mathrm{Mn}$ & Hv00 & $\mathrm{Mn}-\mathrm{KA}$ & 0,9139 & 0,2696 \\
\hline $\mathrm{Ti}$ & Hv00 & Ti-KA & 0,1894 & 0,2404 \\
\hline $\mathrm{Cl}$ & $\mathrm{Cl} 00$ & $\mathrm{Cl}-\mathrm{KA}$ & 0,0917 & 0,1066 \\
\hline $\mathrm{P}$ & P 00 & $P-K A$ & 0,4549 & 0,0659 \\
\hline $\mathrm{Zn}$ & Hv00 & $Z n-K A$ & 0,3764 & 0,0514 \\
\hline $\mathrm{Cr}$ & Hv00 & $\mathrm{Cr}-\mathrm{KA}$ & 0,0837 & 0,0366 \\
\hline $\mathrm{Ni}$ & Hv00 & $\mathrm{Ni}-\mathrm{KA}$ & 0,1121 & 0,0255 \\
\hline $\mathrm{Sr}$ & Hv00 & Sr-KA & 0,4315 & 0,0172 \\
\hline $\mathrm{Zr}$ & Hv0O & $\mathrm{Zr}-\mathrm{KA}$ & 0,1284 & 0,0040 \\
\hline
\end{tabular}




\section{ipen}

Tabela 72 - Análise química normalizada do concreto Com 19.

\begin{tabular}{|c|c|c|c|c|}
\hline Com 19 & & & & \\
\hline \multirow[t]{2}{*}{ Elemento } & Meio & Espectro & Intensidade & Resultado \\
\hline & & & (kcps) & (massa \%) \\
\hline $\mathrm{Fe}$ & Hv00 & Fe-KB1 & 52,7623 & 56,0415 \\
\hline $\mathrm{Ca}$ & $\mathrm{CaOO}$ & Ca-KA & 104,5827 & 25,6612 \\
\hline $\mathrm{Si}$ & SiOO & Si-KA & 7,6941 & 7,7510 \\
\hline $\mathrm{Mg}$ & Mg00 & $M g-K A$ & 0,8195 & 3,4659 \\
\hline Al & Al00 & Al-KA & 2,7126 & 3,1467 \\
\hline S & S 00 & S-KA & 6,3646 & 1,3044 \\
\hline $\mathrm{Ti}$ & Hv00 & Ti-KA & 0,9502 & 1,0277 \\
\hline K & K 00 & $\mathrm{~K}-\mathrm{KA}$ & 2,2872 & 0,7913 \\
\hline $\mathrm{Mn}$ & Hv00 & $\mathrm{Mn}-\mathrm{KA}$ & 1,4427 & 0,3771 \\
\hline$P$ & P 00 & $P-K A$ & 1,0464 & 0,1453 \\
\hline $\mathrm{Cr}$ & Hv00 & $\mathrm{Cr}-\mathrm{KA}$ & 0,2810 & 0,1063 \\
\hline V & Hv00 & V -KA & 0,1193 & 0,0728 \\
\hline $\mathrm{Zn}$ & Hv00 & $Z n-K A$ & 0,4856 & 0,0633 \\
\hline $\mathrm{Ni}$ & Hv00 & $\mathrm{Ni}-\mathrm{KA}$ & 0,0927 & 0,0201 \\
\hline $\mathrm{Sr}$ & Hv00 & Sr-KA & 0,5182 & 0,0198 \\
\hline $\mathrm{Zr}$ & Hv00 & $\mathrm{Zr}-\mathrm{KA}$ & 0,1618 & 0,0048 \\
\hline $\mathrm{Nb}$ & Hv00 & $\mathrm{Nb}-\mathrm{KA}$ & 0,0305 & 0,0008 \\
\hline
\end{tabular}

Tabela 73 - Análise química normalizada do concreto Com 20.

\begin{tabular}{|c|c|c|c|c|}
\hline Com 20 & & & & \\
\hline \multirow[t]{2}{*}{ Elemento } & Meio & Espectro & Intensidade & Resultado \\
\hline & & & (kcps) & (massa \%) \\
\hline $\mathrm{Fe}$ & Hv00 & Fe-KB1 & 55,5655 & 59,9358 \\
\hline $\mathrm{Ca}$ & $\mathrm{CaOO}$ & Ca-KA & 67,5566 & 16,5598 \\
\hline $\mathrm{Si}$ & Si00 & Si-KA & 7,1105 & 7,4930 \\
\hline $\mathrm{Ba}$ & Hv00 & Ba-LA & 2,2780 & 6,7526 \\
\hline Al & Al00 & Al-KA & 2,4389 & 2,9267 \\
\hline $\mathrm{Mg}$ & Mg00 & Mg-KA & 0,5183 & 2,2865 \\
\hline $\mathrm{S}$ & S 00 & $S-K A$ & 10,0362 & 2,1301 \\
\hline $\mathrm{Na}$ & $\mathrm{NaOO}$ & $\mathrm{Na}-\mathrm{KA}$ & 0,0538 & 0,6072 \\
\hline K & K 00 & $\mathrm{~K}-\mathrm{KA}$ & 1,3425 & 0,4850 \\
\hline$P$ & P 00 & $\mathrm{P}-\mathrm{KA}$ & 1,7795 & 0,2552 \\
\hline $\mathrm{Mn}$ & Hv00 & $\mathrm{Mn}-\mathrm{KA}$ & 0,8181 & 0,2180 \\
\hline $\mathrm{Ti}$ & Hv00 & Ti-KA & 0,2000 & 0,1828 \\
\hline Co & Hv00 & Co-KA & 0,3834 & 0,0537 \\
\hline $\mathrm{Cl}$ & $\mathrm{ClOO}$ & $\mathrm{Cl}-\mathrm{KA}$ & 0,0442 & 0,0519 \\
\hline $\mathrm{Sr}$ & Hv00 & Sr-KA & 0,8857 & 0,0346 \\
\hline $\mathrm{Zn}$ & Hv00 & $Z n-K A$ & 0,1556 & 0,0206 \\
\hline $\mathrm{Zr}$ & Hv00 & $\mathrm{Zr}-\mathrm{KA}$ & 0,1667 & 0,0051 \\
\hline $\mathrm{Nb}$ & Hv0O & $\mathrm{Nb}-\mathrm{KA}$ & 0,0566 & 0,0015 \\
\hline
\end{tabular}




\section{ipen}

Tabela 74 - Análise química normalizada do concreto Com 21.

\begin{tabular}{|c|c|c|c|c|}
\hline \multicolumn{5}{|l|}{ Com 21} \\
\hline Elemento & Meio & Espectro & Intensidade & Resultado \\
\hline & & & (kcps) & (massa \%) \\
\hline $\mathrm{Fe}$ & Hv00 & Fe-KB1 & 28,7154 & 41,2479 \\
\hline $\mathrm{Ca}$ & $\mathrm{CaOO}$ & Ca-KA & 91,2910 & 26,7571 \\
\hline $\mathrm{Ba}$ & Hv0O & Ba-LA & 2,6310 & 11,0828 \\
\hline $\mathrm{Si}$ & SiOO & Si-KA & 6,6930 & 7,5617 \\
\hline $\mathrm{Mg}$ & Mg00 & Mg-KA & 0,8287 & 3,7570 \\
\hline$S$ & S 00 & S-KA & 13,4487 & 3,1148 \\
\hline $\mathrm{Al}$ & Al00 & Al-KA & 2,2814 & 2,8993 \\
\hline $\mathrm{Ti}$ & Hv00 & Ti-KA & 1,1896 & 1,5409 \\
\hline K & K 00 & $\mathrm{~K}-\mathrm{KA}$ & 1,7592 & 0,7283 \\
\hline$P$ & P 00 & P-KA & 4,3034 & 0,6671 \\
\hline $\mathrm{Mn}$ & Hv00 & $\mathrm{Mn}-\mathrm{KA}$ & 1,0306 & 0,3860 \\
\hline $\mathrm{Sr}$ & Hv00 & Sr-KA & 2,7955 & 0,1113 \\
\hline $\mathrm{Zn}$ & $\mathrm{Hv00}$ & $\mathrm{Zn}-\mathrm{KA}$ & 0,4021 & 0,0548 \\
\hline $\mathrm{Cr}$ & Hv00 & $\mathrm{Cr}-\mathrm{KA}$ & 0,0868 & 0,0458 \\
\hline $\mathrm{Ni}$ & Hv00 & $\mathrm{Ni}-\mathrm{KA}$ & 0,1138 & 0,0258 \\
\hline $\mathrm{Zr}$ & Hv00 & $\mathrm{Zr}-\mathrm{KA}$ & 0,4978 & 0,0155 \\
\hline $\mathrm{Nb}$ & Hv00 & $\mathrm{Nb}-\mathrm{KA}$ & 0,1338 & 0,0036 \\
\hline
\end{tabular}

Tabela 75 - Análise química normalizada do concreto Com 22.

\begin{tabular}{|c|c|c|c|c|}
\hline Com 22 & & & & \\
\hline \multirow[t]{2}{*}{ Elemento } & Meio & Espectro & Intensidade & Resultado \\
\hline & & & (kcps) & (massa \%) \\
\hline $\mathrm{Fe}$ & Hv00 & Fe-KB1 & 25,4712 & 36,9085 \\
\hline $\mathrm{Ca}$ & $\mathrm{CaOO}$ & Ca-KA & 97,9701 & 28,8707 \\
\hline $\mathrm{Ba}$ & Hv00 & Ba-LA & 3,0568 & 13,2125 \\
\hline $\mathrm{Si}$ & Si00 & Si-KA & 8,2562 & 9,0254 \\
\hline S & S 00 & $S-K A$ & 15,5360 & 3,5368 \\
\hline $\mathrm{Al}$ & Al00 & Al-KA & 2,8155 & 3,4091 \\
\hline $\mathrm{Mg}$ & Mg00 & Mg-KA & 0,6669 & 2,8988 \\
\hline $\mathrm{K}$ & K 00 & $\mathrm{~K}-\mathrm{KA}$ & 2,0413 & 0,8433 \\
\hline$P$ & P 00 & P-KA & 2,4726 & 0,3778 \\
\hline $\mathrm{Ti}$ & Hv00 & Ti-KA & 0,2061 & 0,2734 \\
\hline $\mathrm{Mn}$ & Hv00 & $\mathrm{Mn}-\mathrm{KA}$ & 0,6456 & 0,2471 \\
\hline $\mathrm{Na}$ & $\mathrm{NaOO}$ & $\mathrm{Na}-\mathrm{KA}$ & 0,0196 & 0,2138 \\
\hline $\mathrm{Sr}$ & $\mathrm{Hv00}$ & Sr-KA & 1,6158 & 0,0611 \\
\hline $\mathrm{Cr}$ & Hv00 & $\mathrm{Cr}-\mathrm{KA}$ & 0,0898 & 0,0485 \\
\hline $\mathrm{Zn}$ & Hv00 & $\mathrm{Zn}-\mathrm{KA}$ & 0,2739 & 0,0355 \\
\hline $\mathrm{Ni}$ & Hv00 & $\mathrm{Ni}-\mathrm{KA}$ & 0,1225 & 0,0265 \\
\hline $\mathrm{Zr}$ & Hv00 & $\mathrm{Zr}-\mathrm{KA}$ & 0,3005 & 0,0089 \\
\hline $\mathrm{Nb}$ & Hv0O & $\mathrm{Nb}-\mathrm{KA}$ & 0,0923 & 0,0024 \\
\hline
\end{tabular}


4.6 Cálculo dos coeficientes de atenuação linear com a utilização das composições químicas dos concretos preparados.

As tabelas (76 - 97), apresentadas na sequência, apresentam os cálculos realizados para a determinação das seções de choque em função da composição química dos concretos.

Tabela 76 - Coeficiente de atenuação linear calculado Com 1.

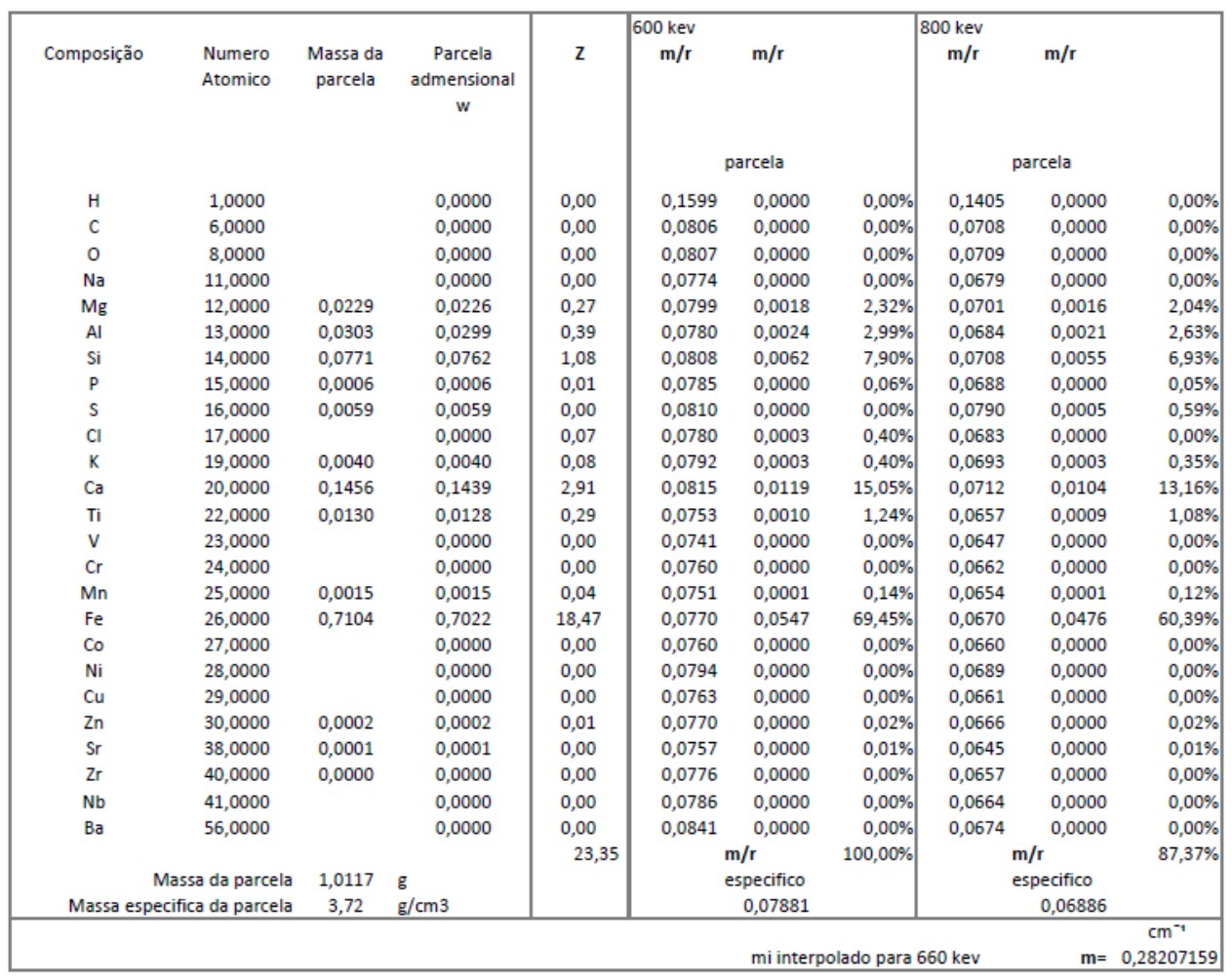


Tabela 77 - Coeficiente de atenuação linear calculado Com 2.

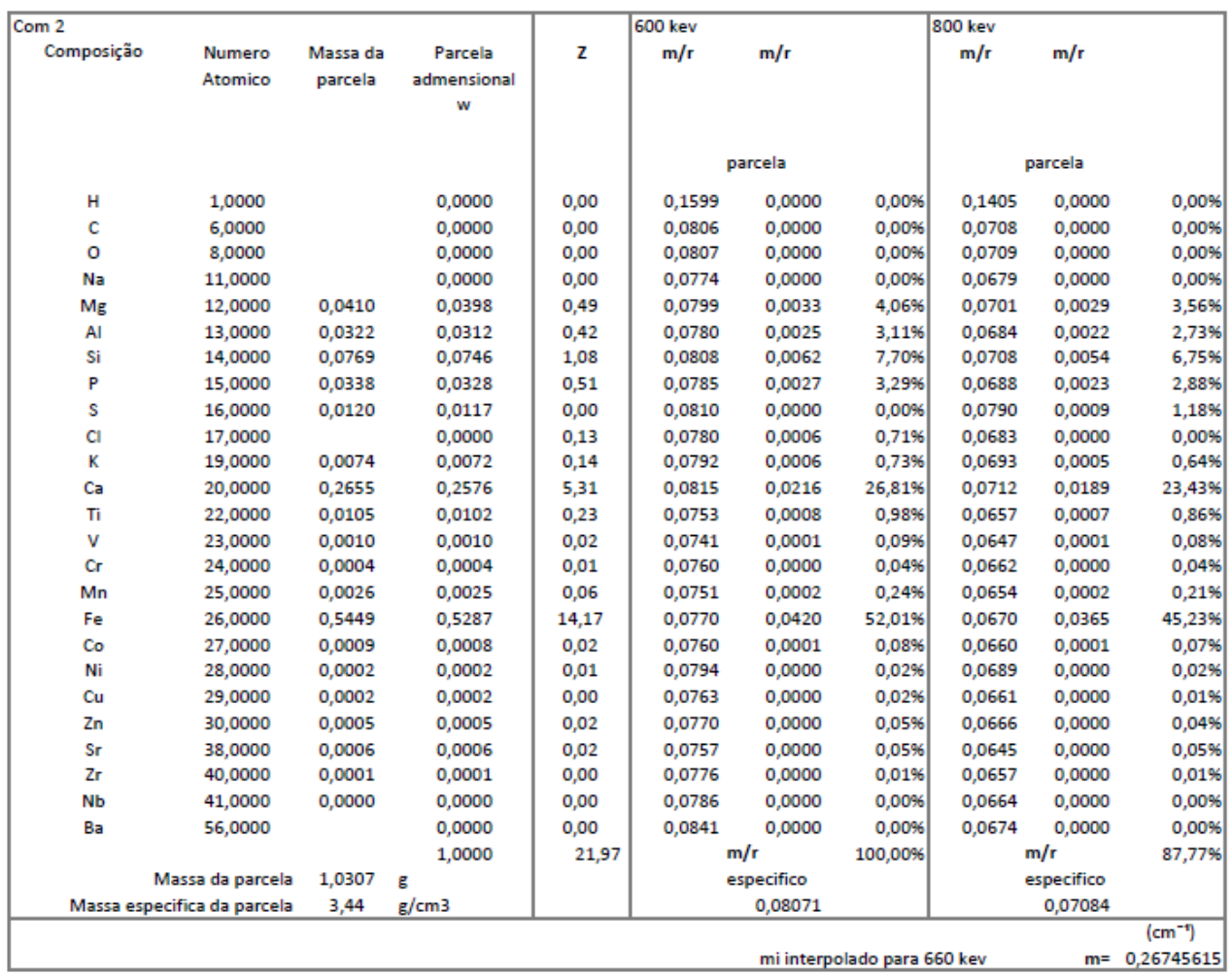

Tabela 78 - Coeficiente de atenuação linear calculado Com 3.

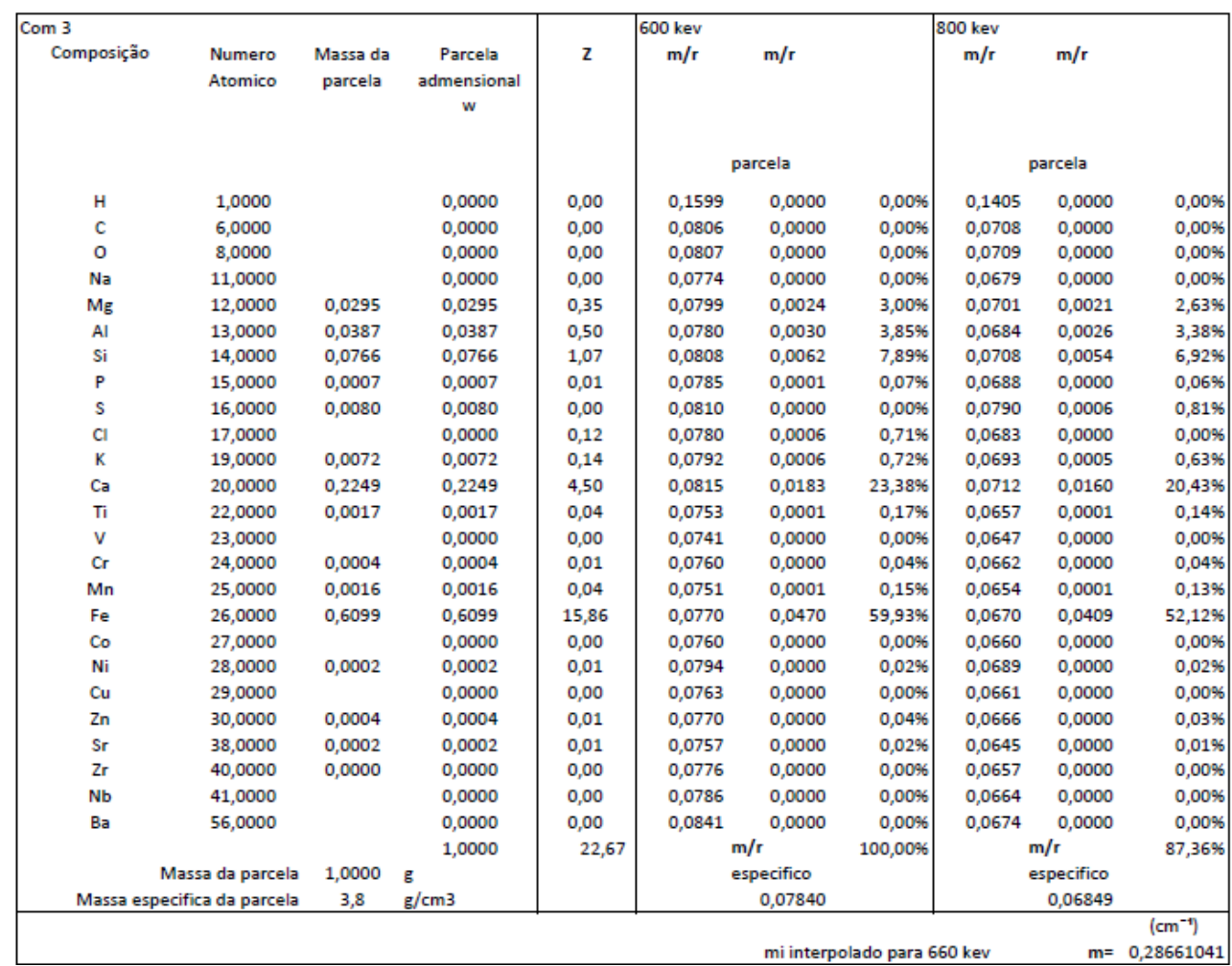


Tabela 79 - Coeficiente de atenuação linear calculado Com 4.

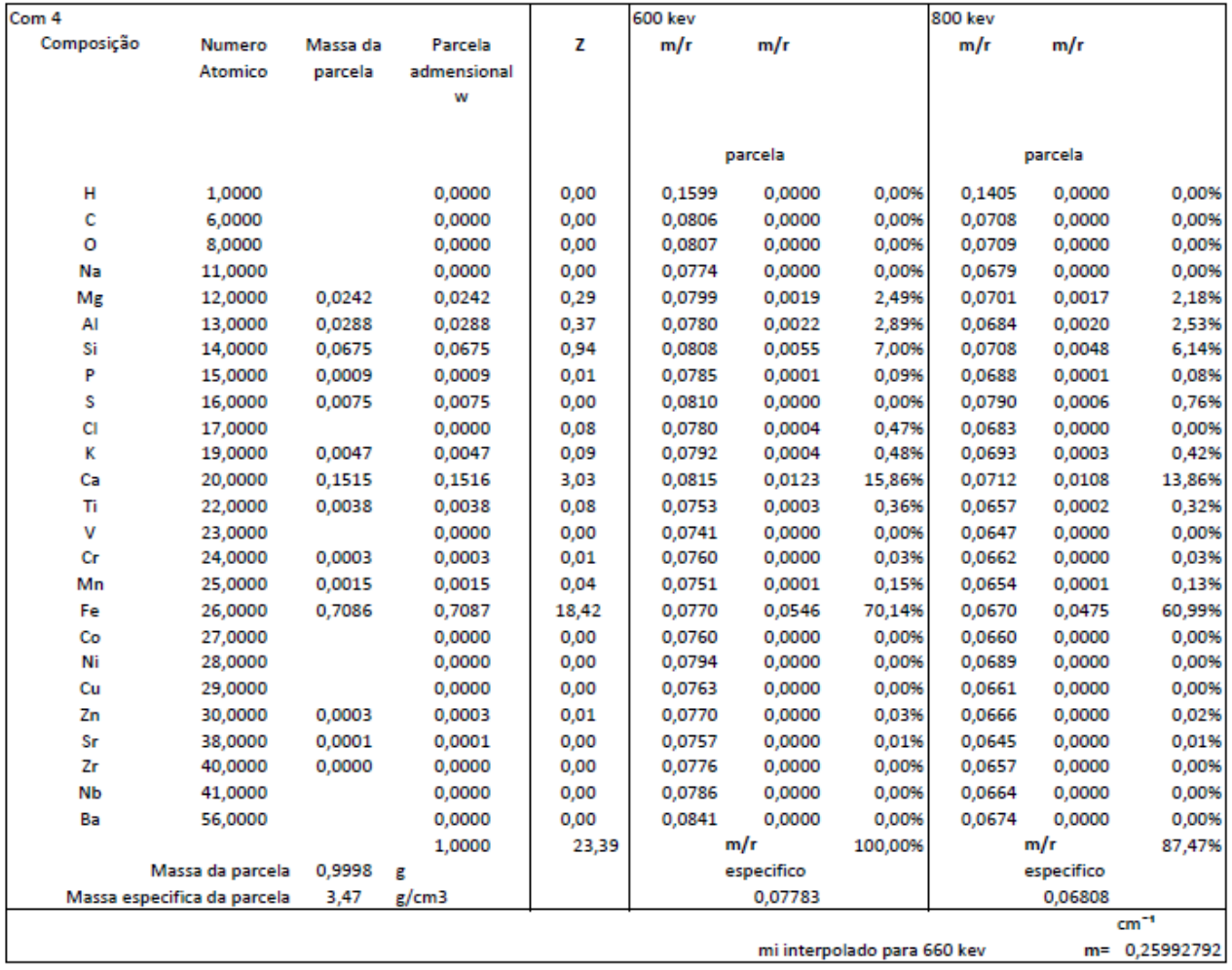

Tabela 80 - Coeficiente de atenuação linear calculado Com 5.

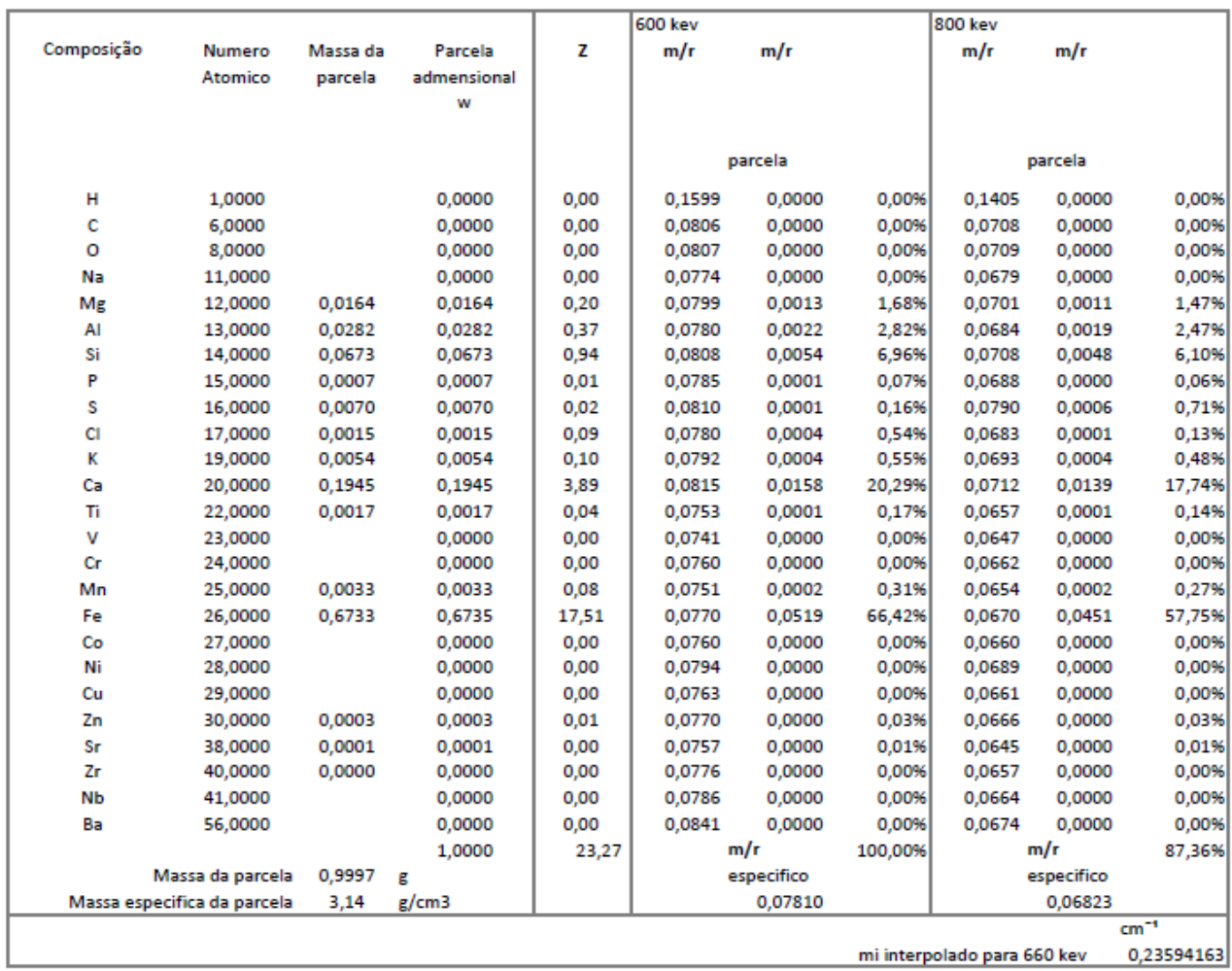


Tabela 81 - Coeficiente de atenuação linear calculado Com 6.

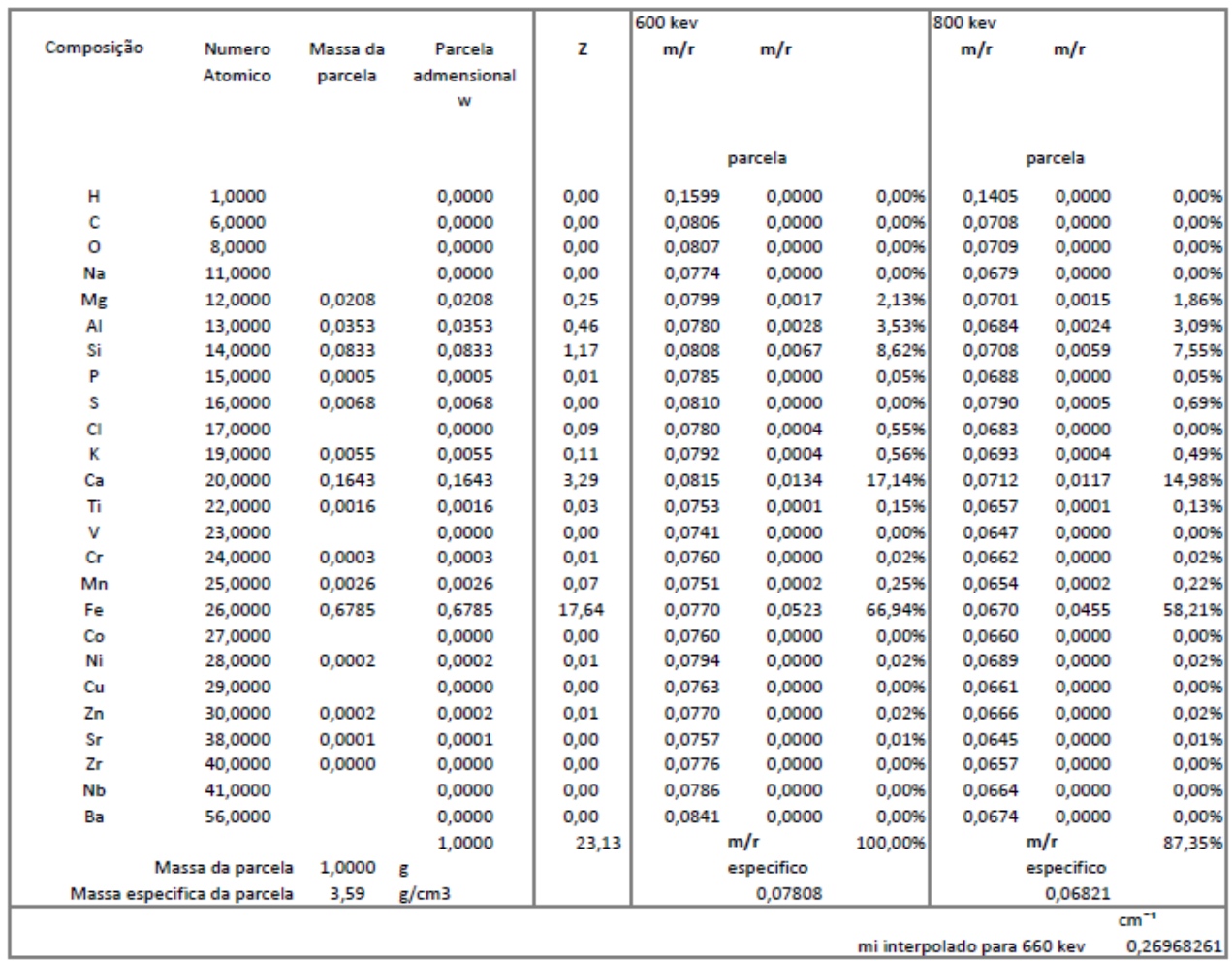

Tabela 82 - Coeficiente de atenuação linear calculado Com 7.

\begin{tabular}{|c|c|c|c|c|c|c|c|c|c|c|}
\hline Composição & $\begin{array}{l}\text { Numero } \\
\text { Atomico }\end{array}$ & $\begin{array}{c}\text { Massa da } \\
\text { parcela }\end{array}$ & $\begin{array}{c}\text { Parcela } \\
\text { admensional } \\
\text { w }\end{array}$ & z & $\begin{array}{r}600 \mathrm{kev} \\
\mathrm{m} / \mathrm{r}\end{array}$ & $\mathrm{m} / \mathrm{r}$ & & $\begin{array}{r}800 \mathrm{kev} \\
\mathrm{m} / \mathrm{r}\end{array}$ & $\mathrm{m} / \mathrm{r}$ & \\
\hline H & \multicolumn{2}{|l|}{1,0000} & 0,0000 & 0,00 & 0,1599 & 0,0000 & $0,00 \%$ & 0,1405 & 0,0000 & $0,00 \%$ \\
\hline c & \multirow{2}{*}{\multicolumn{2}{|c|}{$\begin{array}{l}6,0000 \\
8,0000\end{array}$}} & 0,0000 & 0,00 & 0,0806 & 0,0000 & $0,00 \%$ & 0,0708 & 0,0000 & $0,00 \%$ \\
\hline 0 & & & 0,0000 & 0,00 & 0,0807 & 0,0000 & $0,00 \%$ & 0,0709 & 0,0000 & $0,00 \%$ \\
\hline $\mathrm{Na}$ & \multicolumn{2}{|l|}{11,0000} & 0,0000 & 0,00 & 0,0774 & 0,0000 & $0,00 \%$ & 0,0679 & 0,0000 & $0,00 \%$ \\
\hline $\mathrm{Mg}$ & 12,0000 & 0,0246 & 0,0246 & 0,29 & 0,0799 & 0,0020 & $2,51 \%$ & 0,0701 & 0,0017 & $2,20 \%$ \\
\hline Al & 13,0000 & 0,0356 & 0,0357 & 0,46 & 0,0780 & 0,0028 & $3,55 \%$ & 0,0684 & 0,0024 & $3,11 \%$ \\
\hline $\mathrm{Si}$ & 14,0000 & 0,0813 & 0,0814 & 1,14 & 0,0808 & 0,0066 & $8,39 \%$ & 0,0708 & 0,0058 & $7,36 \%$ \\
\hline $\mathrm{P}$ & 15,0000 & 0,0001 & 0,0001 & 0,00 & 0,0785 & 0,0000 & $0,01 \%$ & 0,0688 & 0,0000 & $0,01 \%$ \\
\hline s & 16,0000 & 0,0089 & 0,0089 & 0,00 & 0,0810 & 0,0000 & $0,00 \%$ & 0,0790 & 0,0007 & $0,90 \%$ \\
\hline $\mathrm{Cl}$ & \multicolumn{2}{|l|}{17,0000} & 0,0000 & 0,13 & 0,0780 & 0,0006 & $0,74 \%$ & 0,0683 & 0,0000 & $0,00 \%$ \\
\hline K & 19,0000 & 0,0074 & 0,0075 & 0,14 & 0,0792 & 0,0006 & $0,75 \%$ & 0,0693 & 0,0005 & $0,66 \%$ \\
\hline $\mathrm{Ca}$ & 20,0000 & 0,2338 & 0,2341 & 4,68 & 0,0815 & 0,0190 & $24,33 \%$ & 0,0712 & 0,0166 & $21,27 \%$ \\
\hline $\mathrm{Ti}$ & 22,0000 & 0,0017 & 0,0017 & 0,04 & 0,0753 & 0,0001 & $0,17 \%$ & 0,0657 & 0,0001 & $0,14 \%$ \\
\hline $\mathrm{v}$ & \multicolumn{2}{|l|}{23,0000} & 0,0000 & 0,00 & 0,0741 & 0,0000 & $0,00 \%$ & 0,0647 & 0,0000 & $0,00 \%$ \\
\hline $\mathrm{Cr}$ & \multicolumn{2}{|l|}{24,0000} & 0,0000 & 0,00 & 0,0760 & 0,0000 & $0,00 \%$ & 0,0662 & 0,0000 & $0,00 \%$ \\
\hline $\mathrm{Mn}$ & 25,0000 & 0,0019 & 0,0019 & 0,05 & 0,0751 & 0,0001 & $0,18 \%$ & 0,0654 & 0,0001 & $0,15 \%$ \\
\hline $\mathrm{Fe}$ & \multicolumn{2}{|l|}{26,0000} & 0,6041 & 15,68 & 0,0770 & 0,0465 & $59,37 \%$ & 0,0670 & 0,0404 & $51,62 \%$ \\
\hline co & \multirow{2}{*}{\multicolumn{2}{|c|}{$\begin{array}{l}27,0000 \\
28,0000\end{array}$}} & 0,0000 & 0,00 & 0,0760 & 0,0000 & $0,00 \%$ & 0,0660 & 0,0000 & $0,00 \%$ \\
\hline $\mathrm{Ni}$ & & & 0,0000 & 0,00 & 0,0794 & 0,0000 & $0,00 \%$ & 0,0689 & 0,0000 & $0,00 \%$ \\
\hline $\mathrm{Cu}$ & \multicolumn{2}{|l|}{29,0000} & 0,0000 & 0,00 & 0,0763 & 0,0000 & $0,00 \%$ & 0,0661 & 0,0000 & $0,00 \%$ \\
\hline $\mathrm{Zn}$ & 30,0000 & 0,0000 & 0,0000 & 0,00 & 0,0770 & 0,0000 & 0,0096 & 0,0666 & 0,0000 & $0,00 \%$ \\
\hline $\mathrm{Sr}$ & 38,0000 & 0,0000 & 0,0000 & 0,00 & 0,0757 & 0,0000 & $0,00 \%$ & 0,0645 & 0,0000 & $0,00 \%$ \\
\hline $\mathrm{Zr}$ & \multicolumn{2}{|l|}{40,0000} & 0,0000 & 0,00 & 0,0776 & 0,0000 & $0,00 \%$ & 0,0657 & 0,0000 & $0,00 \%$ \\
\hline $\mathrm{Nb}$ & \multicolumn{2}{|l|}{41,0000} & 0,0000 & 0,00 & 0,0786 & 0,0000 & $0,00 \%$ & 0,0664 & 0,0000 & $0,00 \%$ \\
\hline $\mathrm{Ba}$ & \multicolumn{2}{|l|}{56,0000} & 0,0000 & 0,00 & 0,0841 & 0,0000 & $0,00 \%$ & 0,0674 & 0,0000 & $0,00 \%$ \\
\hline \multirow{2}{*}{\multicolumn{2}{|c|}{ Massa da parcela }} & & 1,0000 & 22,64 & \multicolumn{2}{|c|}{$\mathrm{m} / \mathrm{r}$} & $100,00 \%$ & & $87,43 \%$ \\
\hline & & 0,9986 & $\mathrm{~g}$ & & \multicolumn{2}{|c|}{ especifico } & & & & especifico \\
\hline \multicolumn{2}{|c|}{ Massa especifica da parcela } & 3,76 & $\mathrm{~g} / \mathrm{cm} 3$ & & & 0,07829 & & \multicolumn{3}{|c|}{0,06844} \\
\hline & & & & & & & & & & \\
\hline
\end{tabular}


Tabela 83 - Coeficiente de atenuação linear calculado Com 8.

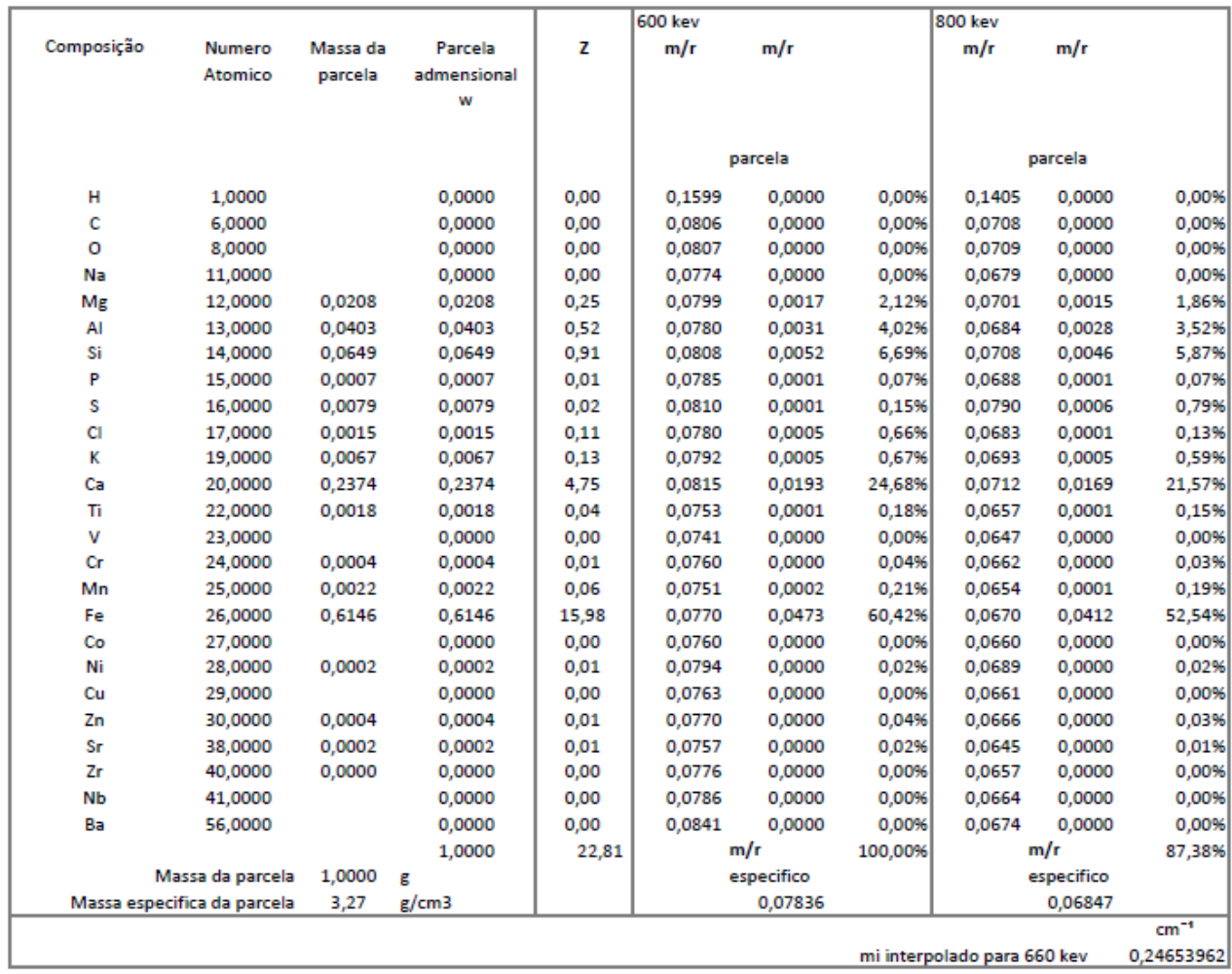

Tabela 84 - Coeficiente de atenuação linear calculado Com 9.

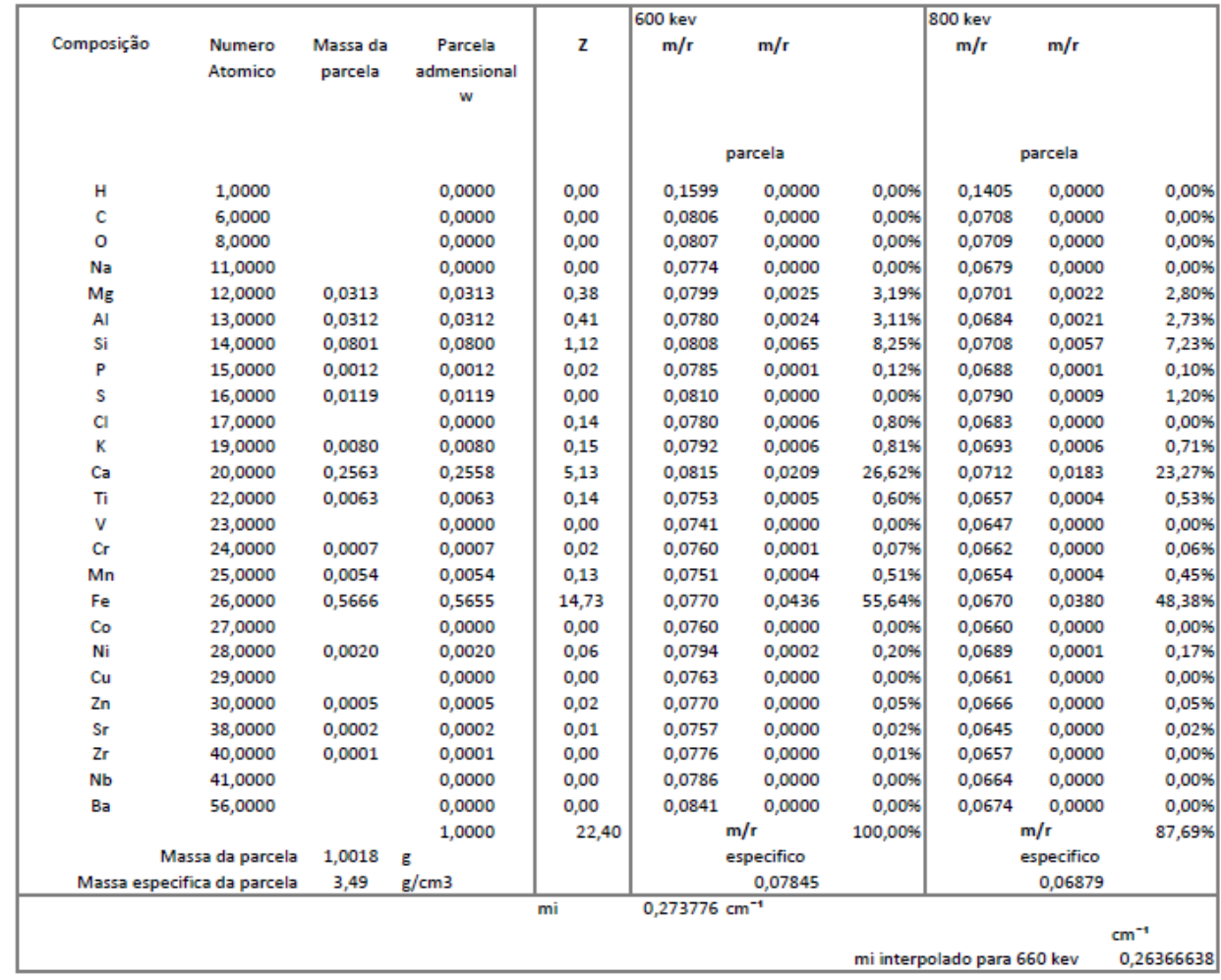


Tabela 85 - Coeficiente de atenuação linear calculado Com 10.

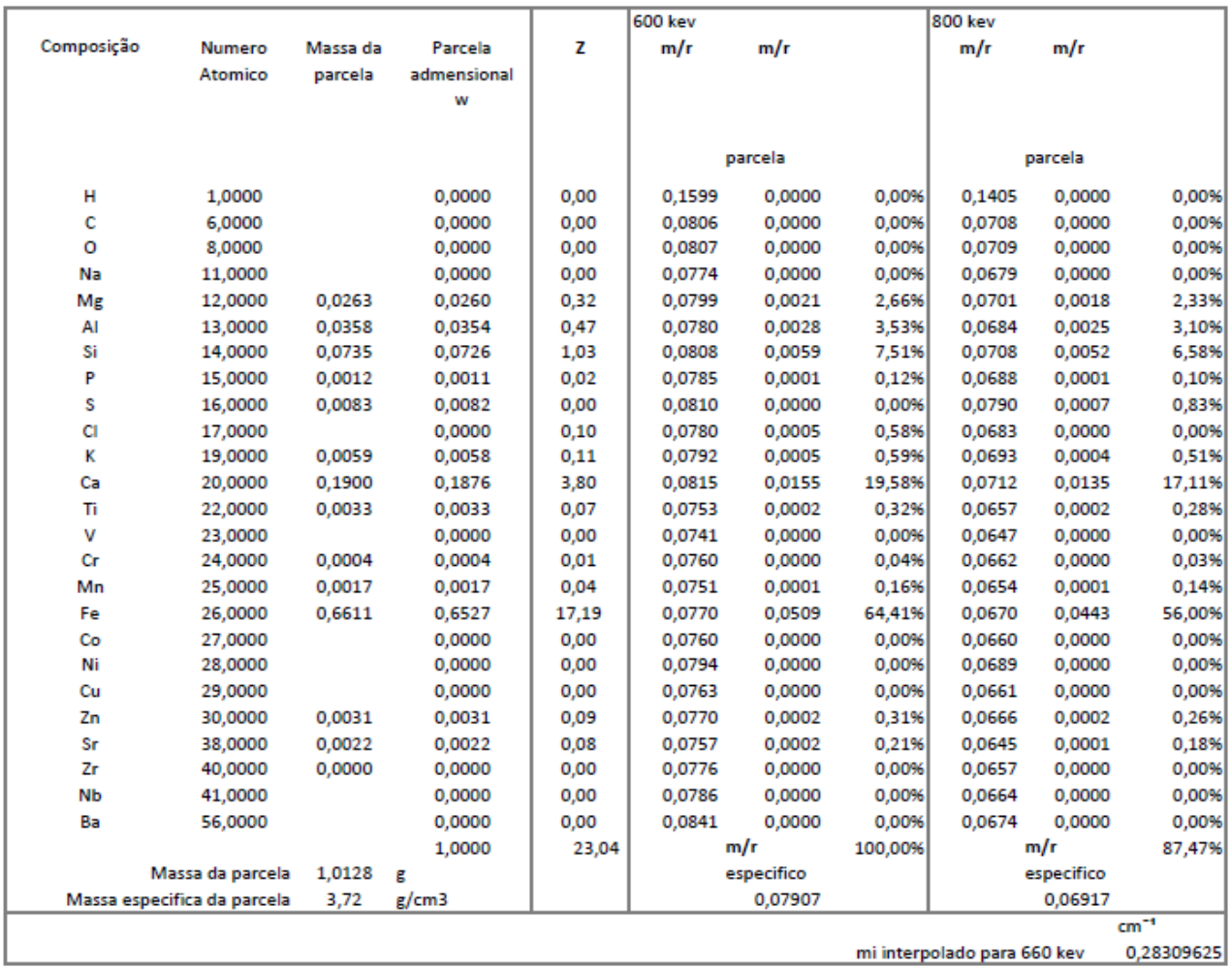

Tabela 86 - Coeficiente de atenuação linear calculado Com 11.

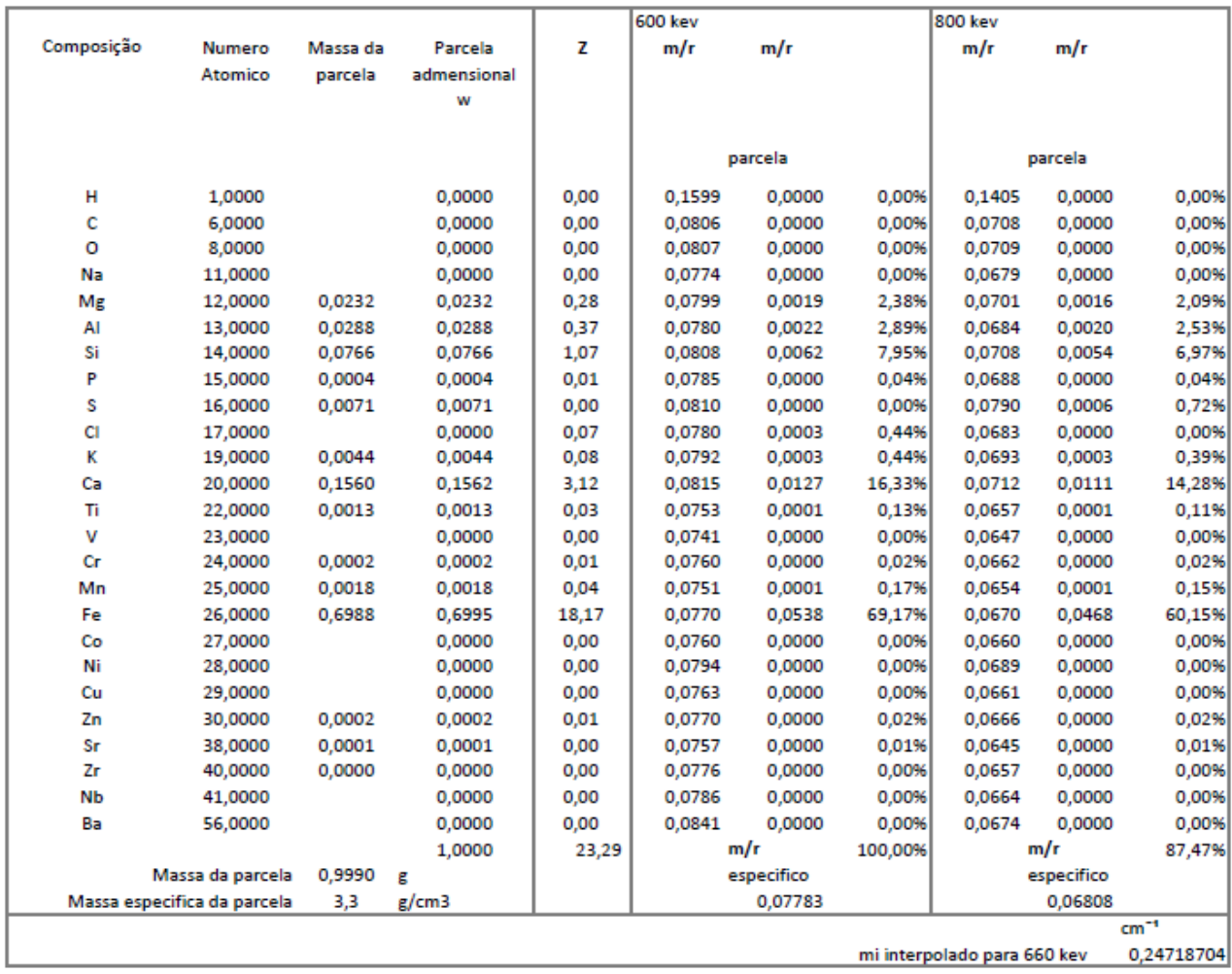


Tabela 87 - Coeficiente de atenuação linear calculado Com 12.

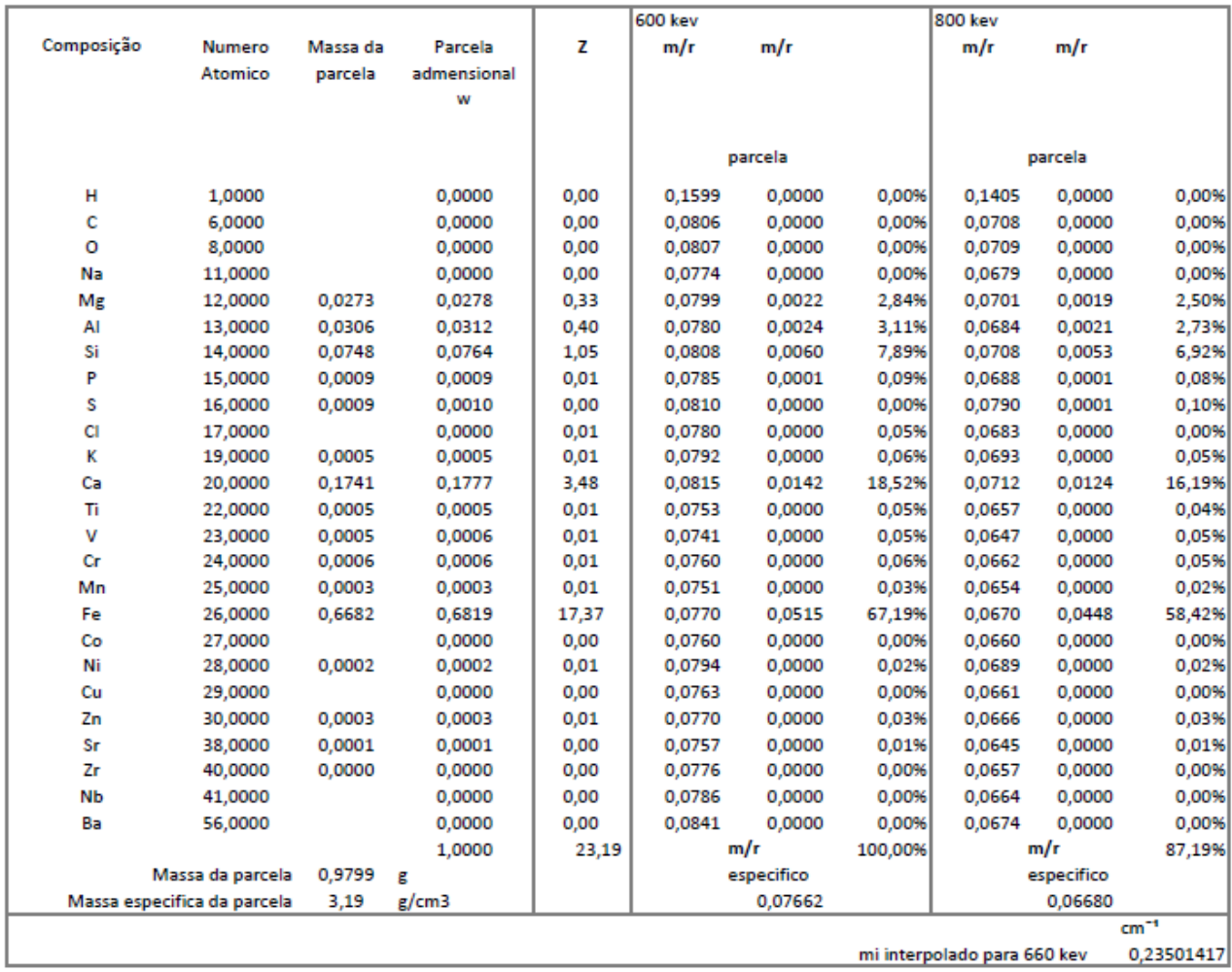

Tabela 88 - Coeficiente de atenuação linear calculado Com 13.

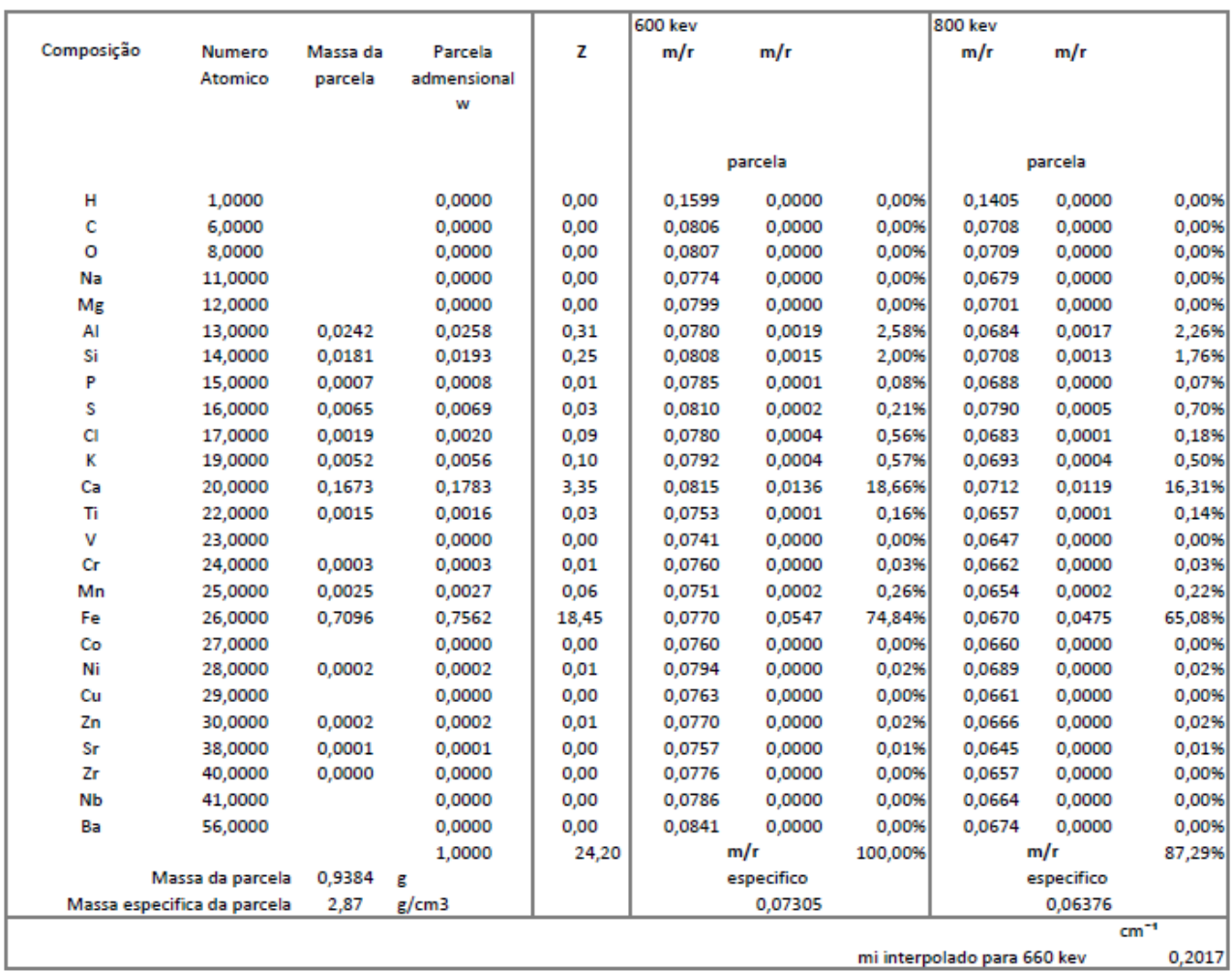


Tabela 89 - Coeficiente de atenuação linear calculado Com 14.

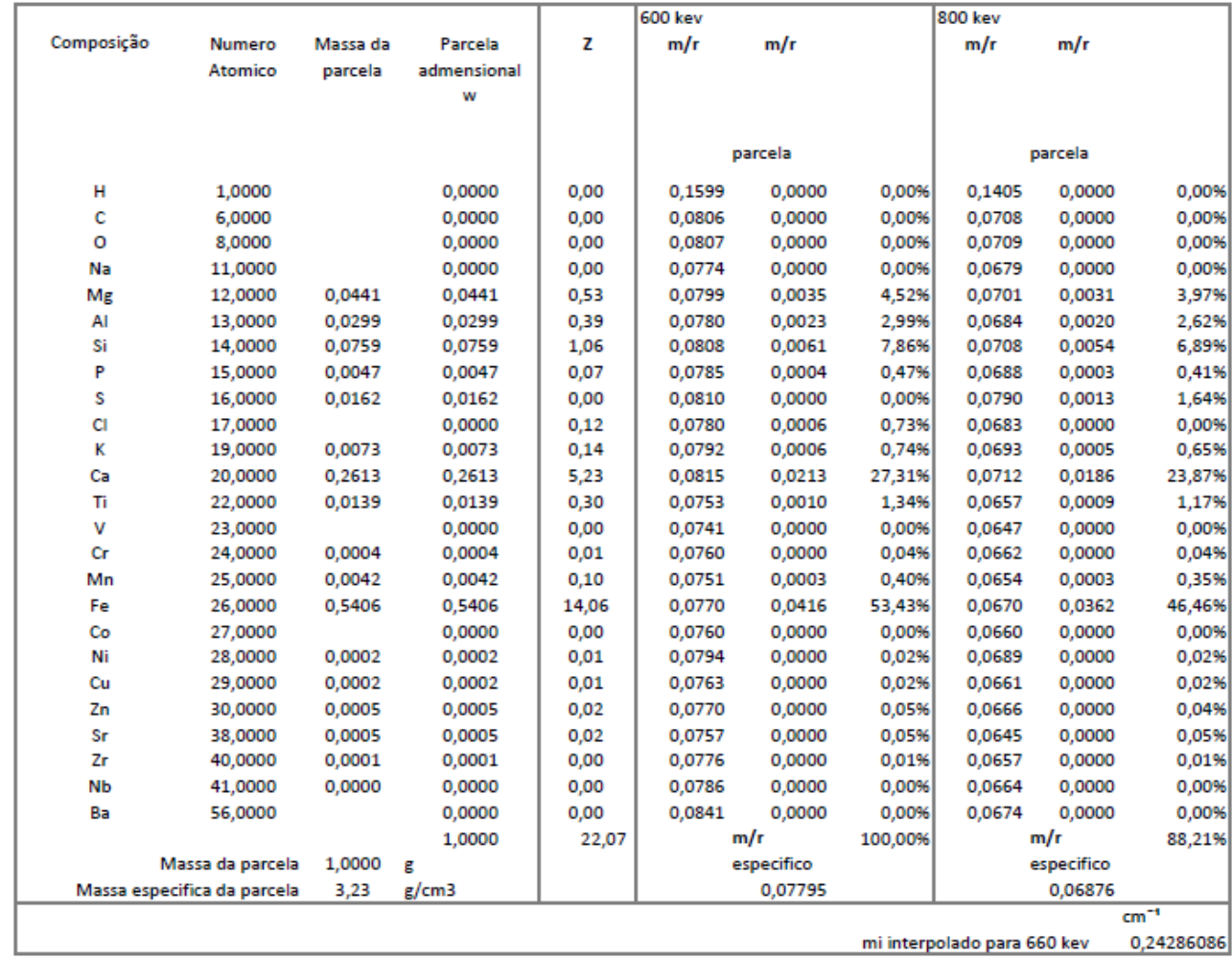

Tabela 90 - Coeficiente de atenuação linear calculado Com 15.

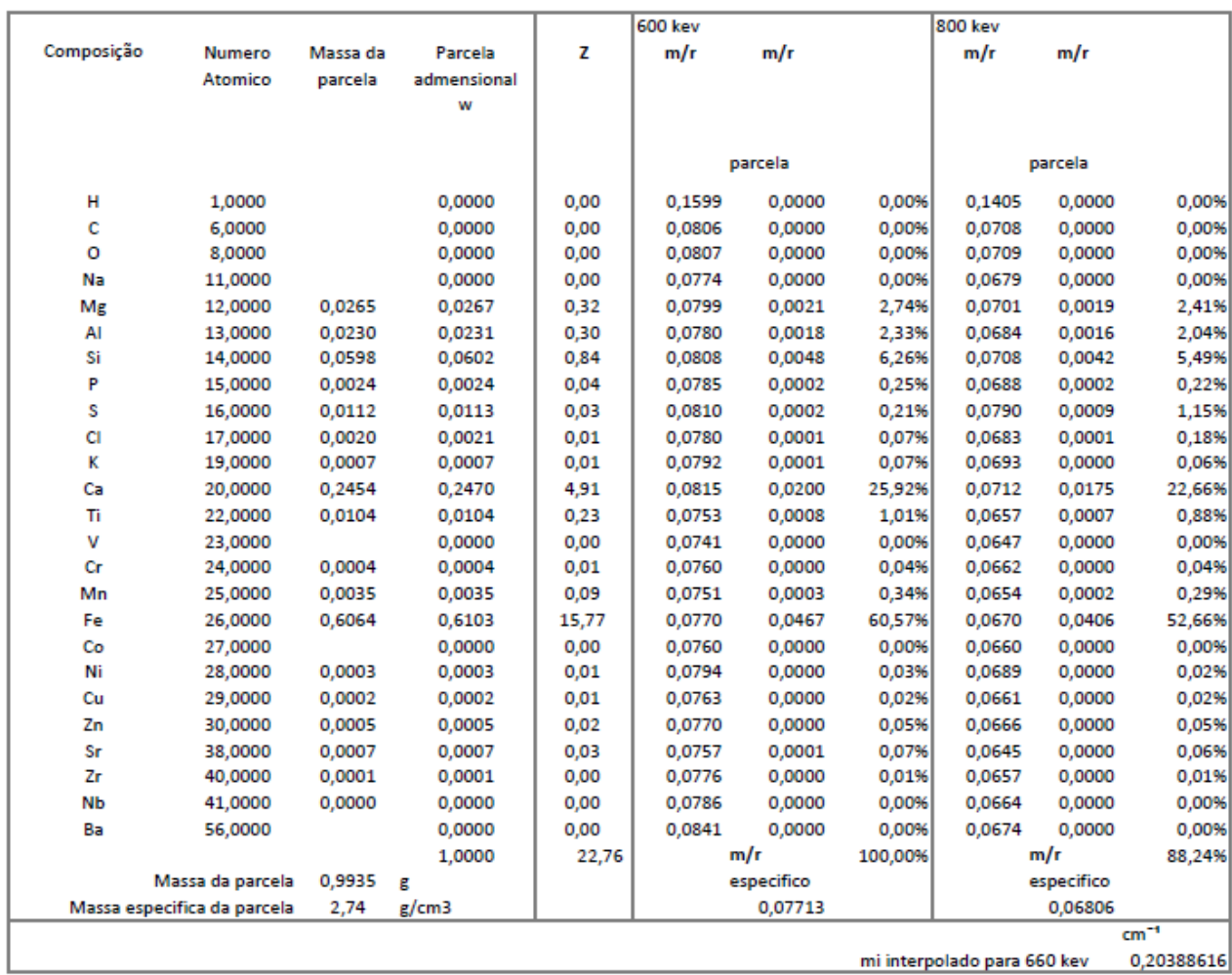


Tabela 91 - Coeficiente de atenuação linear calculado Com 16.

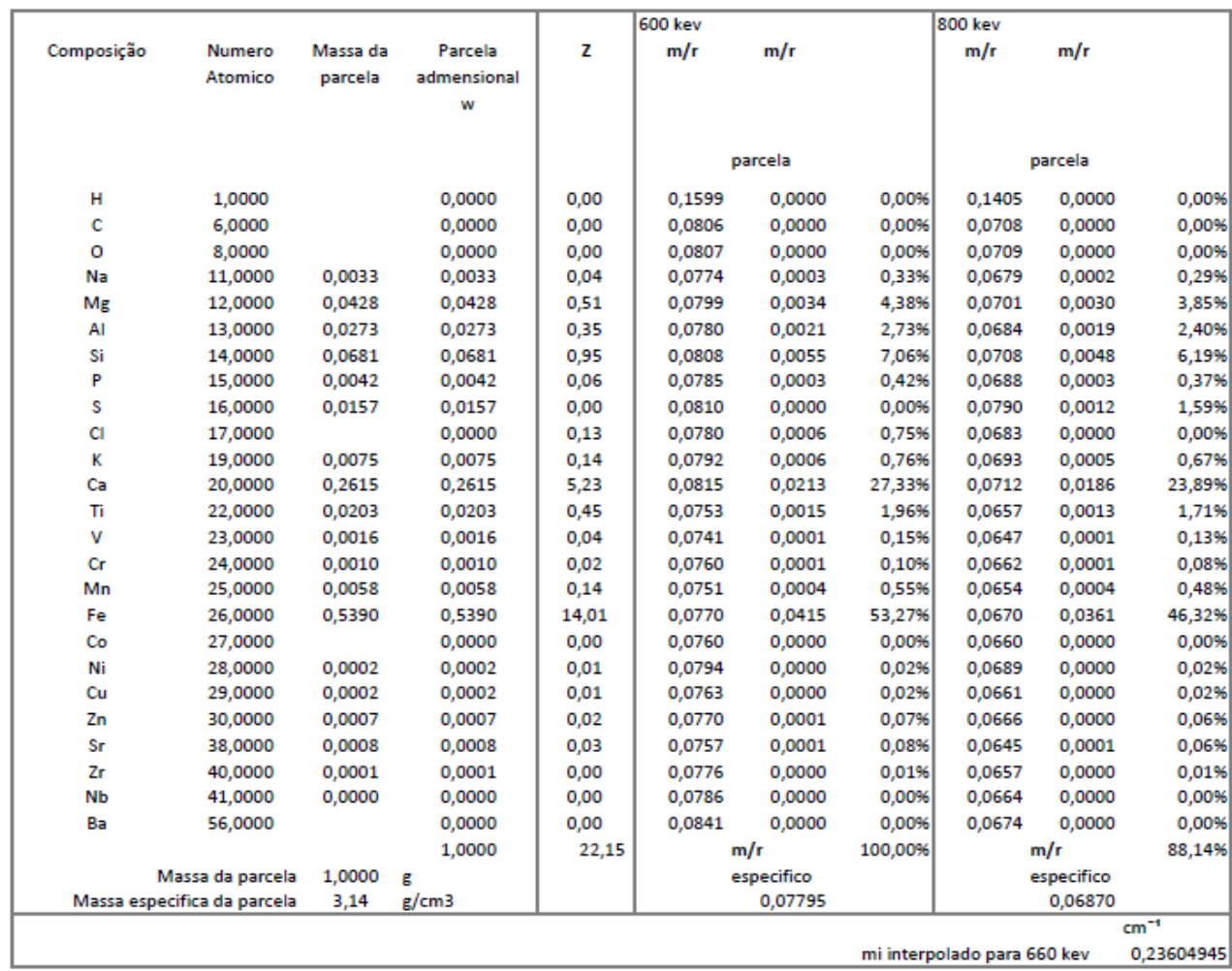

Tabela 92 - Coeficiente de atenuação linear calculado Com 17.

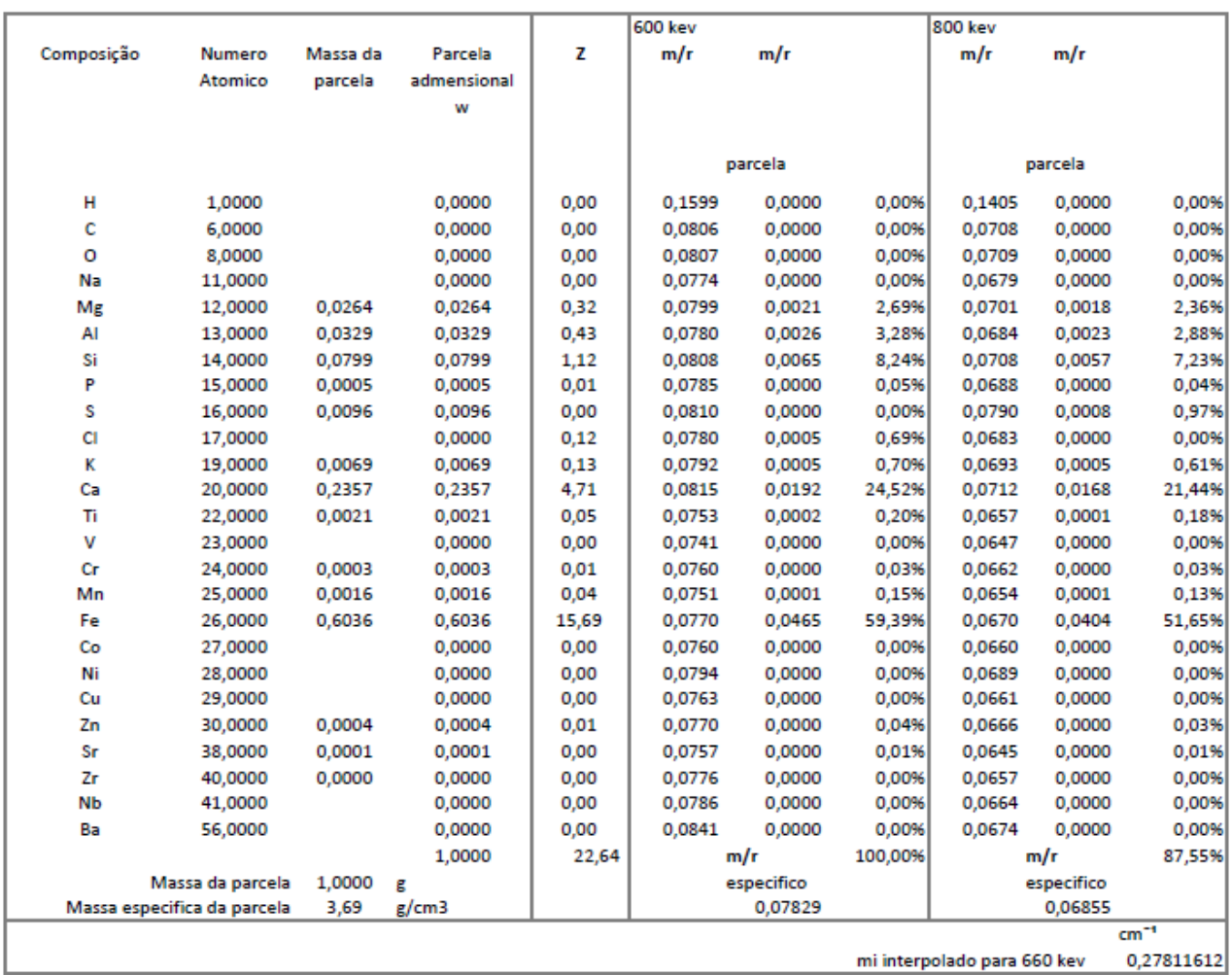


Tabela 93 - Coeficiente de atenuação linear calculado Com 18.

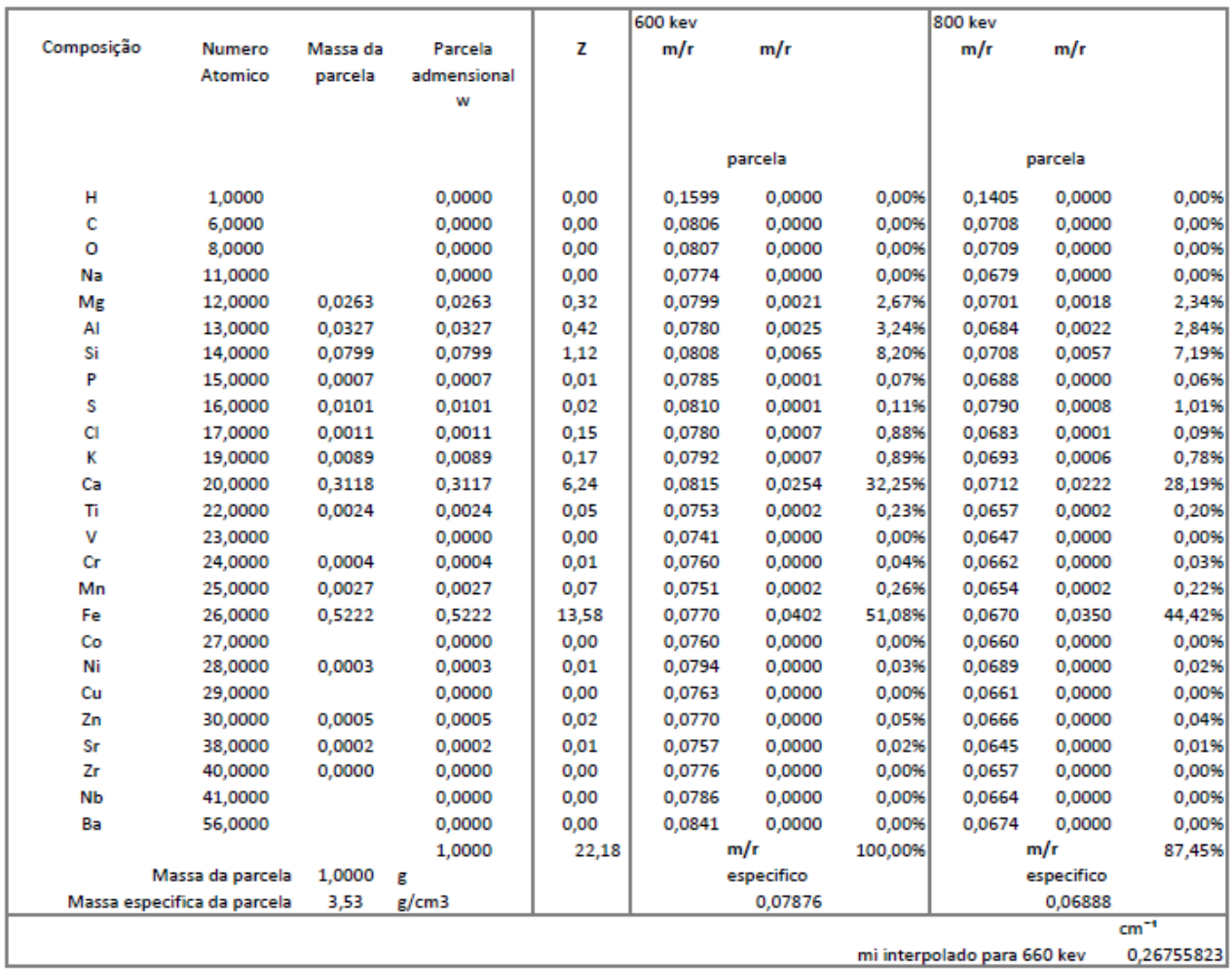

Tabela 94 - Coeficiente de atenuação linear calculado Com 19.

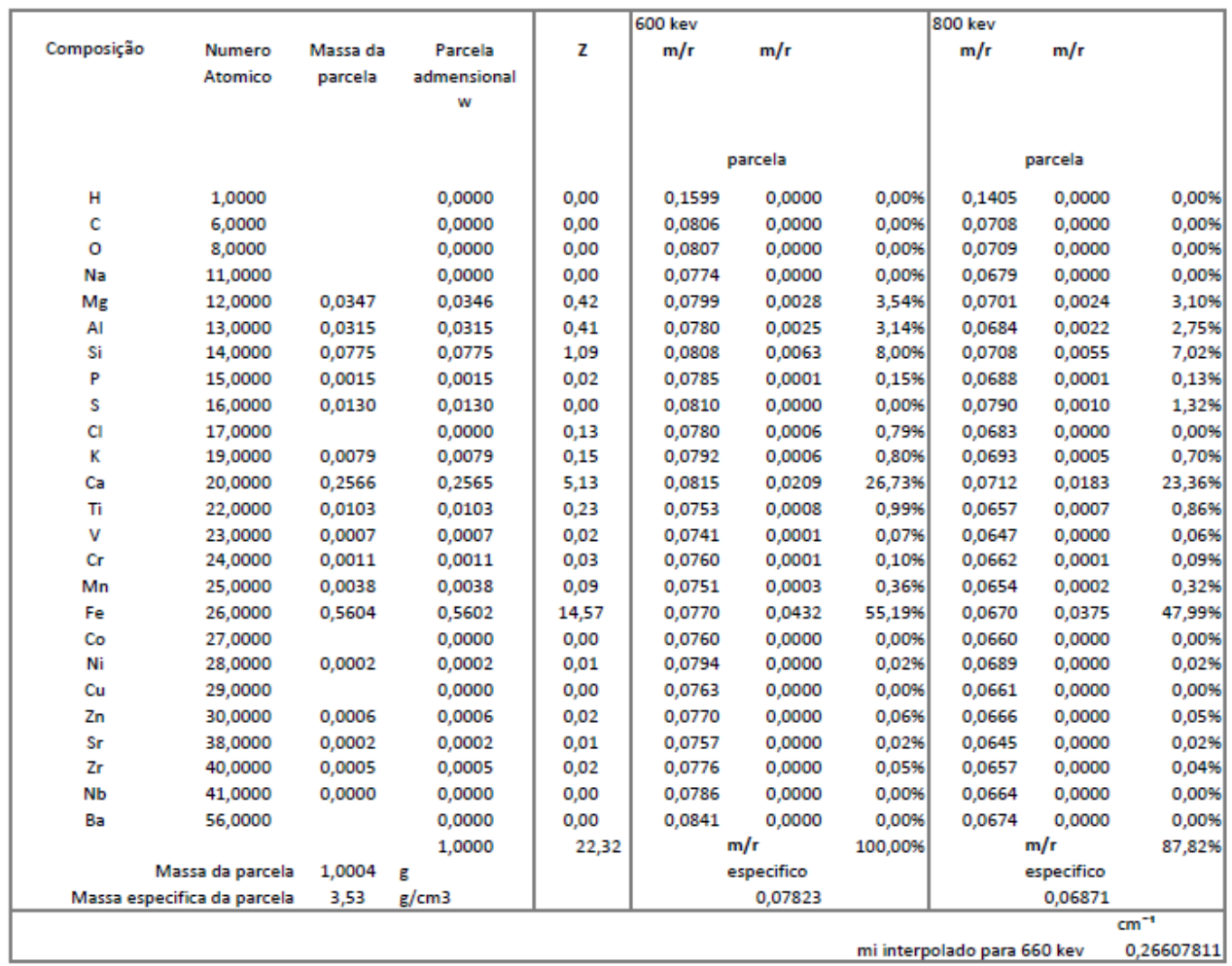


Tabela 95 - Coeficiente de atenuação linear calculado Com 20.

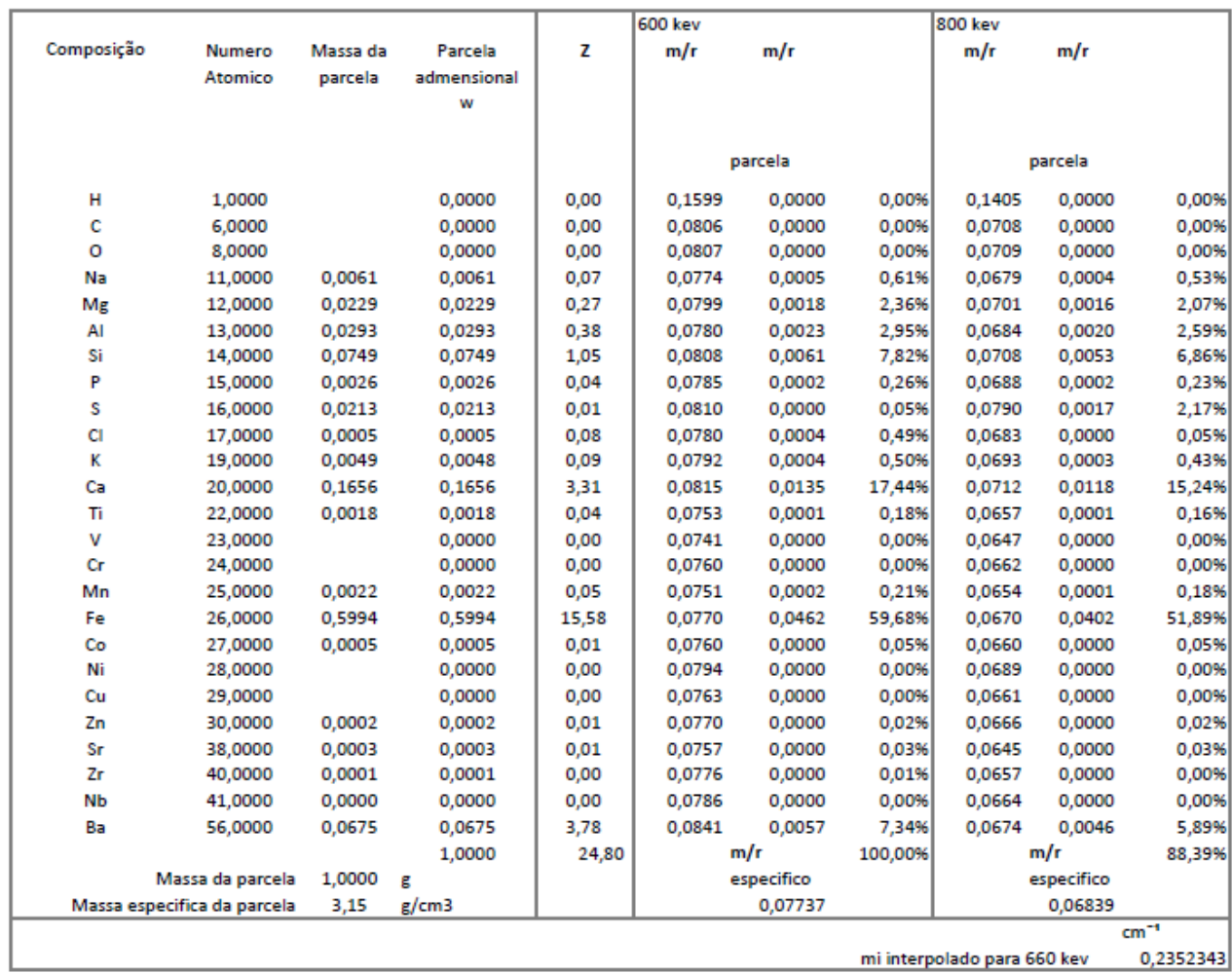

Tabela 96 - Coeficiente de atenuação linear calculado Com 21.

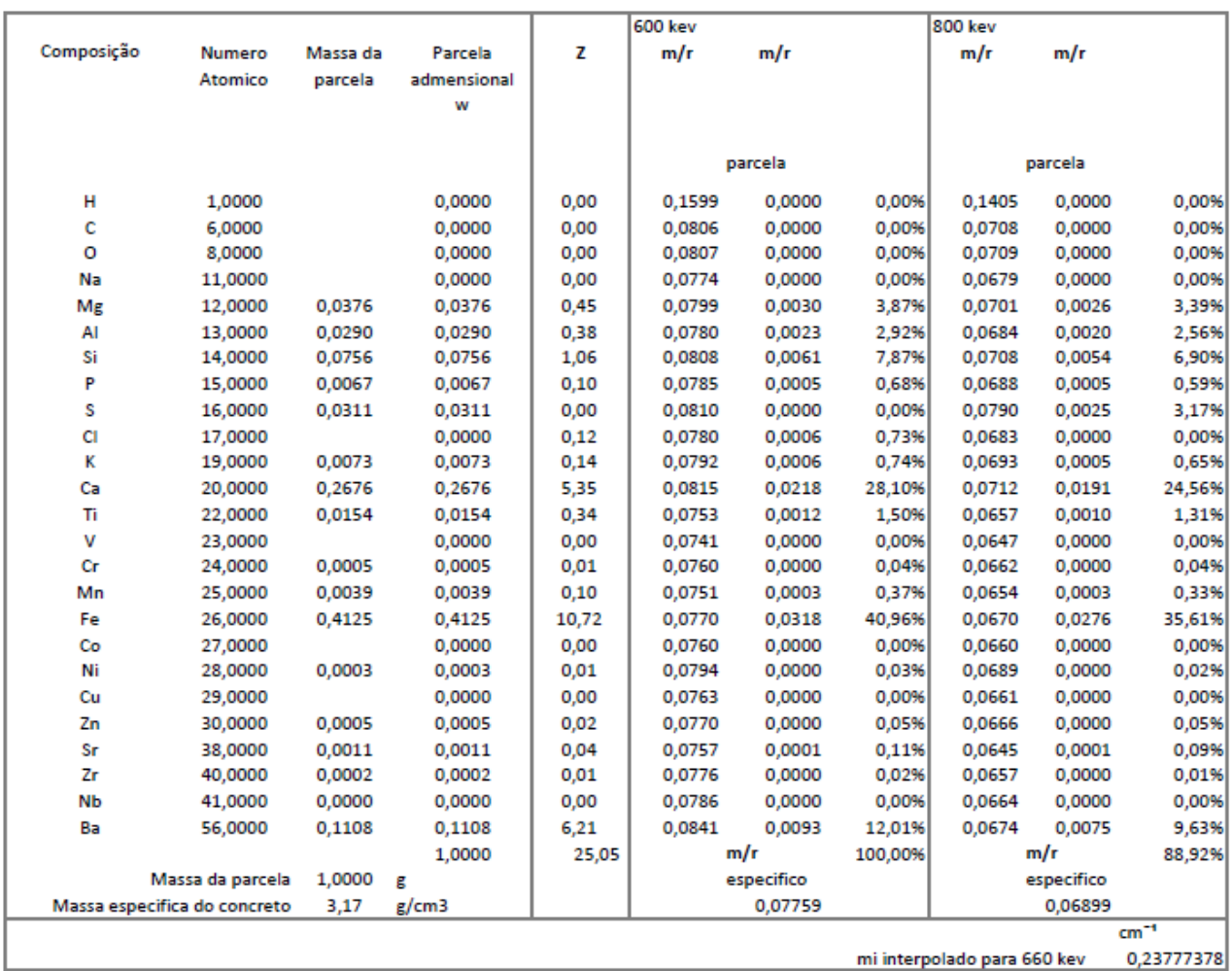


Tabela 97 - Coeficiente de atenuação linear calculado Com 22.

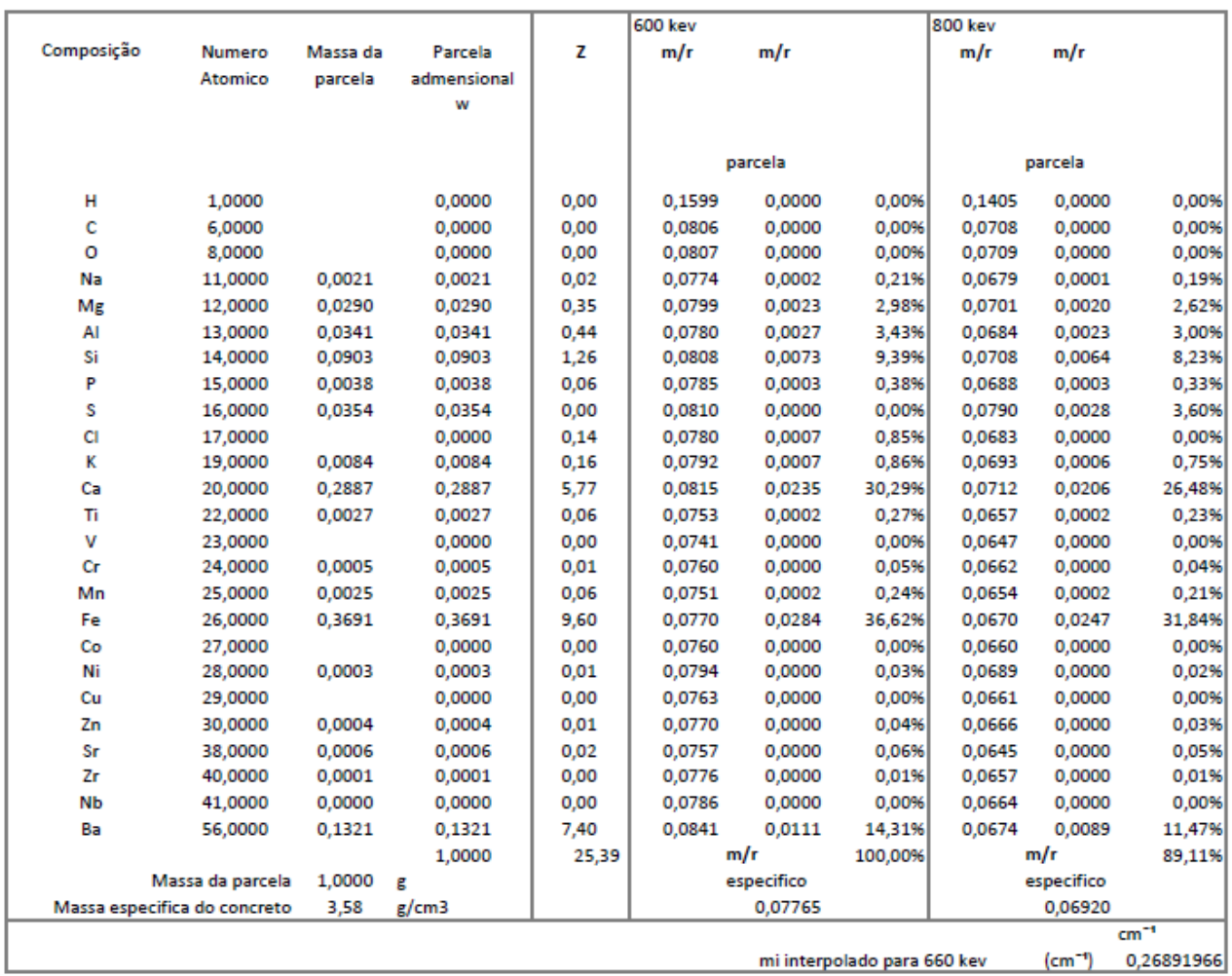


Na tabela (98) é apresentado o resumo dos dados obtidos, e são relacionados os coeficientes de atenuação linear calculados, as massas específicas e os coeficientes mássicos de atenuação.

Tabela 98 - Resumos dos dados encontrados para os coeficientes de atenução linear calculados.

\begin{tabular}{|c|c|c|c|}
\hline Concreto & $\begin{array}{l}\text { Coeficiente de atenuação linear } \\
\text { calculado }\left(\mathrm{cm}^{1}\right) \text { para } 660 \mathrm{keV}\end{array}$ & $\begin{array}{c}\text { Massa específica } \\
\left(\mathrm{kg} / \mathrm{dm}^{3}\right)\end{array}$ & $\begin{array}{l}\text { Coeficiente mássico de atenuação linear } \\
\text { calculado }(\mu / \mathrm{r}) \\
\left(\mathrm{cm}^{2} / \mathrm{g}\right)\end{array}$ \\
\hline 1 & 0,2821 & 3,72 & 0,0758 \\
\hline 2 & 0,2675 & 3,44 & 0,0777 \\
\hline 3 & 0,2791 & 3,70 & 0,0753 \\
\hline 4 & 0,2599 & 3,47 & 0,0749 \\
\hline 5 & 0,2359 & 3,14 & 0,0751 \\
\hline 6 & 0,2697 & 3,59 & 0,0751 \\
\hline 7 & 0,2833 & 3,76 & 0,0753 \\
\hline 8 & 0,2465 & 3,27 & 0,0754 \\
\hline 9 & 0,2637 & 3,49 & 0,0755 \\
\hline 10 & 0,2831 & 3,72 & 0,0761 \\
\hline 11 & 0,2472 & 3,30 & 0,0749 \\
\hline 12 & 0,2350 & 3,19 & 0,0737 \\
\hline 13 & 0,2017 & 2,87 & 0,0703 \\
\hline 14 & 0,2429 & 3,23 & 0,0752 \\
\hline 15 & 0,2039 & 2,74 & 0,0744 \\
\hline 16 & 0,2360 & 3,14 & 0,0752 \\
\hline 17 & 0,2781 & 3,69 & 0,0754 \\
\hline 18 & 0,2675 & 3,53 & 0,0758 \\
\hline 19 & 0,2661 & 3,53 & 0,0754 \\
\hline 20 & 0,2352 & 3,15 & 0,0747 \\
\hline 21 & 0,2378 & 3,17 & 0,0750 \\
\hline 22 & 0,2689 & 3,58 & 0,0751 \\
\hline
\end{tabular}




\subsection{Resultados dos ensaios para determinação dos coeficientes de atenuação linear para a energia de $660 \mathrm{keV}$.}

Nas tabelas a seguir (99-119) são apresentados os dados dos ensaios de atenuação realizados, conforme figura (19), apresentada na página 57 desta tese. $\mathrm{Na}$ coluna PosX é mostrada a posição da linha na qual a contagem dos fótons foi realizada, na coluna PosY é mostrada a posição no eixo $Y$ em que as medições foram feitas.

A coluna contagem, como o nome sugere, refere-se à contagem dos fótons, e a coluna $\mathrm{I} / \mathrm{I}_{0}$ refere-se à razão entre os fótons emitidos pela fonte e os detectados no detector, (mi) é o coeficiente de atenuação linear para a espessura de $1 \mathrm{~cm}$, e a coluna $(\mathrm{m})$ mostra o valor corrigido para a espessura de $4 \mathrm{~cm}$.

$\begin{array}{ll}\text { Data } & \text { Hora } \\ 06 / 12 / 2013 & 17: 25 \\ 06 / 12 / 2013 & 17: 26 \\ 06 / 12 / 2013 & 17: 27 \\ 06 / 12 / 2013 & 17: 29 \\ 06 / 12 / 2013 & 17: 30 \\ 06 / 12 / 2013 & 17: 31 \\ 06 / 12 / 2013 & 17: 32 \\ 06 / 12 / 2013 & 17: 33 \\ 06 / 12 / 2013 & 17: 35 \\ 06 / 12 / 2013 & 17: 36 \\ 06 / 12 / 2013 & 17: 37 \\ 06 / 12 / 2013 & 17: 38 \\ 06 / 12 / 2013 & 17: 40 \\ 06 / 12 / 2013 & 17: 41 \\ 06 / 12 / 2013 & 17: 42 \\ 06 / 12 / 2013 & 17: 43\end{array}$

Tabela 99 - Concreto 1, corpo de prova número AM 5.

$\begin{array}{rr}10=\quad 616570 & \\ \text { PosZ (um) } & \begin{array}{r}\text { Contagem } \\ 100000\end{array} \\ 100000 & 211960 \\ 100000 & 224603 \\ 100000 & 241769 \\ 110000 & 198999 \\ 110000 & 186338 \\ 110000 & 211593 \\ 110000 & 165202 \\ 120000 & 187606 \\ 120000 & 193830 \\ 120000 & 193782 \\ 120000 & 233311 \\ 130000 & 220097 \\ 130000 & 193050 \\ 130000 & 211302 \\ 130000 & 199157\end{array}$

\begin{tabular}{rr}
\multicolumn{1}{l}{ /lo $\mathrm{mi}$} \\
0,41544 & 0,878 \\
0,343773 & 1,068 \\
0,364278 & 1,010 \\
0,392119 & 0,936 \\
0,322752 & 1,131 \\
0,302217 & 1,197 \\
0,343178 & 1,070 \\
0,267937 & 1,317 \\
0,304274 & 1,190 \\
0,314368 & 1,157 \\
0,31429 & 1,157 \\
0,378401 & 0,972 \\
0,35697 & 1,030 \\
0,313103 & 1,161 \\
0,342706 & 1,071 \\
0,323008 & 1,130
\end{tabular}


Tabela 100 - Concreto 2, corpo de prova número AM 7.

Data

05/12/2013 $18: 30$ Hora

05/12/2013 18:32

05/12/2013 $18: 33$

$05 / 12 / 2013 \quad 18: 34$

$05 / 12 / 2013 \quad 18: 35$

$05 / 12 / 2013 \quad 18: 36$

$05 / 12 / 2013 \quad 18: 38$

05/12/2013 18:39

$05 / 12 / 2013 \quad 18: 40$

$05 / 12 / 2013 \quad 18: 41$

$05 / 12 / 2013 \quad 18: 42$

$05 / 12 / 2013 \quad 18: 44$

$05 / 12 / 2013 \quad 18: 45$

$05 / 12 / 2013 \quad 18: 46$

$05 / 12 / 2013 \quad 18: 47$

$05 / 12 / 2013 \quad 18: 49$

$$
10=\quad 585223
$$

$\begin{array}{cc}\text { PosX (um) Pos Z (um) Contagem } \\ 10000 & 100000 \\ 30000 & 100000 \\ 50000 & 100000 \\ 70000 & 100000 \\ 10000 & 110000 \\ 30000 & 110000 \\ 50000 & 110000 \\ 70000 & 110000 \\ 10000 & 120000 \\ 30000 & 120000 \\ 50000 & 120000 \\ 70000 & 120000 \\ 10000 & 130000 \\ 30000 & 130000 \\ 50000 & 130000 \\ 70000 & 130000\end{array}$

\begin{tabular}{llrr}
\multicolumn{1}{l}{ I/lo } \\
0,417323 & $\mathrm{mi}$ & \multicolumn{1}{l}{ desvio } & mcorrigido \\
0,401989 & 0,911 & 0,002 & 0,218474 \\
0,392213 & 0,936 & 0,002 & 0,227833 \\
0,416142 & 0,877 & 0,002 & 0,233988 \\
0,337702 & 1,086 & 0,002 & 0,219182 \\
0,374749 & 0,981 & 0,002 & 0,245374 \\
0,332017 & 1,103 & 0,002 & 0,275642 \\
0,311553 & 1,166 & 0,002 & 0,291546 \\
0,367544 & 1,001 & 0,002 & 0,250228 \\
0,300503 & 1,202 & 0,002 & 0,300575 \\
0,353423 & 1,040 & 0,002 & 0,260023 \\
0,284938 & 1,255 & 0,003 & 0,313871 \\
0,36955 & 0,995 & 0,002 & 0,248867 \\
0,390906 & 0,939 & 0,002 & 0,234822 \\
0,320384 & 1,138 & 0,002 & 0,284559 \\
0,340161 & 1,078 & 0,002 & 0,269584 \\
& & & 0,255126
\end{tabular}

Tabela 101 - Concreto 3, corpo de prova número AM 12.

\begin{tabular}{|c|c|c|}
\hline & 585223 & \\
\hline Pos X (um) & PosZ (um) & Contagem \\
\hline 10000 & 100000 & 223993 \\
\hline 30000 & 100000 & 219245 \\
\hline 50000 & 100000 & 219763 \\
\hline 70000 & 100000 & 221909 \\
\hline 10000 & 110000 & 182633 \\
\hline 30000 & 110000 & 191821 \\
\hline 50000 & 110000 & 171034 \\
\hline 70000 & 110000 & 178454 \\
\hline 10000 & 120000 & 206962 \\
\hline 30000 & 120000 & 162838 \\
\hline 50000 & 120000 & 202080 \\
\hline 70000 & 120000 & 191423 \\
\hline 10000 & 130000 & 197870 \\
\hline 30000 & 130000 & 191168 \\
\hline 50000 & 130000 & 207430 \\
\hline 70000 & 130000 & 227907 \\
\hline
\end{tabular}

\begin{tabular}{rr}
\multicolumn{1}{c}{ I/lo } \\
0,382748 & 0,960 \\
0,374635 & 0,982 \\
0,37552 & 0,979 \\
0,379187 & 0,970 \\
0,312074 & 1,165 \\
0,327774 & 1,115 \\
0,292254 & 1,230 \\
0,304933 & 1,188 \\
0,353646 & 1,039 \\
0,278249 & 1,279 \\
0,345304 & 1,063 \\
0,327094 & 1,118 \\
0,33811 & 1,084 \\
0,326855 & 1,119 \\
0,354446 & 1,037 \\
0,389436 & 0,943
\end{tabular}

desvio

0,002

0,002

0,002

0,002

0,002

0,002

0,003

0,002

0,002

0,003

0,002

0,002

0,002

0,002

0,002

0,002 mcorrigido

0,240095

0.24545

0.244861

0,242431

0,291128

0,278858

0,307533

0,296916

0.259864

0,319809

0,265832

0,279377

0,271096

0,279713

0,259300

0.235764

Tabela 102 - Concreto 4, corpo de prova número AM 21.

$10=$

$\begin{array}{rr}\text { PosX (um) } & \text { PosZ (um) } \\ 10000 & 100000 \\ 30000 & 100000 \\ 50000 & 100000 \\ 70000 & 100000 \\ 10000 & 110000 \\ 30000 & 110000 \\ 50000 & 110000 \\ 70000 & 110000 \\ 10000 & 120000 \\ 30000 & 120000 \\ 50000 & 120000 \\ 70000 & 120000 \\ 10000 & 130000 \\ 30000 & 130000 \\ 50000 & 130000 \\ 70000 & 130000\end{array}$

$$
\begin{array}{r}
\text { Contagem } \\
235475 \\
244255 \\
245096 \\
244187 \\
206046 \\
210166 \\
224264 \\
201072 \\
195273 \\
210161 \\
139975 \\
173678 \\
219048 \\
197999 \\
220790 \\
184805
\end{array}
$$

$\begin{array}{ll}\text { I/lo } & \text { mi } \\ 0,402368 & 0,910 \\ 0,417371 & 0,874 \\ 0,418808 & 0,870 \\ 0,417255 & 0,874 \\ 0,352081 & 1,044 \\ 0,359121 & 1,024 \\ 0,383211 & 0,959 \\ 0,343582 & 1,068 \\ 0,333673 & 1,098 \\ 0,359113 & 1,024 \\ 0,239182 & 1,431 \\ 0,296772 & 1,215 \\ 0,374298 & 0,983 \\ 0,338331 & 1,084 \\ 0,377275 & 0,975 \\ 0,315786 & 1,153\end{array}$

$\begin{array}{rr}\text { desvio } & \text { mcorrigido } \\ 0,002 & 0,227597 \\ 0,002 & 0,218445 \\ 0,002 & 0,217586 \\ 0,002 & 0,218515 \\ 0,002 & 0,260973 \\ 0,002 & 0,256024 \\ 0,002 & 0,239792 \\ 0,002 & 0,267082 \\ 0,002 & 0,274399 \\ 0,002 & 0,25603 \\ 0,003 & 0,357632 \\ 0,003 & 0,303697 \\ 0,002 & 0,245676 \\ 0,002 & 0,270933 \\ 0,002 & 0,243695 \\ 0,002 & 0,288173 \\ & 0,256027\end{array}$


Tabela 103 - Concreto 5, corpo de prova número AM 27.

\begin{tabular}{|c|c|c|}
\hline Data & & \\
\hline & $05 / 12 / 2013$ & $14: 11$ \\
\hline & $05 / 12 / 2013$ & $14: 12$ \\
\hline & $05 / 12 / 2013$ & $14: 13$ \\
\hline & $05 / 12 / 2013$ & $14: 14$ \\
\hline & $05 / 12 / 2013$ & $14: 15$ \\
\hline & $05 / 12 / 2013$ & $14: 17$ \\
\hline & $05 / 12 / 2013$ & $14: 18$ \\
\hline & $05 / 12 / 2013$ & $14: 19$ \\
\hline & $05 / 12 / 2013$ & $14: 20$ \\
\hline & $05 / 12 / 2013$ & $14: 21$ \\
\hline & $05 / 12 / 2013$ & $14: 23$ \\
\hline & $05 / 12 / 2013$ & $14: 24$ \\
\hline & $05 / 12 / 2013$ & $14: 25$ \\
\hline & $05 / 12 / 2013$ & $14: 26$ \\
\hline & $05 / 12 / 2013$ & $14: 28$ \\
\hline & $05 / 12 / 2013$ & $14: 29$ \\
\hline
\end{tabular}

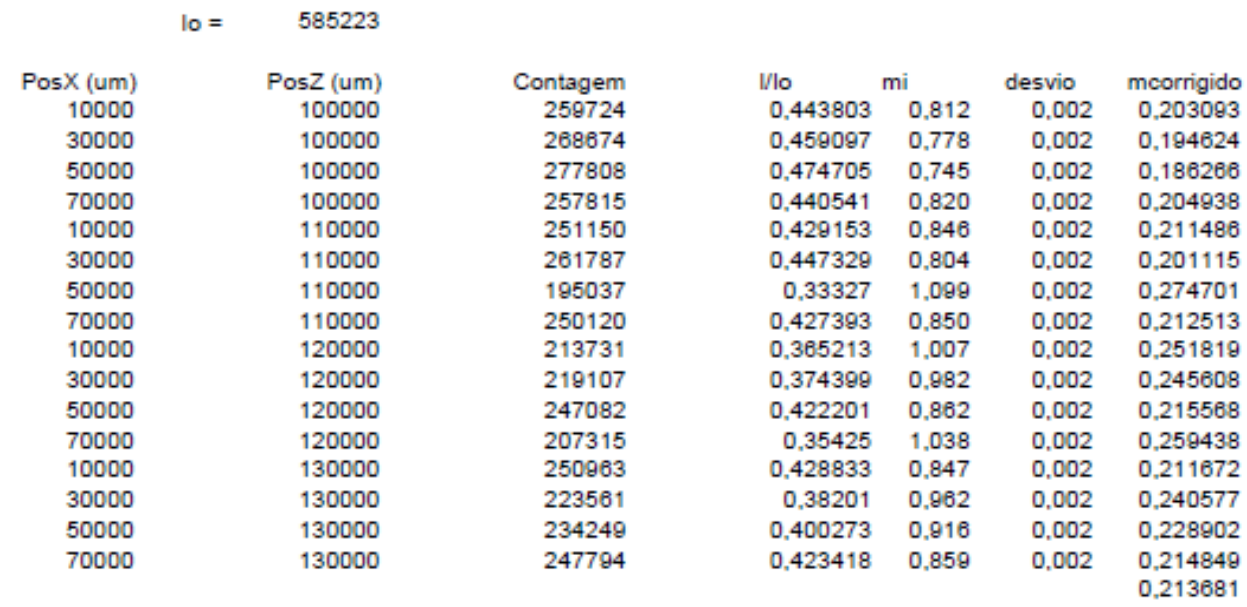

Tabela 104 - Concreto 6, corpo de prova número AM 33.

\begin{tabular}{|c|c|c|}
\hline \multirow[t]{2}{*}{ Data } & \multicolumn{2}{|c|}{ Hora } \\
\hline & $06 / 12 / 2013$ & $18: 10$ \\
\hline & $06 / 12 / 2013$ & $18: 11$ \\
\hline & $06 / 12 / 2013$ & $18: 12$ \\
\hline & $08 / 12 / 2013$ & $18: 14$ \\
\hline & $06 / 12 / 2013$ & $18: 15$ \\
\hline & $06 / 12 / 2013$ & $18: 16$ \\
\hline & $06 / 12 / 2013$ & $18: 17$ \\
\hline & $06 / 12 / 2013$ & $18: 18$ \\
\hline & $06 / 12 / 2013$ & $18: 20$ \\
\hline & $06 / 12 / 2013$ & $18: 21$ \\
\hline & $06 / 12 / 2013$ & $18: 22$ \\
\hline & $06 / 12 / 2013$ & $18: 23$ \\
\hline & $06 / 12 / 2013$ & $18: 25$ \\
\hline & $06 / 12 / 2013$ & $18: 26$ \\
\hline & $06 / 12 / 2013$ & $18: 27$ \\
\hline & $06 / 12 / 2013$ & $18: 28$ \\
\hline
\end{tabular}

$\begin{array}{rrr} & \text { lo }= & 616570 \\ \text { PosX (um) } & \text { PosZ (um) } & \text { Contagem } \\ 10000 & 100000 & 257825 \\ 30000 & 100000 & 255618 \\ 50000 & 100000 & 262758 \\ 70000 & 100000 & 262862 \\ 10000 & 110000 & 255085 \\ 30000 & 110000 & 183136 \\ 50000 & 110000 & 241571 \\ 70000 & 110000 & 243602 \\ 10000 & 120000 & 244274 \\ 30000 & 120000 & 205144 \\ 50000 & 120000 & 216813 \\ 70000 & 120000 & 240892 \\ 10000 & 130000 & 207566 \\ 30000 & 130000 & 222126 \\ 50000 & 130000 & 199876 \\ 70000 & 130000 & 209752\end{array}$

\begin{tabular}{rrrr}
\multicolumn{1}{l}{ I/lo } & mi & desvio & mcorrigido \\
0,41816 & 0,872 & 0,002 & 0,217973 \\
0,414581 & 0,880 & 0,002 & 0,220122 \\
0,426161 & 0,853 & 0,002 & 0,213235 \\
0,42633 & 0,853 & 0,002 & 0,213136 \\
0,413716 & 0,883 & 0,002 & 0,220644 \\
0,297024 & 1,214 & 0,002 & 0,303486 \\
0,391798 & 0,937 & 0,002 & 0,234252 \\
0,395092 & 0,929 & 0,002 & 0,232159 \\
0,396182 & 0,926 & 0,002 & 0,231470 \\
0,332718 & 1,100 & 0,002 & 0,275115 \\
0,351644 & 1,045 & 0,002 & 0,261284 \\
0,390697 & 0,940 & 0,002 & 0,234956 \\
0,336646 & 1,089 & 0,002 & 0,272181 \\
0,360261 & 1,021 & 0,002 & 0,255232 \\
0,324174 & 1,126 & 0,002 & 0,281619 \\
0,340192 & 1,078 & 0,002 & 0,269561 \\
& & & 0,234604
\end{tabular}

Tabela 105 - Concreto 7, corpo de prova número AM 36.

\begin{tabular}{|c|c|c|}
\hline \multirow[t]{2}{*}{ Data } & \multicolumn{2}{|c|}{ Hora } \\
\hline & $07 / 12 / 2013$ & $16: 51$ \\
\hline & $07 / 12 / 2013$ & $16: 52$ \\
\hline & $07 / 12 / 2013$ & $16: 53$ \\
\hline & $07 / 12 / 2013$ & $16: 54$ \\
\hline & $07 / 12 / 2013$ & $16: 56$ \\
\hline & $07 / 12 / 2013$ & $16: 57$ \\
\hline & $07 / 12 / 2013$ & $16: 58$ \\
\hline & $07 / 12 / 2013$ & $16: 59$ \\
\hline & $07 / 12 / 2013$ & $17: 00$ \\
\hline & $07 / 12 / 2013$ & $17: 02$ \\
\hline & $07 / 12 / 2013$ & $17: 03$ \\
\hline & $07 / 12 / 2013$ & $17: 04$ \\
\hline & $07 / 12 / 2013$ & $17: 05$ \\
\hline & $07 / 12 / 2013$ & $17: 07$ \\
\hline & $07 / 12 / 2013$ & $17: 08$ \\
\hline & $07 / 12 / 2013$ & $17: 00$ \\
\hline
\end{tabular}

$\begin{array}{rr}10=\quad 616570 & \\ & \\ \text { PosZ (um) } & 313113 \\ 100000 & 291966 \\ 100000 & 306801 \\ 100000 & 299122 \\ 100000 & 196584 \\ 110000 & 199395 \\ 110000 & 201528 \\ 110000 & 209469 \\ 110000 & 192606 \\ 120000 & 189448 \\ 120000 & 199530 \\ 120000 & 209339 \\ 120000 & 210771 \\ 130000 & 199695 \\ 130000 & 190814 \\ 130000 & 186932 \\ 130000 & \end{array}$

\begin{tabular}{rrr} 
I/lo & \multicolumn{1}{l}{ mi } & desvio \\
0,50783 & 0,678 & 0,002 \\
0,473533 & 0,748 & 0,002 \\
0,497593 & 0,698 & 0,002 \\
0,485139 & 0,723 & 0,002 \\
0,318835 & 1,143 & 0,002 \\
0,323394 & 1,129 & 0,002 \\
0,326853 & 1,118 & 0,002 \\
0,339733 & 1,080 & 0,002 \\
0,312383 & 1,164 & 0,002 \\
0,307261 & 1,180 & 0,002 \\
0,323613 & 1,128 & 0,002 \\
0,339522 & 1,080 & 0,002 \\
0,341844 & 1,073 & 0,002 \\
0,323881 & 1,127 & 0,002 \\
0,309477 & 1,173 & 0,002 \\
0,30318 & 1,193 & 0,002
\end{tabular}

mcorrigido

PosX (um)
10000
30000
50000
70000
10000
30000
50000
70000
10000
30000
50000
70000
10000
30000
50000
70000

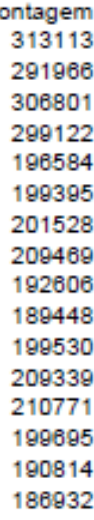

0.169402

0,186884

0,174493

0,180830

0,28577

0,282221

0,279561

0,269898

0,290881

0,295014

0,282052

0,270054

0,268350

0,281845

0,293218

0,298357 


\section{ipen}

Tabela 106 - Concreto 8, corpo de prova número AM 44.

\begin{tabular}{|c|c|}
\hline Data & ora \\
\hline $05 / 12 / 2013$ & $17: 58$ \\
\hline $05 / 12 / 2013$ & $18: 00$ \\
\hline $05 / 12 / 2013$ & $18: 01$ \\
\hline $05 / 12 / 2013$ & $18: 03$ \\
\hline $05 / 12 / 2013$ & 18:04 \\
\hline $05 / 12 / 2013$ & $18: 05$ \\
\hline $05 / 12 / 2013$ & $18: 06$ \\
\hline $05 / 12 / 2013$ & $18: 08$ \\
\hline $05 / 12 / 2013$ & $18: 08$ \\
\hline $05 / 12 / 2013$ & $18: 10$ \\
\hline $05 / 12 / 2013$ & $18: 11$ \\
\hline $05 / 12 / 2013$ & $18: 12$ \\
\hline $05 / 12 / 2013$ & $18: 14$ \\
\hline $05 / 12 / 2013$ & $18: 15$ \\
\hline $05 / 12 / 2013$ & $18: 16$ \\
\hline $05 / 12 / 2013$ & $18: 17$ \\
\hline
\end{tabular}

$\begin{array}{rrr} & \text { lo }= & 585223 \\ \text { PosX (um) } & \text { PosZ (um) } & \text { Contagem } \\ 10000 & 100000 & 256751 \\ 30000 & 100000 & 251326 \\ 50000 & 100000 & 245155 \\ 70000 & 100000 & 258028 \\ 10000 & 110000 & 253088 \\ 30000 & 110000 & 238841 \\ 50000 & 110000 & 259076 \\ 70000 & 110000 & 254805 \\ 10000 & 120000 & 240223 \\ 30000 & 120000 & 235288 \\ 50000 & 120000 & 260379 \\ 70000 & 120000 & 245155 \\ 10000 & 130000 & 213203 \\ 30000 & 130000 & 239348 \\ 50000 & 130000 & 249655 \\ 70000 & 130000 & 212772\end{array}$

\begin{tabular}{cr} 
I/lo & \multicolumn{2}{l}{$\mathrm{mi}$} \\
0,438723 & 0,824 \\
0,429453 & 0,845 \\
0,418909 & 0,870 \\
0,440905 & 0,819 \\
0,432464 & 0,838 \\
0,40812 & 0,896 \\
0,442696 & 0,815 \\
0,435398 & 0,831 \\
0,410481 & 0,890 \\
0,402048 & 0,811 \\
0,444923 & 0,810 \\
0,418909 & 0,870 \\
0,364311 & 1,010 \\
0,408986 & 0,894 \\
0,426598 & 0,852 \\
0,363574 & 1,012
\end{tabular}

$\begin{array}{cr}\text { desvio } & \text { mcorrigido } \\ 0,002 & 0,205972 \\ 0,002 & 0,211311 \\ 0,002 & 0,217526 \\ 0,002 & 0,204731 \\ 0,002 & 0,209564 \\ 0,002 & 0,224049 \\ 0,002 & 0,203718 \\ 0,002 & 0,207874 \\ 0,002 & 0,222606 \\ 0,002 & 0,227796 \\ 0,002 & 0,202464 \\ 0,002 & 0,217526 \\ 0,002 & 0,252437 \\ 0,002 & 0,223519 \\ 0,002 & 0,212978 \\ 0,002 & 0,252943 \\ & 0,215252\end{array}$

Tabela 107 - Concreto 9, corpo de prova número AM 51.

\begin{tabular}{|c|c|c|}
\hline Data & & \\
\hline & $06 / 12 / 2013$ & $18: 31$ \\
\hline & $06 / 12 / 2013$ & $18: 32$ \\
\hline & $06 / 12 / 2013$ & $18: 33$ \\
\hline & $06 / 12 / 2013$ & $18: 34$ \\
\hline & $06 / 12 / 2013$ & $18: 36$ \\
\hline & $06 / 12 / 2013$ & $18: 37$ \\
\hline & $06 / 12 / 2013$ & $18: 38$ \\
\hline & $06 / 12 / 2013$ & $18: 39$ \\
\hline & $06 / 12 / 2013$ & $18: 40$ \\
\hline & $06 / 12 / 2013$ & $18: 42$ \\
\hline & $06 / 12 / 2013$ & $18: 43$ \\
\hline & $06 / 12 / 2013$ & $18: 44$ \\
\hline & $06 / 12 / 2013$ & $18: 45$ \\
\hline & $06 / 12 / 2013$ & $18: 47$ \\
\hline & $06 / 12 / 2013$ & $18: 48$ \\
\hline & $06 / 12 / 2013$ & $18: 49$ \\
\hline
\end{tabular}

$\begin{array}{rrr}\text { PosX (um) } & \text { PosZ (um) } & \text { Contagem } \\ 10000 & 100000 & 248690 \\ 30000 & 100000 & 241062 \\ 50000 & 100000 & 239717 \\ 70000 & 100000 & 231813 \\ 10000 & 110000 & 243859 \\ 30000 & 110000 & 232585 \\ 50000 & 110000 & 240259 \\ 70000 & 110000 & 242453 \\ 10000 & 120000 & 201145 \\ 30000 & 120000 & 235304 \\ 50000 & 120000 & 240032 \\ 70000 & 120000 & 216062 \\ 10000 & 130000 & 238609 \\ 30000 & 130000 & 214376 \\ 50000 & 130000 & 206041 \\ 70000 & 130000 & 227214\end{array}$

\begin{tabular}{cc}
\multicolumn{1}{l}{$\mathrm{l} / \mathrm{lo} \mathrm{mi}$} \\
0,403344 & 0,908 \\
0,390973 & 0,939 \\
0,388791 & 0,945 \\
0,375972 & 0,978 \\
0,395509 & 0,928 \\
0,377224 & 0,975 \\
0,38967 & 0,942 \\
0,393229 & 0,933 \\
0,326232 & 1,120 \\
0,381634 & 0,963 \\
0,389302 & 0,943 \\
0,350426 & 1,049 \\
0,386994 & 0,949 \\
0,347691 & 1,056 \\
0,334173 & 1,096 \\
0,368513 & 0,998
\end{tabular}

$\begin{array}{rr}\text { desvio } & \text { mcorrigido } \\ 0,002 & 0,226991 \\ 0,002 & 0,234779 \\ 0,002 & 0,236178 \\ 0,002 & 0,24456 \\ 0,002 & 0,231895 \\ 0,002 & 0,243729 \\ 0,002 & 0,235614 \\ 0,002 & 0,233341 \\ 0,002 & 0,280036 \\ 0,002 & 0,240823 \\ 0,002 & 0,23585 \\ 0,002 & 0,262152 \\ 0,002 & 0,237336 \\ 0,002 & 0,26411 \\ 0,002 & 0,274024 \\ 0,002 & 0,24957 \\ & 0,23908\end{array}$

Tabela 108 - Concreto 10, corpo de prova número AM 53.

\begin{tabular}{|c|c|}
\hline Data & Hora \\
\hline $06 / 12 / 2013$ & $\quad 16: 24$ \\
\hline $06 / 12 / 2013$ & $16: 25$ \\
\hline $06 / 12 / 2013$ & $16: 27$ \\
\hline $06 / 12 / 2013$ & $16: 28$ \\
\hline $06 / 12 / 2013$ & $16: 28$ \\
\hline $06 / 12 / 2013$ & $16: 30$ \\
\hline $06 / 12 / 2013$ & $16: 32$ \\
\hline $06 / 12 / 2013$ & $16: 33$ \\
\hline $06 / 12 / 2013$ & $16: 34$ \\
\hline $06 / 12 / 2013$ & $16: 35$ \\
\hline $06 / 12 / 2013$ & $16: 36$ \\
\hline $06 / 12 / 2013$ & $16: 38$ \\
\hline $06 / 12 / 2013$ & $16: 38$ \\
\hline $06 / 12 / 2013$ & $16: 40$ \\
\hline $06 / 12 / 2013$ & $16: 41$ \\
\hline $06 / 12 / 2013$ & $16-43$ \\
\hline
\end{tabular}

$\begin{array}{rr}\text { PosX (um) } & \text { PosZ (um) } \\ 10000 & 100000 \\ 30000 & 100000 \\ 50000 & 100000 \\ 70000 & 100000 \\ 10000 & 110000 \\ 30000 & 110000 \\ 50000 & 110000 \\ 70000 & 110000 \\ 10000 & 120000 \\ 30000 & 120000 \\ 50000 & 120000 \\ 70000 & 120000 \\ 10000 & 130000 \\ 30000 & 130000 \\ 50000 & 130000 \\ 70000 & 130000\end{array}$

Contagem
325951
324332
322724
321567
219514
214889
215535
214254
186433
185584
209021
208661
186052
176469
183022
178780

$\begin{array}{cr}\text { desvio } & \text { mcorrigido } \\ 0,002 & 0,159356 \\ 0,002 & 0,160601 \\ 0,002 & 0,161844 \\ 0,002 & 0,162741 \\ 0,002 & 0,258189 \\ 0,002 & 0,263513 \\ 0,002 & 0,262762 \\ 0,002 & 0,264252 \\ 0,002 & 0,299025 \\ 0,002 & 0,300166 \\ 0,002 & 0,270434 \\ 0,002 & 0,270865 \\ 0,002 & 0,299536 \\ 0,002 & 0,312757 \\ 0,002 & 0,303641 \\ 0,002 & 0,309504 \\ & 0,284945\end{array}$




\section{ipen}

Tabela 109 - Concreto 11, corpo de prova número AM 60.

\begin{tabular}{|c|c|c|}
\hline \multirow[t]{2}{*}{ Data } & \multicolumn{2}{|c|}{ Hora } \\
\hline & $04 / 12 / 2013$ & $17: 32$ \\
\hline & $04 / 12 / 2013$ & $17: 33$ \\
\hline & $04 / 12 / 2013$ & $17: 34$ \\
\hline & $04 / 12 / 2013$ & $17: 35$ \\
\hline & $04 / 12 / 2013$ & $17: 37$ \\
\hline & $04 / 12 / 2013$ & $17: 38$ \\
\hline & $04 / 12 / 2013$ & $17: 39$ \\
\hline & $04 / 12 / 2013$ & $17: 40$ \\
\hline & $04 / 12 / 2013$ & $17: 42$ \\
\hline & $04 / 12 / 2013$ & $17: 43$ \\
\hline & $04 / 12 / 2013$ & $17: 44$ \\
\hline & $04 / 12 / 2013$ & $17: 45$ \\
\hline & $04 / 12 / 2013$ & $17: 47$ \\
\hline & $04 / 12 / 2013$ & $17: 48$ \\
\hline & $04 / 12 / 2013$ & $17: 49$ \\
\hline & $04 / 12 / 2013$ & $17: 50$ \\
\hline
\end{tabular}

$\begin{array}{rrr} & \text { io }= & 583962 \\ \text { PosX (um) } & \text { PosZ (um) } & \text { Contagem } \\ 10000 & 100000 & 214710 \\ 30000 & 100000 & 214950 \\ 50000 & 100000 & 213262 \\ 70000 & 100000 & 211290 \\ 10000 & 110000 & 218732 \\ 30000 & 110000 & 216094 \\ 50000 & 110000 & 217578 \\ 70000 & 110000 & 216528 \\ 10000 & 120000 & 215134 \\ 30000 & 120000 & 214238 \\ 50000 & 120000 & 217129 \\ 70000 & 120000 & 212186 \\ 10000 & 130000 & 205964 \\ 30000 & 130000 & 208462 \\ 50000 & 130000 & 211884 \\ 70000 & 130000 & 209725\end{array}$

\begin{tabular}{rr}
\multicolumn{1}{l}{ I/lo mi } \\
0,367678 & 1,001 \\
0,368089 & 0,999 \\
0,365198 & 1,007 \\
0,361821 & 1,017 \\
0,374565 & 0,982 \\
0,370048 & 0,994 \\
0,372589 & 0,987 \\
0,370791 & 0,992 \\
0,368404 & 0,999 \\
0,36687 & 1,003 \\
0,37182 & 0,989 \\
0,363356 & 1,012 \\
0,352701 & 1,042 \\
0,356979 & 1,030 \\
0,362839 & 1,014 \\
0,359142 & 1,024
\end{tabular}

mcorrigido

0,250137

$\begin{array}{lllll}14950 & 0,368089 & 0,999 & 0,002 & 0,249858\end{array}$

$0,002 \quad 0,25182$

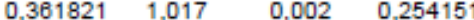

$\begin{array}{lllll}16528 & 0,370791 & 0,992 & 0,002 & 0,248028\end{array}$

$\begin{array}{llll}0,368404 & 0,999 & 0,002 & 0,249644\end{array}$

$0,002 \quad 0,250687$

$0,002 \quad 0,247336$

$0,002 \quad 0,253093$

$0,002 \quad 0,260534$

$0,002 \quad 0,257520$

20,253449

0,256010

0,250412

Tabela 110 - Concreto 12, corpo de prova número AM 66.

Data

\begin{tabular}{ll} 
& \multicolumn{2}{c}{ Hora } \\
$04 / 12 / 2013$ & $16: 41$ \\
$04 / 12 / 2013$ & $16: 42$ \\
$04 / 12 / 2013$ & $16: 43$ \\
$04 / 12 / 2013$ & $16: 44$ \\
$04 / 12 / 2013$ & $16: 46$ \\
$04 / 12 / 2013$ & $16: 47$ \\
$04 / 12 / 2013$ & $16: 48$ \\
$04 / 12 / 2013$ & $16: 49$ \\
$04 / 12 / 2013$ & $16: 51$ \\
$04 / 12 / 2013$ & $16: 52$ \\
$04 / 12 / 2013$ & $16: 53$ \\
$04 / 12 / 2013$ & $16: 54$ \\
$04 / 12 / 2013$ & $16: 56$ \\
$04 / 12 / 2013$ & $16: 57$ \\
$04 / 12 / 2013$ & $16: 58$ \\
$04 / 12 / 2013$ & $16: 59$
\end{tabular}

$10=$

$\begin{array}{rr}\text { PosX (um) } & \text { PosZ (um) } \\ 10000 & 100000 \\ 30000 & 100000 \\ 50000 & 100000 \\ 70000 & 100000 \\ 10000 & 110000 \\ 30000 & 110000 \\ 50000 & 110000 \\ 70000 & 110000 \\ 10000 & 120000 \\ 30000 & 120000 \\ 50000 & 120000 \\ 70000 & 120000 \\ 10000 & 130000 \\ 30000 & 130000 \\ 50000 & 130000 \\ 70000 & 130000\end{array}$

Contagem
234470
225139
227756
226708
221805
222530
216578
219344
213475
211227
211410
215275
216531
214865
215225
218765

\begin{tabular}{ll} 
I/lo & \multicolumn{2}{l}{$\mathrm{mi}$} \\
0,401516 & 0,913 \\
0,385537 & 0,953 \\
0,390019 & 0,942 \\
0,388224 & 0,946 \\
0,379828 & 0,968 \\
0,381069 & 0,965 \\
0,370877 & 0,992 \\
0,375613 & 0,979 \\
0,365563 & 1,006 \\
0,361714 & 1,017 \\
0,362027 & 1,016 \\
0,368646 & 0,998 \\
0,370796 & 0,992 \\
0,367943 & 1,000 \\
0,36856 & 0,998 \\
0,374622 & 0,982
\end{tabular}

$0,002 \quad 0,228127$

$0,002 \quad 0.238279$

$0,002 \quad 0,23539$

$0,002 \quad 0,236543$

$0,002 \quad 0.242009$

$0,002 \quad 0,241193$

$0,002 \quad 0,247971$

$0,002 \quad 0,244799$

$0,002 \quad 0,251579$

$0,002 \quad 0,254226$

$0,002 \quad 0,254009$

$0,002 \quad 0,249480$

$0,002 \quad 0,248026$

$0,002 \quad 0,249956$

$0,002 \quad 0,249538$

$0,002 \quad 0,245459$

Tabela 111 - Concreto 13, corpo de prova número AM 72.

Data

\begin{tabular}{lr} 
& \multicolumn{2}{c}{ Hora } \\
$04 / 12 / 2013$ & $19: 42$ \\
$04 / 12 / 2013$ & $19: 43$ \\
$04 / 12 / 2013$ & $19: 44$ \\
$04 / 12 / 2013$ & $19: 45$ \\
$04 / 12 / 2013$ & $19: 47$ \\
$04 / 12 / 2013$ & $19: 48$ \\
$04 / 12 / 2013$ & $19: 49$ \\
$04 / 12 / 2013$ & $19: 50$ \\
$04 / 12 / 2013$ & $19: 52$ \\
$04 / 12 / 2013$ & $19: 53$ \\
$04 / 12 / 2013$ & $19: 54$ \\
$04 / 12 / 2013$ & $19: 55$ \\
$04 / 12 / 2013$ & $19: 56$ \\
$04 / 12 / 2013$ & $19: 58$ \\
$04 / 12 / 2013$ & $19: 59$ \\
$04 / 12 / 2013$ & $20: 00$
\end{tabular}

PosX (um)
10000
30000
50000
70000
10000
30000
50000
70000
10000
30000
50000
70000
10000
30000
50000
70000

$10=$

PosZ (um)
100000
100000
100000
100000
110000
110000
110000
110000
120000
120000
120000
120000
130000
130000
130000
130000

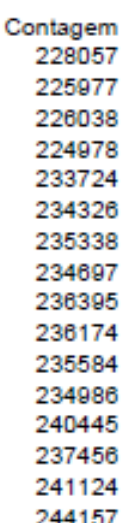

\begin{tabular}{cc} 
I/lo & \multicolumn{2}{l}{$\mathrm{mi}$} \\
0,390534 & 0,940 \\
0,386972 & 0,949 \\
0,387077 & 0,949 \\
0,385261 & 0,854 \\
0,400238 & 0,916 \\
0,401269 & 0,913 \\
0,403002 & 0,909 \\
0,401905 & 0,912 \\
0,404812 & 0,904 \\
0,404434 & 0,905 \\
0,403424 & 0,908 \\
0,402399 & 0,910 \\
0,411748 & 0,887 \\
0,406629 & 0,900 \\
0,41291 & 0,885 \\
0,418104 & 0,872
\end{tabular}

$\begin{array}{rr}\text { desvio } & \text { mcorrigido } \\ 0,002 & 0,235060 \\ 0,002 & 0,237351 \\ 0,002 & 0,237283 \\ 0,002 & 0,238458 \\ 0,002 & 0,228924 \\ 0,002 & 0,228281 \\ 0,002 & 0,227203 \\ 0,002 & 0,227885 \\ 0,002 & 0,226083 \\ 0,002 & 0,226317 \\ 0,002 & 0,226942 \\ 0,002 & 0,227577 \\ 0,002 & 0,221836 \\ 0,002 & 0,224963 \\ 0,002 & 0,221131 \\ 0,002 & 0,218006 \\ & 0,227300\end{array}$




\section{ipen}

Tabela 112 - Concreto 14, corpo de prova número AM 80.

Data

\begin{tabular}{ll} 
& \multicolumn{2}{c}{ Hora } \\
$04 / 12 / 2013$ & $15: 43$ \\
$04 / 12 / 2013$ & $15: 45$ \\
$04 / 12 / 2013$ & $15: 47$ \\
$04 / 12 / 2013$ & $15: 49$ \\
$04 / 12 / 2013$ & $15: 51$ \\
$04 / 12 / 2013$ & $15: 53$ \\
$04 / 12 / 2013$ & $15: 54$ \\
$04 / 12 / 2013$ & $15: 56$ \\
$04 / 12 / 2013$ & $15: 58$ \\
$04 / 12 / 2013$ & $16: 00$ \\
$04 / 12 / 2013$ & $16: 02$ \\
$04 / 12 / 2013$ & $16: 04$ \\
$04 / 12 / 2013$ & $16: 06$ \\
$04 / 12 / 2013$ & $16: 07$ \\
$04 / 12 / 2013$ & $16: 09$ \\
$04 / 12 / 2013$ & $16: 11$ \\
$04 / 12 / 2013$ & $16: 13$ \\
$04 / 12 / 2013$ & $16: 15$ \\
$04 / 12 / 2013$ & $16: 17$ \\
$04 / 12 / 2013$ & $16: 19$
\end{tabular}

$0=$

Pos X (um)
10000
25000
40000
55000
70000
10000
25000
40000
55000
70000
10000
25000
40000
55000
70000
10000
25000
40000
55000
70000

939347

PosZ (um)
100000
100000
100000
100000
100000
110000
110000
110000
110000
110000
120000
120000
120000
120000
120000
130000
130000
130000
130000
130000

\begin{tabular}{llrr} 
I/lo & \multicolumn{1}{l}{ mi } & desvio & mcorrigido \\
0,418267 & 0,872 & 0,002 & 0,217909 \\
0,410087 & 0,891 & 0,002 & 0,222846 \\
0,407211 & 0,898 & 0,002 & 0,224606 \\
0,394424 & 0,930 & 0,002 & 0,232582 \\
0,396472 & 0,925 & 0,002 & 0,231287 \\
0,388042 & 0,947 & 0,002 & 0,236680 \\
0,389348 & 0,943 & 0,002 & 0,235820 \\
0,389301 & 0,943 & 0,002 & 0,235850 \\
0,389774 & 0,942 & 0,002 & 0,235547 \\
0,394243 & 0,931 & 0,002 & 0,232697 \\
0,393171 & 0,934 & 0,002 & 0,233378 \\
0,408425 & 0,895 & 0,002 & 0,223862 \\
0,406721 & 0,900 & 0,002 & 0,224907 \\
0,410376 & 0,891 & 0,002 & 0,222671 \\
0,406639 & 0,900 & 0,002 & 0,224957 \\
0,406047 & 0,901 & 0,002 & 0,225322 \\
0,401677 & 0,912 & 0,002 & 0,228027 \\
0,390427 & 0,941 & 0,002 & 0,235129 \\
0,390929 & 0,939 & 0,002 & 0,234807 \\
0,394104 & 0,931 & 0,002 & 0,232785 \\
& & & 0,231935
\end{tabular}

Tabela 113 - Concreto 15, corpo de prova número AM 84

$10=$

PosX (um)
10000
30000
50000
70000
10000
30000
50000
70000
10000
30000
50000
70000
10000
30000
50000
70000

Contagem
256366
238436
236208
241845
237063
234041
243025
246610
248593
244544
243523
248621
246894
241415
243223
239062

\begin{tabular}{ll} 
I/lo & \multicolumn{2}{l}{$\mathrm{mi}$} \\
0,439011 & 0,823 \\
0,408307 & 0,896 \\
0,404492 & 0,905 \\
0,414145 & 0,882 \\
0,405956 & 0,902 \\
0,400781 & 0,914 \\
0,416168 & 0,877 \\
0,422305 & 0,862 \\
0,425701 & 0,854 \\
0,418767 & 0,870 \\
0,417019 & 0,875 \\
0,425749 & 0,854 \\
0,422791 & 0,861 \\
0,413409 & 0,883 \\
0,416505 & 0,876 \\
0,409379 & 0,893
\end{tabular}

$\begin{array}{cr}\text { desvio } & \text { mcorrigido } \\ 0,002 & 0,205807 \\ 0,002 & 0,223934 \\ 0,002 & 0,226281 \\ 0,002 & 0,220385 \\ 0,002 & 0,225377 \\ 0,002 & 0,228585 \\ 0,002 & 0,219168 \\ 0,002 & 0,215507 \\ 0,002 & 0,213505 \\ 0,002 & 0,217610 \\ 0,002 & 0,218656 \\ 0,002 & 0,213477 \\ 0,002 & 0,215219 \\ 0,002 & 0,220830 \\ 0,002 & 0,218964 \\ 0,002 & 0,223278 \\ & 0,219066\end{array}$

Tabela 114 - Concreto 16, corpo de prova número AM 90.

\begin{tabular}{|c|c|c|}
\hline Data & & \\
\hline & $04 / 12 / 2013$ & $18: 27$ \\
\hline & $04 / 12 / 2013$ & $18: 28$ \\
\hline & $04 / 12 / 2013$ & $18: 30$ \\
\hline & $04 / 12 / 2013$ & $18: 31$ \\
\hline & $04 / 12 / 2013$ & $18: 32$ \\
\hline & $04 / 12 / 2013$ & $18: 33$ \\
\hline & $04 / 12 / 2013$ & $18: 34$ \\
\hline & $04 / 12 / 2013$ & $18: 36$ \\
\hline & $04 / 12 / 2013$ & $18: 37$ \\
\hline & $04 / 12 / 2013$ & $18: 38$ \\
\hline & $04 / 12 / 2013$ & $18: 39$ \\
\hline & $04 / 12 / 2013$ & $18: 41$ \\
\hline & $04 / 12 / 2013$ & $18: 42$ \\
\hline & $04 / 12 / 2013$ & $18: 43$ \\
\hline & $04 / 12 / 2013$ & $18: 44$ \\
\hline & $04 / 12 / 2013$ & $18-45$ \\
\hline
\end{tabular}

$\begin{array}{rrr} & \text { lo }= & 583962 \\ \text { PosX (um) } & \text { Pos } Z \text { (um) } & \text { Contagem } \\ 10000 & 100000 & 217438 \\ 30000 & 100000 & 215253 \\ 50000 & 100000 & 211605 \\ 70000 & 100000 & 212473 \\ 10000 & 110000 & 224517 \\ 30000 & 110000 & 217395 \\ 50000 & 110000 & 216301 \\ 70000 & 110000 & 217556 \\ 10000 & 120000 & 212742 \\ 30000 & 120000 & 222154 \\ 50000 & 120000 & 218652 \\ 70000 & 120000 & 217971 \\ 10000 & 130000 & 224513 \\ 30000 & 130000 & 227223 \\ 50000 & 130000 & 226227 \\ 70000 & 130000 & 223648\end{array}$

\begin{tabular}{rrr}
\multicolumn{1}{l}{ l/lo mi } & desvio \\
0,37235 & 0,988 & 0,002 \\
0,368608 & 0,998 & 0,002 \\
0,362361 & 1,015 & 0,002 \\
0,363847 & 1,011 & 0,002 \\
0,384472 & 0,956 & 0,002 \\
0,372276 & 0,988 & 0,002 \\
0,370403 & 0,993 & 0,002 \\
0,372552 & 0,987 & 0,002 \\
0,364308 & 1,010 & 0,002 \\
0,380425 & 0,966 & 0,002 \\
0,374428 & 0,982 & 0,002 \\
0,373262 & 0,985 & 0,002 \\
0,384465 & 0,956 & 0,002 \\
0,389106 & 0,944 & 0,002 \\
0,3874 & 0,948 & 0,002 \\
0,382984 & 0,960 & 0,002
\end{tabular}

corrigido 0,246981 0,249505 0,253779 0.252755 0,238971 0,24703 0,248291 0,246845 0,252439 0,241616 0,245589 0,246368 0,238976 0,235976 0.237074 0,239941 0,239941
0,246607 


\section{ipen}

Tabela 115 - Concreto 17, corpo de prova número AM 96.

\begin{tabular}{|c|c|}
\hline \multicolumn{2}{|c|}{ Hora } \\
\hline $04 / 12 / 2013$ & $18: 54$ \\
\hline $04 / 12 / 2013$ & $18: 55$ \\
\hline $04 / 12 / 2013$ & $18: 57$ \\
\hline $04 / 12 / 2013$ & 18:58 \\
\hline $04 / 12 / 2013$ & $18: 50$ \\
\hline $04 / 12 / 2013$ & $19: 00$ \\
\hline $04 / 12 / 2013$ & $19: 01$ \\
\hline $04 / 12 / 2013$ & $19: 03$ \\
\hline $04 / 12 / 2013$ & $19: 04$ \\
\hline $04 / 12 / 2013$ & $19: 05$ \\
\hline $04 / 12 / 2013$ & $19: 06$ \\
\hline $04 / 12 / 2013$ & $19: 08$ \\
\hline $04 / 12 / 2013$ & $19: 09$ \\
\hline $04 / 12 / 2013$ & $19: 10$ \\
\hline
\end{tabular}

$10=\quad 583962$

$\begin{array}{rr}\text { PosX (um) } & \text { PosZ (um) } \\ 50000 & 100000 \\ 70000 & 100000 \\ 10000 & 110000 \\ 30000 & 110000 \\ 50000 & 110000 \\ 70000 & 110000 \\ 10000 & 120000 \\ 30000 & 120000 \\ 50000 & 120000 \\ 70000 & 120000 \\ 10000 & 130000 \\ 30000 & 130000 \\ 50000 & 130000 \\ 70000 & 130000\end{array}$

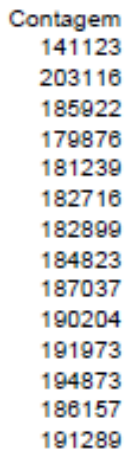

\begin{tabular}{rr}
\multicolumn{1}{l}{ I/lo mi } \\
0,241685 & 1,420 \\
0,347824 & 1,056 \\
0,31838 & 1,145 \\
0,308027 & 1,178 \\
0,310361 & 1,170 \\
0,31289 & 1,162 \\
0,313204 & 1,161 \\
0,316498 & 1,150 \\
0,32029 & 1,139 \\
0,325713 & 1,122 \\
0,328742 & 1,112 \\
0,333708 & 1,097 \\
0,318783 & 1,143 \\
0,327571 & 1,116
\end{tabular}
desvio micorrigido $0,003 \quad 0,355051$ $0,002 \quad 0,264015$ $0,002 \quad 0,286127$ $0,002 \quad 0,294392$ $0,002 \quad 0,292505$ $0,002 \quad 0,290476$ $0,002 \quad 0,290225$ $0,002 \quad 0,287609$ $0,002 \quad 0,284632$ $0,002 \quad 0,280435$ $0,002 \quad 0,278120$ $0,002 \quad 0,274372$ $0,002 \quad 0,285811$ $0,002 \quad 0,279013$ 0,285969

Tabela 116 - Concreto 18, corpo de prova número AM 102.

Data

$\begin{array}{ll}{ }^{2} \text { Hora } \\ 04 / 12 / 2013 & 17: 07 \\ 04 / 12 / 2013 & 17: 08 \\ 04 / 12 / 2013 & 17: 09 \\ 04 / 12 / 2013 & 17: 10 \\ 04 / 12 / 2013 & 17: 12 \\ 04 / 12 / 2013 & 17: 13 \\ 04 / 12 / 2013 & 17: 14 \\ 04 / 12 / 2013 & 17: 15 \\ 04 / 12 / 2013 & 17: 17 \\ 04 / 12 / 2013 & 17: 18 \\ 04 / 12 / 2013 & 17: 19 \\ 04 / 12 / 2013 & 17: 20 \\ 04 / 12 / 2013 & 17: 22 \\ 04 / 12 / 2013 & 17: 23 \\ 04 / 12 / 2013 & 17: 24 \\ 04 / 12 / 2013 & 17: 25\end{array}$
$10=$

PosX (um)
10000
30000
50000
70000
10000
30000
50000
70000
10000
30000
50000
70000
10000
30000
50000
70000

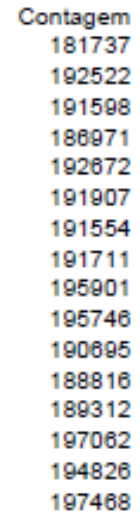

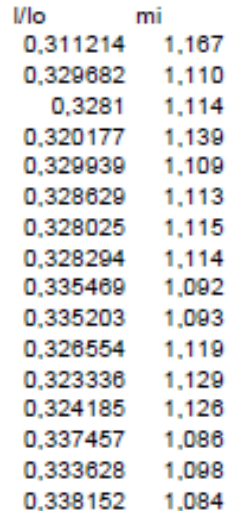

desvio 0,002 0,002 0,002 0,002 0,002 0,002 0,002 0,002
0,002 0,002 0,002 0,002 0,002

0,002

0,002

0,002

0,002 mcorrigido
0,291819
0,277406
0,278609
0,284721
0,277212
0,278206
0,278667
0,278462
0,273057
0,273255
0,27979
0,282266
0,28161
0,271579
0,274432
0,271065
0,278334

Tabela 117 - Concreto 19, corpo de prova número AM 107.

\begin{tabular}{|c|c|c|}
\hline \multirow[t]{2}{*}{ Data } & \multicolumn{2}{|c|}{ Hora } \\
\hline & $04 / 12 / 2013$ & $19: 20$ \\
\hline & $04 / 12 / 2013$ & $19: 21$ \\
\hline & $04 / 12 / 2013$ & $19: 22$ \\
\hline & $04 / 12 / 2013$ & $19: 23$ \\
\hline & $04 / 12 / 2013$ & $19: 25$ \\
\hline & $04 / 12 / 2013$ & $19: 26$ \\
\hline & $04 / 12 / 2013$ & $19: 27$ \\
\hline & $04 / 12 / 2013$ & $19: 28$ \\
\hline & $04 / 12 / 2013$ & $19: 30$ \\
\hline & $04 / 12 / 2013$ & $19: 31$ \\
\hline & $04 / 12 / 2013$ & $19: 32$ \\
\hline & $04 / 12 / 2013$ & $19: 33$ \\
\hline
\end{tabular}

$\begin{array}{rr}\text { PosX (um) } & \text { PosZ (um) } \\ 10000 & 110000 \\ 30000 & 110000 \\ 50000 & 110000 \\ 70000 & 110000 \\ 10000 & 120000 \\ 30000 & 120000 \\ 50000 & 120000 \\ 70000 & 120000 \\ 10000 & 130000 \\ 30000 & 130000 \\ 50000 & 130000 \\ 70000 & 130000\end{array}$

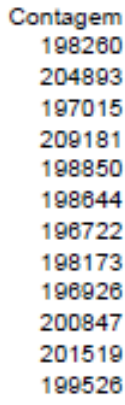

desvio 0,002 0,002

0,002

0,002 0,002

0,002

0,002

0,002

0,002

0,002

0,002

0,002 mcorrigido 0,270064 0,261837 0,271639 0,256659 0,269321

0,269580

0,272011

0,270174

0.271752

0,266823

0,265988

0,268473 


\section{ipen}

Tabela 118 - Concreto 20, corpo de prova número AM 114

\begin{tabular}{|c|c|c|}
\hline Data & & \\
\hline & $04 / 12 / 2013$ & $15: 43$ \\
\hline & $04 / 12 / 2013$ & $15: 45$ \\
\hline & $04 / 12 / 2013$ & $15: 47$ \\
\hline & $04 / 12 / 2013$ & $15: 49$ \\
\hline & $04 / 12 / 2013$ & $15: 51$ \\
\hline & $04 / 12 / 2013$ & $15: 53$ \\
\hline & $04 / 12 / 2013$ & $15: 54$ \\
\hline & $04 / 12 / 2013$ & $15: 56$ \\
\hline & $04 / 12 / 2013$ & $15: 58$ \\
\hline & $04 / 12 / 2013$ & $16: 00$ \\
\hline & $04 / 12 / 2013$ & $16: 02$ \\
\hline & $04 / 12 / 2013$ & $16: 04$ \\
\hline & $04 / 12 / 2013$ & $16: 06$ \\
\hline & $04 / 12 / 2013$ & $16: 07$ \\
\hline & $04 / 12 / 2013$ & $16: 09$ \\
\hline & $04 / 12 / 2013$ & $16: 11$ \\
\hline & $04 / 12 / 2013$ & $16: 13$ \\
\hline & $04 / 12 / 2013$ & $16: 15$ \\
\hline & $04 / 12 / 2013$ & $16: 17$ \\
\hline & $04 / 12 / 2013$ & $16: 19$ \\
\hline
\end{tabular}

$10=$

$\begin{array}{rr}\text { PosX (um) } & \text { PosZ (um) } \\ 10000 & 100000 \\ 25000 & 100000 \\ 40000 & 100000 \\ 55000 & 100000 \\ 70000 & 100000 \\ 10000 & 110000 \\ 25000 & 110000 \\ 40000 & 110000 \\ 55000 & 110000 \\ 70000 & 110000 \\ 10000 & 120000 \\ 25000 & 120000 \\ 40000 & 120000 \\ 55000 & 120000 \\ 70000 & 120000 \\ 10000 & 130000 \\ 25000 & 130000 \\ 40000 & 130000 \\ 55000 & 130000 \\ 70000 & 130000\end{array}$

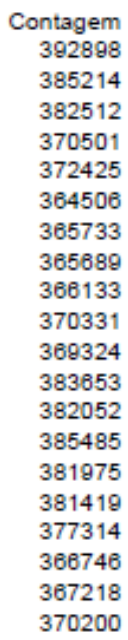

$\begin{array}{cr}\text { desvio } & \text { mcorrgido } \\ 0,002 & 0,217909 \\ 0,002 & 0,222846 \\ 0,002 & 0,224606 \\ 0,002 & 0,232582 \\ 0,002 & 0,231287 \\ 0,002 & 0,23666 \\ 0,002 & 0,23582 \\ 0,002 & 0,23585 \\ 0,002 & 0,235547 \\ 0,002 & 0,232697 \\ 0,002 & 0,233378 \\ 0,002 & 0,223862 \\ 0,002 & 0,224907 \\ 0,002 & 0,222671 \\ 0,002 & 0,224957 \\ 0,002 & 0,225322 \\ 0,002 & 0,228027 \\ 0,002 & 0,235129 \\ 0,002 & 0,234807 \\ 0,002 & 0,232785 \\ & 0,231935\end{array}$

Tabela 119 - Concreto 21, corpo de prova número AM 119.

\begin{tabular}{|c|c|c|}
\hline Data & & \\
\hline & $05 / 12 / 2013$ & $16: 19$ \\
\hline & $05 / 12 / 2013$ & $16: 20$ \\
\hline & $05 / 12 / 2013$ & $16: 21$ \\
\hline & $05 / 12 / 2013$ & $16: 23$ \\
\hline & $05 / 12 / 2013$ & $16: 24$ \\
\hline & $05 / 12 / 2013$ & $16: 25$ \\
\hline & $05 / 12 / 2013$ & $16: 26$ \\
\hline & $05 / 12 / 2013$ & $16: 27$ \\
\hline & $05 / 12 / 2013$ & $16: 29$ \\
\hline & $05 / 12 / 2013$ & $16: 30$ \\
\hline & $05 / 12 / 2013$ & $16: 31$ \\
\hline & $05 / 12 / 2013$ & $16: 32$ \\
\hline & $05 / 12 / 2013$ & $16: 34$ \\
\hline & $05 / 12 / 2013$ & $16: 35$ \\
\hline & $05 / 12 / 2013$ & $16: 36$ \\
\hline & $05 / 12 / 2013$ & $16: 37$ \\
\hline
\end{tabular}

$10=\quad 585223$

$\begin{array}{rr}\text { PosX (um) } & \text { PosZ (um) } \\ 10000 & 100000 \\ 30000 & 100000 \\ 50000 & 100000 \\ 70000 & 100000 \\ 10000 & 110000 \\ 30000 & 110000 \\ 50000 & 110000 \\ 70000 & 110000 \\ 10000 & 120000 \\ 30000 & 120000 \\ 50000 & 120000 \\ 70000 & 120000 \\ 10000 & 130000 \\ 30000 & 130000 \\ 50000 & 130000 \\ 70000 & 130000\end{array}$

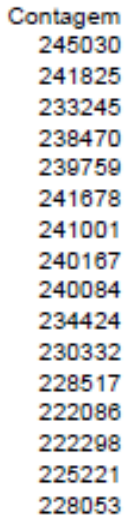

1/1o

\begin{tabular}{rrrr}
\multicolumn{1}{l}{ I/lo } & \multicolumn{1}{l}{ mi } & desvio & mcorrigido \\
0,418695 & 0,871 & 0,002 & 0,217653 \\
0,413219 & 0,884 & 0,002 & 0,220945 \\
0,398557 & 0,920 & 0,002 & 0,229976 \\
0,407486 & 0,898 & 0,002 & 0,224437 \\
0,409688 & 0,892 & 0,002 & 0,22309 \\
0,412967 & 0,884 & 0,002 & 0,221097 \\
0,411811 & 0,887 & 0,002 & 0,221798 \\
0,410385 & 0,891 & 0,002 & 0,222665 \\
0,410244 & 0,891 & 0,002 & 0,222751 \\
0,400572 & 0,915 & 0,002 & 0,228715 \\
0,39358 & 0,932 & 0,002 & 0,233118 \\
0,390479 & 0,940 & 0,002 & 0,235096 \\
0,37949 & 0,969 & 0,002 & 0,242232 \\
0,379852 & 0,968 & 0,002 & 0,241994 \\
0,384846 & 0,955 & 0,002 & 0,238728 \\
0,389686 & 0,942 & 0,002 & 0,235604 \\
& & & 0,226576
\end{tabular}

Tabela 120 - Concreto 22, corpo de prova número AM 125.

\begin{tabular}{|c|c|c|}
\hline \multirow[t]{2}{*}{ Data } & \multicolumn{2}{|c|}{ Hora } \\
\hline & $05 / 12 / 2013$ & $17: 06$ \\
\hline & $05 / 12 / 2013$ & 17:07 \\
\hline & $05 / 12 / 2013$ & $17: 08$ \\
\hline & $05 / 12 / 2013$ & $17: 09$ \\
\hline & $05 / 12 / 2013$ & $17: 10$ \\
\hline & $05 / 12 / 2013$ & $17: 12$ \\
\hline & $05 / 12 / 2013$ & $17: 13$ \\
\hline & $05 / 12 / 2013$ & $17: 14$ \\
\hline & $05 / 12 / 2013$ & $17: 15$ \\
\hline & $05 / 12 / 2013$ & $17: 17$ \\
\hline & $05 / 12 / 2013$ & $17: 18$ \\
\hline & $05 / 12 / 2013$ & $17: 19$ \\
\hline & $05 / 12 / 2013$ & $17: 20$ \\
\hline & $05 / 12 / 2013$ & $17: 21$ \\
\hline & $05 / 12 / 2013$ & $17: 23$ \\
\hline & $05 / 12 / 2013$ & $17: 24$ \\
\hline
\end{tabular}

$10=$

PosX (um)
10000
30000
50000
70000
10000
30000
50000
70000
10000
30000
50000
70000
10000
30000
50000
70000

585223

PosZ (um)
100000
100000
100000
100000
110000
110000
110000
110000
120000
120000
120000
120000
130000
130000
130000
130000

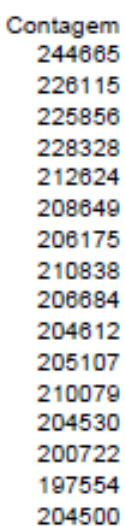

\begin{tabular}{rr}
\multicolumn{1}{l}{ I/lo } \\
0,418071 & 0,872 \\
0,386374 & 0,851 \\
0,385932 & 0,852 \\
0,390156 & 0,941 \\
0,363321 & 1,012 \\
0,356529 & 1,031 \\
0,352302 & 1,043 \\
0,36027 & 1,021 \\
0,353171 & 1,041 \\
0,349631 & 1,051 \\
0,350477 & 1,048 \\
0,358973 & 1,025 \\
0,349491 & 1,051 \\
0,342984 & 1,070 \\
0,33757 & 1,086 \\
0,349439 & 1,051
\end{tabular}

desvio
0,002
0,002
0,002
0,002
0,002
0,002
0,002
0,002
0,002
0,002
0,002
0,002
0,002
0,002
0,002
0,002

micorrigido

0,218026

0.237737

0,238024

0,235302

0,253117

0,257835

0,260817

0,255226

0,260200

0,262719

0,262115

0,256127

0,262820

0,267518

0,271495

0.262850

0,259018 
A seguir, na tabela (121), apresentamos o resumo dos coeficientes de atenuação linear dos concretos ensaiados, cujas medições e contagens foram mostradas anteriormnte.

Tabela 121 - Dados dos ensaios para determinação dos coeficientes de atenuação linear dos concretos.

\begin{tabular}{|c|c|c|}
\hline $\begin{array}{l}\text { Coeficientes de atenuação experimentais, médias } \\
\text { das medidas realizadas para as amostra }\left(\mathrm{cm}^{-1}\right)\end{array}$ & $\begin{array}{l}\text { Concreto } \\
\text { número }\end{array}$ & $\begin{array}{l}\text { Massa específica } \\
\left(\mathrm{kg} / \mathrm{dm}^{3}\right)\end{array}$ \\
\hline 0,2751 & 1 & 3,72 \\
\hline 0,2551 & 2 & 3,44 \\
\hline 0,2685 & 3 & 3,70 \\
\hline 0,2560 & 4 & 3,47 \\
\hline 0,2137 & 5 & 3,14 \\
\hline 0,2346 & 6 & 3,59 \\
\hline 0,2807 & 7 & 3,76 \\
\hline 0,2153 & 8 & 3,27 \\
\hline 0,2391 & 9 & 3,49 \\
\hline 0,2849 & 10 & 3,72 \\
\hline 0,2504 & 11 & 3,30 \\
\hline 0,2467 & 12 & 3,19 \\
\hline 0,2274 & 13 & 2,87 \\
\hline 0,2319 & 14 & 3,23 \\
\hline 0,2191 & 15 & 2,74 \\
\hline 0,2466 & 16 & 3,14 \\
\hline 0,2860 & 17 & 3,69 \\
\hline 0,2783 & 18 & 3,53 \\
\hline 0,2695 & 19 & 3,53 \\
\hline 0,2319 & 20 & 3,15 \\
\hline 0,2266 & 21 & 3,17 \\
\hline 0,2590 & 22 & 3,58 \\
\hline
\end{tabular}




\subsection{Determinação do $Z$ efetivo similar.}

A determinação do $Z$ efetivo similar foi feita através da comparação entre 0 coeficiente de atenuação linear mássico obtido para o concreto à energia de 660 keV e a seção de choque do elemento que apresentasse o valor mais próximo.

$\mathrm{Na}$ tabela (122) são apresentadas as seções de choque dos elementos químicos interpoladas para a energia de $660 \mathrm{keV}$.

Tabela 122 - Seção de choque dos elementos químicos para as energias de 600, 800, 660 $(\mathrm{KeV})$.

\begin{tabular}{|c|c|c|c|c|}
\hline & & $600 \mathrm{keV}$ & $800 \mathrm{keV}$ & $660 \mathrm{keV}$ \\
\hline Elemento químico & $\begin{array}{l}\text { Número } \\
\text { Atômico do } \\
\text { elemento } \\
\text { químico }\end{array}$ & $\begin{array}{c}\text { Seção de choque } \\
\mathrm{m} / \mathrm{r}\end{array}$ & $\begin{array}{c}\text { Seção de } \\
\text { choque m/r }\end{array}$ & $\begin{array}{c}\text { Seção de choque } \\
\mathrm{m} / \mathbf{r}\end{array}$ \\
\hline $\mathrm{H}$ & 1,0000 & 0,1599 & 0,1405 & 0,154080 \\
\hline $\mathrm{C}$ & 6,0000 & 0,0806 & 0,0708 & 0,077634 \\
\hline 0 & 8,0000 & 0,0807 & 0,0709 & 0,077751 \\
\hline $\mathrm{Na}$ & 11,0000 & 0,0774 & 0,0679 & 0,074516 \\
\hline $\mathrm{Mg}$ & 12,0000 & 0,0799 & 0,0701 & 0,076940 \\
\hline $\mathrm{Al}$ & 13,0000 & 0,0780 & 0,0684 & 0,075137 \\
\hline $\mathrm{Si}$ & 14,0000 & 0,0808 & 0,0708 & 0,077785 \\
\hline $\mathrm{P}$ & 15,0000 & 0,0785 & 0,0688 & 0,075630 \\
\hline $\mathrm{S}$ & 16,0000 & 0,0810 & 0,0790 & 0,080408 \\
\hline $\mathrm{Cl}$ & 17,0000 & 0,0780 & 0,0683 & 0,075043 \\
\hline $\mathrm{K}$ & 19,0000 & 0,0792 & 0,0693 & 0,076241 \\
\hline $\mathrm{Ca}$ & 20,0000 & 0,0815 & 0,0712 & 0,078400 \\
\hline $\mathrm{Ti}$ & 22,0000 & 0,0753 & 0,0657 & 0,072419 \\
\hline $\mathrm{V}$ & 23,0000 & 0,0741 & 0,0647 & 0,071300 \\
\hline $\mathrm{Cr}$ & 24,0000 & 0,0760 & 0,0662 & 0,073046 \\
\hline $\mathrm{Mn}$ & 25,0000 & 0,0751 & 0,0654 & 0,072174 \\
\hline $\mathrm{Fe}$ & 26,0000 & 0,0770 & 0,0670 & 0,074025 \\
\hline Co & 27,0000 & 0,0760 & 0,0660 & 0,073040 \\
\hline $\mathrm{Ni}$ & 28,0000 & 0,0794 & 0,0689 & 0,076281 \\
\hline $\mathrm{Cu}$ & 29,0000 & 0,0763 & 0,0661 & 0,073190 \\
\hline $\mathrm{Zn}$ & 30,0000 & 0,0770 & 0,0666 & 0,073833 \\
\hline $\mathrm{Sr}$ & 38,0000 & 0,0757 & 0,0645 & 0,072331 \\
\hline $\mathrm{Zr}$ & 40,0000 & 0,0776 & 0,0657 & 0,074005 \\
\hline $\mathrm{Nb}$ & 41,0000 & 0,0786 & 0,0664 & 0,074932 \\
\hline $\mathrm{Ba}$ & 56,0000 & 0,0841 & 0,0674 & 0,079100 \\
\hline
\end{tabular}


A tabela (123) apresenta os coeficientes de atenuação linear dos concretos, a massa específica, o coeficiente mássico, o número atômico do concreto e o elemento similar.

Tabela 123 - Coeficiente de atenuação linear experimental e elemento similar

\begin{tabular}{|c|c|c|c|c|c|}
\hline $\begin{array}{c}\text { Concreto } \\
\text { número }\end{array}$ & $\begin{array}{c}\text { Coeficiente de } \\
\text { atenuação linear } \\
\text { experimental } \\
660 \mathrm{keV}\left(\mathrm{cm}^{-1}\right)\end{array}$ & $\begin{array}{c}\text { Massa } \\
\text { específica } \\
\left(\mathrm{kg} / \mathrm{dm}^{3}\right)\end{array}$ & $\begin{array}{c}\text { Coeficiente } \\
\text { mássico de } \\
\text { atenuação } \mathrm{m} / \mathrm{r} \\
\left(\mathrm{cm}^{-2} / \mathrm{g}\right)\end{array}$ & $\begin{array}{c}\mathrm{Z} \\
\text { do } \\
\text { concreto } \\
\text { calculado }\end{array}$ & $\begin{array}{c}\text { Elemento } \\
\text { químico similar }\end{array}$ \\
\hline 1 & 0,2751 & 3,7200 & 0,0740 & 23,6453 & $\mathrm{Zr}$ \\
\hline 2 & 0,2551 & 3,4400 & 0,0742 & 22,7101 & $\mathrm{Fe}$ \\
\hline 3 & 0,2685 & 3,8000 & 0,0726 & 22,6728 & $\mathrm{Ti}$ \\
\hline 4 & 0,2560 & 3,4700 & 0,0738 & 23,4280 & $\mathrm{Zn}$ \\
\hline 5 & 0,2137 & 3,1400 & 0,0681 & 23,2868 & $\mathrm{~V}$ \\
\hline 6 & 0,2346 & 3,5900 & 0,0653 & 23,1456 & $\mathrm{~V}$ \\
\hline 7 & 0,2807 & 3,7600 & 0,0747 & 22,6285 & $\mathrm{Na}$ \\
\hline 8 & 0,2153 & 3,2700 & 0,0658 & 22,8287 & $\mathrm{~V}$ \\
\hline 9 & 0,2391 & 3,4900 & 0,0685 & 22,4914 & $\mathrm{~V}$ \\
\hline 10 & 0,2849 & 3,7200 & 0,0766 & 23,3631 & $\mathrm{~K}$ \\
\hline 11 & 0,2504 & 3,3000 & 0,0759 & 23,3069 & $\mathrm{P}$ \\
\hline 12 & 0,2467 & 3,1900 & 0,0773 & 22,7292 & $\mathrm{Mg}$ \\
\hline 13 & 0,2274 & 2,8700 & 0,0792 & 22,7305 & $\mathrm{Ba}$ \\
\hline 14 & 0,2280 & 3,2300 & 0,0706 & 22,2018 & $\mathrm{~V}$ \\
\hline 15 & 0,2191 & 2,7400 & 0,0800 & 22,7772 & $\mathrm{~S}$ \\
\hline 16 & 0,2466 & 3,1400 & 0,0785 & 22,2759 & $\mathrm{Ca}$ \\
\hline 17 & 0,2860 & 3,6900 & 0,0775 & 22,6728 & $\mathrm{Mg}$ \\
\hline 18 & 0,2783 & 3,5300 & 0,0788 & 22,1896 & $\mathrm{Ca}$ \\
\hline 19 & 0,2695 & 3,5300 & 0,0763 & 22,4083 & $\mathrm{Ni}$ \\
\hline 20 & 0,2280 & 3,1500 & 0,0724 & 25,0587 & $\mathrm{Ti}$ \\
\hline 21 & 0,2266 & 3,1700 & 0,0715 & 25,4256 & $\mathrm{~V}$ \\
\hline
\end{tabular}

\subsection{Principais elementos presentes nos concretos ensaiados.}

$\mathrm{Na}$ tabela (124) apresentamos os principais elementos que compõem os concretos preparados.

As análises são apresentadas sem os elementos leves $\mathrm{H}, \mathrm{O}$. Os resultados foram normalizados para a somatória dos elementos presentes. 
Tabela 124 - Composição química dos elementos encontrados nos concretos ensaiados, normalizados para elementos presentes.

\begin{tabular}{|c|c|c|c|c|c|c|c|c|c|c|c|c|}
\hline Elemento & $\mathrm{Mg}$ & Al & $\mathrm{Si}$ & $\mathbf{P}$ & $S$ & K & $\mathrm{Ca}$ & $\mathrm{Ti}$ & $M n$ & $\mathrm{Fe}$ & $\mathrm{Ba}$ & Somatória \\
\hline & 12 & 13 & 14 & 15 & 16 & 19 & 20 & 22 & 25 & 26 & 56 & \\
\hline Com1 & 2,29 & 3,02 & 7,71 & 0,06 & 0,59 & 0,40 & 14,56 & 0,16 & 0,15 & 71,04 & & $99,98 \%$ \\
\hline Com2 & 4,10 & 3,22 & 7,69 & 0,34 & 1,25 & 0,74 & 26,55 & 1,05 & 0,23 & 54,49 & & $99,66 \%$ \\
\hline Com3 & 2,95 & 3,87 & 7,65 & 0,07 & 0,80 & 0,72 & 22,49 & 0,17 & 0,16 & 60,99 & & $99,87 \%$ \\
\hline Com4 & 2,42 & 2,88 & 6,78 & 0,09 & 0,75 & 0,46 & 15,15 & 0,38 & 0,15 & 70,85 & & $99,91 \%$ \\
\hline Com5 & 1,64 & 2,82 & 6,73 & 0,07 & 0,70 & 0,54 & 19,45 & 0,17 & 0,33 & 67,33 & & $99,78 \%$ \\
\hline Com6 & 2,08 & 3,53 & 8,33 & 0,05 & 0,68 & 0,55 & 16,42 & 0,15 & 0,26 & 67,85 & & $99,90 \%$ \\
\hline Com7 & 2,45 & 3,56 & 8,13 & 0,06 & 0,88 & 0,74 & 23,38 & 0,15 & 0,18 & 60,33 & & $99,86 \%$ \\
\hline Com8 & 2,08 & 4,03 & 6,49 & 0,07 & 0,79 & 0,66 & 23,74 & 0,18 & 0,22 & 61,46 & & $99,72 \%$ \\
\hline Com9 & 3,13 & 3,12 & 8,02 & 0,12 & 1,18 & 0,80 & 25,63 & 0,63 & 0,54 & 56,65 & & $99,82 \%$ \\
\hline Com10 & 2,63 & 3,58 & 7,34 & 0,12 & 0,83 & 0,58 & 18,19 & 0,33 & 0,17 & 66,10 & & $99,87 \%$ \\
\hline Com11 & 2,32 & 2,98 & 7,66 & 0,04 & 0,71 & 0,44 & 15,60 & 0,13 & 0,18 & 69,88 & & $99,94 \%$ \\
\hline Com12 & 2,73 & 3,06 & 7,48 & 0,09 & 0,95 & 0,54 & 17,41 & 0,49 & 0,26 & 66,81 & & $99,82 \%$ \\
\hline Com13 & 1,81 & 2,42 & 6,16 & 0,07 & 0,65 & 0,52 & 16,73 & 0,15 & 0,25 & 70,96 & & $99,72 \%$ \\
\hline Com14 & 4,41 & 2,99 & 7,59 & 0,05 & 1,62 & 0,73 & 26,13 & 1,38 & 0,42 & 54,06 & & $99,38 \%$ \\
\hline Com15 & 2,65 & 2,30 & 5,98 & 0,24 & 1,12 & 0,72 & 24,54 & 1,04 & 0,35 & 60,64 & & $99,58 \%$ \\
\hline Com16 & 4,28 & 2,73 & 6,82 & 0,42 & 1,57 & 0,75 & 26,15 & 2,03 & 0,57 & 53,90 & & $99,22 \%$ \\
\hline Com17 & 2,64 & 3,29 & 7,99 & 0,05 & 0,96 & 0,69 & 23,57 & 0,21 & 0,16 & 60,36 & & $99,92 \%$ \\
\hline Com18 & 2,63 & 3,27 & 7,99 & 0,06 & 1,01 & 0,89 & 31,17 & 0,24 & 0,29 & 52,22 & & $99,77 \%$ \\
\hline Com19 & 3,47 & 3,15 & 7,75 & 0,15 & 1,30 & 0,79 & 25,66 & 1,03 & 0,38 & 56,04 & & $99,72 \%$ \\
\hline Com20 & 2,29 & 2,93 & 7,49 & 0,25 & 2,13 & 0,48 & 16,56 & 0,18 & 0,22 & 59,94 & 6,75 & $99,22 \%$ \\
\hline Com21 & 3,75 & 2,90 & 7,56 & 0,67 & 3,12 & 0,72 & 26,75 & 1,54 & 0,39 & 41,25 & 11,08 & $99,73 \%$ \\
\hline Com22 & 2,90 & 3,40 & 9,03 & 0,38 & 3,54 & 0,84 & 28,87 & 0,27 & 0,25 & 36,91 & 13,21 & $99,60 \%$ \\
\hline
\end{tabular}

Observando a tabela acima podemos verificar que todos os concretos apresentaram elevado teor de óxido de ferro, elemento responsável pela elevada densidade e imprescindível para o preparo de concretos de elevada densidade.

É possível que sejam produzidos outras matérias primas naturais com elevada densidade porém não conseguimos identificar.

Massa específicas mais elevadas podem ser obtidas com a utilização de agregados com granulometrias mais graúdas porém podem dificultar o preparo e a aplicação devido a dimensão máxima da matéria prima.

Não fez parte do presente estudo a utilização de agregados artificiais, preparados com o corte de barras de aço em equenas dimensões pelo fato de serem extremamente caros.

\subsection{Montagem do banco de dados.}

Os dados resultantes dos ensaios realizados de acordo com a metodologia empregada são apresentados no Anexo II do presente trabalho.

Os dados mostrados são para um tipo de concreto, o banco de dados final será desenvolvido para ser disponibilizado em um arquivo aberto de fácil acesso

pela internet. 


\section{if \\ CAPITULO 5}

\section{DISCUSSÃO DOS RESULTADOS ENCONTRADOS}

5.1 Massa específica.

$\mathrm{Na}$ tabela (125) apresentamos os resultados das massas específicas encontradas, que variaram de $2,74 \mathrm{~kg} / \mathrm{dm}^{3}$ até $3,76 \mathrm{~kg} / \mathrm{dm}^{3}$, variação esta igual a $37,2 \%$.

As massas específicas encontradas nos concretos preparados são similares às encontradas em trabalhos internacionais, quando utilizados agregados naturais de massa específica elevada para o preparo dos concretos. Na tabela (129), apresentada no item 5.5, podem ser verificados os dados encontrados em trabalhos publicados.

Tabela - 125 - Massas específicas dos concretos ensaiados.

\begin{tabular}{|c|c|}
\hline Concreto número & Massa específica $\left(\mathrm{kg} / \mathrm{dm}^{3}\right)$ \\
\hline 15 & 2,74 \\
\hline 13 & 2,87 \\
\hline 5 & 3,14 \\
\hline 16 & 3,14 \\
\hline 20 & 3,15 \\
\hline 21 & 3,17 \\
\hline 12 & 3,19 \\
\hline 8 & 3,23 \\
\hline 11 & 3,27 \\
\hline 2 & 3,30 \\
\hline 4 & 3,44 \\
\hline 9 & 3,47 \\
\hline 18 & 3,49 \\
\hline 19 & 3,53 \\
\hline 22 & 3,53 \\
\hline 6 & 3,58 \\
\hline 17 & 3,59 \\
\hline 3 & 3,69 \\
\hline 1 & 3,70 \\
\hline 10 & 3,72 \\
\hline 7 & 3,72 \\
\hline Média & 3,76 \\
\hline Devio & 3,46 \\
\hline Maximo & 0,28 \\
\hline Minimo & 3,74 \\
\hline & 3,17 \\
\hline
\end{tabular}


Determinamos também a massa específica média de nossas vinte e duas amostras e seu desvio padrão, cujo valor encontrado é $0,28 \mathrm{~kg} / \mathrm{dm}^{3}$, tornando a variação da massa média $=3,46 \pm 0,28 \mathrm{~kg} / \mathrm{dm}^{3}$.

A partir desses valores, verificamos quais concretos se encontram dentro do intervalo. Dezesseis se encontram dentro do intervalo, cinco se apresentam abaixo e um acima, sendo:

Traços cujas massas específicas se encontram abaixo do intervalo;

Concretos de número 5, 13, 15, 16, 20.

Traços cujas massas específicas se encontram dentro do intervalo;

Concretos de números 1, 2, 3, 4, 6, 8, 9, 10, 11, 12, 14, 17, 18, 19, 21, 22.

Traço cuja massa específica se encontra acima do intervalo;

Concretos de número 7.

\subsection{Coeficiente de atenuação linear experimental.}

A seguir, apresentamos a tabela (126), com os dados encontrados para os coeficientes de atenuação linear experimentais. Observamos que os concretos que apresentam os maiores coeficientes de atenuação linear são os concretos identificados com os números 17,10 e 7, que são justamente alguns dos concretos que apresentaram as mais elevadas massas específicas, coincidindo com os conceitos básicos em que a seção de choque para o efeito Compton depende primordialmente da massa específica do composto.

Determinamos o coeficiente de atenuação linear médio das vinte e duas amostras, sendo o valor encontrado $0,2486 \mathrm{~cm}^{-1}$ e o desvio padrão $0,0232 \mathrm{~cm}^{-1}$.

A partir desses valores, verificamos quais concretos se encontram dentro do intervalo. Encontramos quatorze traços que se encontram dentro dos valores, três que se apresentam abaixo e cinco que estão acima, sendo:

Traços cujas massas específicas se encontram abaixo do intervalo; 
Concretos de número 5, 8, 15.

Traços cujas massas específicas se encontram dentro do intervalo;

Concretos de número 2, 3, 4, 6, 9, 11, 12, 13, 14, 16, 19, 20, 21, 22.

Traços cuja massa específica se encontra acima do intervalo;

Concretos de número 1, 7, 10, 17, 18.

Tabela 126 - Coeficientes de atenuação linear e densidades dos concretos ensaiados

\begin{tabular}{|c|c|}
\hline Concreto & Coeficientes de atenuação linear experimental $\mu\left(\mathrm{cm}^{-1}\right)$ \\
\hline 5 & 0,2137 \\
\hline 8 & 0,2153 \\
\hline 15 & 0,2191 \\
\hline 13 & 0,2267 \\
\hline 14 & 0,2274 \\
\hline 20 & 0,2319 \\
\hline 6 & 0,2319 \\
\hline 9 & 0,2346 \\
\hline 16 & 0,2391 \\
\hline 12 & 0,2466 \\
\hline 11 & 0,2467 \\
\hline 2 & 0,2504 \\
\hline 4 & 0,2551 \\
\hline 22 & 0,2560 \\
\hline 3 & 0,2590 \\
\hline 19 & 0,2685 \\
\hline 1 & 0,2695 \\
\hline 18 & 0,2751 \\
\hline 7 & 0,2783 \\
\hline 10 & 0,2807 \\
\hline 17 & 0,2849 \\
\hline Média & 0,2860 \\
\hline Maximo & 0,2486 \\
\hline Minimo & 0,0232 \\
\hline & 0,2718 \\
\hline 10 & 0,2253 \\
\hline
\end{tabular}

Os coeficientes de atenuação linear experimental variam de $0,2137 \mathrm{~cm}^{-1}$ para o concreto número 5 até $0,2860 \mathrm{~cm}^{-1}$ para o concreto número 17 , variação esta que fez com que o valor aumentasse em 33,8\%, enquanto a massa específica aumentou em $37,2 \%$. 


\subsection{Coeficientes de atenuação linear calculados, comparados com os} coeficientes de atenuação linear experimentais.

$\mathrm{Na}$ tabela (127) é apresentado o comparativo entre os coeficientes de atenuação linear calculados e os coeficientes de atenuação linear experimentais; as diferenças encontradas são mostradas na última coluna da tabela.

Tabela 127 - Comparativo entre coeficientes.

\begin{tabular}{|c|c|c|c|}
\hline Concreto & $\begin{array}{l}\text { Coeficientes de atenuação linear } \\
\text { calculados para } 660 \mathrm{keV}\left(\mathrm{cm}^{1}\right)\end{array}$ & $\begin{array}{l}\text { Coeficientes de atenuação } \\
\text { linear experimental } \mu\left(\mathrm{cm}^{-1}\right)\end{array}$ & $\begin{array}{c}\text { Diferença } \\
\text { percentual (\%) }\end{array}$ \\
\hline 1 & 0,2821 & 0,2751 & $2,54 \%$ \\
\hline 2 & 0,2675 & 0,2551 & $4,86 \%$ \\
\hline 3 & 0,2791 & 0,2685 & $3,95 \%$ \\
\hline 4 & 0,2599 & 0,2560 & $1,52 \%$ \\
\hline 5 & 0,2359 & 0,2137 & $10,39 \%$ \\
\hline 6 & 0,2697 & 0,2346 & $14,96 \%$ \\
\hline 7 & 0,2833 & 0,2807 & $0,93 \%$ \\
\hline 8 & 0,2465 & 0,2153 & $14,49 \%$ \\
\hline 9 & 0,2637 & 0,2391 & $10,29 \%$ \\
\hline 10 & 0,2831 & 0,2849 & $-0,63 \%$ \\
\hline 11 & 0,2472 & 0,2504 & $-1,28 \%$ \\
\hline 12 & 0,235 & 0,2467 & $-4,74 \%$ \\
\hline 13 & 0,2017 & 0,2274 & $-11,30 \%$ \\
\hline 14 & 0,2429 & 0,2319 & $4,74 \%$ \\
\hline 15 & 0,2039 & 0,2191 & $-6,94 \%$ \\
\hline 16 & 0,236 & 0,2466 & $-4,30 \%$ \\
\hline 17 & 0,2781 & 0,2860 & $-2,76 \%$ \\
\hline 18 & 0,2675 & 0,2783 & $-3,88 \%$ \\
\hline 19 & 0,2661 & 0,2695 & $-1,26 \%$ \\
\hline 20 & 0,2352 & 0,2319 & $1,42 \%$ \\
\hline 21 & 0,2378 & 0,2267 & $4,90 \%$ \\
\hline 22 & 0,2689 & 0,2590 & $3,82 \%$ \\
\hline
\end{tabular}

Os valores percentuais que representam as diferenças encontradas entre os coeficientes de atenuação linear experimentais e os calculados têm uma aproximação razoável. A utilização do cálculo do coeficiente de atenuação linear com a utilização da análise química do concreto pode servir de parâmetro orientativo quando da avaliação prévia de como se comportará quando submetido ao fluxo de radiação, sem a necessidade de se fazer testes de irradiação com fontes radioativas ou equipamentos de raios- $X$. 


\section{ipen}

As variações são justificadas pelo fato de que, no concreto, os arranjos estruturais entre as partículas das matérias-primas e os vazios deixados pela evaporação da água são diferentes daquelas dos elementos químicos, o que faz com que os coeficientes de atenuação linear sejam próximos, mas não idênticos.

Alguns tipos de concretos foram preparados com teores de materiais finos elevados, o que gera um consumo de água elevado devido à superfície específica do agregado, o que faz com que o volume de vazios ou a porosidade aumente e, consequentemente, diminua o coeficiente de atenuação linear.

\subsection{Custos de produção.}

Os custos de produção dos concretos preparados foram calculados com base nos preços dos agregados, aglomerantes, aditivo e cimento, praticados para a cidade de São Paulo no primeiro mês do ano de 2014. Não foram considerados os custos de preparo e lançamento, pois são característicos de cada tipo de aplicação ou serviço.

$\mathrm{Na}$ tabela (128), apresentada a seguir, apresentamos os custos do metro cúbico encontrados para os concretos avaliados.

Classificando os resultados encontrados, três concretos ficaram abaixo do intervalo, concretos estes de números 14, 15, 16.

Treze concretos ficaram dentro do intervalo, concretos estes de números 1 , 2, 4, 5, 6, 9, 11, 12, 13, 17, 19, 20, 21.

Seis concretos ficaram acima dos valores máximos, cujos números são 3,7 , 8, 10, 18, 22. 
Tabela 128 - Custos de produção dos concretos preparados.

\begin{tabular}{|c|c|}
\hline Concreto & $\begin{array}{c}\text { Custo do concreto } \\
\text { Preço de origem São Paulo - SP }\left(\mathrm{R} \$ / \mathrm{m}^{3}\right)\end{array}$ \\
\hline 16 & $\mathrm{R} \$ 1.375,97$ \\
\hline 14 & $\mathrm{R} \$ 1.528,41$ \\
\hline 15 & $\mathrm{R} \$ 1.545,16$ \\
\hline 12 & $\mathrm{R} \$ 1.586,34$ \\
\hline 1 & $\mathrm{R} \$ 1.666,72$ \\
\hline 4 & $\mathrm{R} \$ 1.710,40$ \\
\hline 21 & $\mathrm{R} \$ 1.731,46$ \\
\hline 2 & $\mathrm{R} \$ 1.734,00$ \\
\hline 20 & $\mathrm{R} \$ 1.735,31$ \\
\hline 19 & $\mathrm{R} \$ 1.737,62$ \\
\hline 13 & $\mathrm{R} \$ 1.768,29$ \\
\hline 9 & $\mathrm{R} \$ 1.770,40$ \\
\hline 11 & $\mathrm{R} \$ 1.841,59$ \\
\hline 6 & $\mathrm{R} \$ 1.859,03$ \\
\hline 5 & $\mathrm{R} \$ 1.925,98$ \\
\hline 17 & $\mathrm{R} \$ 1.939,40$ \\
\hline 22 & $\mathrm{R} \$ 1.960,54$ \\
\hline 8 & $\mathrm{R} \$ 1.964,53$ \\
\hline 10 & $\mathrm{R} \$ 2.013,98$ \\
\hline 18 & $\mathrm{R} \$ 2.020,07$ \\
\hline 3 & $\mathrm{R} \$ 2.027,65$ \\
\hline 7 & $\mathrm{R} \$ 2.049,21$ \\
\hline Média & $\mathrm{R} 1.769,35$ \\
\hline Desvio & $\mathrm{R} \$ 183,87$ \\
\hline Mínimo & $\mathrm{R} 1.585,48$ \\
\hline Máximo & $\mathrm{R} \$ 1.953,21$ \\
\hline
\end{tabular}

\subsection{Resultados de outros trabalhos.}

A seguir, apresentamos a tabela (129), os dados encontrados no presente trabalho em comparação com dados de trabalhos internacionais.

Como podemos verificar na tabela apresentada a seguir, os valores obtidos para os coeficientes de atenuação linear, encontrados experimentalmente na tese variam em até $19,05 \%$ comparando-se os resultados, o que confirma que concretos com mesma densidade podem ter comportamento diferente para o coeficiente de atenuação linear quando utilizados para a blindagem das radiações gama e $X$ na energia de $660 \mathrm{keV}$, região predominante do efeito Compton, governada pela densidade e pelo número atômico. 
Tabela 129 - Massa específica e coeficiente de atenuação linear encontrados em outros trabalhos publicados.

\begin{tabular}{|c|c|c|c|c|}
\hline \multirow{2}{*}{ Origem dos dados } & \multirow{2}{*}{$\begin{array}{c}\text { Massa } \\
\text { específica } \\
\left(\mathrm{kg} / \mathrm{dm}^{3}\right)\end{array}$} & \multirow{2}{*}{$\begin{array}{c}\text { Coeficiente de atenuação linear } \\
\left(\mathrm{cm}^{-1}\right)\end{array}$} & \multicolumn{2}{|c|}{ Diferença \% } \\
\hline & & & Massa & $\mu$ \\
\hline Tese - Com 1 & 3,74 & 0,2751 & $-0,53 \%$ & $-5,82 \%$ \\
\hline $\begin{array}{l}\text { Engenering Compendium on } \\
\text { Radiation Shielding }-1-2 a\end{array}$ & 3,76 & 0,2911 & & \\
\hline Tese - Com 2 & 3,44 & 0,2551 & $0,00 \%$ & $-3,96 \%$ \\
\hline $\begin{array}{l}\text { Engenering Compendium on } \\
\text { Radiation Shielding - INRU e }\end{array}$ & 3,44 & 0,2652 & & \\
\hline Tese - Com 3 & 3,7 & 0,2685 & $1,08 \%$ & $-4,92 \%$ \\
\hline $\begin{array}{l}\text { Engenering Compendium on } \\
\text { Radiation Shielding }-1-2 b\end{array}$ & 3,66 & 0,2817 & & \\
\hline Tese - Com 4 & 3,46 & 0,256 & $-1,16 \%$ & $-10,94 \%$ \\
\hline $\begin{array}{l}\text { Engenering Compendium on } \\
\text { Radiation Shielding - BA - a }\end{array}$ & 3,5 & 0,284 & & \\
\hline Tese - Com 5 & 3,15 & 0,2137 & $-3,81 \%$ & $-19,05 \%$ \\
\hline $\begin{array}{l}\text { Engenering Compendium on } \\
\text { Radiation Shielding - M-HW2 }\end{array}$ & 3,27 & 0,2544 & & \\
\hline Tese - Com 6 & 3,59 & 0,2346 & $-0,84 \%$ & $-14,07 \%$ \\
\hline $\begin{array}{l}\text { Engenering Compendium on } \\
\text { Radiation Shielding - M- c }\end{array}$ & 3,62 & 0,2676 & & \\
\hline Tese - Com 7 & 3,59 & 0,2807 & $-4,74 \%$ & $-3,71 \%$ \\
\hline $\begin{array}{l}\text { Engenering Compendium on } \\
\text { Radiation Shielding }-1-2 a\end{array}$ & 3,76 & 0,2911 & & \\
\hline Tese - Com 8 & 3,27 & 0,2153 & $0,00 \%$ & $-18,16 \%$ \\
\hline $\begin{array}{l}\text { Engenering Compendium on } \\
\text { Radiation Shielding - H-MW2 }\end{array}$ & 3,27 & 0,2544 & & \\
\hline Tese - Com 9 & 3,49 & 0,2391 & $-0,29 \%$ & $-18,78 \%$ \\
\hline $\begin{array}{l}\text { Engenering Compendium on } \\
\text { Radiation Shielding }-\mathrm{Ba}-\mathrm{a}\end{array}$ & 3,5 & 0,284 & $0,00 \%$ & $2,25 \%$ \\
\hline Concreto 5 trabalho BASHTER & 3,5 & 0,2776 & & \\
\hline \multirow[t]{2}{*}{ Tese - Com 10} & 3,7 & 0,2849 & $1,08 \%$ & $1,12 \%$ \\
\hline & 3,66 & 0,2817 & & \\
\hline Tese - Com 11 & 3,3 & 0,2504 & & $-6,43 \%$ \\
\hline $\begin{array}{l}\text { Engenering Compendium on } \\
\text { Radiation Shielding - Ba - OR }\end{array}$ & 3,3 & 0,2665 & & \\
\hline Tese - Com 12 & 3,2 & 0,2467 & $-2,19 \%$ & $-3,12 \%$ \\
\hline $\begin{array}{l}\text { Engenering Compendium on } \\
\text { Radiation Shielding - } \mathrm{M}-\mathrm{HW} 2\end{array}$ & 3,27 & 0,2544 & & \\
\hline Tese - Com 13 & 2,9 & 0,2274 & & $-0,18 \%$ \\
\hline Concreto 3 trabalho BASHTER & 2,9 & 0,2278 & & \\
\hline
\end{tabular}




\begin{tabular}{|c|c|c|c|c|}
\hline Tese - Com 14 & 3,3 & 0,228 & $0,30 \%$ & $-12,37 \%$ \\
\hline $\begin{array}{l}\text { Engenering Compendium on } \\
\text { Radiation Shielding - M - HW } 1\end{array}$ & 3,29 & 0,2562 & & \\
\hline Tese - Com 15 & 2,8 & 0,2191 & & \\
\hline Tese - Com 16 & 3,2 & 0,2466 & $-2,19 \%$ & $-3,16 \%$ \\
\hline $\begin{array}{l}\text { Engenering Compendium on } \\
\text { Radiation Shielding }-\mathrm{M}-\mathrm{HW} 2\end{array}$ & 3,27 & 0,2544 & & \\
\hline Tese - Com 17 & 3,7 & 0,286 & $1,08 \%$ & $1,50 \%$ \\
\hline $\begin{array}{l}\text { Engenering Compendium on } \\
\text { Radiation Shielding }-1-2 b\end{array}$ & 3,66 & 0,2817 & & \\
\hline Tese - Com 18 & 3,5 & 0,2676 & $0,00 \%$ & $-2,13 \%$ \\
\hline $\begin{array}{l}\text { Engenering Compendium on } \\
\text { Radiation Shielding }-1-1 a\end{array}$ & 3,5 & 0,2733 & & \\
\hline Tese - Com 19 & 3,5 & 0,2661 & $0,00 \%$ & $-2,71 \%$ \\
\hline $\begin{array}{l}\text { Engenering Compendium on } \\
\text { Radiation Shielding }-1-1 a\end{array}$ & 3,5 & 0,2733 & & \\
\hline Tese - Com 20 & 3,2 & 0,2352 & & \\
\hline Tese - Com 21 & 3,2 & 0,2378 & & \\
\hline Tese - Com 22 & 3,6 & 0,2689 & $-0,56 \%$ & $0,48 \%$ \\
\hline $\begin{array}{l}\text { Engenering Compendium on } \\
\text { Radiation Shielding - Mc }\end{array}$ & 3,62 & 0,2676 & & \\
\hline
\end{tabular}


5.6 Discussões englobando a densidade, o coeficiente de atenuação linear e o custo do concreto.

Observando os valores que se encontram dentro dos limites tratados, massa específica, coeficiente de atenuação linear experimetal e custo de produção, achamos 8 concretos cujos números são: 12, 4, 21, 2, 19, 9, 11, 6 .

Portanto, o concreto de número 12 seria o de menor custo, seguido pelos concretos $4,21,2,19$ etc.

Esta solução, que pode ser afirmada por um incauto, está equivocada, pois o preço é um fator que deve ser avaliado pelo fator de redução na dose, e deve ser corrigido. Neste caso, corrigimos os preços dos concretos pelo comprimento de relaxação $\mu . x=1$ em que $x$ é a espessura da amostra.

Neste caso, partindo da amostra mais densa, determinou-se o acréscimo percentual no custo, relacionado ao livre caminho médio, ver tabela (130), montada para os concretos que se apresentam dentro dos limites calculados para a combinação, massa específica e coeficiente de atenuação linear em conjunto.

Tabela 130 - Custos dos concretos corrigidos

\begin{tabular}{|c|c|c|c|c|c|c|}
\hline Concreto & $\begin{array}{l}\text { Coeficiente de } \\
\text { atenuação } \\
\text { linear } \\
\text { experimental } \\
\mu\left(\mathrm{cm}^{-1}\right)\end{array}$ & $\begin{array}{l}\text { Cust } \\
\text { sóm } \\
\text { Preço }\end{array}$ & $\begin{array}{l}\text { concreto } \\
\text { e para os } \\
\text { eriais } \\
\text { rigem São } \\
o-\mathrm{SP} \\
\left./ \mathrm{m}^{3}\right)\end{array}$ & $1 / \mu$ & $\begin{array}{c}\text { Fator } \\
\text { de } \\
\text { Ponderação }\end{array}$ & $\begin{array}{c}\text { Preço Corrigido } \\
\left(\mathrm{R} \$ / \mathrm{m}^{3}\right)\end{array}$ \\
\hline 12 & 0,2467 & $\mathrm{R} \$$ & $1.586,34$ & 4,0535 & 1,159 & $\mathrm{R} \$ 1.838,57$ \\
\hline 19 & 0,2695 & $\mathrm{R} \$$ & $1.737,62$ & 3,7106 & 1,061 & $\mathrm{R} \$ 1.843,61$ \\
\hline 4 & 0,256 & $\mathrm{R} \$$ & $1.710,40$ & 3,9063 & 1,117 & $R \$ 1.910,52$ \\
\hline 2 & 0,2551 & $\mathrm{R} \$$ & $1.734,00$ & 3,9200 & 1,121 & $R \$ 1.943,81$ \\
\hline 11 & 0,2504 & $\mathrm{R} \$$ & $1.841,59$ & 3,9936 & 1,142 & $R \$ 2.103,10$ \\
\hline 9 & 0,2391 & $\mathrm{R} \$$ & $1.770,40$ & 4,1824 & 1,196 & $R \$ 2.117,40$ \\
\hline 21 & 0,2266 & $\mathrm{R} \$$ & $1.731,46$ & 4,4131 & 1,262 & $R \$ 2.185,10$ \\
\hline 6 & 0,2346 & $\mathrm{R} \$$ & $1.859,03$ & 4,2626 & 1,219 & $R \$ 2.266,16$ \\
\hline
\end{tabular}

Fazendo uma análise dos resultados encontrados para os custos corrigidos, obtivemos como opção mais econômica o concreto número 12, seguido pelos concretos 19, 4, 2, 11, 9, 21 e 6 . 
O concreto que apresentou o menor preço corrigido é o concreto 12, cujo valor orçado é de $\mathrm{R} \$ 1.838,37 / \mathrm{m}^{3}$. Se não houver problemas com relação à restrição de espaço, será o concreto escolhido para a blindagem das radiações gama e $X$ na energia de $660 \mathrm{keV}$, por apresentar o menor custo.

Isso não significa que as outras opções devam ser eliminadas, pois o cliente poderá necessitar, além das características atenuantes do concreto, outras como resistência à compressão, módulo de deformação elevado, dentre outras.

Essa discussão é válida de acordo com a curva do gráfico, apresentado na figura (38), quando as condições remetam à região do efeito Compton.

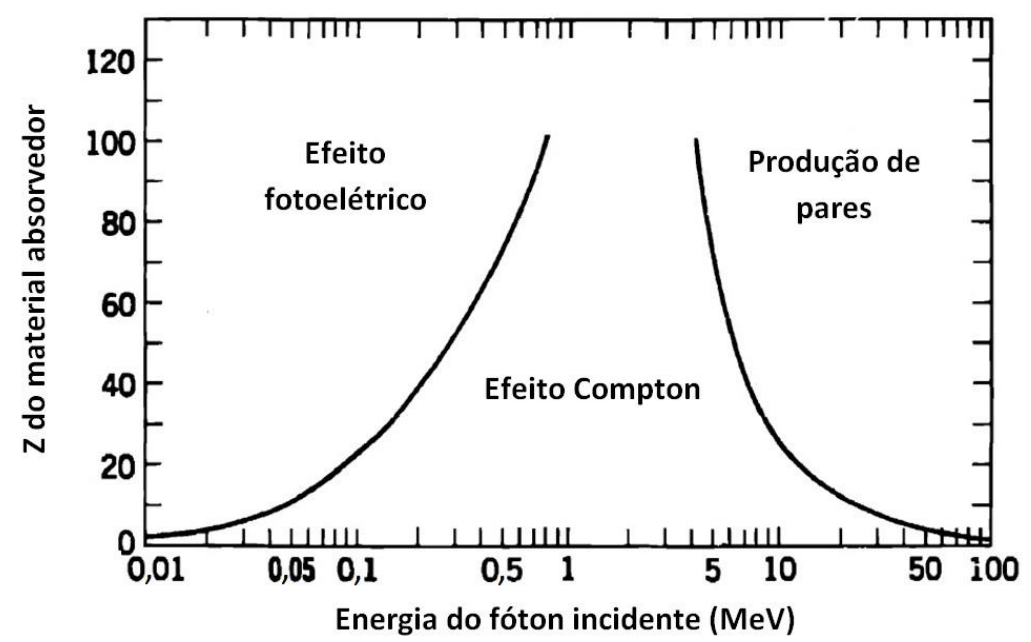

Fig. 36 - Importância relativa dos três principais tipos de interação para radiação $\gamma$ (2)

$\mathrm{Na}$ região do efeito fotoelétrico, devemos desconsiderar a densidade e o número atômico efetivo $Z$, pois, conforme já mencionado, a probabilidade de interação fotoelétrica depende de $Z^{4}$.

Calculado o valor médio e o desvio padrão encontramos o valor médio de

$Z^{4}=279.841 \pm 113.182,8$. Considerando os dados encontrados, classificamos 15 concretos dentro do intervalo para os quais calculamos os preços corrigidos, sendo só para os concretos que apresentaram os menores preços os de números 12, 1, 4, 3, 2, 14, 11, 7, 21, 9, 6, 5, 8, 20 e 22.

Utilizando o mesmo raciocínio aplicado para avaliar os concretos que se encontram dentro dos limites da média e desvio, encontramos o valor medio para $Z^{4}$ = 279.841士113.182 para a predominância do efeito fotoelétrico, podemos dizer que, 
não havendo problemas com o valor a ser pago, para a blindagem, o concreto mais indicado seria é o concreto de número 3 , seguido dos concretos de número 7, 11, 2, 4 e assim por diante, conforme apresentado na tabela (131).

Tabela 131 - Resumo de dados para avaliação dos concretos cuja interação predominante é o efeito fotoelétrico.

\begin{tabular}{|c|c|c|c|}
\hline Concreto número & Elemento químico similar & Z & $\mathrm{Z}^{4}$ \\
\hline 15 & $S$ & 16 & 65536 \\
\hline 10 & $\mathrm{~K}$ & 19 & 130321 \\
\hline 16 & $\mathrm{Ca}$ & 20 & 160000 \\
\hline 13 & $\mathrm{Ca}$ & 20 & 160000 \\
\hline 17 & $\mathrm{Ca}$ & 20 & 160000 \\
\hline 18 & $\mathrm{Ca}$ & 20 & 160000 \\
\hline 20 & $\mathrm{Ti}$ & 22 & 234256 \\
\hline 22 & $\mathrm{Ti}$ & 22 & 234256 \\
\hline 14 & v & 23 & 279841 \\
\hline 21 & $\mathrm{v}$ & 23 & 279841 \\
\hline 9 & v & 23 & 279841 \\
\hline 6 & $\mathrm{v}$ & 23 & 279841 \\
\hline 5 & v & 23 & 279841 \\
\hline 8 & $\mathrm{v}$ & 23 & 279841 \\
\hline 12 & $\mathrm{Cr}$ & 24 & 331776 \\
\hline 1 & $\mathrm{Cr}$ & 24 & 331776 \\
\hline 4 & $\mathrm{Cr}$ & 24 & 331776 \\
\hline 2 & $\mathrm{Cr}$ & 24 & 331776 \\
\hline 11 & $\mathrm{Al}$ & 24 & 331776 \\
\hline 7 & $\mathrm{Cr}$ & 24 & 331776 \\
\hline 3 & $\mathrm{Mn}$ & 25 & 390625 \\
\hline 19 & $\mathrm{Ni}$ & 28 & 614656 \\
\hline & & Media & 279841 \\
\hline & & desvio & 113182,8 \\
\hline & & Minimo & 166658,2 \\
\hline & & Maximo & 393023,8 \\
\hline
\end{tabular}

Da mesma maneira que descrito nas avaliações anteriores, os outros concretos não estão descartados, e a escolha dependerá de fatores locais e da aplicação. 


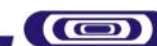 \\ ipen \\ CAPITULO 6}

\section{CONCLUSÕES.}

a) Conseguimos concluir todos objetivos e chegar a bom êxito com a finalidade proposta para este trabalho.

b) Caracterizamos vinte e dois tipos de concretos com a utilização de matérias-primas nacionais, obtivemos concretos com as mais diversas combinações e massas específicas que resultaram em diferentes coeficientes de atenuação lineares e mássicos.

c) Para os concretos preparados, o número atômico maior, encontrado dentro do intervalo, foi similar ao elemento químico manganês, cujo $Z$ é 25 . Na tabela 121 apresentamos os valores e os elementos que apresentam comportamento similar aos concretos preparados na energia de $660 \mathrm{keV}$.

d) Probabilidade de ocorrência do efeito fotoelétrico. Se elevarmos o número atômico do manganês $\mathrm{Mn}=25$, maior número atômico encontrado para os concretos preparados, à quarta potência, encontraremos o valor de 390.625. Valor este que, se dividirmos pelo valor do número atômico do argônio 18, válido para o concreto convencional elevado à quarta potência, encontraremos uma razão de 3,72 entre os valores, que é o aumento percentual da probabilidade de ocorrer o efeito fotoelétrico.

e) Probabilidade da ocorrência do efeito Compton. A razão entre a maior massa específica classificada e encontrada para os concretos preparados foi de $3,72 \mathrm{~kg} / \mathrm{dm}^{3}$. Considerando que a massa específica do concreto convencional é de aproximadamente $2,35 \mathrm{~kg} / \mathrm{dm}^{3}$, a razão entre as duas massas específicas nos fornece o aumento da probabilidade de ocorrência do efeito Compton de 58,29\% a mais.

f) Avaliando os dados obtidos para as seções de choque calculadas e experimentais para cada concreto preparado, observamos que a dispersão entre os resultados dos coeficientes de atenuação linear calculados e experimentais situamse, no máximo, em 15\%, resultado encontrado com aproximação razoável para ser 
utilizado quando se pretende avaliar o resultado esperado de um concreto, utilizando-se da composição química do concreto para prever seu comportamento.

g) A metodologia proposta é prática, e não apresenta dificuldades técnicas, utiliza ensaios que são normalmente aplicados pelos técnicos, a custos acessíveis.

h) Cria uma base de dados embrionária, que foi obtida com dados resultantes de ensaios realizados em concretos produzidos no Brasil, com matériasprimas nacionais.

i) Os dados resultantes são similares aos encontrados em trabalhos de pesquisas internacionais, que avaliaram concretos para blindagem na energia de $660 \mathrm{keV}$.

j) A utilização da análise química do concreto a ser avaliado, realizada excluindo os elementos leves, que facilita e barateia o ensaio, apresentou-se eficiente com relação aos resultados encontrados.

\section{Sugestões para futuros trabalhos.}

Concluído o presente trabalho, entendemos ser importante:

a) Desenvolver novos traços e ensaiá-los em outras energias.

b) Avaliar a diferença que os elementos leves promovem no cálculo do coeficiente de atenuação linear.

c) Identificar novas fontes fornecedoras de agregados naturais que possam ser utilizados na produção de concretos de massa específica elevada e repetir este trabalho com eles.

d) Acrescentar outros tipos de agregados, isto é, a utilização de agregados não naturais, como barras de aço, cortadas, limalhas granalhas de jato de aço reaproveitadas, dentre outros. 


\section{Referência}

(1) INSTITUTO NACIONAL DO CÂNCER. BLINDAGEM EM RADIOTERAPIA TÉCNICAS E NORMAS. Programa de Qualidade em Radioproteção. Instituto Nacional de Câncer, 2002.

(2) EVANS, R. D. THE ATOMIC NUCLEOS. Robrt E. Krieger Publishing Company, Inc. Malabar, Florida, 1985.

(3) MEHTA, P, K; MONTEIRO, P, J, M; "Concreto Microestrutura, Propriedades e Materiais", Instituto Brasileiro do Concreto, São Paulo, SP, 2008.

(4) ASSOCIAÇÃO BRASILEIRA DO CIMENTO PORTLAND, https://www.abcp.org.br , último acesso em dezembro de 2013.

(5) SILVA, M. G. " Cimento Portland com adições minerais" In: "Materiais de construção civil e princípios de enegenharia e ciência dos materiais". 1 edição, São Paulo, Geraldo Cechella Isaia IBRACON, 2007. V1, capítulo V. Paginas 761-795.

(6) ASSOCIAÇÃO BRASILEIRA DE NORMAS TÉCNICAS. ADITIVOSQUIMICOS PARA CONCRETO DE CIMENTO PORTLAND - REQUISITOS - NBR 11768. Rio de Janeiro, 2011.

(7) ASSOCIAÇÃO BRASILEIRA DE NORMAS TÉCNICAS. AGREGADOS TERMINOLOGIA- NBR 9935, 2011.

(8) ASSOCIAÇÃO BRASILEIRA DE NORMAS TÉCNICAS. AGREGADO PARA CONCRETO -ESPECIFICAÇÕES - NBR 7211. Rio de Janeiro, 2009.

(9) ASSOCIAÇÃO BRASILEIRA DE NORMAS TÉCNICAS. AGREGADOS ÁNALISE PETROGRÁFICA DE AGREGADOS PARA CONCRETO PARTE 1 E 2. NBR 7389. Rio de Janeiro, 2009.

(10) SBRIGH C. N. "Importancia dos conceitos tecnológicos na seleção dos agregados para argamassas e concretos". Revista Areia e Brita, São Paulo, SP, 2001, n 12, pg. 26-28.

(11) AMERICAN STANDARD TEST METHOD C 637-09. AGGREGATES FOR RADIATIONSHIELING.

(12) AMERICAN STANDARD TEST METHOD C 638-09. STANDRT DESCRIPTIVE NOMENCLATURE OF CONSTITUENTS OF AGGREGATES FOR RADIATION-SHIELDING CONCRETE.

(13) HELENE, P. L. TUTIKIAN B. F. "Dosagem dos concretos de cimento Portland" In: "Concreto: Ciencia e tecnologia". 1 edição, São Paulo, Geraldo Cechella Isaia IBRACON, 2011. V1, capítulo XII. Paginas.

(14) NATIONAL INSTITUTE OF STANDARDS AND TECHNOLY. Disponível em <http:www.nist.gov>. Acesso em: 20 de maio de 2013. 
(15) AITICIN, P. C. "Concreto de Alto Desempenho". Associação Brasileira de Cimento Portland, Editora Pini, São Paulo, 2000.

(16) BROWNELL, G. L. HINE, G. L. "Radiation Dosimetry". Academic Press Inc. New York, 1956.

(17) ATOMIC ENERGY COMMISSION REPORT - NYO-3075. "Calculations of the Gamma Rays". New York, 1954.

(18) ROCKWELL III, T. "Reactor Shielding Design Manual". D. Van Nostrand Company, Inc. Princeton, New Jersey, 1956.

(19) WESTINGHOUSE ELECTRIC CORPORATION ATOMIC POWER DEPARTMENT. WAPD -TN 217.

(20) C. ANDRELLO, ALBUQUERQUE, S. M. "Avaliação da influência da granulometria de agregados utilizados em micro concretos de massa específica elevada sobre o coeficiente de atenuação linear a radiação gama". In: Congresso Brasileiro do Concreto, IBRACON 50, Salvador Bahia, 2008, pg.272.

(21) A. FACURE, A. X. SILVA. "The use of high-density concretes in radiotherapy treatment room design". Science Direct, Applied radiation and isotopes, $n^{\circ} 65$, Elsevier, pg 1023-1028. 2007.

(22) A. N. KOMAROVSKII. "Evaluating the economic feasibility of using special heavy concretes for radiation shielding". The Soviet Journal of Atomic Energy, Russian, 1958.

(23) A.A.P. MANSUR, H. S. MANSUR. "Caracterização de materias primas utilizadas na produção de concreto celular". Anais, $17^{\circ}$ Congresso Brasileiro de Engenharia e Ciência dos Materiais. Foz do Iguaçu, Paraná, 2006.

(24) A.P. PROSHIN, V. S. DEMJANOVA, D. V. KALASHNICOV, O. V. GRINTSOVA, SUPER HEAVY "High-strength concrete for protection against radiation". Asian Journal of Civil Engeeniring, Building and housing, v 6, $n^{\circ}$ 1-2, pg 67-73. 2005.

(25) D. J. SIMPKIN. "Transmission data for shielding diagnostic x-ray facilities". Health Physics, v 68, n 5, pg 704-709. 1995.

(26) F. BOUZARJOMEHRI, T. BAYAT, M. H. DASHTI R, J. GHISARI, N. ABDOLI, F. BOUZARJOMEHRI, T. BAYAT, M. H. DASHTI R, J. GHISARI, N. ABDOLI. CO "Gama-ray attenuation coefficiente of barite concrete". Iran. J. Radiat. Res, v 4 n 2; 71-75. 2006.

(27) G. HOFF, S. F. FIRMINO, G. HOFF, S. F. FIRMINO. "Transmission curves to primary beams to diagnostic radiology, a comparison among barite concrete, barite mortar and concrete". Nuclear Science Symposium Conference Record. Honolulu, HI, 2007. 
(28) I. AKKURT, C. BASYIGIT, S. KILINCARSLAN, B. MAVI, A. AKKURT. "Radiation Shielding of concretes containing different aggregates". Science Direct, Elsevier, $n^{\circ} 28 ; p g$ 153-157. 2006.

(29) I. AKKURT, H. AKYILDIRIM, B. MAVI, S. KILINCARSLAN, C. BASYIGIT. "Radiation shieling of concrete containing zeolit”. Radiation Measurements. Elsevier, n 45, pg 827-830. 2010.

(30) I. C. P. SALINAS, C.C. CONTI, R.T. LOPES. "Effective density and mass attenuation coefficient for building material in Brazil”. Science Direct, Elsevier, n 64. pg 13-18. 2006.

(31) I. I. BASHTER. "Calculation of radiation attenuation coefficients for shielding concretes". Ann.Nucl.Energy,1997, v 24 n¹7, pg 1389-1401.

(32) I. I. BASHTER, A. EL-SAYED ABDO, M SAMIR ABDEL-AZIM. "Magnetite ores with steel or basalt for concrete radiation shielding". Japanese Journal of Applied Physics, v 36. 1997.

(33) I.I. BASHTER, A.S. MAKARIOUS, A.EL-SAYED ABDO. "Investigation of hematiteserpentine and IImenite-limonite concretes for reactor radiation shielding". Ann. Nucl. Energy, v. $23 n^{\circ}$ 1 pg. 65-71. 1996.

(34) K.H.LOKAN, N.K. SHERMAN, R.W. GELLIE, W.H. HENRY, R. LEVESQUE, A. NOWAK, G.G. TEATHER. "Bremsstrahlung attenuation measurements in ilmenite loaded concretes". Health Physics. Northern Ireland, v 23, pg. 193-199. 1972.

(35) K.R.KASE, W. R. NELSON, A. FASSO, J. C. LIU, X. MAO, T. M. JENKINS, J. H. KLECK. "Measurements of accelerator-produced leakage neutrons and photon transmission through concrete". Health Physics, v 84, n², pg 180-187. 2003.

(36) M. A. G. PeReirA, L. S. SeVero, S. M. Albuquerque, P. B. BILESKy, C. LOPES. "Produção de micro concreto de alta massa específica para blindagem contra radiação ionizante com a utilização de agregado miúdo de areia de magnetita". Anais Congresso Brasileiro do Concreto, IBRACON 50. Salvador, Bahia, 2008, pg 389.

(37) M. H. KAHARITA, M. TAKEYEDDIN, M. ALNASSAR, S. YOUSEF. "Development of special radiation shielding concretes using natural local materials and evaluation of their shielding characteristics". Science Direct. Elsevier, v 50 pg 33-36. 2008.

(38) P.SELTEBORG, A. POLANSKI, S. PETROCHENKOV, A.LOPATKIN, W. GUDOWSKI, V. SHVETSOV. "Radiation shielding of high-energy neutrons in SAD". Research and Development Institute of Power Engeneering. Nuclear Instruments and Methods in Physics Research Section A, v 550, pg. 313-328. 2005.

(39) R.J.BARISH. "Evaluation of a new high-density shielding material". Health Physics, v 64, pg 412-416. 1993.

(40) S.M.J MORTAZAVI, M.A. MOSLEH-SHIRAZI, M.BARADARAN-GHAHFAROKHI, Z. SIAVASHPOUR, A. FARSHADI, M. GHAFOORI, A.SHAHVAR. "Production of an economic high- 
density concrete for shielding megavoltage radiotherapy rooms and nuclear reactors". Iran. J. Radiat. Res, v 5; pg 143-146. 2007.

(41) S.M.J MORTAZAVI, M.A. MOSLEH-SHIRAZI, M.R. MAHERI, H. YOUSEFNIA, S. ZOLGHADRI, A. HAJI-POUR. "Production of an economic high-density concrete for shielding megavoltage radiotherapy rooms and nuclear reactors". Iran. J. Radiat. Res.;v 5 n 3; pg 143-146. 2007.

(42) T.MARUYAMA, Y.KUMAMOTO, Y.KATO, T.HASHIZUME. M. YAMAMOTO. "Attenuation of 4-32 MV X-Ray in ordinary concrete, heavy concrete, iron and lead". Health Physics, $v$ 10, pg. 277-284. 1971.

(43) V. I. PAVLENKO, R. N. YASTREBINSKII, D. V. VORONOV. "Investigation of heavy radiation-shielding concrete after activation by fast neutrons and gamma radiation". Journal of Engeneering Physics and Themophysics, v 81 n 4, pg 686-691. 2008.

(44) V. SOPKO, K. TRTÍK, F. VODÁK. "Influence of Gama irradiation on concrete strength". Acta polytecnica, v $44 \mathrm{n}^{\circ}$ 1, pg 57-58. 2004.

(45) YU-CHENG KAN, KUANG-CHIH PEI, CHIEN-LUNG CHANG. "Strength and fracture toughness of havy concrete with various iron aggregate". Elsevier, Nuclear Engineering and Design, $v$ 228, pg 119-127. 2004.

(46) S.PRISZKULNIK. "Concretos pesados na construção civil". Anais $52^{\circ}$ Congresso Brasileiro do Concreto IBRACON, pg 1-18, 2010.

(47) DANTAS, F. A. S. COSTA, M. M. TAKASHIMA, S. "Controle tecnológico do concreto pesado para blindagem do setor de radioterapia da Casa de Saúde Santa Marcelina". In Congresso Brasileiro do Concreto $40^{\circ}$, Instituto Brasileiro do Concreto, Rio de Janeiro 1988.

(48) ASSOCIAÇÃO BRASILEIRA DE NORMAS TÉCNICAS. - NBR 5733. Cimento Portland de alta resistência inicial. Rio de Janeiro, 1991.

(49) TUTIKIAN, B. F. DAL MOLIN, D.C. "Concreto Auto-Adensável”. Editora Pini Itda. São Paulo-SP, 2008.

(50) ASSOCIAÇÃO BRASILEIRA DE NORMAS TÉCNICAS. CONCRETO - ensios de compressáo de corpos cilindrico. Rio de Janeiro, 2007.

(51) DANA, D. J. MANUAL DE MINERALGIA. Livros Técnios e Científicos Editora S.A. Rio de Janeiro, 1974. 


\section{ANEXO I}

Barita $-\mathrm{BaSO}_{4}(51)$

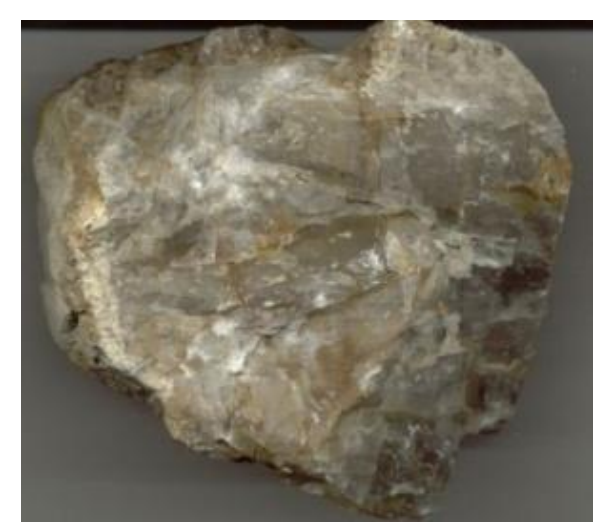

Figura 37 - Rocha de barita - Foto:Eurico Zimbres (51)

Critalografia. Ortorrômbico, bipiramidal. Os cristais são usualmente tubulares, paralelamente à base, muitas vezes configurados em losângulos, por causa da presença de um prisma vertical. Usualmente estão presentes prismas de primeira e de segunda ordens, seja biselando os vértices dos cristais configurados em losango, seja se as $\{110\}$ faces estão faltando, biselando as arestas das bases e formando cristais prismáticos retangulares, alongados paralelamente ao eixo $a$ ou $b$. Os cristais podem ser muito complexos, frequentemente em grupos de cristais tabulares divergentes formando a Barita em cristais ou rosas de barita. Apresenta-se também em lâminas grossas, granular, terrosa.

Propriedades físicas. Clivagem perfeita $\{001\}$, menos perfeita $\{210\}$. D 33,5. D 4,5 (pesada para mineral não metálico). Brilho vítreo, em alguns espécimes, nacarada base. Incolor, branca e com matizes claros de azul, amarelo e vermelho. Transparente e translucida.

Composição. Sulfato de bário, $\mathrm{BaSO}_{4}$. Sendo de $\mathrm{BaO} 65,7 \%-\mathrm{SO}_{3} 34,3 \%$. O estrôncio substitui o bário e uma solução sólida completa chega, provavelmente, até a celestita, porem a maior parte do material está próximo de uma extremidade, ou da outra, da série. Uma pequena quantidade de chumbo pode substituir o bário.

Aspectos diagnósticos. Entende-se como a forma física que esta apresenta na natureza, por sua massa específica relativa elevada, clivagem característica e cristais. 


\section{ipen}

Ocorrência. A barita é um mineral comum, de distribuição ampla. Ocorre geralmente como mineral de ganga nos filões metálicos, associada normalmente com minério de prata, chumbo, cobre, cobalto, manganês e antimônio. Encontrada veios no calcário, junto a calcita, ou como massa residuais na argila que recobre o calcário. Também nos arenitos, juntamente com minérios de cobre. Em certos lugares, age como cimento no arenito. Depositada ocasionalmente como sínter pelas águas das fontes termais. As localidades notáveis pela ocorrência de cristais de barita no Brasil são: Estado da Bahia, Minas Gerais, Goiás e Paraíba.

Uso - Empregado na preparação de nitrato de estrôncio para fogos de artifícios e balas traçadoras e de outros sais de estrôncio usados na refinação de açúcar de beterraba.

Nome - Derivado da palavra latina caelestis, em alusão à cor azul-pálido dos primeiros espécimes descritos. 


\section{Hematita $-\mathrm{Fe}_{2} \mathrm{O}_{3}(51)$}

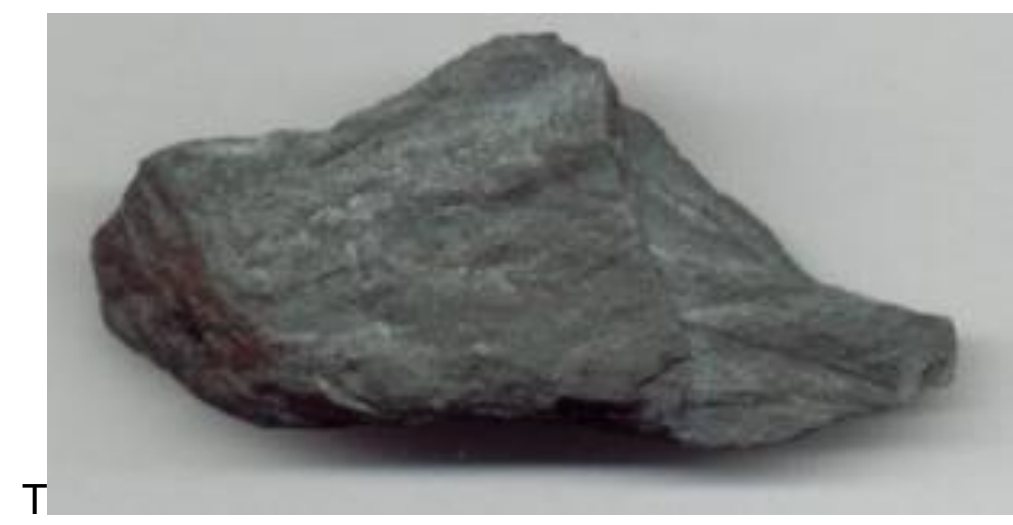

Figura 38 - Rocha de Hematita Foto: Eurico Zimbres (51)

Cristalografia - Hexagonal - R; escalenoedrica-hexagonal. Cristais usualmente tabulares entre espessos e delgados. Planos basais acentuados mostrando muitas vezes marcas triangulares. As arestas das placas podem ser biseladas conformas romboédricas. Placas delgadas podem estar agrupadas em forma de rosetas (rosas de ferro). Mais raramente, os cristais são nitidamente romboédricos, muitas vezes com ângulos quase cúbicos. Usualmente terrosas. Também em configurações botrioidais a reniformes com estrutura radiada, minério em forma de rim pg 117. Também pode ser micácia e laminada, especular. Chamase martita quando em pseudomorfos octaédricos sobre a magnetita.

Propriedades físicas - Participação $\{0001\}$ e $\{1011\}$ com ângulos quase cúbicos D 5,5 - 6,5 d 5,26 para cristais. Brilho metálico nos cristais e opaco nas variedades terrosas. Cor, castanho-avermelhado a preto. Conhece-se como ocra vermelha a variedade terrosa vermelha. Traço vermelho-claro a escuro que se torna preto pelo aquecimento. Translucida.

Composição - Óxido férrico, $\mathrm{Fe}_{2} \mathrm{O}_{3}$. Sendo de $\mathrm{Fe} 70 \%$ - O 30\%. Pode conter titânio.

Aspectos diagnósticos - Distingue-se principalmente por seu traço vermelho.

Ocorrência - A hematita é um mineral amplamente distribuído em rochas de todas as idades e forma o minério de ferro mais abundante e importante. Pode 


\section{ipen}

ocorrer como produto de sublimação em conexão com as atividades vulcânicas. Ocorre nos depósitos metamórficos de contacto e, como mineral acessório, nas rochas ígneas, feldspaticas tais como granito. Substitui também as rochas silícicas. Encontrada desde a forma de escamas microscópicas até a de massas enormes em relação com as rochas metamórficas regionais, onde se pode ter originado pela alteração da limonita, siderita ou magnetita. Tal como a limonita pode ser formada em massas ou camadas irregulares como resultado da ação do tempo sobre as rochas contendo ferro. Os minérios ooliticos são de origem sedimentar e podem ocorrer em camadas de tamanho considerável. Encontradas nos arenitos vermelhos com material de cimentação que liga entre si os grânulos de quartzo.

O Brasil tem reservas significativas em relação às reservas mundiais com 9,8\% de um montante de 340 bilhões de toneladas de reservas mundiais (pg 87 Sumario Mineral DNPM 2008). As reservas brasileiras com um teor médio de 56,1\% de ferro, estão localizadas, em quase totalidade, nos estados de Minas Gerais (63,1\%), Pará (18,0\%) e Mato Grosso do Sul (17,2\%).

Uso - A hematita é o mais importante minério de ferro. Usada também em pigmentos, ocra vermelha, e como pó para polir.

Nome - Derivado de uma palavra grega significando sangue, em alusão à cor do mineral pulverizado. 


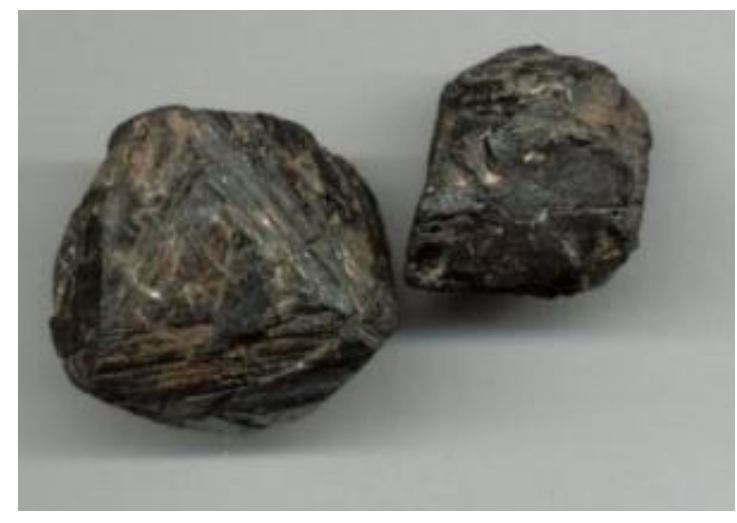

Figura 39 - Rocha de Magnetita Foto:Eurico Zimbres (51)

Cristalografia - Isométrico, hexaoctaédrica. Frequentemente em cristais de hábito octaédrico, geminado ocasionalmente. Os dodecaedros são mais raros. Os dedocaédricos podem ser estriados paralelamente às interseções com as faces do octaedro. Outras formas são raras. Usualmente maciça granular, granulação grossa ou fina.

Propriedades físicas - Partição octaédrica em algumas espécimes. D 6. D 5,18. Brilho metálico. Côr: preto do ferro. Traço preto. Fortemente magnética, comporta-se como um imã natural, conhecida como lodestone. Opaca.

Composição - $\mathrm{Fe}_{2} \mathrm{O}_{3}$ ou $\mathrm{FeFe}_{2} \mathrm{O}_{4}$. Sendo de $\mathrm{Fe} 72,4 \%$ - O 27,6\%. A composição da magnetita usualmente corresponde àquela mostrada pela formula. Contudo, algumas análises mostram alguns por cento de magnésio e manganês bivalente.

Ensaios - Infusível. Vagarosamente solúvel em acido clorídrico, a solução reagindo tanto para o ferro ferroso como para o ferro férrico.

Aspectos diagnósticos - Caracterizada principalmente pelo seu forte magnetimo, cor preta e sua dureza seis. Distingue-se da franklinita magnética pelo traço.

Ocorrência - A magnetita é um minério de ferro comum. Encontra-se distribuída, sob a forma de um mineral acessório, em muitas rochas magnéticas. Em certos tipos de rocha, através de segregação magnética, torna-se um dos principais constituintes e pode, assim, formar grandes corpos de minério. Estes corpos são 


\section{ipen}

muitas vezes altamente titaníferos. A magnetita está associada, mais comumente, com rochas metamórficas cristalinas, ocorre também frequentemente em rochas ricas de minerais ferro-magnesianos, a saber, dioritos, garbos e peridotitos. Ocorre também sob a forma de camadas ou lentes imensas, incluídas em rochas metamórficas antigas. Encontra-se nas areias pretas de praias. Aparece em placas delgadas e sob a forma de crescimentos dentríticos entre as lâminas das micas. Associa-se intimamente, muitas vezes, com o córidon, para formar o material conhecido pela designação esmeril.

Uso - importante minério de ferro.

Nome - Deriva-se provavelmente da localidade Magnésia, nos limites da Macedônia. Uma fábula, atribuída a Plínio, liga seu nome a um pastor chamado Mangnes, que descobriu o mineral pela primeira vez no monte lda, ao notar que os pregos de seus sapatos e a argola de ferro de seu bordão aderiam ao chão.

Espécimes semelhantes - $\mathrm{A}$ magnésio-ferrita, $\mathrm{MgFe}_{2} \mathrm{O}_{4}$ é um mineral raro que se encontra principalmente em fumarolas. A jacobsita, $\mathrm{MnFe}_{2} \mathrm{O}_{4}$, é um mineral raro, que se encontra em Langban, na Suécia. 


\section{ANEXO II}

\section{FICHAS PARA INSERÇÃO NO BANCO DE DADOS}

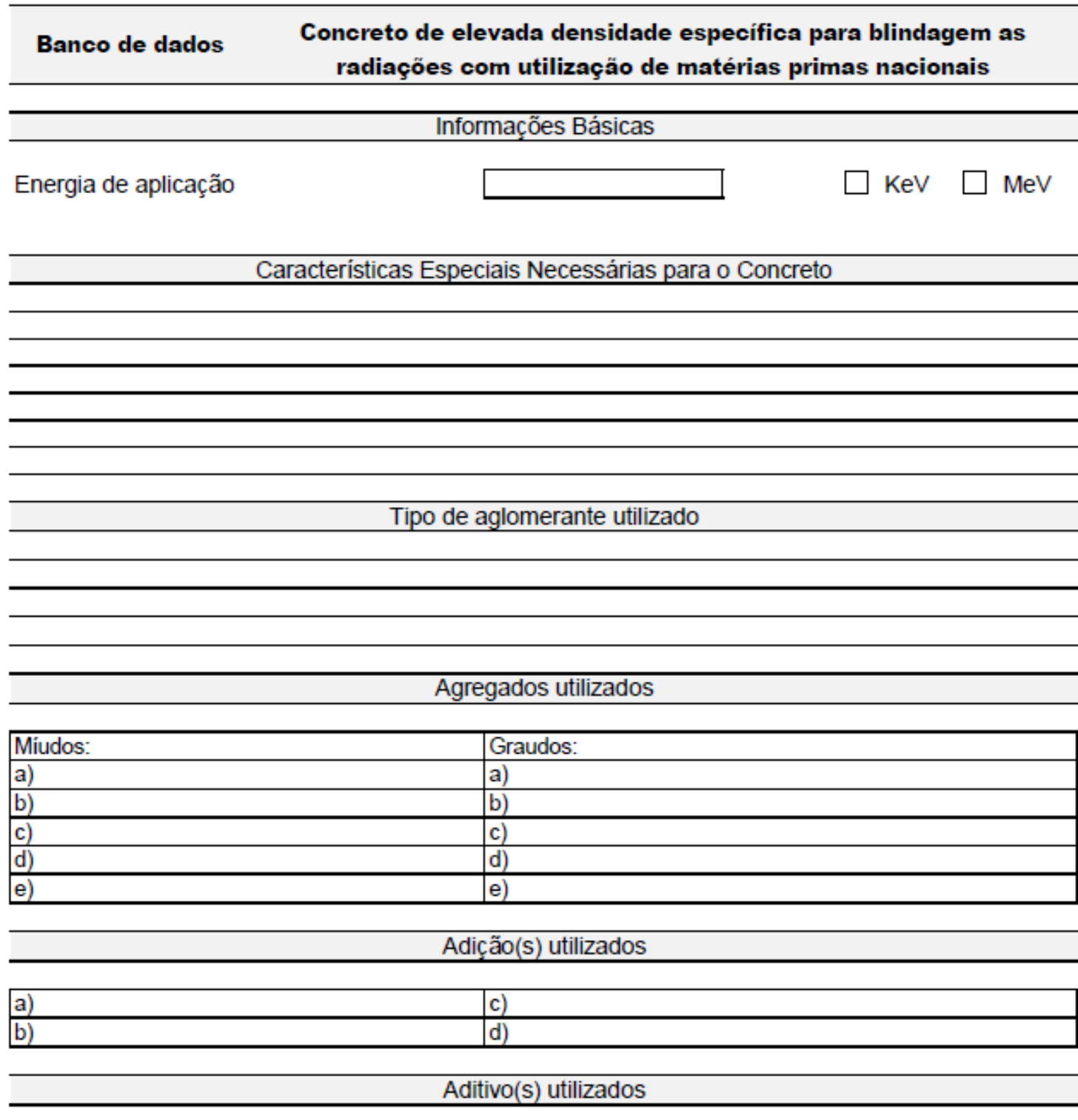


Características química do(s) aglomerante(s)

\begin{tabular}{lcc}
\hline \multicolumn{3}{c}{ Aglomerante } \\
\hline Cimento & Tipo ABNT
\end{tabular}

\begin{tabular}{|c|c|c|}
\hline \multicolumn{3}{|c|}{ Ensaios físicos no cimento } \\
\hline Determinações & Resultados & Unidade \\
\hline Finura-Resíduo na peneira $0,0075 \mathrm{~mm}$ & & $\%$ \\
\hline Agua para pasta normal & & $\%$ massa do cimento \\
\hline Ínicio de pega & & h:min \\
\hline Fim de pega & & h:min \\
\hline
\end{tabular}

Resistência

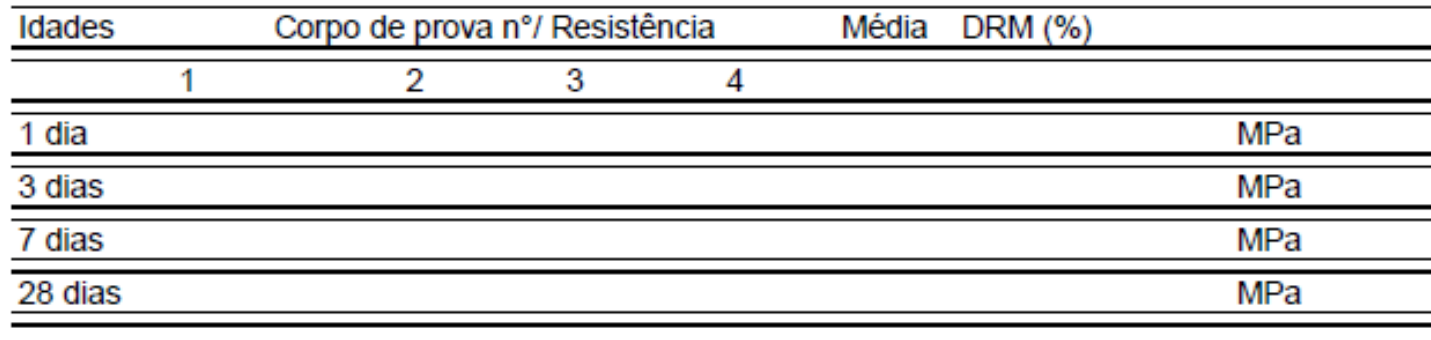

Finura (NBR-11579/91) Residuo na peneira de 0,075 mm (\%)

Agua para pasta normal (NBR-NM-43/03) (\% massa do cimento)

Inicio de pega (NBR-NM-65/03) (h-min)

Fim de pega (NBR-NM-65/03) (h:min)

ndice de consistência da argamassa (NBR-7215/96) (mm)

Ensaio mecánico - Resistência à compressão (MPa) - (NBR-7215/96)

Resisténcia - Limites da NBR 5733/91 
Características química do(s) aglomerante(s)

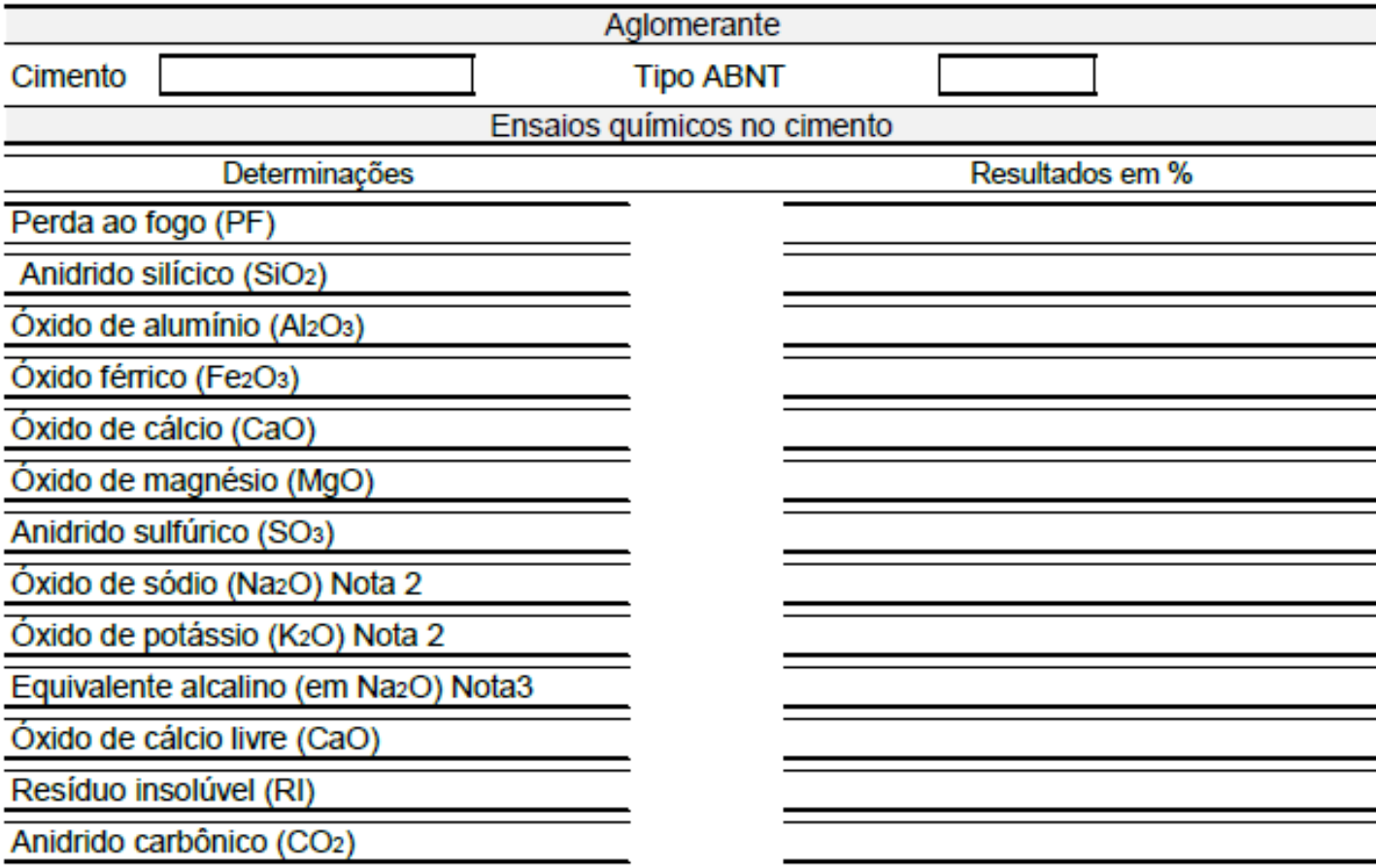

Nota 1 Perda ao fogo: NBR-NM 18/12 "Cimento Portland - Análise química - Determinaçäo de perda ao fogo", item 5.1 (CT-OBRAS-LMCC-Q-PE001, Método A e Método B).

Nota 20 resultado apresentado foi determinado por absorção atômica. Nota 3 Equivalente alcalino $(\mathrm{em} \mathrm{Na2O})=\% \mathrm{Na} 2 \mathrm{O}+0,658 \times \%$ K2O

Anidrido silicico (SiO2): NBR-NM 11-2/12 "Cimento Portland - Analise quimica - Método optativo para determinaçăo de óxidos principais por complexometria - Parte 2: Método ABNT", item 5.1.2. NBR-NM 22/12 "Cimento Portland com adiçoes de materiais pozolânicos - Análise Química Método de arbitragem". (CT-OBRAS-LMCC-Q-PE-003, Método A e Método B).

Oxido férrico (Fe2O3): NBR-NM 11-2/12 'Cimento Portland - Análise quimica - Método optativo para determinação de oxidos principais por complexometria - Parte 2: Método ABNT", item 5.2.1. (CT-OBRAS-LMCC-Q-PE-005, Método A e Método B).

Oxido de aluminio (AI2O3): NBR-NM 11-2/12 "Cimento Portland - Analise quimica - Método optativo para determinação de óxidos principais por complexometria - Parte 2: Método ABNT", item 5.2.2 (CT-OBRAS-LMCC-Q-PE-006, , Método A e Método B)-

Óxido de cálcio (CaO): NBR-NM 11-2/12 "Cimento Portland - Analise quimica - Método optativo para determinação de oxidos principais por 
Características química do agregado

\begin{tabular}{|l|l|}
\hline & Agregados 1 \\
\hline \hline Agregado & Identificação: \\
\hline \hline
\end{tabular}

Ensaios químicos dos agregados - Parte 1

\begin{tabular}{|c|c|c|}
\hline Agregado & Nome & \\
\hline Determinações & & Resultados \\
\hline \multicolumn{3}{|l|}{ Sai solúveis em água } \\
\hline \multicolumn{3}{|l|}{ İons sulfato $\left(\mathrm{SO}_{4} 4^{2-}\right)$} \\
\hline İons cloreto $(\mathrm{Cl})$ solúveis em água & & \\
\hline
\end{tabular}

Ensaio químico do agregado - Parte 2

Metodo de análise:

\begin{tabular}{ll}
\hline Elemento & \% em massa \\
\hline $\mathrm{Ca}$ \\
$\mathrm{Mg}$ \\
$\mathrm{Al}$ \\
$\mathrm{Fe}$ \\
$\mathrm{K}$ \\
$\mathrm{S}$ & \\
$\mathrm{Ni}$ & \\
$\mathrm{Sr}$ & \\
$\mathrm{Zr}$ & \\
\hline
\end{tabular}


Características física do agregado

\begin{tabular}{|c|c|c|}
\hline & Agregados & \\
\hline Agregado & Identifica & \\
\hline & Ensaios químicos dos ag & dos - Parte 1 \\
\hline & Nome & \\
\hline Dete & nações & Resultados \\
\hline Determinação da c & osição granulométrica & \\
\hline Peneiras & Material retido $(\%)$ & \\
\hline Abertura (mm) & individual retido & \\
\hline 9,5 & & \\
\hline 6,3 & & \\
\hline 4,75 & & \\
\hline 2,4 & & \\
\hline 1,18 & & \\
\hline 0,6 & & \\
\hline 0,3 & & \\
\hline 0,15 & & \\
\hline$<0,15$ & & \\
\hline
\end{tabular}

Módulo de finura

Dimensão máxima característica $(\mathrm{mm})$

Absorção (\%)

Massa específica saturada superfície seca $\left(\mathrm{g} / \mathrm{cm}^{3}\right)$

Massa especifica aparente $\left(\mathrm{g} / \mathrm{cm}^{3}\right)$

Massa específica $\left(\mathrm{g} / \mathrm{cm}^{3}\right)$

Material fino passante na peneira de $75 \mu \mathrm{m}$ por lavagem (\%)

Torões de argila

Materiai carbonosos

Materiais pulverulentos 


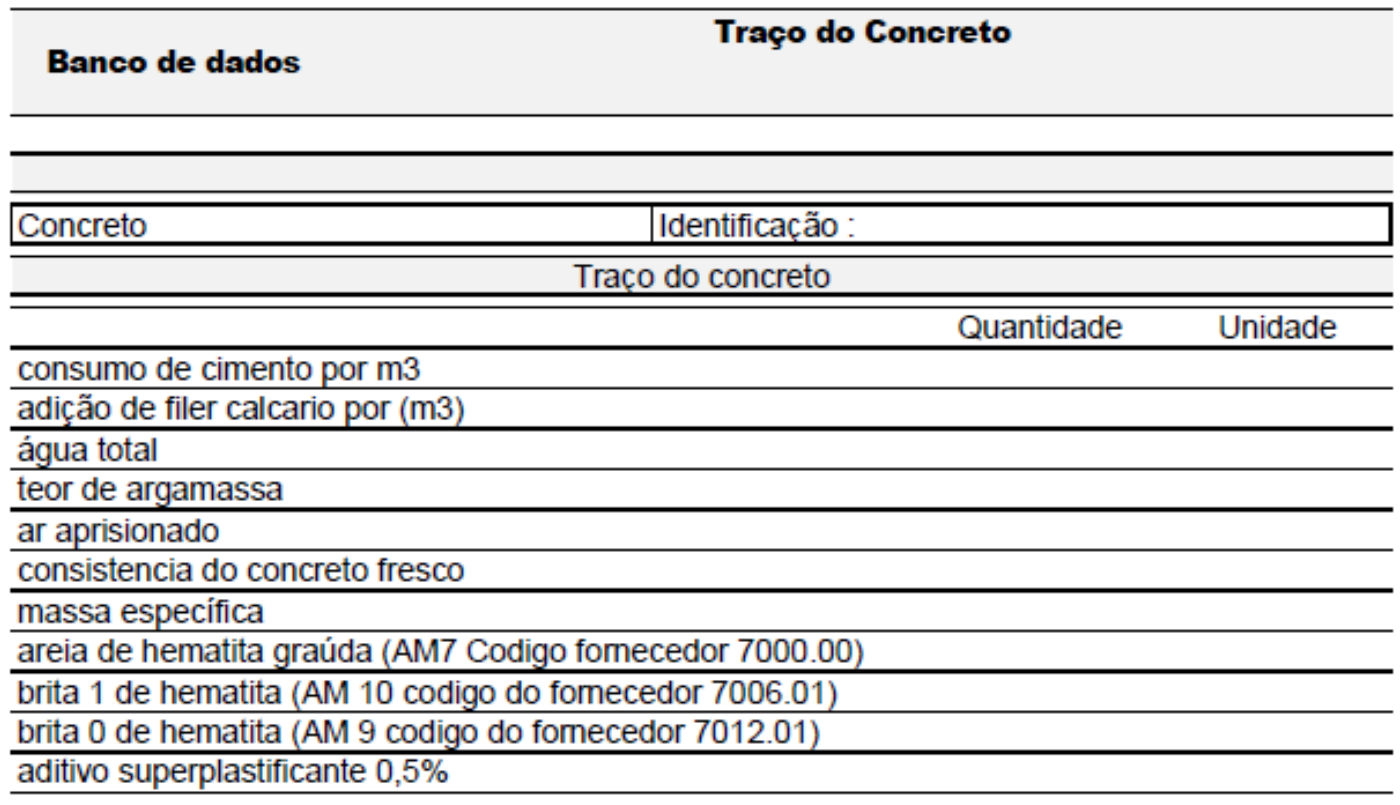




\begin{tabular}{|c|c|}
\hline \multicolumn{2}{|r|}{ Caracterizaçäo do Traço do Concreto } \\
\hline Concreto & IIdentificação: \\
\hline \multicolumn{2}{|r|}{ Ensaio químico do concreto } \\
\hline \multicolumn{2}{|l|}{ Metodo de análise: } \\
\hline Elemento & $\%$ em massa \\
\hline $\mathrm{Fe}$ & \\
\hline $\mathrm{Ca}$ & \\
\hline $\begin{array}{c}\mathrm{Si} \\
\end{array}$ & \\
\hline $\mathrm{Mg}$ & \\
\hline Al & \\
\hline S & \\
\hline $\mathrm{K}$ & \\
\hline $\mathrm{Ti}$ & \\
\hline $\mathrm{Mn}$ & \\
\hline$P$ & \\
\hline $\mathrm{Cr}$ & \\
\hline $\mathrm{Zn}$ & \\
\hline $\mathrm{Sr}$ & \\
\hline $\mathrm{Ni}$ & \\
\hline $\mathrm{Zr}$ & \\
\hline & Ensaio Físico \\
\hline & Resultado \\
\hline Massa específica & \\
\hline Resistência & \\
\hline
\end{tabular}




\begin{tabular}{|c|c|}
\hline \multicolumn{2}{|r|}{ Moldagem dos Corpos de Prova } \\
\hline Concreto & Identificação: \\
\hline \multicolumn{2}{|r|}{ Dimensões } \\
\hline Lagura = & Espessura= \\
\hline & Energia de Vibração \\
\hline & Tempo de Cura \\
\hline
\end{tabular}




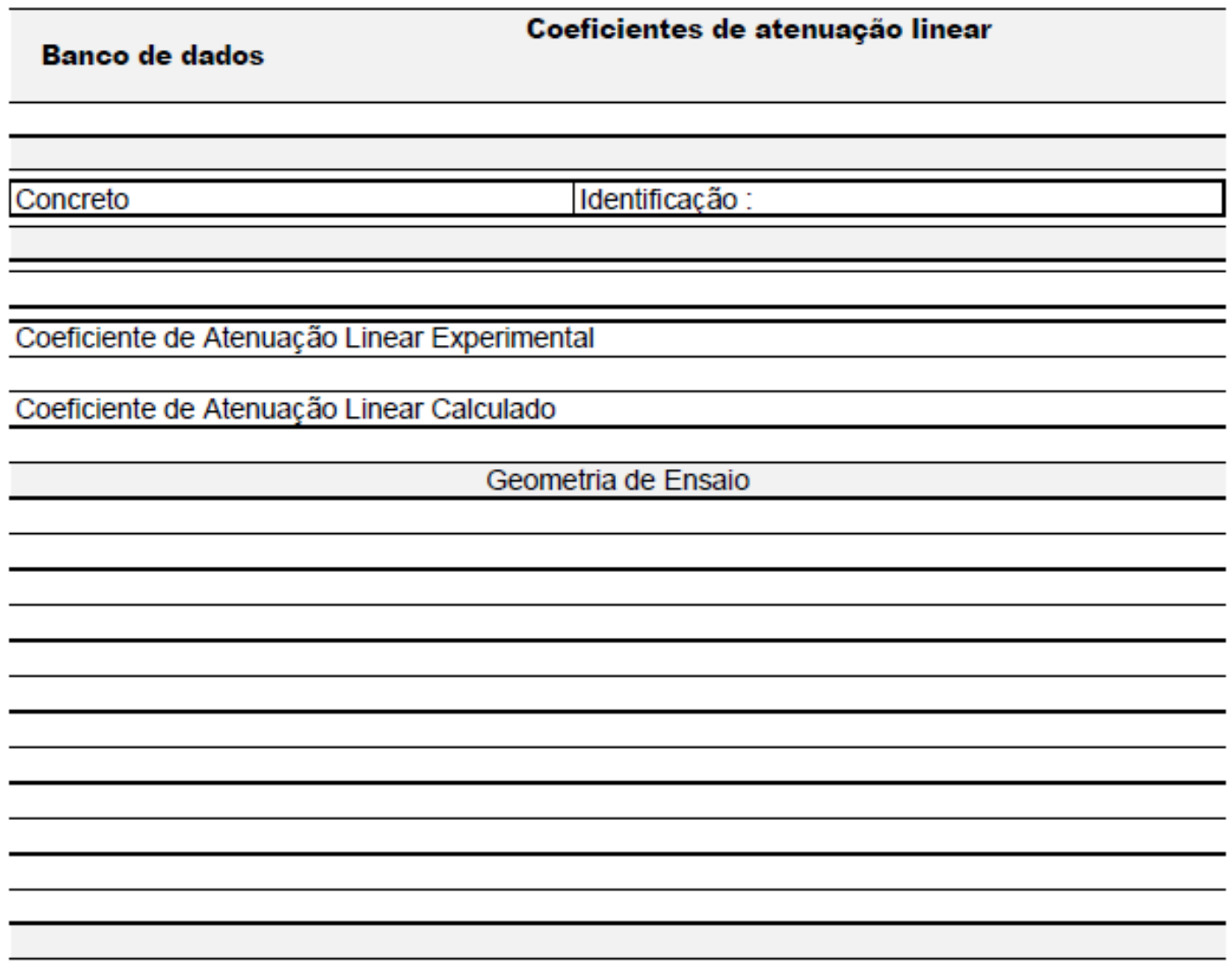

